\title{
The impact of ants on the aboveground and belowground ecological network - field studies in a grassland and experiments with microcosms
}

\author{
Dissertation
}

Zur Erlangung des Doktorgrades der Mathematisch-

Naturwissenschaftlichen Fakultäten der Georg-August-Universität zu Göttingen

vorgelegt von

\section{Evelyn Schumacher}

aus Göttingen

Göttingen, im März 2010 
Referent: Prof. Dr. Matthias Schaefer

Korreferent: Prof. Dr. Klaus Hövemeyer

Tag der mündlichen Prüfung: 30.04.2010 


\section{Table of contents}

\section{Chapter 1}

General introduction

\section{Chapter 2}

Nutrient dynamics in a tritrophic system of ants, aphids and beans

Evelyn Schumacher and Christian Platner

\section{Chapter 3}

The role of ants and homopteran honeydew on the nutrient flow from above- to belowground systems and on the soil microbial community

Evelyn Schumacher, Birgit Pfeiffer, Rolf Daniel and Christian Platner

\section{Chapter 4}

The impact of Lasius ants on soil properties and microfungal communities of a temperate grassland

Evelyn Schumacher, Sonja Migge-Kleian and Christian Platner

\section{Chapter 5}

The impact of Lasius ants on soil properties and functional diversity of soil microbes

Evelyn Schumacher, Sonja Migge-Kleian and Christian Platner

\section{Chapter 6}

Microbial functional diversity - a molecular approach

Evelyn Schumacher, Birgit Pfeiffer, Rolf Daniel and Christian Platner

\section{Chapter 7}

General conclusions

Summary

\section{Acknowledgements}

\section{Curriculum vitae}


Chapter 1

General Introduction 
A central issue in ecology is the understanding of food web structure. In the past, studies in community ecology have been dominated by investigations on interactions between two trophic levels, but ecological interactions between two species are often mediated by a third or forth species. This makes food-webs more complex (Tscharntke and Hawkins, 2002), and direct and indirect interactions between two species can link multiple interactions in a community. Herbivores for example are involved in a complex interaction network. On the one hand, herbivores can be affected from bottom-up by nutrient quality and defence mechanism of their host plant. On the other hand predators and parasitoids can alter herbivore abundance from top-down. The outcome of these interactions can change however, when mutualistic relationship between herbivores and ants exist. For example, parasitoids (Encyrtidae) used for biological control of the mealybugs was only successful when mealybugs were not protected by ants (Gonzáles-Hernandez et al., 1999), indicating that ants have a strong impact on aboveground food web structure.

Concepts of food web ecology often rely on aboveground systems, but aboveand belowground systems are closely connected. Plant-mediated links between above- and belowground organisms are well documented (Wardle et al., 2004a and b). Soil inhabiting animals and microfloral populations like mycorrhizas, rhizophagous insects, earthworms and collembola can influence the growth of phytophagous insects aboveground, commonly due to nutritional changes in their host plant (Gange, 2000). Aboveground plant consumers in turn can affect soil food webs (Wardle et al., 2004a and b; 2005).

Activity of ecosystem engineers like earthworm or ants can affect soil organisms also in a non-trophic way by changing soil organisms' habitat conditions. It has been long known that soil organisms are integral to soil fertility. Belowground organisms are important structuring forces in terrestrial ecosystems acting as drivers of ecosystem functioning, such as decomposition, nutrient cycling and plant nutrition (Bardgett et al., 2005), thereby affecting the plant community and their consumers.

Ants play a key role in ecosystems, because they are involved in the aboveground, as well as in the belowground food web. In many habitats ants belong to the dominant group of arthropods and their presence influences numerous populations of animals and plants. By their function as ecosystem engineers, mutualistic partners and predators, ants have an important ecological impact 
(Hölldobler and Wilson, 1990; Jones, 1994). Ants are eusocial insects and they can control the ecosystem from top-down by grazing pressure on their prey as well as from bottom-up by changing soil properties due to nest building activity. Moreover, workers transport organic substances and food into their nest, thus altering nutrient availability for soil organism (Figure 1).

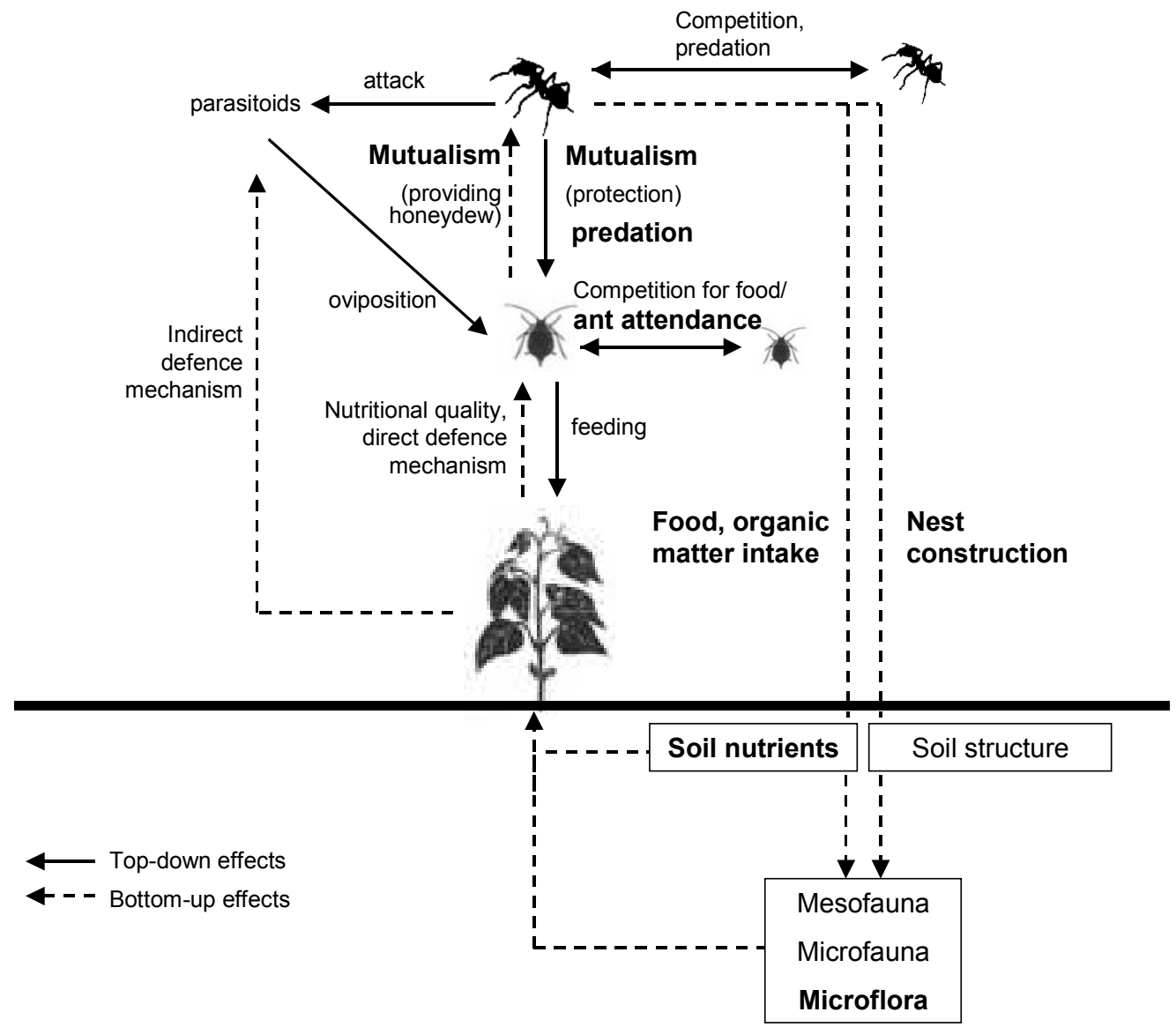

Figure 1. Top-down and bottom-up effects exert by ants on above- and belowground systems. Bold parts within the food-web will be discussed in my study. Solid lines represent top-down effects, bottom up effects are shown in dottet lines.

The interaction network between mound building ants, their trophobionts and the nest inhabiting microflora is a model system for studying facilitation, multitrophic interactions and microbial community structures.

\section{Aboveground food-web activity of ants}

Ants influence the aboveground tritrophic food-chain of ants-aphids-plants by preying on aphids and/or collecting their sugar-rich honeydew as an energy resource. Ants act as mutualistic partners of aphids (trophobiosis), but also prey on them to cover their demand on protein (Pontin, 1958). When ants switch between tending 
and predation, they can modify homopteran populations and consequently exert indirect effects on the aphids' host plant (Carroll and Janzen, 1973).

The honeydew of aphids contains different sugars and amino acids. Fischer et al. (2005) found up to ten different sugars in the honeydew of Aphis fabae Scopoli on different host plants. The honeydew was mostly dominated by the trisaccharide melezitose, the disaccharide trehalose and the monosaccharides glucose and fructose. Woodring et al. (2004) investigated the amino acids in honeydew and found predominantly aspargine, glutamine and serine in the honeydew of five different aphid species. This mixture of sugars and amino acids is a high-quality food resource not only for ants. Stadler and Müller (1996) investigated the role of honeydew as potential energy source for microorganisms in the phyllosphere of conifer trees. The presence of honeydew increased the growth of bacteria, yeasts and filamentous fungi on the surface of needles. Ants can reduce the amount of honeydew reaching the plant leaves by tending aphids and providing hygienic service to their colonies, thus reducing the risk of microbial infections on leaves and needles.

The intensity of mutualism between ants and aphids and consequently the protection and cleaning services of ants depends on the quality and quantity of aphids' honeydew. Both vary between aphid species (Hendrix et al., 1992; Völkl et al., 1999) and within species living on different host plants (Douglas, 1993). The presence of ants can increase the production of honeydew; moreover, the composition of honeydew can change with ant presence (Fischer et al., 2005) increasing the attractiveness for ants which leads to better protection by ant workers against aphid enemies.

Under natural conditions tending ants alone may consume more than two-thirds of the honeydew available (Müller, 1956 and 1960) while approximately 1/3 of honeydew may fall straight to ground (Wellenstein, 1980). Thus, ants can alter resource availability for microorganisms not only in the phyllosphere but also in litter and soil, promoting further ant effects from bottom-up. 


\section{Belowground activity effects of ants by soil engineering and substrate accumulation}

Ants can affect the belowground system by their soil engineering activity and substrat accumulation within their nest. Belowground food-webs and soil processes are mainly regulated by microorganisms, plant roots and the decomposer fauna, by which decomposition processes, nutrient cycles and energy flow are controlled. Soil microorganisms and animals depend on resource input. Some of this input, consisting of prey, organic substances, excreta and honeydew, the input of which can reach up to $15200 \mathrm{~kJ} / 5$ min of honeydew carried in on a single trail (Skinner, 1980), is controlled by ants. Stadler et al. (2006) found a significant increase of organic carbon and a decrease of inorganic nitrogen in spruce litter, when honeydew was added. Honeydew seemed to stimulate the development of microorganisms which led to an immobilisation of inorganic nitrogen. Whether these changes could be attributed to the microbial community and if ants have an effect on microorganisms by altering the amount of honeydew reaching the litter/soil was not investigated.

The nutrient cycle in soil is strongly connected to the carbon cycle, because microbial biomass and its activity in soils depend on carbon sources (Perelo and Munch, 2005). In most ecosystems, soil carbon is the limiting element for the microbial community (Smith, 1994; van Veen et al., 1984; Scheu and Schaefer, 1998), and nitrogen mineralisation can be limited by the lack of easily available Csources, such as dissolved organic carbon (DOC; Magill and Aber, 2000). By changing the amount of available carbon for microorganisms, ants can have a strong impact on microorganisms and associated ecological processes. But not only nutrient accumulation alone can have effects on soil microbial communities, also structural changes in soil by nest-building activity of ants can alter the habitat structure and microclimate for microorganisms.

Due to their nest-building activity, ants change the soil structure by mixing different soil layers and by establishing chambers within the nest (Nkem et al., 2000). The lateral and vertical network of chambers increases aeration (Czerwinski et al., 1971), water infiltration (Nkem et al., 2000) and the movement of water-soluble substances in soil (Wang et al., 1996). Thereby ants are indirectly involved in the 
mineralisation process. The bioturbation activity does not necessarily lead to higher nitrogen mineralisation, but the mixing of soil and the intake of organic material can create better conditions for the microbial populations and intensive microbial activity can lead to a higher nitrogen dynamic.

Also, the degree of decomposition is dependent on the diversity of the decomposer community (Tiunov and Scheu, 2005). For example, an increase in microfungal diversity can lead to an increase of the decomposition rate (measured as $\mathrm{CO}_{2}$ production: Setälä and McLean, 2004). The special habitat conditions within ant nests influence the abundance of special physiological groups of microorganisms (Pêtal, 1998). The accumulation of easily available nutrient components and organic substances is associated with a more intense fungal and bacterial development (Czerwinski et al., 1971), whereby the development of different physiological groups of the microflora is promoted or inhibited by ants (Czerwinski et al., 1969; Jacubczyk et al., 1975). Additionally, the composition of the microbial community depends on ant species (Pêtal and Kusinska, 1994; Dauber and Wolters, 2000).

Altogether, the low amounts of carbon and humic acids in ant nests show, that in nests better condition for mineralisation of organic substances exist than for their humification (Pêtal and Kusinska, 1994). Wagner (1997) reported a significantly higher $\mathrm{N}$-mineralisation rate in nests of Formica perpilosa Wheeler in comparison to the surrounding soil. Dauber and Wolters (2000) measured higher C-mineralisation rate (and microbial activity) in nest mounds of three different ant species in comparison to the surroundings. Moreover, it was demonstrated that Lasius niger $\mathrm{L}$. stimulates the microbial utilization of amino acids. Thus, this ant species promotes microorganisms which are able to utilize nitrogen-rich compounds. Other studies show that Myrmica spp. stimulate the development of ammonifying bacteria, while Lasius flavus Fabricius has a positive effect on actinomycetes to the detriment of bacteria (Pêtal, 1978). Bacteria and fungi are key groups for the belowground foodweb. They play an important role in the bacterial- and fungal-based food-web, and changes in the microbial community can have consequences for higher trophic level. Most studies of terrestrial systems focus on aboveground plant productivity and ignore that plant development depends on the activity of the decomposer system. By 
the accumulation of different nutrients in ant nests, a wider range of nutrients is available for microorganisms than would normally be present in soil.

\section{Outline of my study}

In my work, two areas of ants' functioning in ecosystem were studied descriptively and experimentally: I investigated how ants affect (1) the aboveground system by acting as mutualistic partners and predators of honeydew producers and (2) the belowground system by modulating resource availability for microorganisms. The effect of ants on the microbial activity and diversity in soil is of special interest and should be compared to the influence of aphids as honeydew producers without ants being present.

\section{I addressed the following questions}

(1) Does tending by ants affect the aphid colonies and does tending intensity of ants change when sugar and protein resources are available as alternative resource?

(2) What influence has the trophobiosis between ants and aphids in combination with the structural changes by nest construction on material flow between the above- and belowground system and on the microbial community?

(3) How do ants affect soil parameters and soil microbial community and functioning in natural systems? 


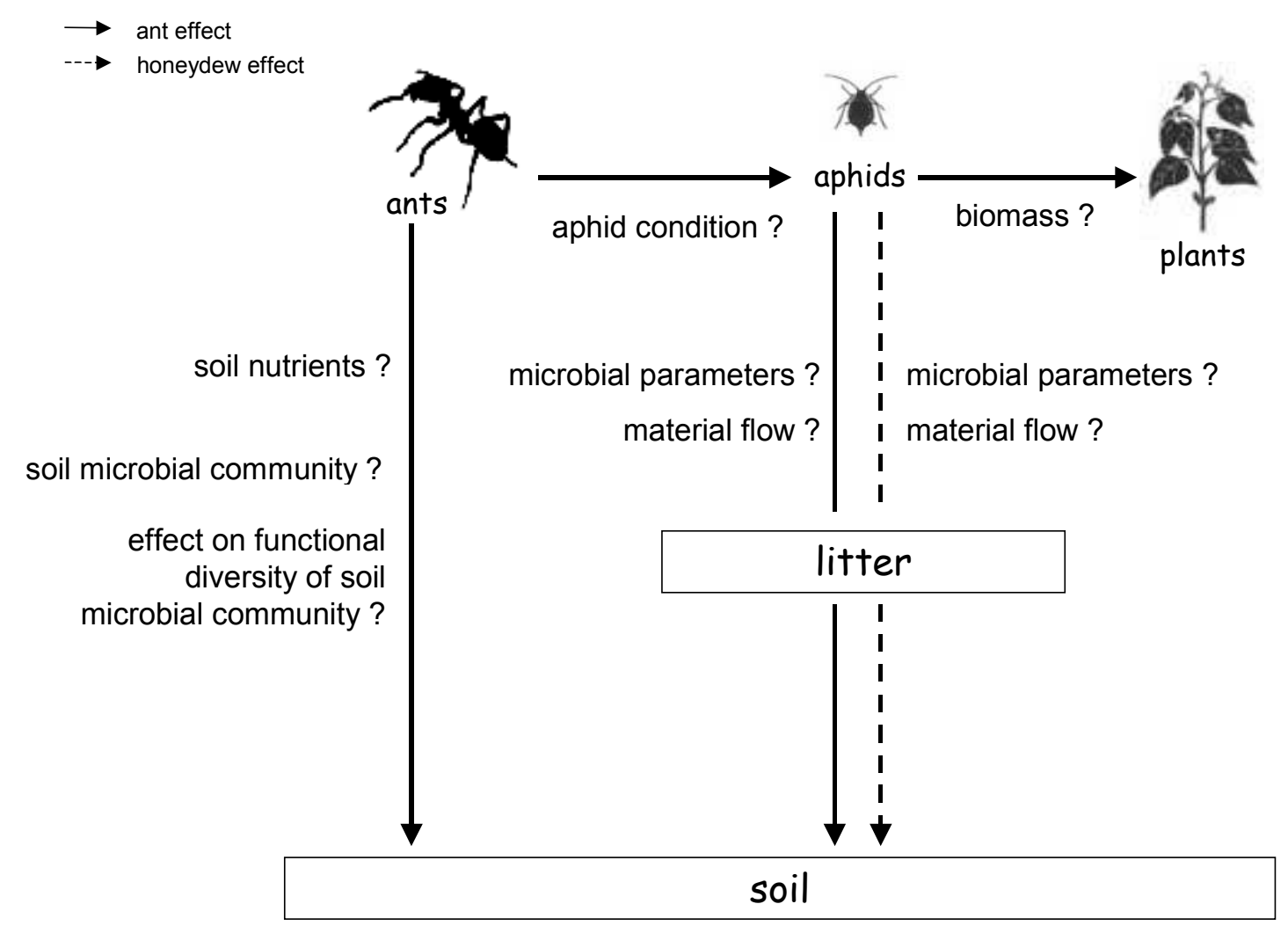

Figure 2. Questions that are addressed in the following chapters. Solid line=ant effect, dotted line=honeydew effect.

These questions will be addressed in five chapters. The first laboratory experiment (Chapter 2) is a detailed analysis of the interactions between ants, aphids and plants with the focus on trophic interactions. In this experiment Phaseolus vulgaris L. plants infested with Aphis fabae were used to analyse how Lasius niger ants affect aphids from top down by tending and predation and whether tending activity of ants changes, when an alternative sugar/protein resource is available for ants. Moreover, I induced a bottom-up effect on the plant by increasing the soil nutrient level by adding fertilizer. The low content of ${ }^{15} \mathrm{~N}$ in fertilizer and the different carbon stable isotope ratios $\left({ }^{13} \mathrm{C} /{ }^{12} \mathrm{C}\right)$ between the different protein/sugar resources served as markers to follow the nutrient flow and to trace the fate of the sugar/protein resource. In this experiment I observed that honeydew promoted fungal growth on $P$. vulgaris leaves. The same was reported by Stadler and Müller (1996), who measured increased microbial growth on the surface of conifer needles. These observations led to the question how honeydew falling on the ground affects the soil microbial community and whether ants influence the material flow from aboveground to 
belowground by tending aphids and consequently altering honeydew amounts reaching the litter and soil.

To obtain further insights into the role of ants and homopteran honeydew in nutrient flows under controlled conditions, another laboratory experiment was conducted (Chapter 3 ). In this study, Phaseolus vulgaris plants were labelled with the stable isotope method $\left({ }^{13} \mathrm{C} /{ }^{15} \mathrm{~N}\right)$ and infested with Aphis fabae, which produced ${ }^{13} \mathrm{C}$ - and ${ }^{15} \mathrm{~N}$-labelled honeydew. This allowed me to follow the nutrient flow via honeydew into the system. To assess changes in microbial parameters due to ant presence and honeydew input to soil, basal respiration and microbial biomass were measured with the substrate induced respiration method (SIR). To get deeper insights into the structure of the microbial community, the bacterial profile was analysed by the denaturing gradient gel electrophoresis (DGGE) method. Aditionally, sequences were evaluated from bacterial DGGE.

As mentioned above, not only honeydew input influences microbial communities but also the nest-building activities of ants. Earlier studies focussed more on overall physiological community patterns while detailed investigations on, for example, fungal taxa in ant nests are rare. The experiment in Chapter $\mathbf{4}$ was carried out on soil samples from the field, reflecting natural soil conditions. I analysed the diversity of fungal communities, microbial parameters and soil properties in four different Lasius ant nests in comparison to the surrounding soil in the course of the year. To detect microfungal diversity in soils, the classic plating technique was used.

To also take into account the bacterial part of microbial communities, I quantified the functional diversity of soil microorganisms by in situ respiration response to an array of 13 carbon substrates in the same four Lasius ant nests, to compare the substrate utilization with the respective surroundings without ant activity (Chapter 5). An additional study (Chapter 6) was carried out with higher number of ant nests samples from two different sites, taking into account the location effects. Furthermore, out of the 13 carbon substrates 8 substrates were chosen that separated best nest from surrounding soil in the previous study (Chapter 5). In addition DGGE method was applied, but this method does not allow to distinguish between active and inactive stages of microorganisms, thus it was simultaneously 
combined with a measurement of the functional aspect of microbial community by functional diversity measurement. 


\section{References}

Bardgett, R.D., Bowman, W.D., Kaufmann, R., Schmidt, S.K., 2005. A temporal approach to linking aboveground and belowground ecology. Trends Ecol. Evol. 20, 634-641.

Carroll, C.R., Janzen, D.H., 1973. Ecology of foraging by ants. Annu. Rev. Ecol. Syst. 4, 231-251.

Czerwiński, Z., Pêtal, J., Jakubczyk, H., 1969. The influence of ants of the genus Myrmica on the physico-chemical and microbiological properties of soil within the compass of anthill in Strzeleckie meadows. Pol. J. Soil Sci. 2, 51-58.

Czerwiński, Z., Jakubczyk, H., Pêtal, J., 1971. Influence of Ant hills on the Meadow Soils. Pedobiologia 11, 277-285.

Dauber, J., Wolters, V., 2000. Microbial activity and functional diversity in the mounds of three different ant species. Soil Biol. Biochem. 32, 93-99.

Douglas, A.E., 1993. The nutritional quality of phloem sap utilized by natural aphid populations. Ecol. Entomol. 18, 31-38.

Fischer, M.K., Völkl, W., Hoffmann, H., 2005. Honeydew production and honeydew sugar composition of polyphagous black bean aphid, Aphis fabae (Hemiptera, Aphididae) on various host plants and implications for ant attendance. Eur. J. Entomol. 102, 155-160.

Gonzáles-Hernandez, H., Johnson, M., Reimer, W., 1999. Impact of Pheidole megacephala (F.) (Hymenoptera: Formicidae) on the biological control of Dysmicoccus brevipes (Cockerell) (Homoptera: Pseudococcidae). Biological Control 15, 145-152.

Hendrix, D.L., Wei, Y., Legget, J.E., 1992. Homopteran honeydew is determined by both the insect and the plant species. Comp. Biochem. Physiol. 101, 23-27.

Hölldobler, B., Wilson, E.O., 1990. The ants. Springer, Berlin, Heidelberg, New York. Jakubczyk, H., Pêtal, J., Czerwinski, Z., Chmielewski, K., 1975. Influence of ants on changes of the microbial activity of the soil in environment treated by mineral nitrogen compounds. Deteriorization regionis II. CEAV. Most 1, 42-53.

Jones, C.G., Lawton, J.H., Shachak, M., 1994. Organisms as ecosystem engineers. Oikos 69, 373-386.

Magill, A.H., Aber, J.D., 2000. Variation in soil net mineralisation rates with dissolved organic carbon additions. Soil Biol. Biochem. 32, 587-601. 
Müller, H., 1956. Können Honigtau liefernde Baumläuse (Lachnidae) ihre Wirtspflanzen schädigen? Z. Angew. Entomol. 39, 168-177.

Müller, H., 1960. Der Honigtau als Nahrung der hügelbauenden Waldameisen. Entomophaga 5, 55-75.

Nkem, J.N., Lobry de Bruyn, L.A., Grant, C.D., Hulugalle, N.R., 2000. The impact of ant bioturbation and foraging activities on surrounding soil properties. Pedobiologia 44, 609-621.

Perelo, L.W., Munch, J.C., 2005. Microbial immobilisation and turnover of $13 \mathrm{C}$ labelled substrates in two arable soils under field and laboratory conditions. Soil Biol. Biochem. 37, 2263-2272.

Pêtal, J., Kusinska, A., 1994. Fractional composition of organic matter in the soil of anthills and of the environment of meadows. Pedobiologia 38, 493-501.

Pêtal, J., 1978. The role of ants in ecosystems. Production ecology of ants and termites (ed M. V. Brian), Cambridge University Press, Cambridge.

Pêtal, J., 1998. The influence of ants on carbon and nitrogen mineralization in drained fen soil. Appl. Soil Ecol. 9, 271-275.

Pontin, A.J., 1958. A preliminary note on the eating of aphids by ants of the genus Lasius (Hym., Formicidae). Entomol. Monthly Mag. 94, 9-11.

Scheu, S., Schaefer, M., 1998. Bottom-up control of the soil macrofauna community in a beechwood on limestone: Manipulation of food resources. Ecology 79, 1573-1585.

Setälä, H., McLean, M.A., 2004. Decomposition rate of organic substrates in relation to the species diversity of soil saprophytic fungi. Oecologia 139, 98-107.

Smith, J.L., 1994. Cycling of nitrogen through microbial activity. In: J.C. Hadfield and B.A. Steward, Editors, Soil Biology: Effects on soil quality, Lewis Publishers, Boca Raton, FL (1994), pp. 91-120.

Skinner, G.J., 1980. The Feeding Habits of the Wood-Ant, Formica rufa (Hymenoptera: Formicidae), in Limestone Woodland in North-West England. J. Anim. Ecol. 49, 417-433.

Stadler, B., Müller, B., 1996. Aphid honeydew and its effect on the phyllosphere microflora of Picea abies (L.) Karst. Oecologia 108, 771-776.

Stadler, B., Schramm, A., Kalbitz, K., 2006. Ant-mediated effect on spruce litter decomposition, solution chemistry, and microbial activity. Soil Biol. Biochem. 38, 561-572. 
Tiunov, A.V., Scheu, S., 2005. Facilitative interactions rather than resource partitioning drive diversity-functioning relationship in laboratory fungal communities. Ecology Letters 8, 618-625.

Tscharntke, T., Hawkins, B.A., 2002. Multitrophic level interactions. Cambridge University Press.

van Veen J.A., Lass, J.N., Frissel, M.J., 1984. Modelling C and N turnover through the microbial biomass in soil. Plant Soil 76, 703-707.

Völkl, W., Woodring, J., Fischer, M., Lorenz, M.W., Hoffmann, K.H., 1999. Ant-aphid mutualisms: the impact of honeydew production and honeydew sugar composition on ant preferences. Oecologia 118, 483-491.

Wagner, D., Brown, M.J.F., Gordon, D.M., 1997. Harvester ant nests, soil biota and soil chemistry. Oecologia 112, 232-236.

Wang, D., Lowery, B., Norman, J.M., McSweeney, K., 1996. Ant burrow effects on water flow and soil hydraulic properties of Sparta sand. Soil Tillage Res. 37, 8393.

Wardle, D.A., 2002. Communities and ecosystems: linking the aboveground and belowground components. Princeton, New Jersey: Princeton University Press.

Wardle, D.A., Yeates, G.W., Williamson, W.M., Bonner, K.I., Barker, G.M., 2004a. Linking aboveground and belowground communities: the indirect influence of aphid species identity and diversity on a three trophic level soil food web. Oikos 107, 283-294.

Wardle, D.A., Bardgett, R.D., Klironomos, J.N., Setala, H., van der Putten, W.H., Wall, D.H., 2004b. Ecological linkages between aboveground and belowground biota. Science 304, 1629-1633.

Wardle, D.A., Williamson, W.M., Yeates, G.W., Bonner, K.I., 2005. Trickle-down effects of aboveground trophic cascades on the soil food web. Oikos 111, 348358.

Wellenstein, G., 1980. Auswirkung hügelbauender Waldameisen der Formica rufaGruppe auf forstschädliche Raupen und das Wachstum der Waldbäume. Z. Ang. Entomol. 89, 144-157.

Woodring, J., Wiedemann, R., Fischer, M.K., Hoffmann, K.H., Völkl, W., 2004. Honeydew amino acids in relation to sugars and their role in the establishment of ant-attendance hierarchy in eight species of aphids feeding on tansy (Tanacetum vulgare). Physiol. Entomol. 29, 311-319. 
Chapter 2

Nutrient dynamics in a tritrophic system of ants, aphids and beans

Evelyn Schumacher and Christian Platner

Journal of Applied Entomology 133, 33-46 


\section{Abstract}

The interactions between ants (Lasius niger), aphids (Aphis fabae) and plants (Phaseolus vulgaris) were studied in a laboratory experiment with the following treatments: application of $\mathrm{N}$-fertilizer for plants, supply of mealworms or sugar solution or their combination as alternative food sources for ants. Three main questions were studied: (1) Do ants reduce tending to honeydew-producing aphids when an alternative sugar or protein resource was available? (2) Is aphid predation/protein consumption by ants higher when additional carbon is offered to maintain the carbon/protein balance? (3) Does fertilizer treatment propagate in the food web?

For the experimental analysis stable isotope techniques were applied. $\delta^{15} \mathrm{~N}$ served as a marker for the pathway from plants to higher trophic levels. Low $\delta^{15} \mathrm{~N}$ value of fertilizer spread from plant shoots to aphids and ants. To trace which sugar/protein source was consumed by ants, the different ${ }^{13} \mathrm{C} /{ }^{12} \mathrm{C}$ - ratios of $\mathrm{C}_{3^{-}}$and $\mathrm{C}_{4^{-}}$ plants were used with aphids feeding on $\mathrm{C}_{3}$-plant material, while mealworm food and sugar solution originated from $\mathrm{C}_{4}$-plant material. Fertilizer application had no effect on biomasses of plants, consumers or microflora. Ant biomass was significantly higher when additional sugar solution was offered. Higher contents of ${ }^{13} \mathrm{C}$ indicated a high incorporation rate of additional sugar. Additional protein had no effect on colony biomass and no increasing predation on aphids could be observed when carbon was in excess. However, due to the lack of queens and newly produced larvae, protein requirements of experimental colonies were lower than in natural systems. Ants positively affected aphid populations, but reduced tending, whilst having access to an alternative sugar resource. When sugar/protein was offered to ants, the host plant had an increased root/shoot ratio. This indicates that decreasing aboveground activity of ants could lead to reduced plant growth of aphid-infested plants, presumably due to higher fungal attack on shoots.

\section{Keywords}

Carbohydrate, delta $\mathrm{C}-13$, delta $\mathrm{N}-15$, dietary mixing, formicidae, nitrogen 


\section{Introduction}

Ants are dominant in most terrestrial ecosystems and may have a high impact on many plant and animal populations (Hölldobler and Wilson, 1990). Their social behaviour enables them to use resources effectively. Due to communication and cooperation, ants can influence their environment to a high degree (Brian, 1983; Hölldobler and Wilson, 1990), and can also have effects on the structure of foodwebs (Letourneau and Dyer, 1998). Mutualistic relationships between ants and aphids are common and ants collect the honeydew produced by aphids as a sugar resource. In return, the ants protect the aphids against their enemies (Way, 1954; Banks, 1962; Banks and Macauley, 1967) and provide other services like shelter brood care (Wood, 1982; Bristow, 1983; Cushman and Whitham, 1989), removing dead bodies and exuviae (Banks, 1962), and transport to feeding sites (Way, 1954). Moreover, aphid-produced honeydew can be used as a C-resource by soil microbes. Ant-attendance can positively affect the number of aphids on a host plant, but this positive effect depends on several factors including the natural enemy level (Bristow, 1984), ant abundance (Cushman and Whitham, 1991; Morales, 2000) and availability of alternative sugar-resources for ants. When honeydew is in excess, ants can have a negative effect on the aphid population (Sakata, 2000). For Lasius flavus ants, Pontin (1958) hypothesised that with increasing sugar intake more protein would be needed to maintain a balanced protein-carbohydrate diet. Hence, ant-homopteran interactions range from mutualism (by collecting honeydew and provide services) to exploitative predation (Cushman and Addicott, 1991; Bronstein, 1994). However, little is known about the mechanisms underlying this switching behaviour. Experimental studies examining factors which might cause a change in the ant-homopteran interaction included only short periods (hours) of observation (Del-Claro and Oliveira, 1993; Offenberg, 2001).

We tested Pontin's hypothesis for a longer time period (2.5 month) by using stable isotopes. The analysis of stable isotopes is a promising method for characterizing the origin of food resources under certain conditions (Post, 2002). For ants this method was used in tropical and temperate regions to characterise food webs (Blüthgen et al., 2003; Sanders and Platner, 2006) and the material flow in mutualistic interactions between ants and myrmecophytes (Fisher et al., 1990; Treseder et al., 1995; Sagers et al., 2000). In our study we used microcosms with Phaseolus vulgaris L. seedlings infested with Aphis fabae Scopoli to examine 
whether ants would produce a top-down effect on aphids and reduce the tending of honeydew-producing aphids when offered an alternative sugar/protein resource. When ants switch from attendance to predation or vice versa they modify homopteran populations and their feeding rates, and consequently exert positive or negative effects on the host plant (Carroll and Janzen, 1973). The homopterans gain food and habitat from the plant, while the plants suffer from tissue damage, loss of metabolites and incidence of infection by microbial pathogens. For the plant, possible advantages of the presence of aphids include the attraction of ants, which may defend the plant against external herbivores (Buckley, 1997a) and reduce fungal diseases by removing honeydew.

In the last years, the interest in costs and benefits for the partners in direct interactions between ants and their trophobionts has been growing (Cushman and Addicott, 1989; Stadler and Dixon, 1998; Yao et al., 2000; Morales, 2000), and also tritrophic interactions between ants, aphids, and plants have been examined. However only the top-down effect of ants was considered (Buckley, 1997a and b; Morales, 2000), although ants belong to the few organisms which influence the system (or parts of it) top-down as well as bottom-up. To assess the relations between both these effects they need to be tested simultaneously. We did this by inducing a bottom-up effect on the plant by increasing the soil nutrient level, in addition to the top-down effect by alternative food for ants.

Fertilizer application should increase the nutrient level of plants and by that, it should increase biomass of aphid-colonies because of better nutrient availability. Dependent on the quality of the alternative food resource in comparison to aphids honeydew, ants could profit from higher biomass of aphid colonies, especially when aphid colonies are the only food resource in the microcosms. The low ${ }^{15} \mathrm{~N}$ content of the applicated fertilizer should be traceable in the different compartments of the food web, if the participant of the system incorporated the additional nutrient directly or indirectly, thus ${ }^{15} \mathrm{~N}$ content of fertilizer can be used as a marker to follow the nutrient, which is taken up by the plants, through the whole system. The use of different stable isotope ratios $\left({ }^{13} \mathrm{C} /{ }^{12} \mathrm{C}\right.$ ) between $\mathrm{C}_{3}$ - (aphids on bean) and $\mathrm{C}_{4}$-plants (mealworm food, cane sugar) enabled us to trace the fate of the sugar/protein resources in all compartments of the microcosm system (shoots, roots, aphids and ants). Mealworms contained high ${ }^{15} \mathrm{~N}$ values and should lead to higher ${ }^{15} \mathrm{~N}$ values when they were consumed by ants. 
We tested three groups of hypotheses:

Group 1 (bottom-up-effects): The addition of fertilizer leads to an increase of plant and microfloral biomass and the biomass of the further components of the food web. After fertilization root biomass will decrease. The lower ${ }^{15} \mathrm{~N}$-value in comparison to the legumes of the fertilizer will propagate through the food webs until the trophic level of the ants.

Group 2 (direct top-down-effects): The supply of sugar and/or protein for ants will lead to an increase of ant and plant biomass and to a decrease of aphid biomass. Additional protein will enhance production of the colony as compared to additional sugar. The higher ${ }^{13} \mathrm{C}$-content of sugar and protein will produce higher ${ }^{13} \mathrm{C}$-content in ants; higher ${ }^{15} \mathrm{~N}$-contents of protein will be mirrored in higher ${ }^{15} \mathrm{~N}$-content in ants.

Group 3 (indirect top-down-effects): Offering additional sugar/protein, lower tending of aphids by ants combined with lower honeydew collection will lead to higher microbial biomass in the soil, due to better $\mathrm{C}$ availability.

Our study demonstrated that additional resources from bottom-up lead to an increase of aboveground plant biomass, from top-down to an increase of ant biomass. Stable isotopes could serve as markers for nitrogen and carbon flow in the food chain. Indirect negative effects between ants and plants are a dominant characteristic feature of the system.

\section{Materials and Methods}

\section{Microcosm set-up}

Experimental microcosms were designed with ants, plants and aphid colonies as constituent elements and kept in a greenhouse at natural light conditions for two and a half months ( "july" to "september" 2003). Each microcosm contained one experimental ant colony consisting of 50 workers, 30 pupae and 20 larvae of Lasius niger L., which were collected in Göttingen (Germany) from a dry hillside in July 2003. A microcosm consisted of a pot (alumina $20 \mathrm{~cm}$ id $19 \mathrm{~cm}$ high) filled with nutrient-poor soil from a dry grassland near Göttingen and closed by a transparent perspex cylinder ( $19 \mathrm{~cm}$ id $25 \mathrm{~cm}$ high) with removable mesh $(2 \mu \mathrm{m})$ as a lid. The soil was also covered by mesh to separate the above- and belowground compartment. Via plastic tubes, ants had access a) to the plant and aphids and b) to a foraging 
area (plaster-floored jar with lid) where water and alternative food of the respective treatment were offered (Appendix A).

In each microcosm, a Phaseolus vulgaris seedling (breed Solido) was planted 20 days before the experiment started. A Rhizobium solution was added to the soil around every plant to encourage the development of root nodules. In fertilizer treatments $2 \times 10 \mathrm{ml}$ of an ammonium-nitrate solution were applied on the third and 11 th day after planting the seedling. Each plant was infested with 50 apterous Aphis fabae individuals of the same size, the black bean aphid. A. fabae is a facultative myrmecophilous aphid species commonly tended by Lasius niger (Pontin, 1958). The aphid culture used for this experiment had been kept in the Institute of Phytopathology (Göttingen University). Aphids were reared on Phaseolus vulgaris before adding them to the experimental containers. Plants and aphids were allowed to develop for 14 days, before ant workers and brood were added.

\section{Diet treatments}

We used a blocked, three-factorial design with the factors "additional carbohydrate" (with and without sugar solution), "additional protein" (with and without mealworms) and "fertilizer" (with and without). The 32 microcosms were divided into four blocks; we arranged the eight treatments randomly within each block, which additionally contained a control with aphids but no ants. One data-logger in every control microcosm registered eventual differences in microclimatic conditions between blocks. The four blocks rotated every five days during the experiment to minimize the block effect caused by different light conditions in the greenhouse.

According to the treatment factors, several ant colonies were exposed to alternative sugar and/or protein resources. Supplementary carbohydrate food was a 1:1 solution of cane sugar (Saccharum officinarum L.) and demineralised water. Protein food consisted of freshly killed Tenebrio molitor L. larvae (mealworm) which were reared on Zea mays L. products (cornmeal, semolina and parts of fresh plants). Sugar solution and $T$. molitor larvae were offered to ants for five days, until they were replaced with fresh food. 


\section{Data collection and statistical analyses}

During the incubation time the activity of ants was observed for 17 days by recording the number and location of ants in each microcosm. At the end of the experiment, Lasius niger workers and larvae were collected by hand and frozen at $-24^{\circ} \mathrm{C} 5$ days after the last additional food offer. Afterwards freeze-dried biomass of ants and ant larvae was measured. All aphids from each microcosm were removed from the shoots which were clipped at ground level. We froze 50 aphids of each microcosm, while the rest was washed off the plant material and stored in $70 \%$ ethanol. To assess differences in aphid biomass, total dry mass was determined (drying at $60^{\circ} \mathrm{C}$, four days). Plant biomass was determined by separately drying the shoots and roots. $\left(105^{\circ} \mathrm{C}\right.$, three days). We measured stable isotopes $\left({ }^{15} \mathrm{~N}^{13} \mathrm{C}\right)$ and total nitrogen of two samples of pulverized plant material and freeze-killed ants and aphids, each. We analysed ants in total to avoid skew results due to different isotopic signatures among tissues (Tillberg et al., 2006). The period after the last additional food offer should reduce the influence of crop content to a marginal rate. Ratios of ${ }^{13} \mathrm{C}$ and ${ }^{15} \mathrm{~N}$ were estimated by a coupled system consisting of an elemental analyzer (Carlo Erba NA 2500) and a gas isotope mass spectrometer (Finnigan Deltaplus). The system is computer-controlled allowing measurement of ${ }^{13} \mathrm{C}$ and ${ }^{15} \mathrm{~N}$ (Reineking et al., 1993). Isotopic contents were expressed in $\delta$ units as the relative difference between sample and conventional standards with $\delta^{15} \mathrm{~N}$ or $\delta^{13} \mathrm{C}[\%]=\left(R_{\text {sample }}-\right.$ $\left.\mathrm{R}_{\text {Standard }}\right) / \mathrm{R}_{\text {Standard }} \mathrm{x} 1000$, where $\mathrm{R}$ is the ratio of ${ }^{15} \mathrm{~N} /{ }^{14} \mathrm{~N}$ or ${ }^{13} \mathrm{C} /{ }^{12} \mathrm{C}$ content, respectively. The conventional standard for ${ }^{15} \mathrm{~N}$ is atmospheric nitrogen and for ${ }^{13} \mathrm{C}$ PD-belemnite (PDB) carbonate. Acetanilide $\left(\mathrm{C}_{8} \mathrm{H}_{9} \mathrm{NO}\right.$, Merck, Darmstadt) served for internal calibration with a mean standard deviation of samples $<0.1$. From each microcosm, a subsample of mixed soil was taken to analyse for microbial basal respiration, microbial biomass (SIR, Anderson and Domsch, 1978; Scheu, 1992), and gravimetrically determined soil water content.

Data were analysed by three factor analysis of variances (SAS 8.1, SAS Institute Inc., Cary, USA), means of different treatments were tested for significant differences by Tukeys test (Sokal and Rohlf, 2001). To assess effect of ants on soil conditions and aphids, controls without ants were compared with unfertilized microcosms inhabited by ant colonies in a one factor GLM. 


\section{Results}

Soil and microflora

Soil moisture did not differ significantly between treatments with and without fertilizer application, but it was lowest in controls, where ants were absent (GLM for treatments without fertilizer: $F_{1,15}=4.15, p=0.06$ for the effect of ants). Overall, soil moisture did not consistently differ between food treatments (Appendix B). However, soil moisture differed significantly between the blocks (Table 1). Microbial biomass did not differ significantly between treatments. Basal respiration decreased significantly in treatments with fertilizer application, but alternative food supply for ants had no effects on basal respiration (Table 1).

Table 1. Influence of fertilizer application and additional food for Lasius niger on percent soil moisture, microbial biomass, and basal respiration. Data for basal respiration were logtransformed $\left(\log _{10} X+1\right)$. $C=$ carbohydrate, $P=$ protein, $F=$ fertilizer, $d f=$ degrees of freedom.

\begin{tabular}{|c|c|c|c|c|c|c|c|}
\hline & \multirow[b]{2}{*}{ df } & \multicolumn{2}{|c|}{ soil moisture } & \multicolumn{2}{|c|}{ microbial biomass } & \multicolumn{2}{|c|}{$\begin{array}{c}\text { basal respiration } \\
(\mathrm{log})\end{array}$} \\
\hline & & $\mathrm{F}$ & $P$ & $F$ & $P$ & $\mathrm{~F}$ & $\mathrm{P}$ \\
\hline C & 1 & 0.07 & 0.7975 & 0.30 & 0.5902 & 0.31 & 0.5825 \\
\hline $\mathrm{P}$ & 1 & 0.00 & 0.9660 & 2.04 & 0.1680 & 0.01 & 0.9278 \\
\hline $\mathrm{F}$ & 1 & 0.02 & 0.8810 & 0.80 & 0.3820 & 7.84 & 0.0107 \\
\hline$C \times P$ & 1 & 4.78 & 0.0402 & 1.49 & 0.2352 & 0.84 & 0.3701 \\
\hline$C \times F$ & 1 & 1.07 & 0.3162 & 1.44 & 0.2434 & 0.01 & 0.9157 \\
\hline$P \times F$ & 1 & 0.07 & 0.7956 & 1.09 & 0.3077 & 0.86 & 0.3630 \\
\hline$C \times P \times F$ & 1 & 0.15 & 0.7021 & 0.01 & 0.9181 & 0.79 & 0.3856 \\
\hline block & 3 & 6.80 & 0.0022 & 1.06 & 0.3875 & 1.23 & 0.3220 \\
\hline
\end{tabular}

\section{Phaseolus vulgaris}

Total plant biomass was not affected by fertilizer application or additional food for ants (Figure 1a, Table 2). Root/shoot ratio was significantly affected by fertilizer application leading to increased shoot biomass (from $1.42 \mathrm{~g}$ to $1.52 \mathrm{~g}$ ) and decreased root biomass (from $0.25 \mathrm{~g}$ to $0.21 \mathrm{~g}$ ) (Figure $1 \mathrm{~b}$, Table 2). Decreasing shoot biomass and unaffected root biomass were observed when ants had access to the sugar solution (mean shoot biomass without and with sugar $1.58 \mathrm{~g}$ and $1.32 \mathrm{~g}$, respectively) or Tenebrio larvae (mean shoot biomass without and with protein $1.66 \mathrm{~g}$ and $1.25 \mathrm{~g}$, respectively). Root/shoot ratio differed significantly between carbohydrate treatments and between the blocks (Table 2). Additional fertilization had no effect on the total nitrogen in plants (Table 4). 

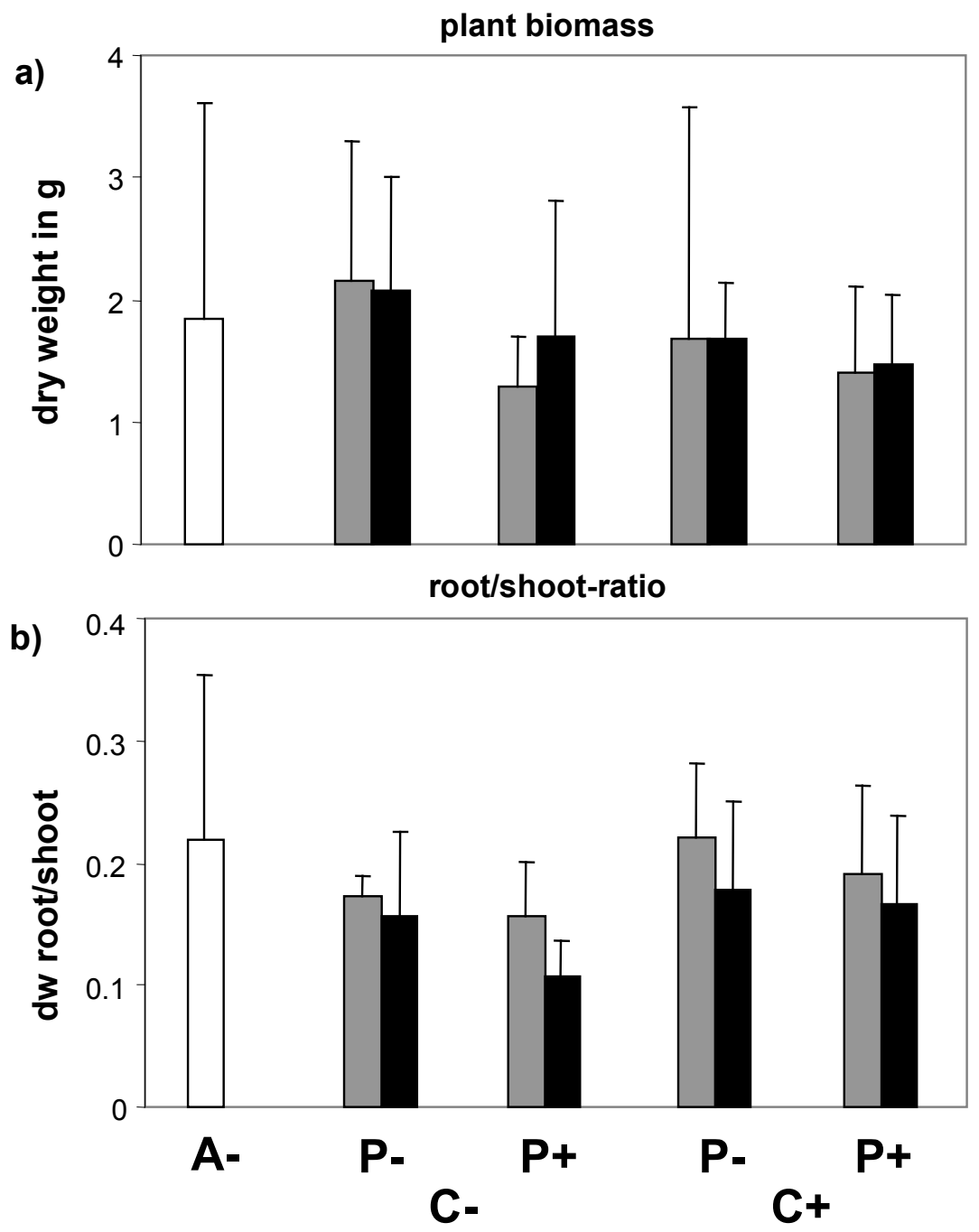

Figure 1. Influence of fertilizer application and additional food for Lasius niger on plant biomass (a) and root/shoot-ratio (b). Bars represent means $(n=4)$ of Phaseolus vulgaris dry weight or root/shoot-ratio in each microcosm in control (open bars) and ant treatments without (shaded bars) and with fertilizer (black bars) respectively. Error bars are standard deviations ignoring the block effect. $A=$ control without ants, $C=$ carbohydrate, $P=$ protein, $\mathrm{F}=$ fertilizer; +=with, -=without, dw=dry weight.

\section{Aphis fabae}

Total biomass of aphids was not significantly influenced by alternative food supply for ants (Table 3). A comparison with the controls revealed no significant overall effect of ants as well. However, in unfertilized microcosms with ants which had access to alternative protein resource aphid biomass was one third higher than in the controls without ants (Figure 2a; GLM for treatments without fertilizer: $F_{1,15}=3.48, p=0.08$ for the effect of protein). Application of fertilizer tended to increase aphid biomass, but means did not differ significantly (Figure $2 a$, Table 3 ). We could detect a marginally 
positive effect of fertilizer on the total nitrogen amount of aphids (Table 4, Appendix C).

Table 2. Influence of fertilizer application and additional food for Lasius niger on the total plant biomass and on root-/shoot-ratio. Data for root-/shoot-ratio were log-transformed $(\log 10 X+1) . C=$ carbohydrate, $P=$ protein, $F=f e r t i l i z e r, ~ d f=$ degrees of freedom.

\begin{tabular}{lcccccc}
\hline & & \multicolumn{2}{c}{ plant biomass } & & \multicolumn{2}{c}{ root/shoot-ratio (log) } \\
\cline { 3 - 4 } \cline { 6 - 7 } & df & $\mathrm{F}$ & $\mathrm{P}$ & & $\mathrm{F}$ & $\mathrm{P}$ \\
\hline $\mathrm{C}$ & 1 & 0.07 & 0.7941 & & $\mathbf{8 . 7 6}$ & $\mathbf{0 . 0 0 7 5}$ \\
$\mathrm{P}$ & 1 & 0.55 & 0.4644 & & $\mathbf{3 . 5 4}$ & $\mathbf{0 . 0 7 3 9}$ \\
$\mathrm{F}$ & 1 & 0.02 & 0.8824 & & $\mathbf{5 . 0 5}$ & $\mathbf{0 . 0 3 5 6}$ \\
$\mathrm{C} \times \mathrm{P}$ & 1 & 0.34 & 0.5650 & & 0.06 & 0.8037 \\
$\mathrm{C} \times \mathrm{F}$ & 1 & 0.30 & 0.5865 & & 0.52 & 0.4791 \\
$\mathrm{P} \times \mathrm{F}$ & 1 & 0.00 & 1.0000 & & 1.02 & 0.3245 \\
$\mathrm{C} \times \mathrm{P}$ x F & 1 & 0.19 & 0.6676 & & 1.21 & 0.2829 \\
block & 3 & 2.04 & 0.1344 & & $\mathbf{7 . 0 9}$ & $\mathbf{0 . 0 0 1 9}$ \\
\hline
\end{tabular}

Table 3. Influence of fertilizer application and additional food for Lasius niger on aphid biomass, biomass of ant colonies, and ant activity. $\mathrm{C}=$ carbohydrate, $\mathrm{P}=$ protein, $\mathrm{F}=$ fertilizer, $\mathrm{df}=$ degrees of freedom.

\begin{tabular}{|c|c|c|c|c|c|c|c|}
\hline & \multirow[b]{2}{*}{ df } & \multicolumn{2}{|c|}{ aphid biomass } & \multicolumn{2}{|c|}{$\begin{array}{c}\text { biomass of ant } \\
\text { colonies }\end{array}$} & \multicolumn{2}{|c|}{ ant activity } \\
\hline & & $\mathrm{F}$ & $P$ & $\mathrm{~F}$ & $P$ & $\mathrm{~F}$ & $P$ \\
\hline C & 1 & 0.80 & 0.3807 & 24.03 & $<0.0001$ & 4.09 & 0.0601 \\
\hline $\mathrm{P}$ & 1 & 1.32 & 0.2639 & 0.46 & 0.5035 & 0.19 & 0.7024 \\
\hline $\mathrm{F}$ & 1 & 2.51 & 0.1282 & 1.60 & 0.2201 & 1.38 & 0.2576 \\
\hline$C \times P$ & 1 & 0.92 & 0.3496 & 0.00 & 1.0000 & 2.74 & 0.1174 \\
\hline$C \times F$ & 1 & 0.75 & 0.3976 & 0.66 & 0.4270 & 3.00 & 0.1026 \\
\hline$P \times F$ & 1 & 0.19 & 0.6638 & 1.89 & 0.1849 & 7.38 & 0.0153 \\
\hline$C \times P \times F$ & 1 & 1.27 & 0.2726 & 0.60 & 0.4482 & 2.97 & 0.1043 \\
\hline block & 3 & 0.44 & 0.7246 & 0.20 & 0.8943 & 25.76 & $<0.0001$ \\
\hline
\end{tabular}



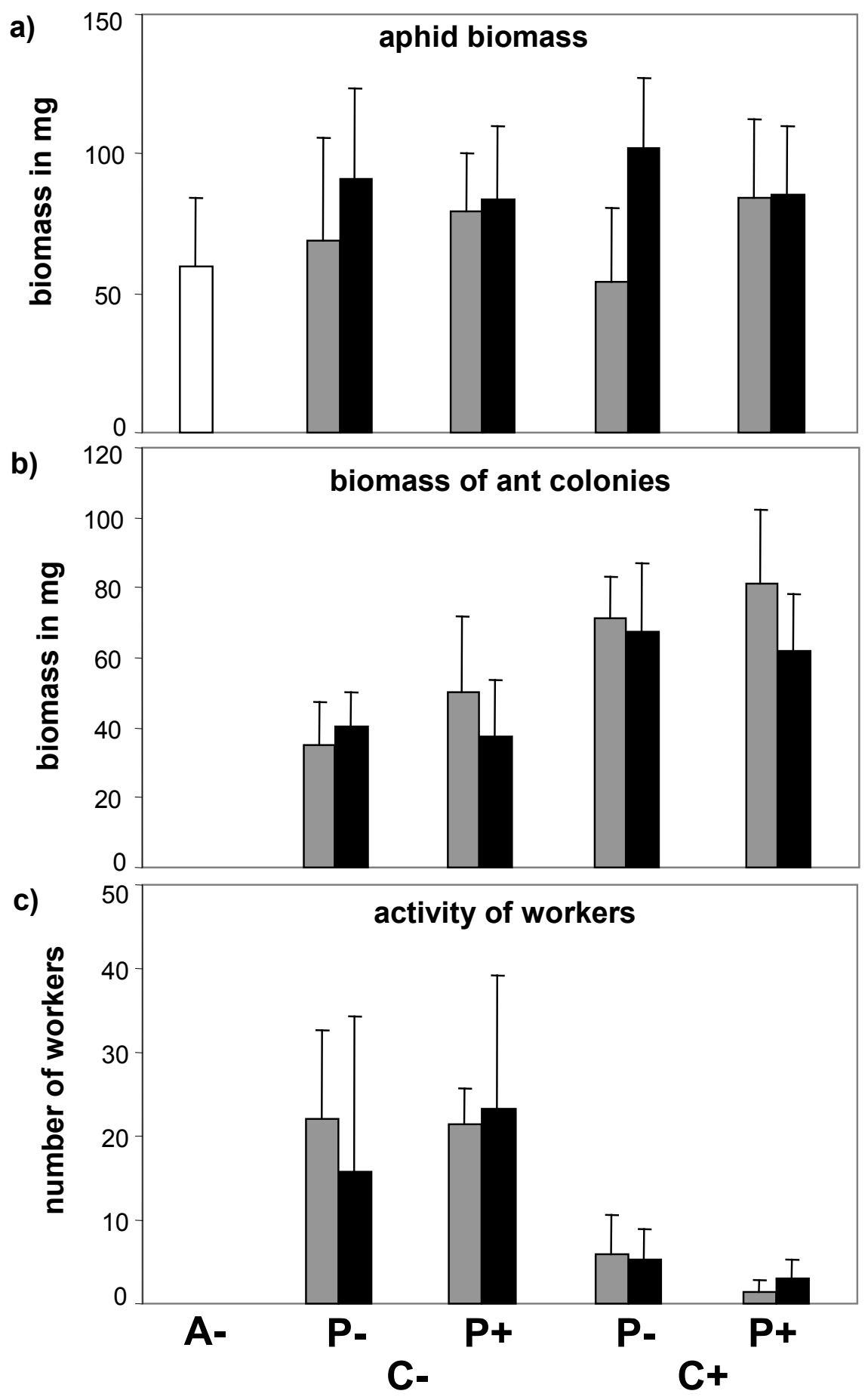

Figure 2. Influence of fertilizer application and additional food for Lasius niger on aphid biomass (a), ant colony biomass (b) and activity of workers (c). Bars represent means $(n=4)$ of Aphis fabae dry weight, total biomass of freeze-dried Lasius niger workers and larvae or number of ant workers observed in each microcosm in control (open bars) and ant treatments without (shaded bars) and with fertilizer (black bars) respectively. Error bars are standard deviations ignoring the block effect. $A-=$ control without ants, $C=$ carbohydrate, $\mathrm{P}=$ protein, $\mathrm{F}=$ fertilizer; +=with, -=without. 


\section{Lasius niger}

Total colony biomass of ants increased by the factor 1.75 with available sugar resource (Figure $2 b$, Table 3), but biomass was not significantly influenced by either additional prey or fertilizer application. The nitrogen content of $L$. niger workers and larvae decreased (from $7.04 \%$ to $4.72 \%$ and from $5.21 \%$ to $4.32 \%$ respectively) when additional sugar was offered to ants, whereas the total nitrogen (related to colony biomasses) in ants increased (from $2.81 \mathrm{mg}$ to $3.28 \mathrm{mg}$ ), due to higher biomass (Table 4, Appendix C). We observed ant activity by recording number and position of ants in each microcosm. Aboveground activity of workers was highest in treatments without access to a cane sugar solution, activity was about 5 times lower when sugar solution was available for the ants (Figure 2c, Table 3). In the presence of cane sugar solution, ants fed preferably on this food resource, an observation which was supported by increased $\delta^{13} \mathrm{C}$-values in ants and ant larval tissue in these treatments.

Table 4. Influence of fertilizer application and additional food for Lasius niger on total nitrogen in plants, aphids, and ants. $\mathrm{C}=$ carbohydrate, $\mathrm{P}=$ protein, $\mathrm{F}=$ fertilizer, $\mathrm{df}=$ degrees of freedom.

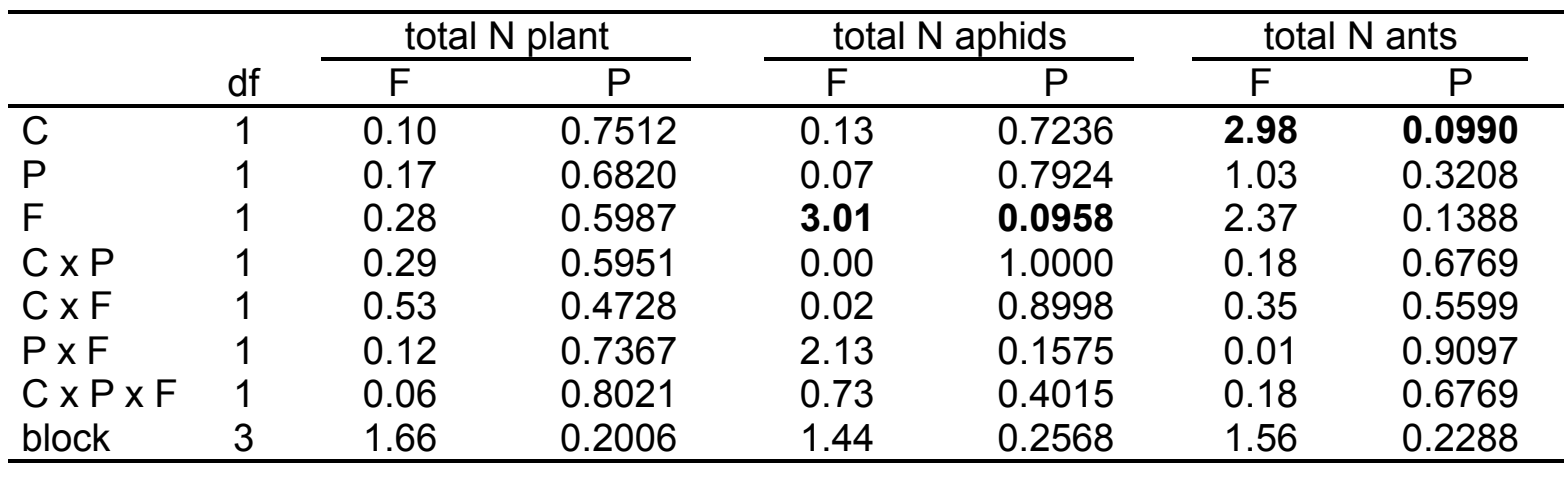

Bottom-up effects traced by stable isotopes

Fertilizer application resulted in lower $\delta^{15} \mathrm{~N}$-values in shoots (with fertilizer $3.93 \%$, without fertilizer $4.69 \%$ ), while it caused higher $\delta^{15} \mathrm{~N}$-values in roots (with fertilizer $3.13 \%$, without fertilizer $2.08 \%$ ), i.e. the fertilized plants sequestered relatively more of the light ${ }^{14} \mathrm{~N}$ - isotopes in shoots and more of the heavy ${ }^{15} \mathrm{~N}$-isotopes in roots (Figure 3a, 3b, Table 5). The $\delta^{15} \mathrm{~N}$-values of aphids were lower when aphids fed on fertilized plants (with fertilizer 3.63\%o, without fertilizer 4.51\%) (Figure 4a, Table 5), however, differences 
$\delta^{15} \mathrm{~N}$ shoots

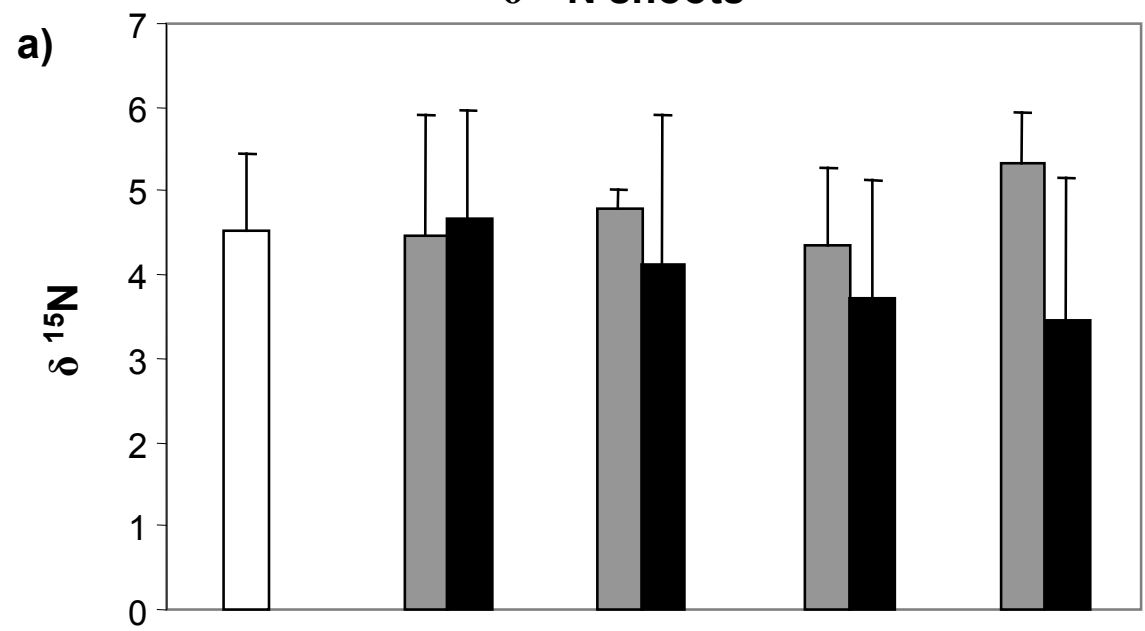

$\delta^{15} \mathrm{~N}$ roots

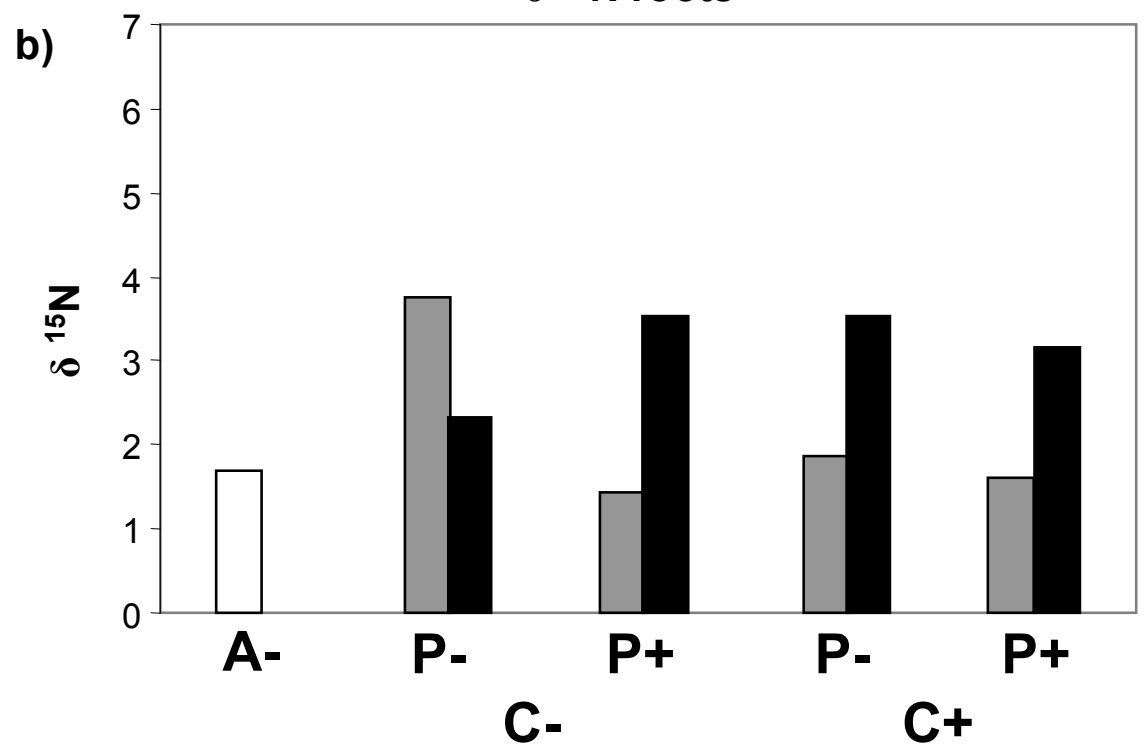

Figure 3. Influence of fertilizer application and additional food for Lasius niger on quantity of nitrogen-isotopes in shoots (a) and roots (b) of bean plants. Bars represent means $(n=4)$ of Phaseolus vulgaris shoot $\delta^{15} \mathrm{~N}$ values in each microcosm or the $\delta^{15} \mathrm{~N}$ value of roots in each microcosm of one block in control (open bars) and ant treatments without (shaded bars) and with fertilizer (black bars) respectively. Error bars in the upper panel are standard deviations ignoring the block effect. $A=$-control without ants, $C=$ carbohydrate, $P=$ protein, $F=$ fertilizer; $+=$ with, $-=$ without. 


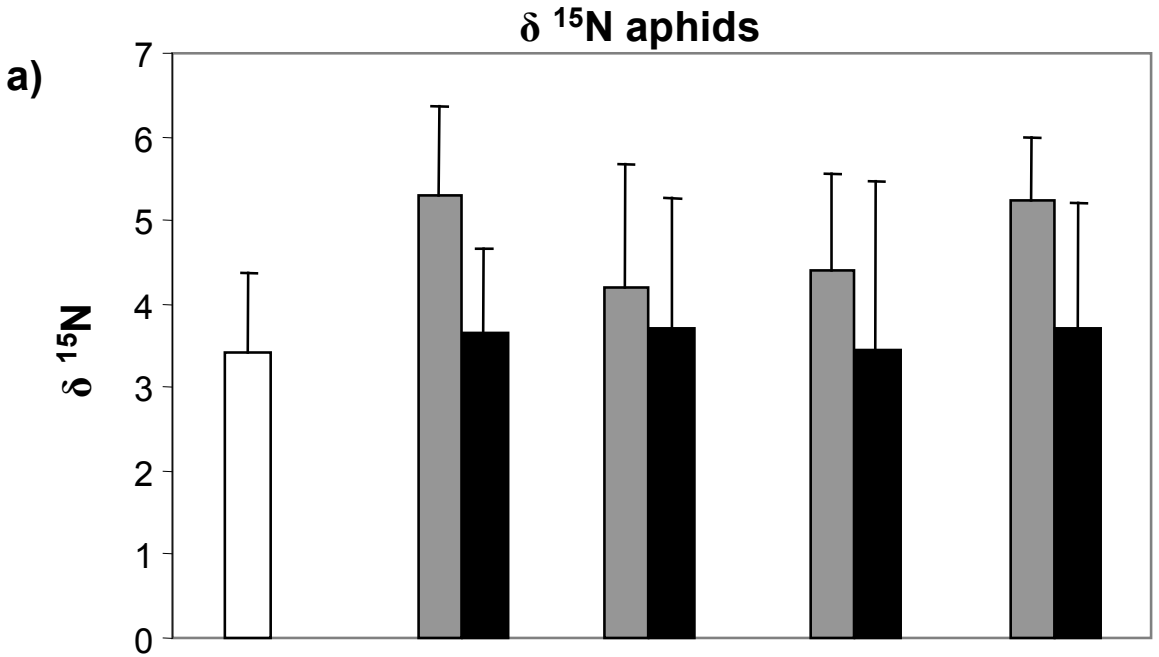

b)

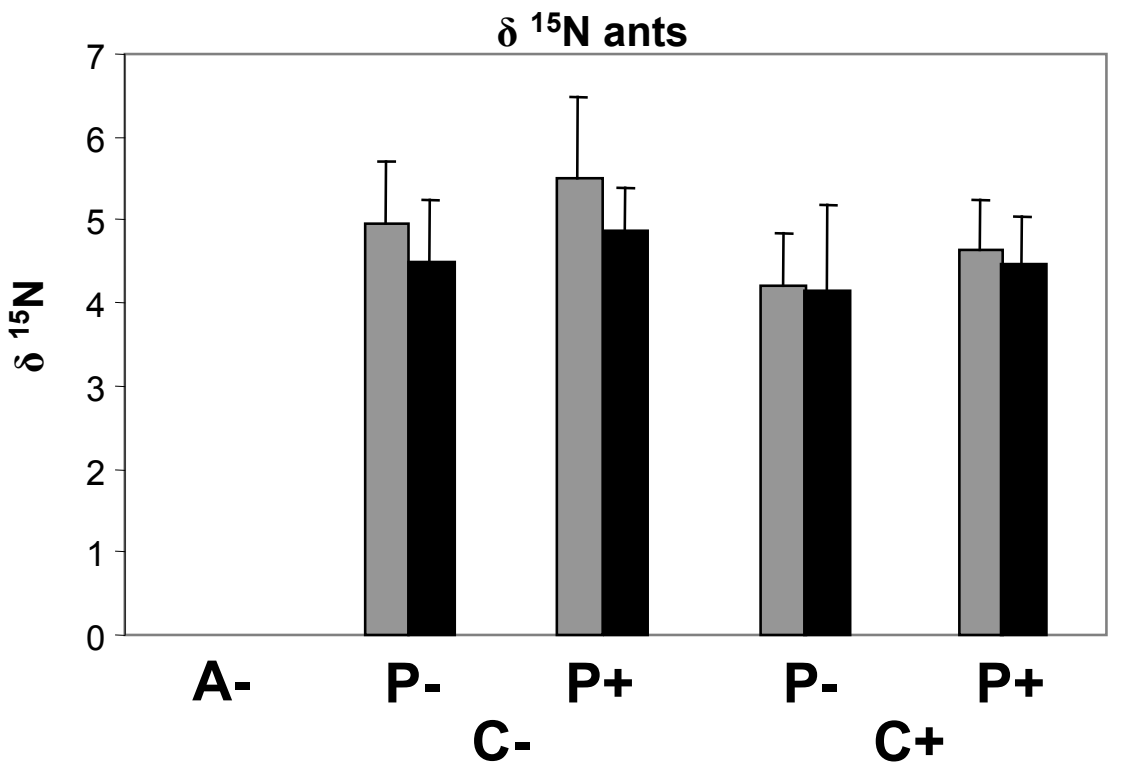

Figure 4. Influence of fertilizer application and additional food for Lasius niger on quantity of nitrogen-isotopes in aphids (a) and ants (b). Bars represent means $(n=4)$ of Aphis fabae $\delta^{15} \mathrm{~N}$ values or Lasius niger worker $\delta^{15} \mathrm{~N}$ values from two samples in each microcosm in control (open bars in upper panel) and ant treatments without (shaded bars) and with fertilizer (black bars) respectively. Error bars are standard deviations ignoring the block effect. $A-=$ control without ants, $\mathrm{C}=$ carbohydrate, $\mathrm{P}=$ protein, $\mathrm{F}=$ fertilizer; +=with, -=without. 
Table 5. Influence of fertilizer application and additional food for Lasius niger on the quantity of nitrogen-isotopes in shoots and aphids. $\mathrm{C}=$ carbohydrate, $\mathrm{P}=$ protein, $\mathrm{F}=$ fertilizer, $\mathrm{df}=$ degrees of freedom.

\begin{tabular}{lcccccc}
\hline & & \multicolumn{2}{c}{$\delta{ }^{15} \mathrm{~N}$ shoots } & & \multicolumn{2}{c}{$\delta^{15} \mathrm{~N}$ aphids } \\
\cline { 3 - 4 } \cline { 6 - 7 } & df & $\mathrm{F}$ & $\mathrm{P}$ & & $\mathrm{F}$ & $\mathrm{P}$ \\
\hline $\mathrm{C}$ & 1 & 0.39 & 0.5393 & & 0.00 & 0.9628 \\
$\mathrm{P}$ & 1 & 0.08 & 0.7858 & & 0.00 & 0.9633 \\
$\mathrm{~F}$ & 1 & 2.71 & 0.1149 & & $\mathbf{0 . 3 6}$ & $\mathbf{0 . 0 8 1 7}$ \\
$\mathrm{C} \times \mathrm{P}$ & 1 & 0.94 & 0.4391 & & 1.45 & 0.2574 \\
$\mathrm{C} \times \mathrm{F}$ & 1 & 0.28 & 0.6054 & & 0.79 & 0.3861 \\
$\mathrm{P} \times \mathrm{F}$ & 1 & 1.32 & 0.2643 & & 0.03 & 0.8678 \\
C x P x F & 1 & 1.31 & 0.2660 & & 0.08 & 0.7765 \\
block & 3 & 0.04 & 0.8440 & & 0.30 & 0.5869 \\
\hline
\end{tabular}

Table 6. Influence of fertilizer application and additional food for Lasius niger on the quantity of nitrogen- and carbon-isotopes in ants. $\mathrm{C}=$ carbohydrate, $\mathrm{P}=$ protein, $\mathrm{F}=\mathrm{fertilizer}, \mathrm{df}=\mathrm{deg}$ rees of freedom.

\begin{tabular}{lcccccc}
\hline & & \multicolumn{2}{c}{$\delta{ }^{15} \mathrm{~N}$ ants } & & \multicolumn{2}{c}{$\delta{ }^{13} \mathrm{C}$ ants } \\
\cline { 3 - 4 } \cline { 6 - 7 } & df & $\mathrm{F}$ & $\mathrm{P}$ & & $\mathrm{F}$ & $\mathrm{P}$ \\
\hline $\mathrm{C}$ & 1 & $\mathbf{1 9 . 0 1}$ & $\mathbf{0 . 0 0 0 3}$ & & $\mathbf{1 8 5 . 6 3}$ & $<\mathbf{0 . 0 0 0 1}$ \\
$\mathrm{P}$ & 1 & $\mathbf{9 . 6 6}$ & $\mathbf{0 . 0 0 5 5}$ & & $\mathbf{3 . 2 3}$ & $\mathbf{0 . 0 8 8 1}$ \\
$\mathrm{F}$ & 1 & $\mathbf{5 . 7 6}$ & $\mathbf{0 . 0 2 6 2}$ & & 1.59 & 0.2223 \\
$\mathrm{C} \times \mathrm{P}$ & 1 & 0.15 & 0.7012 & & 0.89 & 0.3578 \\
$\mathrm{C} \times \mathrm{F}$ & 1 & 0.94 & 0.3428 & & 0.00 & 1.0000 \\
$\mathrm{P} \times \mathrm{F}$ & 1 & 1.94 & 0.1804 & & 0.00 & 0.9805 \\
$\mathrm{C} \times \mathrm{P} \times \mathrm{F}$ & 1 & 0.54 & 0.4724 & & 0.00 & 0.9581 \\
block & 3 & 18.70 & $<\mathbf{0 . 0 0 0 1}$ & & 0.87 & 0.4748 \\
\hline
\end{tabular}

were not significant. Fertilizer application had significant influences on the $\delta^{15} \mathrm{~N}$ values of ants in the same way (with fertilizer $4.49 \%$, without fertilizer $4.81 \%$ ) (Figure 4b, 5, Table 6).

Top-down effects traced by stable isotopes

We calculated the differences of ${ }^{15} \mathrm{~N} /{ }^{13} \mathrm{C}$-values between the experimental ant colony and the sampled colony. The values for stable isotopes differed between the origin colonies and experimental colonies at the end of the experiment. The $\delta^{13} \mathrm{C}$-values of ants without access to additional cane sugar solution were between their origin $\delta^{13} \mathrm{C}$ values and the $\delta^{13} \mathrm{C}$-values of the aphids, while $\delta^{13} \mathrm{C}$-values of ants with alternative 


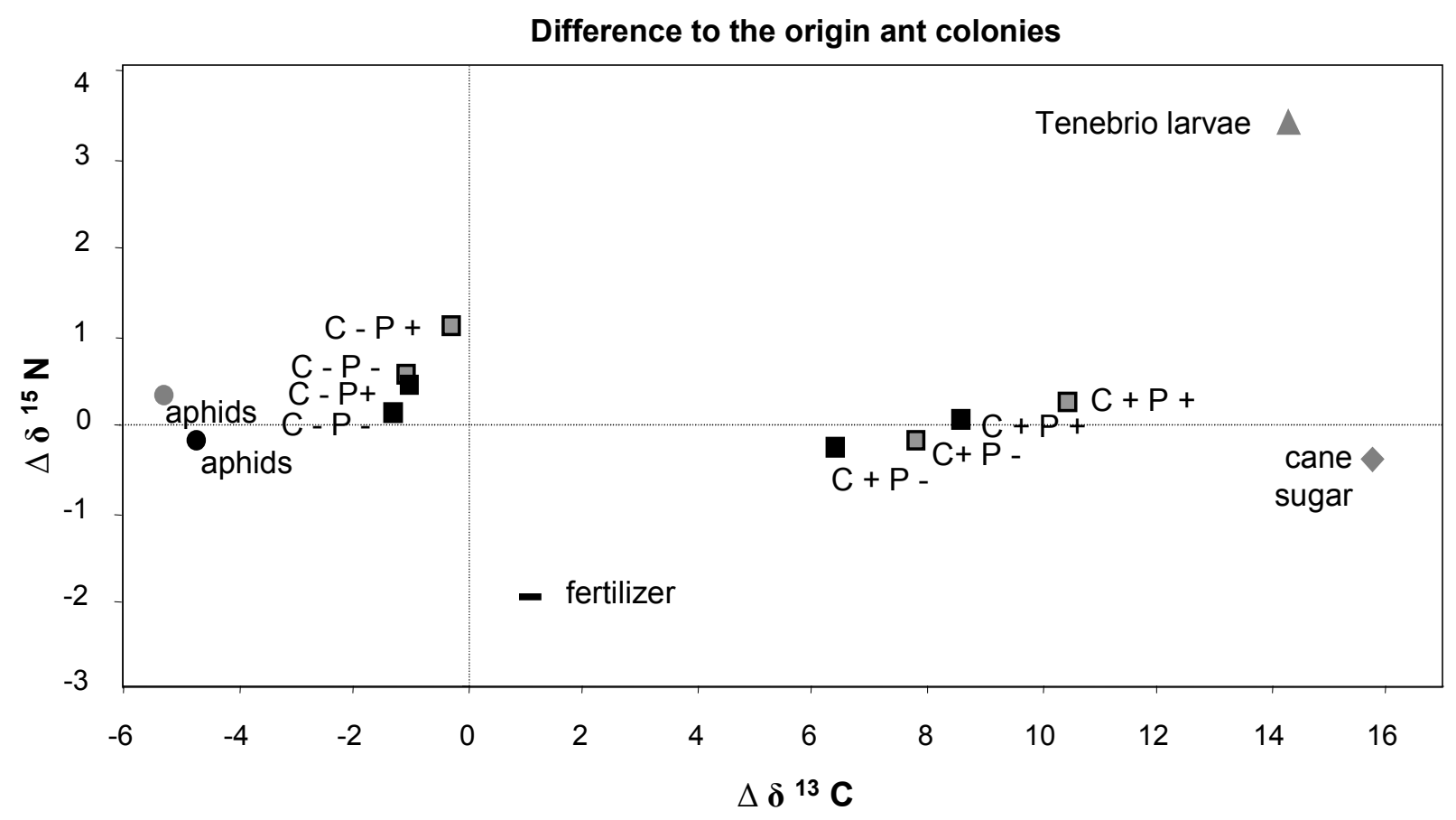

Figure 5. Influence of fertilizer application and alternative carbohydrate-/protein-resource for Lasius niger on their $\delta^{13} \mathrm{C}-/ \delta^{15} \mathrm{~N}$-composition. Values are standardized as the difference to the origin ant colonies. Squares represent $\delta^{15} \mathrm{~N}$ and $\delta^{13} \mathrm{C}$ values as mean $(\mathrm{n}=4$, each with two samples) differences between Lasius niger workers from the same colony before and after incubation in microcosms without (shaded squares) and with fertilizer (black squares), respectively. Mean $\delta^{15} \mathrm{~N}$ and $\delta^{13} \mathrm{C}$ values of Tenebrio molitor larvae (triangle), cane sugar (diamond), $\mathrm{NH}_{4} \mathrm{NO}_{3}$-fertilizer (dash), Aphis fabae grown in unfertilized microcosms (shaded circles) and Aphis fabae grown in fertilized microcosms (black circles) are shown as differences to the mean of origin ant colonies, respectively. $\mathrm{C}=$ carbohydrate, $\mathrm{P}=$ protein, $\mathrm{F}=$ fertilizer; +=with, $-=$ without.

sugar resource corresponded to $\delta^{13} \mathrm{C}$-values of cane sugar solution (Figure 5 ). In the presence of cane sugar solution, ants fed preferably on this food resource, an observation which was supported by increased $\delta^{13} \mathrm{C}$-values in ants in these treatments. Additional supply with Tenebrio molitor larvae enhanced $\delta^{13} \mathrm{C}$-values of ants. Ants had lower $\delta^{15} \mathrm{~N}$-values in treatments with an alternative carbohydrate resource as compared to treatments without sugar supply (mean with additional sugar $4.35 \%$, without additional sugar $4.95 \%$ ). In treatments without access to an additional carbohydrate resource, $\delta^{15} \mathrm{~N}$-values of ants were lower in fertilized as compared to unfertilized microcosms. Ants feeding on additional protein had higher $\delta^{15} \mathrm{~N}$-values as compared to treatment without additional protein source (Figure 5). 


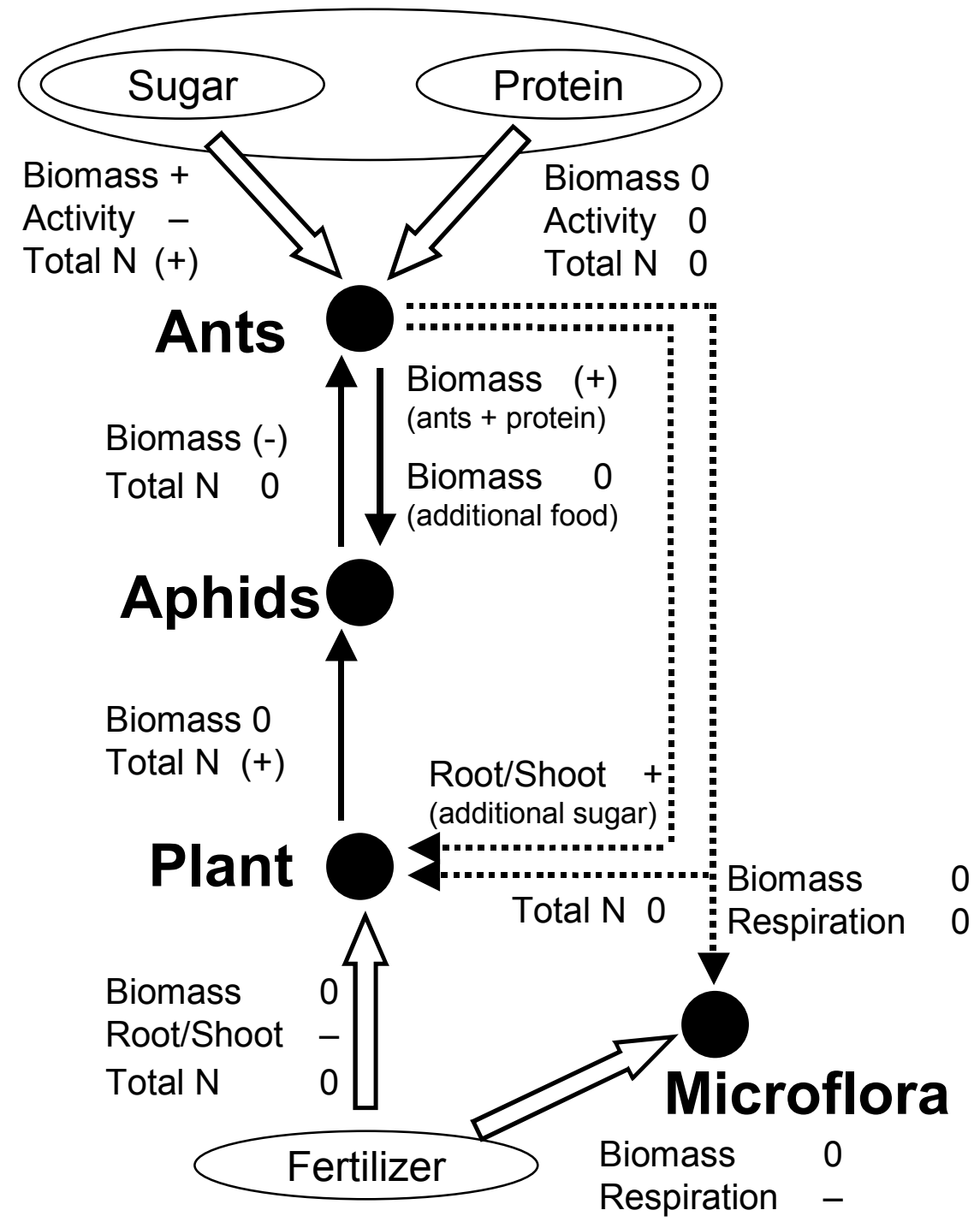

Figure 6. Top-down and bottom-up effects of additional food for Lasius niger and fertilizer application on the different compartments of the system. 


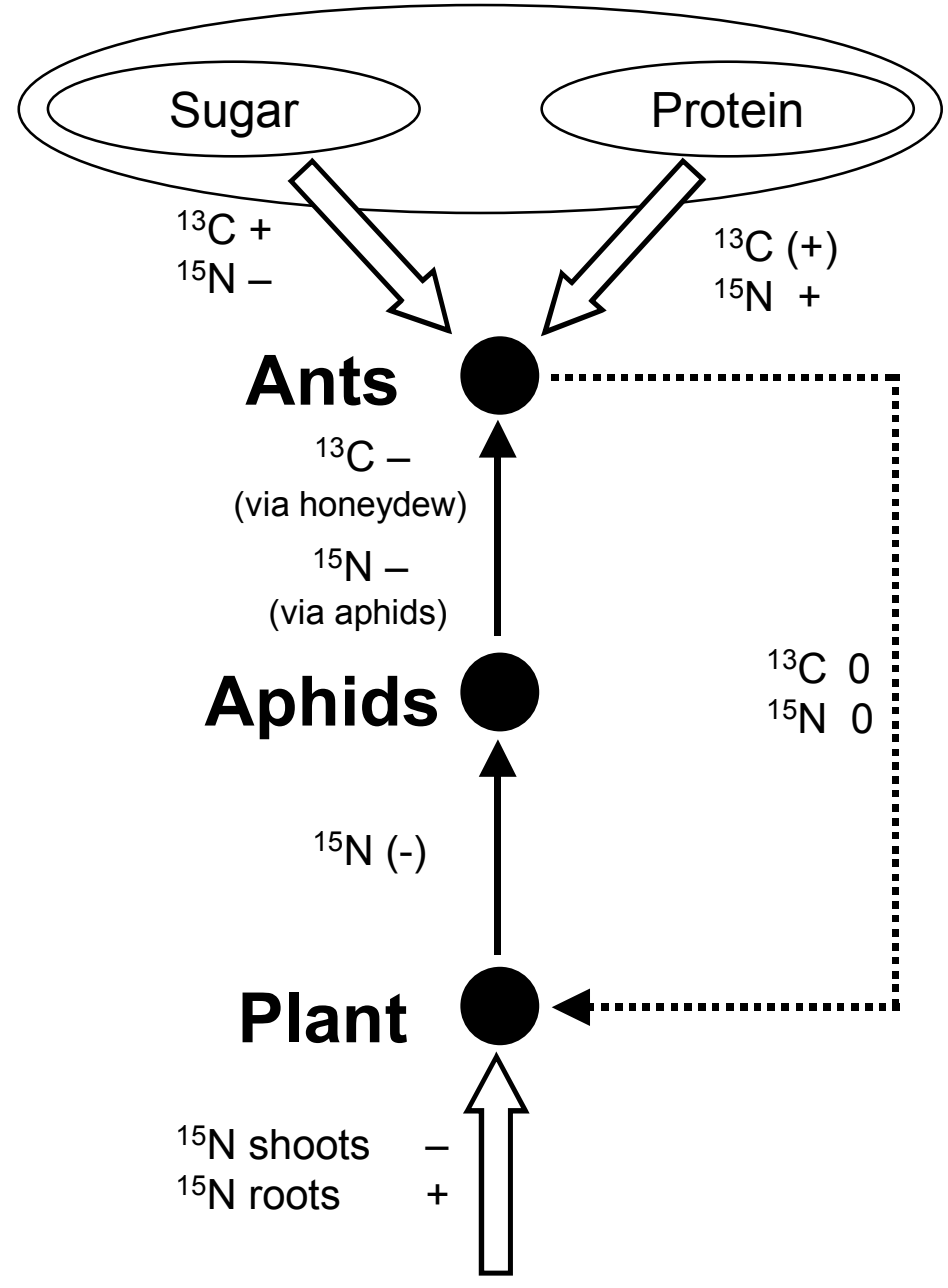

\section{Fertilizer}

Figure 7. Carbon and nitrogen fluxes traced by $\delta^{13} \mathrm{C}-/ \delta^{15} \mathrm{~N}$-composition of ants, aphids, and plants. 


\section{Discussion}

\section{Effect of fertilizer application}

Basal respiration decreased when fertilizer was applied, whereas microbial biomass did not differ between the treatments. Decreasing basal respiration in fertilized treatments could be caused by lower stress for microbes when additional nitrogen is present in soil which creates better conditions for development. Fertilizer application caused an increases in shoot biomass, while root biomass of Phaseolus vulgaris decreased. Similar trends were observed in other studies. Bååth et al. (1978) found high root/shoot ratios in pine seedlings in the absence of nitrogen and interpreted this effect as an evidence for nitrogen limitation of the plants. Ingestad (1962) showed that pine seedlings invested more resources into root growth than into shoot growth under nitrogen-deficient conditions. Looking at plant productivity from an energetic point of view, it is better to invest more energy in a larger shoot system, when fertilizer is applied. The plant can reduce its root system, because nitrogen is in excess and easily available (Figure 6).

Although fertilizer treatments reduced plant root-to-shoot ratio by increasing shoot biomass, this had only little effect on aphids feeding on the shoots. In our experiment, we could not detect significant differences in aphid biomass between fertilized and unfertilised microcosms, maybe due to a strong block effect in root/shoot ratio. Additional fertilization had no effect on the total nitrogen in plants. Beans are $\mathrm{N}$-fixers, so the $\mathrm{N}$-limitation was minimal. Total nitrogen of aphids weakly increased when they fed on fertilized plants. Some herbivores evolved mechanisms to find the most $\mathrm{N}$-rich plant part and enrich the available nitrogen from plant in their tissue (William et al., 1980).

Fertilizer application caused a marginally negative effect on total colony biomass of ants (Figure 6). Higher nitrogen concentration in soil is likely to enhance the nitrogen status of plants thereby inducing production of secondary compounds as a defence mechanism against herbivores (Buckley, 1997a). Thus plant biochemistry can have complex indirect influences on herbivore susceptibility to predators and parasites (Haukioja, 1980). Homoptera possess a range of strategies to overcome host plant defences (Rosenthal and Janzen, 1979). In particular, some Homoptera can sequester secondary compounds from the host plant, and use them for their own defence (Wink et al., 1982). Price et al. (1980) suggested that herbivores absorbing 
toxins from the plant, could lead to direct toxic effect to their enemies. Our study could not confirm such a toxic effect since there was only a weak influence of fertilizer treatment on ant colony biomass.

\section{Effects of alternative food for ants}

Soil moisture increased when ants were present in the microcosms. The construction of chambers and canals as a result of ants nest building activity could lead to better water holding capacity in soil and consequently to higher soil moisture. Soil microflora was not affected by food treatments. Offering alternative sugar and/or protein resources for ants had a negative effect on aboveground plant biomass. Shoot biomass decreased, while root biomass was not influenced (Figure 6). On average, we detected a higher root/shoot-ratio when sugar/protein was offered to ants. Honeydew exuded by Homoptera may encourage colonisation of the plant shoot by fungi (Haines and Haines, 1978a and b), which might be detrimental to the plant. Presumably decreasing aboveground activity of ants caused higher fungal attack on shoots by less cleaning activity, when ants had access to alternative sugar. We could not detect significant differences in aphid biomass or nitrogen content of aphids, when ants had access to alternative sugar or protein resources, even though decreasing aboveground activity of ants indicated that ants neglected aphids when sugar solution was available. Presumably, aphids still profited from ant attendance since honeydew collection by ants never stopped completely when they could feed on cane sugar, whereas the predation rate by ants apparently decreased, when they could feed on mealworms. Beneficial effects of ants on aphids in this experiment was limited to the reduction of fungal attack by removing honeydew; there were no competitors, predators or parasitoids in the microcosms which could have affected the aphids or the relationship between aphids and ants. In the field, the benefits for aphids from the presence of ants should be more pronounced. For example, attendance by Anoplolepis longipes or Formica rufa caused significant population increases of Ceroplastes rubens in the Seychelles (Haines and Haines, 1978a and b) and Periphyllus testudinaceus in the U. K. (Skinner and Whittaker, 1981), respectively. Our experiments demonstrate that potentially positive indirect effects of ants on aphids by even low levels of honeydew collection can be concealed by bottom up effects like fertilization and top down effects like predation. 
Blüthgen et al. (2004) reported, that preferences and monopolization by the dominant weaver-ant (Oecophylla smaragdina) were associated with high-quality resource, whereas low-quality nectars were used more opportunistically. This could explain why ants did not completely stop tending aphids: in our case, cane sugar represents a preferably used high-quality resource, while honeydew of aphids represents a low-quality resource which is used opportunistically, but not given up completely. The concentration of sugar seemed to have the strongest effect on ants' feeding behaviour, so quality of resource for ants under experimental conditions is more dependent on the sugar concentration of resource than on amino acids in aphids' honeydew, but the availability of amino acids in honeydew could explain why ants did not stop tending aphids. Another reason for the incomplete switch of ants could be, that under field conditions, one single resource could be exhausted, so it would be advantageous not to rely on only one high-quality resource. The incomplete switch from one resource to another seems to have advantages, because ants can reach another resource without searching for it. Unprotected aphid colonies, as potential sugar resource, suffer under attack by other predators, and aphid colonies could be decimated during the time of ant absence, so it would be advantageous for ants to attend more aphid colonies at the same time, but with varying frequencies of visitation.

We have shown that ants depend mainly on sugar supply, and that top-down effects mediated by them are strongly influenced by foraging behaviour and nutrient supply. The biomass of ants increased significantly, when additional sugar was offered (Figure 6). With additional sugar we found two times more pupae/larvae developed to workers than in colonies which fed on honeydew only. This could be related to a different sugar concentration between offered sugar solution and honeydew: Auclair (1963) reported, that a 50\% sugar-solution has a higher sugar concentration than honeydew normally has. The decreasing aboveground activity of ant workers having access to additional sugar supply suggests, that ants tended to prefer the sugar resources with higher concentration. Sugar composition can be a further component of quality. Völkl et al. (1999) reported that ants' preference for aphids honeydew depends on the sugar composition of the honeydew. Blüthgen et al. (2004) reported that honeydew and nectar sources, particularly rich in amino acids were defended and monopolized by the competitively dominant ant Oecophylla smaragdina. The key traits influencing the foraging patterns of this ant were amino 
acid composition and high total concentration of amino acid and sugars. Presumably, in our experiments honeydew was not only used as a carbohydrate resource, and amino acids are important ingredients, which influence the foraging behaviour of the ants. Another reason for higher ant biomass in treatments with additional sugar resources could be that honeydew-dependent colonies need more time and energy to collect honeydew from their aphids as compared to colonies using the alternative sugar resource in an easily accessible place. In addition, in honeydew-dependent colonies more workers were recruited protecting the aphids (we observed that objects near the aphids were attacked by ants), while it could not be observed that workers protected the cane sugar. Altogether, the positive effect of an alternative carbohydrate resource on ants might be due to higher sugar concentrations and lower foraging costs.

Offering additional protein had no direct effect on the ant colonies. Ants rely on sugar as an energy resource for all their activities and are therefore strongly dependent on this resource (Carroll and Janzen, 1973). Ant workers depend less on prey, as only queen and larvae need significant amounts of protein (Beattie, 1985). Colonies in our experiment did not contain any queens, thus no new larvae developed and only already existing larvae were fed with protein-rich food. However, there was no difference between larval biomass in treatments with and without additional protein. Thus only carbohydrate supply could modulate top-down effects of ants on aphids and plants.

\section{Bottom-up effects traced by stable isotopes}

Due to low $\delta^{15} \mathrm{~N}$ values of fertilizer, the application resulted in lower $\delta^{15} \mathrm{~N}$-values in shoots and in higher $\delta^{15} \mathrm{~N}$-values in roots (Figure 7). These differences in enrichment between plant parts could be caused by developmental strategies of the plant. In experiments with ${ }^{15} \mathrm{~N}$ - labelled fertilizer, Weigelt et al. (2005) could divide different grassland plants into slow growing and fast growing species, based on the amount of ${ }^{15} \mathrm{~N}$-label incorporated in shoots, roots and total plant biomass and based on biomass root/shoot ratios. Slow growing species were characterized by a low root/shoot ratio (0.4), while fast growing species had significantly higher root/shoot ratio (ranging between 0.9 to 1.5). In our experiments Phaseolus had a root/shoot ratio of about 0.18 and can thus be assigned to the slow growing species type. Comparing the ${ }^{15} \mathrm{~N}$ concentrations, the slow growing species in Weigelt's experiment had greater values 
of ${ }^{15} \mathrm{~N}$ in root than in shoot tissue, whereas for fast growing species shoot the ${ }^{15} \mathrm{~N}$ concentration was two to three times greater in shoots than in roots. Also the overall ${ }^{15} \mathrm{~N}$ uptake (sum of root and shoot ${ }^{15} \mathrm{~N}$ concentration) was significant greater in fast growing compared to slow growing species. This indicates that Phaseolus, in comparison to different grasses, has a slow growing developmental strategy with a high ${ }^{15} \mathrm{~N}$ concentration in roots. Apparently, fertilization increases the differences between root and shoot ${ }^{15} \mathrm{~N}$ concentration mainly by increased ${ }^{15} \mathrm{~N}$ sequestration in roots.

Aphids feed on phloem sap of shoots, and use the phloem sap to built up their own tissue. Our stable isotope analyses showed that the ${ }^{15} \mathrm{~N}$-ratio in aphids on fertilized plants reflected the isotope distribution in the shoots of these plants. Under fertilized conditions plant shoots and aphids stored less ${ }^{15} \mathrm{~N}$-isotopes (Figure 7), which demonstrates that aphids are influenced by their host plant. Reports of other authors show that aphids are sensible to changes in the nutrient quality of their host plant. A higher nitrogen concentration can promote development and increase reproduction of herbivores, because they are often N-limited (Mattson, 1980; White, 1993). Fertilizer application caused a decrease in ${ }^{14} \mathrm{~N} /{ }^{15} \mathrm{~N}$-ratio of plants and aphids. This effect continued from bottom-up within the system and was significant even in the ants as a third trophic level. The difference was pronounced in treatments, where honeydew was the only sugar resource for the ants: in treatments without access to an additional carbohydrate resource for ants, the ants in unfertilized microcosms showed higher $\delta^{15} \mathrm{~N}$-values (difference original colonies - experimental colonies $0.835 \%$ ) as compared to ants in fertilized microcosms (difference original colonies experimental colonies $0.285 \%$ ). The lower $\delta^{15} \mathrm{~N}$ values of plant shoots in fertilized microcosms caused a decrease in $\delta^{15} \mathrm{~N}$ values of aphids (without fertilizer $4.502 \%$; with fertilizer $3.626 \%$ ). Their honeydew influenced the ${ }^{15} \mathrm{~N}$-values of ants and this indicates, that the bottom-up effect by fertilizer application passes through the system at all trophic levels.

Top-down effects traced by stable isotopes

We found higher $\delta^{15} \mathrm{~N}$-values of ants in treatments without an alternative carbohydrate resource compared to treatments with this resource (Figure 7). These differences could be caused by higher honeydew or aphid consumption in the absence of alternative sugar. This interpretation is supported by the higher $\mathrm{N}$ content 
and the more conspicuous trace signal of fertilizer in ants without access to cane sugar solution. When ants fed on honeydew in order to collect sugar, they simultaneously consumed amino acids. Honeydew production should be higher in treatments without fertilizer application. Aphids need to consume more phloem sap to get the same amount of nitrogen in comparison to fertilized treatments and thereby their ${ }^{15} \mathrm{~N}$ values increased due to decreasing shoot ${ }^{14} \mathrm{~N}$-values in unfertilised treatments. Offered protein for ants increased their $\delta^{15} \mathrm{~N}$-values by consumption of mealworms.

Food components of organisms in trophic relationships can be differentiated by their $\delta^{13} \mathrm{C}$-values: the aphids feed on phloem-sap, use it for growth and excrete the rest by producing honeydew; the $\delta^{13} \mathrm{C}$-values of aphids were similar to those of plants. In concordance with our results, Blüthgen et al. (2003) found that isotope signatures of homopterans are in a range similar to those of their host plants. For ants without additional cane sugar solution, honeydew represented the only sugar resource in the microcosm. $\delta^{13} \mathrm{C}$-values of ants approximated the $\delta^{13} \mathrm{C}$-values of the aphids, because ants fed exclusively on honeydew. Blüthgen et al. (2003) presumed that $\delta^{13} \mathrm{C}$ data are good measures to characterize food substrates like nectar, honeydew or prey. He emphasized that further studies using controlled diets will be needed to assess the proportions of $\mathrm{C}$ - and $\mathrm{N}$-flows from different source and compounds.

The idea to separate the two resources (aphids feeding on $\mathrm{C}_{3}$ plants and alternative food originating of $C_{4}$ plants) due to different $\delta^{13} \mathrm{C}$ values between of $C_{3}$ and $\mathrm{C}_{4}$ plants (Codron et al., 2005) was a good method to identify the food resource and differences were pronounced. It is well documented that these differences persists in the tissue of animals feeding on these plants (Cerling and Harris, 1999).

In conclusion, ants had a positive effect on aphids, but we were not able to support Pontin's hypothesis that with increasing sugar intake more protein is needed to maintain a balanced protein-carbohydrate intake. The limited protein need of ants in our study due to the absence of a queen within the colonies allows no direct comparison to studies based on natural colonies, so Pontin's hypothesis cannot be rejected. Furthermore, the limited protein need could be the reason that ants in our experiment neglected aphids when they had access to an alternative sugar resource. In further studies the presence of a queen would be important for assessing the amount of protein needed to sustain a colony. 


\section{Acknowledgements}

We thank Matthias Schaefer and Sonja Migge-Kleian for valuable discussions and comments on the manuscript. Bernd Ulber provided the aphids and Reiner Bohnhorst the seeds. The Deutsche Forschungsgemeinschaft financially supported this study. 


\section{References}

Anderson, J.P.E., Domsch, K.H., 1978. A physiological method for quantitative measurement of microbial biomass in soils. Soil Biol. Biochem. 10, 519-525.

Auclair, J.L., 1963. Aphid feeding and nutrition. Annu. Rev. Entomol. 8, 439-490.

Bååth, E., Lohm, U., Lundgren, B., Rosswall, T., Sönderström, B., Sohlenius, B., 1978. The effect of nitrogen and carbon supply on the development of soil organism populations and pine seedlings: a microcosm experiment. Oikos 31, 153-163.

Bååth, E., Lohm, U., Lundgren, B., Rosswall, T., Sönderström, B., Sohlenius, B., Wirén, A., 1981. Impact of microbial-feeding animals on total soil activity and nitrogen dynamics: a microcosm experiment. Oikos 37, 257-264.

Banks, J.C., 1962a. Effects of the ant Lasius niger (L.) on the feeding and excretion of the bean aphid, Aphis fabae (Scop.). J. Exp. Biol. 35, 703-711.

Banks, J.C., 1962b. Effects of the ant Lasius niger (L.) on insects preying on small populations of Aphis fabae (Scop.) on bean plants. Ann. Appl. Biol. 50, 669-679.

Banks, J.C., Macaulay, E.D.M., 1967. Effects of Aphis fabae (Scop.) and of its attendant ants and insects predators on yields of field beans (Vicia faba L.). Ann. Appl. Biol. 60, 445-453.

Beattie, A.J., 1985. The evolutionary ecology of ant-plant mutualisms. Cambridge University Press, Cambridge.

Blüthgen, N., Gebauer, G., Fiedler, K., 2003. Disentangling a rainforest food web using stable isotopes: dietary diversity in a species-rich ant community. Oecologia 137, 426-435.

Blüthgen, N., Fiedler, K., 2004. Competition for composition: lesson from nectarfeeding ant communities. Ecology 85, 1479-1485.

Brian, M.V., 1983. Social insects. Chapman and Hall, London.

Bristow, C.M., 1983. Treehoppers transfer parental care to ants: a new benefit of mutualism. Science 220, 532-533.

Bristow, C.M., 1984. Differential benefits from ant attendance to two species of Homoptera on New York iron weed. J. Anim. Ecol. 53, 775-726.

Bronstein, J.L., 1994. Conditional outcomes in mutualistic interactions. Trends Ecol. Evol. 9, 214-217. 
Buckley, R.C., 1997a. Interactions involving Plants, Homoptera, and Ants. Annu. Rev. Ecol. Syst. 18, 111-135.

Buckley, R.C., 1997b. Ant-Plant-Homopteran Interactions. Adv. Ecol. Res. 16, 53-85.

Carroll, C.R., Janzen, D.H., 1973. Ecology of foraging by ants. Annu. Rev. Ecol. Syst. 4, 231-251.

Cerling, T.E., Harris, J.M., 1999. Carbon isotope fractionation between diet and bioapatite in ungulate mammals and implications for ecological and palaeoecological studies. Oecologia 120, 347-363.

Codron, J., Codron, D., Lee-Thorp, J.A., Sponheimer, M., Bond, W.J., de Ruiter, D., Grant, R., 2005. Taxonomic, anatomical, and spatio-temporal variations in the stable carbon and nitrogen isotopic composition of plants from an African savanna. J. Archaeol. Sci. 32, 1757-1772.

Cushman, J.H., Addicot, J.F., 1989. Intraspecific and interspecific competition for mutualists: ants as a limited and limiting resource for aphids. Oecologia 79, 315-321.

Cushman, J.H.,. Addicot, J.F., 1991. Conditional interactions in ant-herbivore mutualism. In: Ant-plant interactions. Ed. by Huxley, C.R., Cutler, D.F., Oxford University Press, 92-119.

Cushman, J.H., Whitham, T.G., 1989. Conditional mutualism in a membracid-ant association: temporal, age-specific, and density- dependent effects. Ecology 70 , 1040-1047.

Cushman, J.H., Whitham, T.G., 1991. Competition mediating the outcome of a mutualism: protective services of ants as a limiting resource for membracids. Am. Nat. 138, 789-797.

Del-Claro, K., Oliveira, P.S., 1993. Ant-Homoptera interaction: do alternative sugar sources distract tending ants? Oikos 68, 202-206.

Fisher, B.L., Sternberg, S.L., Price, D., 1990. Variation in the use of orchid extrafloral nectar by ants. Oecologia 83, 263-266.

Haines, I.H., Haines, J.B., 1978a. Colony structure, seasonality and food requirements of the crazy ant Anoplolepis longipes in the Seychelles. Ecol. Entomol. 3, 109-118.

Haines, I.H., Haines, J.B., 1978b. Pest status of the crazy ant Anoplolepis longipes (Hymenoptera, Formicidae) in the Seychelles. Bull. Entomol. Res. 68, 627-638. 
Haukioja, E., 1980. On the role of plant defenses in the fluctuation of herbivore populations. Oikos $35,202-213$.

Hölldobler, B., Wilson, E.O., 1990. The ants. Springer, Berlin Heidelberg New York. Ingestad, T., 1962. Macro element nutrition of pine, spruce, and birch seedlings in nutrient solutions. Medd. Skogsforskn. Inst. Stockholm 51 (7).

Letourneau, D.K., Dyer, L.A., 1998. Experimental test in lowland tropical forest shows top-down effects through four trophic levels. Ecology 79, 1678-1687.

Mattson, W.J., 1980. Herbivory in relation in relation to plant nitrogen content. Annu. Rev. Ecol. Syst. 11, 119-161.

Morales, M.A., 2000. Survivorship of ant-tended membracid as a function of ant recruitment. Oikos 90, 469-476.

Offenberg, J., 2001. Balancing between mutualism and exploitation: the symbiotic interaction between Lasius ants and aphids. Behav. Ecol. Soc. 49, 304-310.

Pontin, A.J., 1958. A preliminary note on the eating of aphids by ants of the genus Lasius (Hym., Formicidae). Entomol. Monthly Mag. 94, 9-11.

Post, D.M., 2002. Using stable isotopes to estimate trophic position: models methods and assumptions. Ecology 83, 703-718.

Price, P.W., Bouton, C.E., Gross, P., Mc Pheron, B.A., Thompson, J.N., Weis, A.E., 1980. Interactions among three trophic levels: Influence of plants on interactions between insect herbivores and natural enemies. Ann. Rev. Ecol. Syst. 11, 4165.

Reineking, A., Langel, R., Schikowski, J., 1993. 15N, 13C-on-line measurements with an elemental analyser (carbo erber, NA 1500), a modified trapping box and a gas isotope mass spectrometer (Finnigan, MAT 251). Isotopenraxis Environmental Health Studies 29, 169-174.

Rosenthal, G.A., Janzen, D.H., 1979. Herbivores: their Interaction with Secondary Plant Metabolites. Academic Press.

Sagers, C.L., Ginger, S.M., Evans, R.D., 2000. Carbon and nitrogen isotopes trace nutrient exchange in an ant-plant mutualism. Oecologia 123, 582-586.

Sakata, H., Hashimoto, Y., 2000. Should aphids attract or repel ants? Effect of rival aphids and extrafloral nectaries on ant-aphid interactions. Popul. Ecol. 42, 171178.

Sanders, D., Platner, C., 2007. Intraguild interactions between spiders and ants and top down control in a grassland food web. Oecologia 150, 611-624. 
Scheu, S., 1992. Automated measurement of the respiratory response of soil microcompartments: active microbial biomass in earthworm faeces. Soil Biol. Biochem. 24, 1113-1118.

Skinner, G.J., Whittaker, J.B., 1981. An experimental investigation of interrelationships between the wood ant (Formica rufa) and some tree-canopy herbivores. J. Anim. Ecol. 50, 313-326.

Sokal, R.R., Rohlf, F.J., 2001. Biometry, $4^{\text {th }}$ edition WH Freeman and Co, New York.

Stadler, B., Dixon, A.F.G., 1998. Cost of ant attendance for aphids. J. Anim. Ecol. 67, 454-326.

Tillberg, C.V., McCarthy, D.P., Dolezal, A.G., Suarez, A.V., 2006. Measuring the trophic ecology of ants using stable isotopes. Insect Soc. 53, 65-69.

Treseder, K.K., Davidson, D.W., Ehleringer, J.R., 1995. Absorption of ant-provided carbon dioxide and nitrogen by a tropical epiphyte. Nature 375, 137-139.

Völkl, W., Woodring, J., Fischer, M., Lorenz, M.W., Hoffmann, K.H., 1999. Ant-aphid mutualisms: the impact of honeydew production and honeydew sugar composition on ant preferences. Oecologia 118, 483-491.

Way, M.J., 1954. Studies on the association of the ant Oecophylla longinoda (Latr.) (Formicidae) with the scale insect Saissetia zanzibarensis Williams (Coccidae). Bull. Entomol. Res. 45, 113-134.

Weigelt, A., Bol, R., Bardgett, D., 2005. Preferential uptake of soil nitrogen forms by grassland plant species. Oecologia 142, 627-635.

White, T.C.R., 1993. The inadequate environment: nitrogen and the abundance of animals. Springer, Berlin Heidelberg New York.

William, J., Mattson, J.R., 1980. Herbivory in relation to plant nitrogen content. Ann. Rev. Ecol. Syst. 11, 119-161.

Wink, M., Hartmann, T., Witte, L., Rheinheimer, J., 1982. Interrelationships between quinolizidine alkaloid producing legumes and infecting insects: exploitation of the alkaloid containing phloem sap of Cytisus scoparius by the broom aphid Aphis cytisorum. Z. Naturforsch. 37C, 1091-1086.

Wood, T.K., 1982. Ant-attended nymphal aggregations in the Enchenopa binotata complex (Homoptera: Membracidae). Ann. Entomol. Soc. Am. 45, 649-653.

Yao, I., Shibao, H., Akimoto, S., 2000. Costs and benefits of ant attendance to the drepanosiphid aphid Tuberculatus quercicola. Oikos 89, 3-10. 


\section{Appendix}

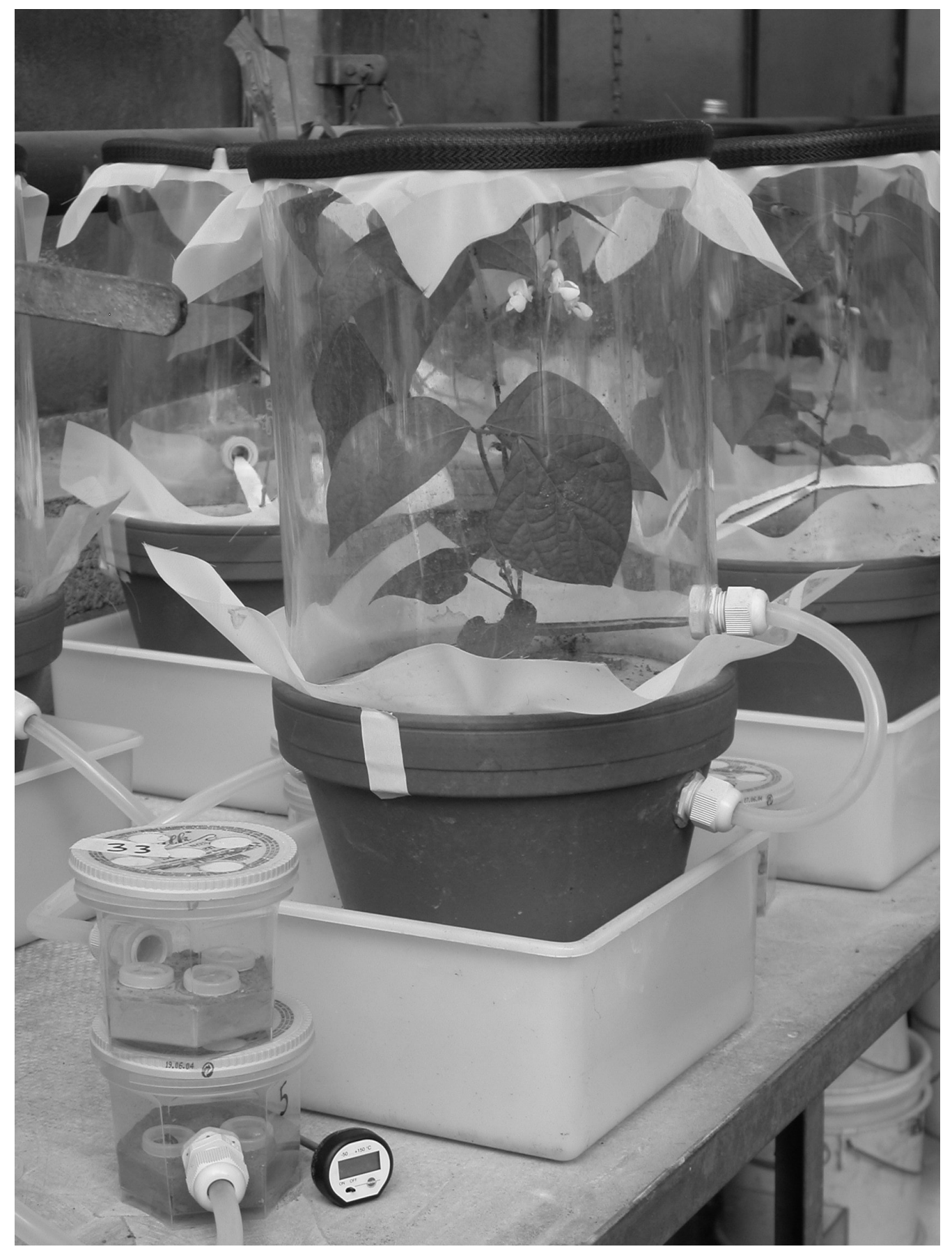

Appendix A. Laboratory microcosm with a bean plant (Phaseolus vulgaris) infested with Aphis fabae, containing an ant nest (Lasius niger) in the soil. Via plastic tubes ants had access to the separated aboveground system with the plant and the aphids and to a separated foraging area, where water and alternative food of the respective treatment (cane sugar solution and/or freeze dried mealworms) was offered. 
a)

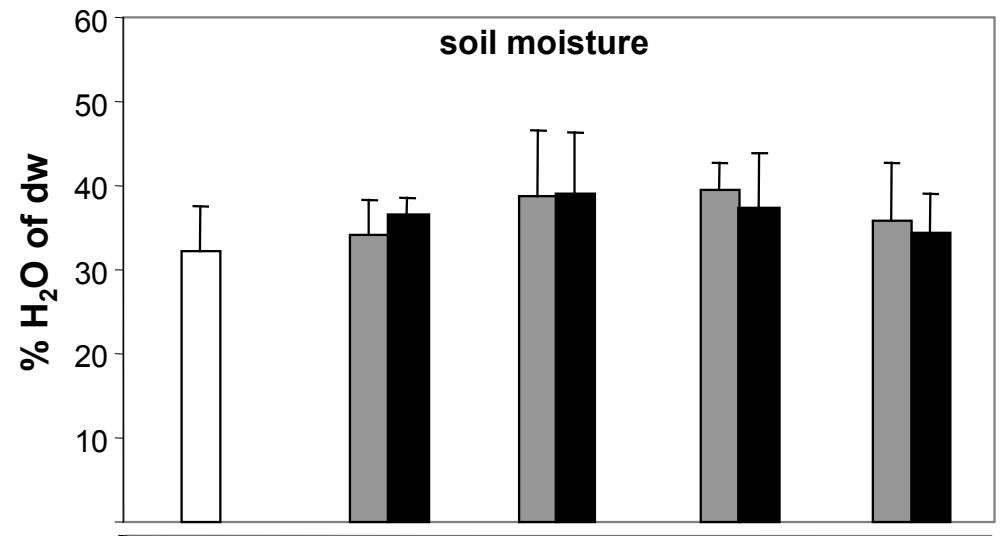

b)
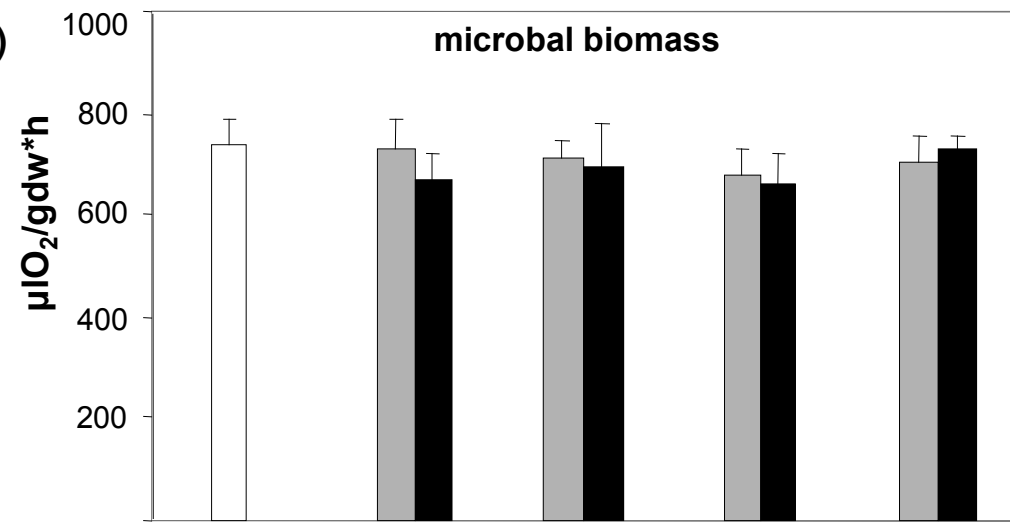

c)

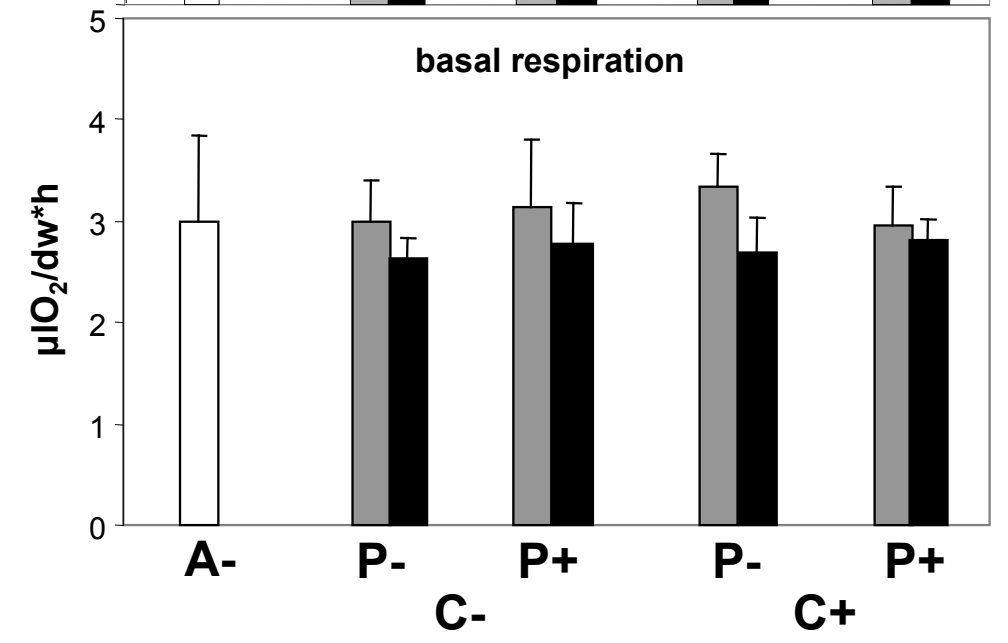

Appendix B. Influence of fertilizer application and additional food for Lasius niger on a) soil moisture, b) microbial biomass, and c) basal respiration. Means \pm SD are given. Grey bars=without fertilizer, black bars=with fertilizer, A $=$ =control without Lasius niger, $\mathrm{C}=$ carbohydrate, $\mathrm{P}=$ protein, $\mathrm{F}=$ fertilizer; +=with, $-=$ without. 
a)

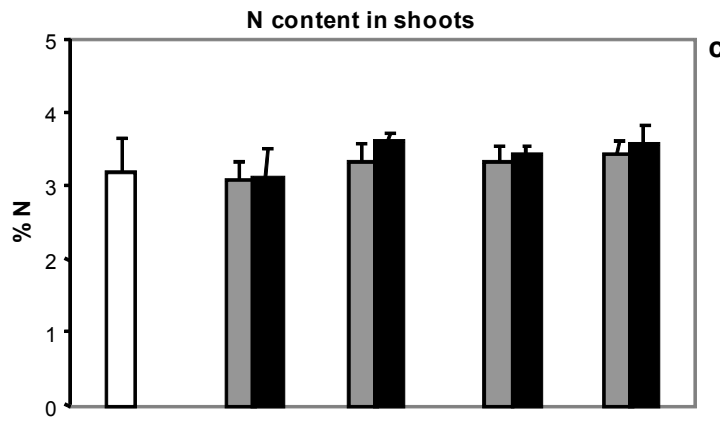

b)

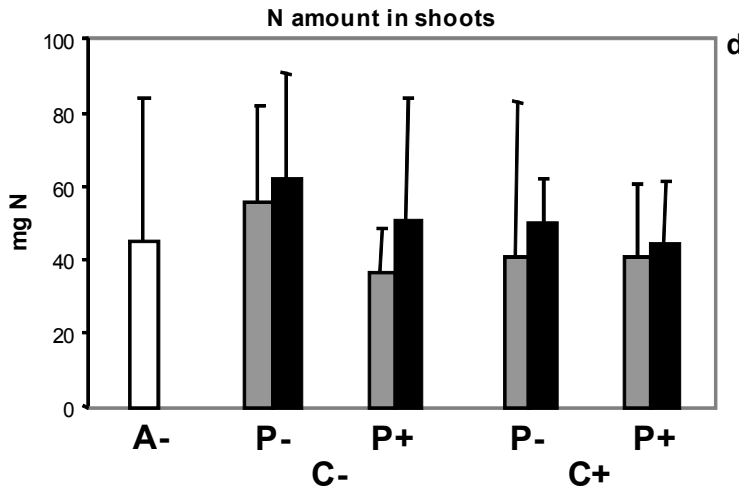

$\mathrm{N}$ content in ants

e)

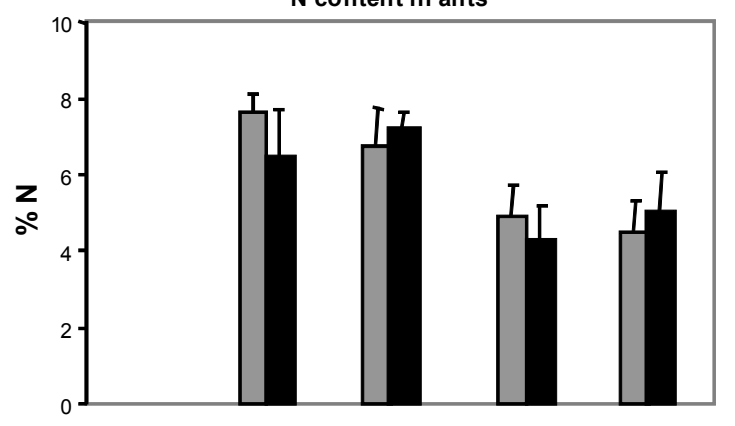

f)

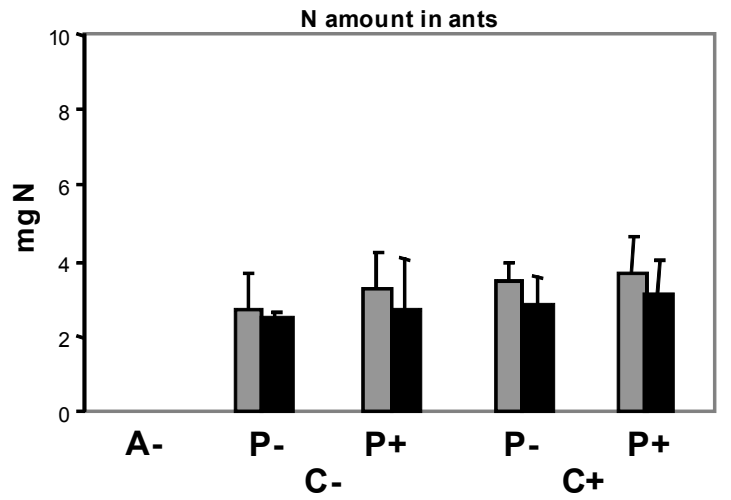

c)
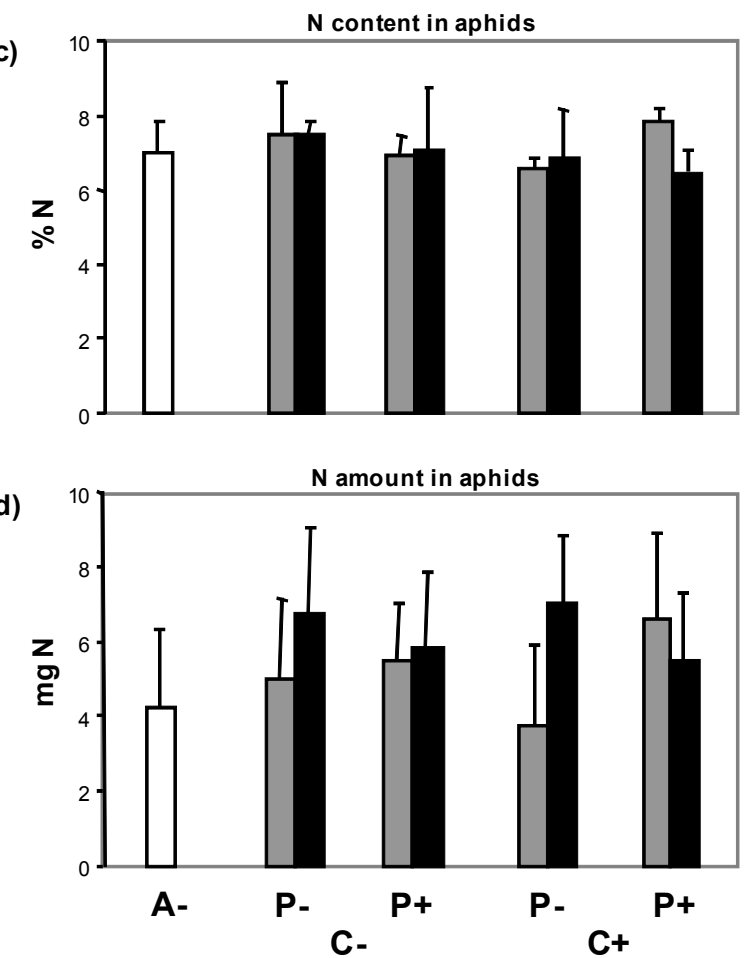

Appendix C. Influence of fertilizer application and additional food for Lasius niger on a) nitrogen content in shoots, b) total amount of nitrogen in shoots, c) nitrogen content of aphids, d) total amount of nitrogen in aphids, e) nitrogen content in ants, and f) total amount of nitrogen in ants. Means \pm SD are given. Grey bars=without fertilizer, black bars=with fertilizer, $A-=$ control without Lasius niger, $\mathrm{C}=$ carbohydrate,$\quad \mathrm{P}=$ protein, $\mathrm{F}=$ fertilizer; +=with, -=without, $\mathrm{dw}=$ dry weight. 


\section{Chapter 3}

The role of ants and homopteran honeydew on the nutrient flow from above- to belowground systems and on the soil microbial community

Evelyn Schumacher, Birgit Pfeiffer, Rolf Daniel and Christian Platner 


\section{Abstract}

In this microcosm experiment, we studied the interaction between ants (Lasius niger), aphids (Aphis fabae) and the soil microbial community. We addressed the question whether ants alter carbon and nitrogen flow between above- and belowground systems. Stable isotope techniques and DGGE were applied. The common bean, Phaseolus vulgaris, was labelled successfully with $\delta^{15} \mathrm{~N}$ and served as host plant for aphids. The $\delta^{15} \mathrm{~N}$ content in aphids increased to $136.1 \%$. Consequently, labelled aphids' honeydew, allowed a quantification of the material flow of nitrogen via honeydew and soil within the microcosm system and to a neighbouring Arrhenaterum elatius plant.

After eight weeks, ant larvae incorporated a mean amount of $2.7 \%$ nitrogen originating from the plant/aphid-system into their tissue (increase of $\delta^{15} \mathrm{~N}$ from $2 \%$ up to $5.6 \%$ during the experiment), while in adult ant workers $\delta^{15} \mathrm{~N}$ values increased from $2.4 \%$ to $16.9 \%$, representing the material flow from aphids to ants and a proportion of $10.8 \%$ nitrogen gained from this flow. . The presence of aphids increased microbial biomass in the litter overlay and increased the abundance of the already existing soil bacterial populations in microcosm soil. The presence of ants reduced honeydew amounts dropping on the litter surface, which led to lower microbial biomass in the litter layer in systems with ants. The activity of ants promoted the material flow from the aboveground to the belowground system. The $\delta^{15} \mathrm{~N}$ signature of labelled honeydew reached from litter to soil when ants were present and transmitted this trace to the upper soil samples. Thus, basal respiration and microbial biomass in these soils increased, possibly due to higher nutrient input (faeces, food remains etc.). Molecular approaches revealed an effect of ants on the structure of bacterial populations in soil by promoting a more balanced dominance structure between populations.

\section{Keywords}

Formicidae, delta $\mathrm{C}-13$, delta $\mathrm{N}-15$, nitrogen, microbial activity 


\section{Introduction}

Ants are dominant in most terrestrial ecosystems and have an high impact on the aboveground and belowground food webs (Letourneau and Dyer, 1998; Hölldobler and Wilson, 1990; Pêtal, 1998). Due to communication and cooperation, ants influence their environment to a high degree (Brian, 1983; Hölldobler and Wilson, 1990). In addition, ants act as ecosystem engineers (Jones, 1994) and influence soil properties, such as soil structure, soil $\mathrm{pH}$, water holding capacity, organic matter content and exchangeable $\mathrm{Ca}, \mathrm{Mg}, \mathrm{K}$, and $\mathrm{PO}_{4}$ by nest construction (Lobry de Bruyn and Conacher, 1990). The transport of honeydew, prey animals, and organic substances into their nest and the addition of secretions and excreta have effects on the nutrient distribution in soil. Furthermore, ants can also have effects on the structure of food webs (Letourneau and Dyer, 1998) by acting as mutualistic partners and predators (Schumacher and Platner, 2009). Mutualistic relationships between ants and aphids are common. Ants collect the honeydew produced by aphids as food. Honeydew is a sugary excretion of carbohydrates, amino acids and water. It is typically rich in sugar, but low in nitrogen and derived from plant phloem (Styrsky, 2007). In return, the ants provide different services (Way, 1954 and 1963; Matsuura and Yashiro, 2006), for example they protect the aphids against their enemies (Way, 1954 and 1963; Stadler and Dixon, 2005) and remove dead bodies and exuviae (Banks, 1962). The intensity of ant-aphid mutualism is mostly positively correlated with honeydew quality and quantity (Bristow, 1984; Fischer et al., 2001). Due to ant presence, some aphid species alter quantity and quality of produced honeydew. In the presence of ants, aphids excrete smaller droplets of honeydew in a higher rate, and honeydew contains significantly higher concentration of amino acids (Yao and Akimoto, 2002) sucrose, and trehalose (Yao and Akimoto, 2001) than honeydew of unattended aphids.

Ants are directly connected to soil fertility, as they can alter the amount of honeydew falling on the soil surface by collecting aphids' honeydew as well as they can change the physical soil conditions by constructing chambers and galleries in the soil. In this way, carbon and nitrogen flow within the system are altered.

Under natural conditions, approximately one-third of the honeydew may fall straight to the ground (Wellenstein, 1980), which could be an important component of soil fertility (Choudhury, 1985). Stadler (2006) analyzed the effects of ants and aphid honeydew on spruce litter: addition of honeydew significantly increased dissolved 
organic carbon (DOC) as a direct result of honeydew leaching, and decreased inorganic $\mathrm{N}$ concentrations in leachates. The author proposed that the dropped honeydew fuels the growth of microorganisms on the needles, which immobilize inorganic $\mathrm{N}$.

For our experimental analysis, stable isotope techniques were applied. The analysis of stable isotopes is a promising method for characterizing the origin of food resources under given conditions (Post, 2002). With respect to ants, this method was used in a previous laboratory experiment to characterise the origin of ants' food (Schumacher and Platner, 2009) and in field studies to investigate the structure of food webs (Sanders and Platner, 2007).

In our study, we used microcosms with Phaseolus vulgaris L. seedlings labelled with ${ }^{13} \mathrm{C} /{ }^{15} \mathrm{~N}$ and infested with Aphis fabae Scopoli to follow the nutrient flow from plant to aphids' honeydew into the system. Moreover, we wanted to gain insight into the effect of ants on carbon and nitrogen flow between aboveground and belowground systems.

The establishment of bacterial communities in microcosms with different ant and honeydew treatments was studied by a molecular analysis and respiration measurements.

\section{Material and Methods}

\section{Labelling procedure and microcosm set-up}

A microcosm consisted of a pot (alumina $20 \mathrm{~cm}$ id $19 \mathrm{~cm}$ height) filled with $2.4 \mathrm{~kg}$ autoclaved loamy sand soil (LUFA Standard Soil Type 2.2; $2.36 \pm 0.29 \%$ organic C, $\mathrm{pH}\left[0.01 \mathrm{M} \mathrm{CaCl}_{2}\right] 5.6 \pm 0.4$, cation exchange capacity $\left.11 \pm 2 \mathrm{mval} / 100 \mathrm{~g}\right)$. Before the experiment started, we added $100 \mathrm{ml}$ of a $0.9 \% \mathrm{NaCl}$-inoculant to every microcosm to establish comparable conditions for microbial growth. For the inoculant, $1 \mathrm{~kg}$ fresh soil from a dry hillside of the Werra valley (Witzenhausen Freudenthal, Northern Hesse, Germany, for details see Platner 2006) was mixed with 1 I of $0.9 \% \mathrm{NaCl}$ solution and shaken for half an hour. The soil for the inoculant was a shallow Pararendzina (Leptosol) on Triassic limestone with a diverse herb layer dominated by Brachypodium pinnatum (L.).

To each microcosm, a layer of $10 \mathrm{~g}$ of dry grass litter was added. Microcosms were closed by a transparent perspex cylinder $(19 \mathrm{~cm}$ id $25 \mathrm{~cm}$ height) with removable gaze $(2 \mu \mathrm{m})$ as a lid (Appendix A). In each cylinder a dividing-wall of $2 \mu \mathrm{m}$ 
gaze was inserted to separate two compartments in the microcosm in order to keep aphids in one compartment only. In one compartment five Arrhenatherum elatius (L.) seedlings were planted (=A. elatius side) to detect a putative ${ }^{15} \mathrm{~N}$ flow from honeydew to the neighboured plants. Outside each microcosm, a pot with labelled Phaseolus vulgaris was fixed, only their shoot hanging in the other compartment of the cylinder (=P. vulgaris side) (Appendix A). P. vulgaris seeds (breed Solido) were sown six weeks before the experiment started. These plants were labelled and served as host plants for aphids (Aphis fabae). Labelling started when the beans were at the twoleave stage. Seedling-shoots were brushed daily with a 97 atom $\%{ }^{13} \mathrm{C}, 2$ atom $\%{ }^{15} \mathrm{~N}$ urea solution for 23 days (Schmidt and Scrimgeour, 2001). In summary, every plant was labelled with approximately $4 \mathrm{~mL}$ of urea solution $\left(2 \mathrm{~g} \mathrm{~L}^{-1}\right)$. Each $P$. vulgaris shoot was infested with 25 apterous $A$. fabae individuals of the same size. Aphids were reared on unlabelled $P$. vulgaris before adding them to the experimental containers. Aphid colonies were allowed to develop for two days before experimental ant colonies, consisting of 100 Lasius niger (L.) workers and 80 larvae, were added in respective treatments. All experimental colonies originated from one ant colony that was collected from a dry grassland located near Göttingen, Germany, in September 2007.

The honeydew produced by the aphids from their labeled host plant could be collected by workers when ants were present. In the absence of ants, the honeydew fell on the ground or attached to bean leaves. In treatments with honeydew exclusion, the experimental microcosms included an additional Perspex pane beneath the $P$. vulgaris shoot to prevent honeydew from falling onto the ground. During the experiment, the panes were changed every fifth day. The experiment was conducted in a heated greenhouse in Göttingen from September to November 2007. Additional lighting was provided by Osram lamps (36 W/21-840 Lumilux plus) to allow a 12 hour period of light.

We used a blocked, two-factorial design with the factors 'ants' (with and without ant presence) and 'honeydew' (with and without pane). The 32 microcosms were divided into eight blocks; we arranged the four treatments randomly within each block. Four control microcosms without aphids and ants were established between every second block. The eight blocks rotated every third days during the experiment to minimize the block effect. 
Data collection and statistical analyses

At the end of the experiment, L. niger workers and larvae were collected by hand and frozen at $-20{ }^{\circ} \mathrm{C}$. Afterwards freeze-dried biomass of ants and ant larvae was measured. $P$. vulgaris shoots were clipped at the point where shoots reached the microcosm. Living aphids of each microcosm were collected by hand and frozen at $20{ }^{\circ} \mathrm{C}$ before freeze-drying and biomass determination. After aphid removal, shoot biomass of $P$. vulgaris was determined by drying shoots at $105^{\circ} \mathrm{C}$ for three days. $A$. elatius was divided into shoots and roots (roots were washed with distilled water) and dried separately at $105^{\circ} \mathrm{C}$ for three days to determine biomass.

We measured stable isotopes $\left({ }^{15} \mathrm{~N},{ }^{13} \mathrm{C}\right)$ and total nitrogen from pulverized plant material, litter, soil, and frozen ants and aphids, with two replicates for each sample. We analyzed ants in total to avoid skew results due to different isotopic signatures among tissues (Tillberg et al., 2006). Bean shoots with the aphid colonies were removed 5 days before the ants were collected. The period after ants had the last possibility to collect honeydew was supposed to reduce the influence of crop content to a marginal rate. Ratios of ${ }^{13} \mathrm{C}$ and ${ }^{15} \mathrm{~N}$ were estimated by a coupled system consisting of an elemental analyzer (Carlo Erba NA 2500) and a gas isotope mass spectrometer (Finnigan Deltaplus). The system is computer-controlled allowing measurement of ${ }^{13} \mathrm{C}$ and ${ }^{15} \mathrm{~N}$ (Reineking et al., 1993). Isotopic contents were expressed in $\delta$ units as the relative difference between sample and conventional standards with $\delta^{15} \mathrm{~N}$ or $\delta^{13} \mathrm{C}[\%]=\left(\mathrm{R}_{\text {Sample }}-\mathrm{R}_{\text {Standard }}\right) / \mathrm{R}_{\text {Standard }} \mathrm{X} 1000$, where $\mathrm{R}$ is the ratio of ${ }^{15} \mathrm{~N} /{ }^{14} \mathrm{~N}$ or ${ }^{13} \mathrm{C} /{ }^{12} \mathrm{C}$ content, respectively. The conventional standard for ${ }^{15} \mathrm{~N}$ is atmospheric nitrogen and for ${ }^{13} \mathrm{C}$ PD-belemnite (PDB) carbonate. Acetanilide $\left(\mathrm{C}_{8} \mathrm{H}_{9} \mathrm{NO}\right.$, Merck, Darmstadt) served for internal calibration with a mean standard deviation of samples $<0.1$.

Grass litter was removed by hand. In each microcosm, three soil samples were collected: one from the surface $(3 \mathrm{~cm})$ of the $P$. vulgaris compartment $(P$. vulgaris side), one from the surface $(3 \mathrm{~cm})$ of the $A$. elatius compartment ( $A$. elatius side), and one between the compartments in a depth of about $10 \mathrm{~cm}$ (ground soil) (Appendix A). Litter and soil samples were stirred carefully to homogenize each sample, and a subsample was taken to analyse microbial basal respiration, microbial biomass (SIR, Anderson and Domsch, 1978; Scheu, 1992), and soil water content (gravimetrically).

Additionally, in each microcosm the bacterial community of the ground soil samples was analysed by denaturing gradient gel electrophoresis (DGGE). Soil 
samples for molecular analyses were stored at $-80{ }^{\circ} \mathrm{C}$ until use. Genomic DNA was isolated from $250 \mathrm{mg}$ of soil by employing the UltraClean PowerSoil ${ }^{\mathrm{TM}}$ DNA Isolation Kit (MO BIO Laboratories Inc., Carlsbad, CA, USA) according to the manufacturer's protocol. The final DNA elution step was carried out with $100 \mu \mathrm{l} \mathrm{H}_{2} \mathrm{O}$.

For DGGE, 16S rRNA genes were amplified by employing the primers 5 'CCTACGGGAGGCAGCAG-3' (BAC 341F) and 5'-CCGTCAATTCCTTTRAGTTT-3 (BAC 907R) (Muyzer et al., 1995; Muyzer and Smalla 1998). To primer BAC 341F a GC clamp (5'-CGCCCGCCGCGCCCCGCGCCCGTCCCGCCGCCCCCGCCCG-3') was attached at the 5 ' terminus (Muyzer et al., 1995). The PCR reaction mixture (50 $\mu \mathrm{l})$ for amplification of $16 \mathrm{~S}$ rRNA genes contained $5 \mu \mathrm{l} \mathrm{Mg-free} \mathrm{polymerase} \mathrm{buffer}$ (MBI Fermentas, St. Leon-Rot, Germany), $200 \mu \mathrm{M}$ of each of the four deoxynucleoside triphosphates, $2 \mathrm{mM} \mathrm{MgCl} 2,2 \mu \mathrm{M}$ of each of the primers, $1 \mathrm{U}$ of Taq DNA polymerase (MBI Fermentas), and $20 \mathrm{ng}$ of isolated DNA as template. The following thermal cycling scheme was used: initial denaturation at $95^{\circ} \mathrm{C}$ for $2 \mathrm{~min}, 13$ cycles of denaturation at $94{ }^{\circ} \mathrm{C}$ for $1 \mathrm{~min}$, annealing for $1 \mathrm{~min}$ at a decreasing temperature gradient ranging from $64{ }^{\circ} \mathrm{C}$ to $51{ }^{\circ} \mathrm{C}\left(1{ }^{\circ} \mathrm{C}\right.$ decrease per cycle), and extension at $72{ }^{\circ} \mathrm{C}$ for $3 \mathrm{~min}$. Subsequently, 12 cycles of denaturation at $94^{\circ} \mathrm{C}$ for 1 min, annealing for $1 \mathrm{~min}$ at $51^{\circ} \mathrm{C}$, and extension at $72{ }^{\circ} \mathrm{C}$ for 3 min were performed. A final extension period at $72{ }^{\circ} \mathrm{C}$ for 10 min was carried out. The size of the resulting PCR products was controlled by agarose gelelectrophoresis. Subsequently, the PCR products were purified by using CyclePure PCR purification kit (Peqlab Biotechnologie $\mathrm{GmbH}$, Erlangen, Germany) as recommended by the manufacturer. The concentration of purified PCR products was quantified using a NanoDrop ND1000 spectrophotometer (Peqlab Biotechnologie $\mathrm{GmbH}$ ).

DGGE analysis of $16 \mathrm{~S}$ rRNA genes was performed using the INGENY phorU system (Ingeny International BV, The Netherlands). Purified bacterial amplicons (500 ng) were applied to a $9 \%(\mathrm{wt} / \mathrm{vol})$ polyacrylamide gel containing a $45 \%$ to $60 \%$ denaturing gradient ( $100 \%$ denaturant consisted of $7 \mathrm{M}$ urea and $40 \%$ formamide). Electrophoresis was performed at $60{ }^{\circ} \mathrm{C}$ and $100 \mathrm{~V}$ for $16 \mathrm{~h}$ in Tris-Acetate-EDTA (TAE) buffer, which consisted of $40 \mathrm{mM}$ Tris, $20 \mathrm{mM}$ acetic acid, and $1 \mathrm{mM}$ EDTA. Subsequently, the gels were stained with SYBR Gold (Invitrogen, Karlsruhe, Germany).

The resulting DGGE profiles were analyzed using GelCompare II software (Applied Maths, Kortrijk, Belgium). Clustering was performed using the unweighted 
pair group method with mathematical averages (dice coefficient of similarity). Background subtraction was applied and position tolerance was set to $1 \%$.

Prominent bands were excised and stored in $100 \mu \mathrm{l} 1$ fold TAE overnight. One $\mu \mathrm{l}$ of the buffer containing DNA was used as template for reamplification by employing the above mentioned primers BAC 341F without attached GC-clamp and BAC 907R. The PCR was performed as described above. Subsequently, purified PCR products were ligated into PCR2.1 vector using TOPO TA Cloning Kit and resulting plasmids were transferred to $E$. coli $\mathrm{DH} 5 a$ cells, according to the manufacturer's protocol (Invitrogen $\mathrm{GmbH}$, Darmstadt Germany). Plasmids have been isolated from recombinant clones and the inserts were sequenced by the Göttingen Genomics Laboratory. For the phylogenetic analysis of the thereby obtained 16S rRNA gene sequences the Ribosomal Database Project (http://rdp.cme.msu.edu/) was used.

Biomass and isotope data were analyzed by two factor analyses of variance (SAS 8.1, SAS Institute Inc., Cary, USA), and means of different treatments were tested for significant differences by Tukey's test (Sokal and Rohlf, 2001). The effect of 'aphids' was analyzed in a one-way GLM comparing controls with the treatment 'no ants' and 'honeydew' (A-H+; Figure 8). Data of basal respiration and microbial biomass were analysed by a MANCOVA (Scheiner, 2001) with the mean soil water content as covariable.

\section{Results}

Plant and aphid biomasses

Aboveground biomass of $P$. vulgaris did not differ between treatments, but biomass in experimental microcosms with aphids (mean $\pm S E, n=8$ : $1112.2 \pm 533.1 \mathrm{mg}$ dry weight beans and shoot within microcosm) was significantly higher than in controls without aphids (mean \pm SE, $n=4: 527.5 \pm 79.2 \mathrm{mg}$; GLM with factor 'aphids', Table 1, Figure 8). Plants without aphids produced nearly no beans (one plant with a yield of $100 \mathrm{mg}$ dry weight), whereas those in experimental microcosms with aphids produced in every treatment a mean yield of $564.1 \pm 72.4 \mathrm{mg}$ dry weight $(n=32)$. In $A$. fabae colonies, the number of living alate aphids increased significantly due to ant presence (8.6 \pm 5.4 individuals without ants, $25.1 \pm 7.5$ ind. with ants, $n=16 ; F_{1,21}=4.48$, $p=0.0464$, for factor 'ant' in a two-factorial ANOVA; Figure 7). A. elatius shoots and roots were not affected by treatments (Figure 7 ). 
Table 1. Effects of 'aphids' on the biomass (dry weight), $\delta^{15} \mathrm{~N}$ content (\%), $\mathrm{H}_{2} \mathrm{O}$ of soil dry weight (\%), basal respiration $\left(\mu \mathrm{g} \mathrm{O}_{2} \mathrm{~g}^{-1}\right.$ dry wt $\mathrm{h}^{-1}$ ) and microbial biomass $\left(\mu \mathrm{g} \mathrm{C}_{\text {mic }} \mathrm{g}^{-1}\right.$ dry wt). All comparisons between 'control' and 'A-H+' treatment were made using a one-way GLM. Pvalues of significant effects $(p<0.05$ ) are presented in bold letters, those of marginal significant effects $(p<0.1)$ are presented with three decimal places. Degrees of freedom: effect $=1$, error $=14$.

\begin{tabular}{|c|c|c|}
\hline & $\mathrm{F}$ & $\mathrm{p}$ \\
\hline Biomass $P$. vulgaris shoot & 18.29 & 0.0008 \\
\hline Biomass $A$. elatius shoot & 1.84 & 0.20 \\
\hline Biomass $A$. elatius root & 0.90 & 0.36 \\
\hline$\delta^{15} \mathrm{~N} P$. vulgaris shoot & 5.28 & 0.0375 \\
\hline$\delta^{15} \mathrm{~N} A$. elatius shoot & 3.44 & 0.085 \\
\hline$\delta^{15} \mathrm{~N} A$. elatius root & 3.72 & 0.074 \\
\hline$\delta^{15} \mathrm{~N}$ litter & 6.29 & 0.0250 \\
\hline$\delta^{15} \mathrm{~N}$ soil $P$. vulgrais side & 3.70 & 0.075 \\
\hline$\delta^{15} \mathrm{~N}$ soil ground & 11.29 & 0.0047 \\
\hline$\delta^{15} \mathrm{~N}$ soil $A$. elatius side & 1.08 & 0.32 \\
\hline Litter moisture & 7.64 & 0.0152 \\
\hline Soil moisture $P$. vulgrais side & 4.86 & 0.0447 \\
\hline Soil moisture ground & 10.50 & 0.0059 \\
\hline Soil moisture $A$. elatius side & 9.43 & 0.0083 \\
\hline Basal respiration litter & 3.77 & 0.073 \\
\hline Basal respiration $P$. vulgaris side & 0.02 & 0.88 \\
\hline Basal respiration ground & 3.55 & 0.080 \\
\hline Basal respiration A.elatius side & 4.74 & 0.0470 \\
\hline Microbial biomass litter & 128.90 & $<0.0001$ \\
\hline Microbial biomass $P$. vulgaris side & 0.70 & 0.42 \\
\hline Microbial biomass ground & 8.59 & 0.0109 \\
\hline Microbial biomass A.elatius side & 0.12 & 0.74 \\
\hline
\end{tabular}

\section{Stable isotopes}

A comparison of the isotope signature between unlabelled $P$. vulgaris shoots $\left(\delta^{15} \mathrm{~N}\right.$ $4.5 \%$, see Schumacher and Platner, 2009) and labelled shoots (148.5\%o), both inhabited by aphids and grown under same conditions, allows to assess the success of labelling. Labelling strongly increased $\delta^{15} \mathrm{~N}$ values in shoots. The strongest ${ }^{15} \mathrm{~N}$ labelling of $P$. vulgaris shoots was measured in control microcosms without aphids with $\delta^{15} \mathrm{~N}$ values of $223.8 \pm 53.6 \%(\mathrm{n}=4)$, whereas in aphid-infested shoots $\delta^{15} \mathrm{~N}$ values were significantly lower $(\mathrm{A}-\mathrm{H}+$ : $141.7 \pm 6.5 \%$, $\mathrm{n}=8$; GLM with factor 'aphids', Table 1, Figure 1 and Figure 8). On average, $\delta^{15} \mathrm{~N}$ values in living aphids were lower than in $P$. vulgaris shoots (difference between aphids and $P$. vulgaris shoots $10.3 \%$, Figure 1). The $\delta^{15} \mathrm{~N}$ values in ants and their larvae increased during the course of the experiment (on average $14.43 \%$ and $3.39 \%$, respectively, Figure 1). 
The $\delta^{15} \mathrm{~N}$ values in shoots and roots of $A$. elatius measured in control microcosms were slightly lower than in microcosms with aphids (GLM with factor 'aphids', Table 1, Figure 1 and Figure 8). Stable isotopes of both plant parts were not affected by 'ants' or 'honeydew'.

The $\delta^{15} \mathrm{~N}$ values in the litter layer of controls $(-0.9 \%$ ) were significantly lower than in experimental microcosms (1.72 \%, GLM with factor 'aphids', Table 1, Figure 8). Ant presence and honeydew falling on the ground led to marginal significant higher $\delta^{15} \mathrm{~N}$ values in the litter (without ants $1.74 \%$, with ants $1.96 \%$; without honeydew $0.68 \%$, with honeydew $2.76 \%$; Table 2, Figure 7). Additionally, ants significantly increased $\delta{ }^{15} \mathrm{~N}$ values in samples from the soil surface on both, the $P$. vulgaris (without ants $0.62 \%$, with ants $1.05 \%$ ) and the A. elatius side (without ants $0.89 \%$, with ants $1.17 \%$ ) (Table 2, Figure 7).

Table 2. Effects of 'ants' and 'honeydew' on the $\delta^{15} \mathrm{~N}$ contents. All comparisons were made using a two-way ANOVA. P-values of marginal significant effects $-p<0.1-$ are presented with three decimal places. $\mathrm{df}=$ degree of freedom.

\begin{tabular}{lccccccccccc}
\hline & & \multicolumn{3}{c}{$\delta^{15} \mathrm{~N}$ aphid } & \multicolumn{2}{c}{ log $\delta^{15} \mathrm{~N}$ litter } & \multicolumn{2}{c}{$\delta^{15} \mathrm{~N}$ soil $P$} & \multicolumn{2}{c}{$\delta^{15} \mathrm{~N}$ ground } & \multicolumn{2}{c}{$\delta^{15} \mathrm{~N}$ soil $A}$. \\
& df & $\mathrm{F}$ & $\mathrm{p}$ & $\mathrm{F}$ & $\mathrm{p}$ & $\mathrm{F}$ & $\mathrm{p}$ & $\mathrm{F}$ & $\mathrm{p}$ & $\mathrm{F}$ & $\mathrm{p}$ \\
\hline ants & 1 & 0.39 & 0.54 & 3.19 & 0.092 & $\mathbf{4 . 7 3}$ & $\mathbf{0 . 0 4 1 1}$ & 0.03 & 0.86 & $\mathbf{5 . 2 7}$ & $\mathbf{0 . 0 3 2 0}$ \\
honeydew & 1 & 2.37 & 0.14 & 3.22 & 0.091 & 0.08 & 0.78 & 0.62 & 0.44 & 0.06 & 0.82 \\
block & 7 & 2.21 & 0.087 & 0.44 & 0.87 & $\mathbf{6 . 5 5}$ & $\mathbf{0 . 0 0 0 4}$ & $\mathbf{6 . 0 6}$ & $\mathbf{0 . 0 0 0 6}$ & $\mathbf{9 . 3 5}$ & $<\mathbf{0 . 0 0 0 1}$ \\
ants*ho & 1 & 0.09 & 0.77 & 0.53 & 0.48 & 0.23 & 0.64 & 0.03 & 0.87 & 1.26 & 0.27 \\
\hline
\end{tabular}




\section{$\delta^{15} \mathrm{~N}$ contents}
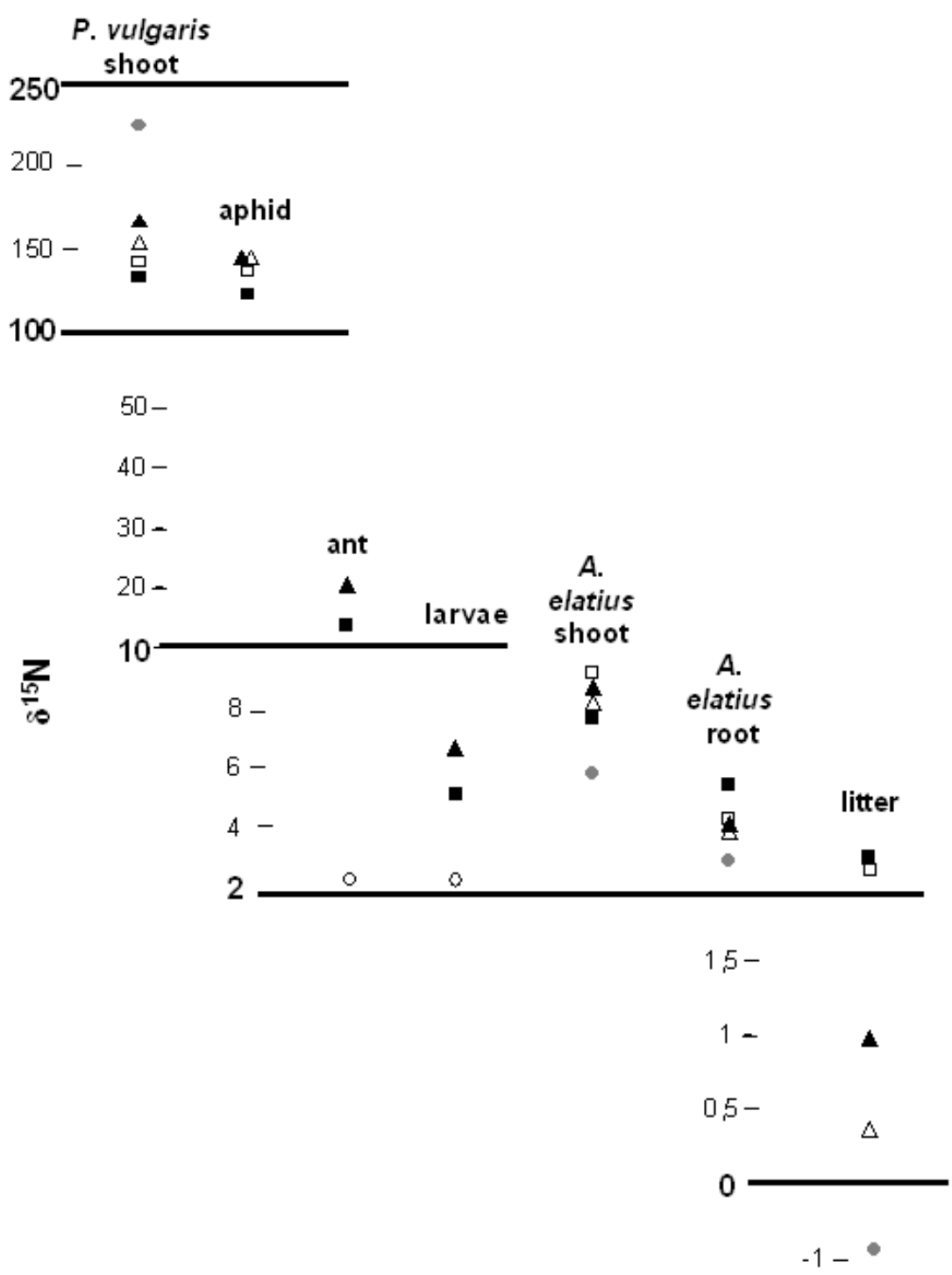

Figure 1. $\delta^{15} \mathrm{~N}$ content (\%o) in Phaseolus vulgaris, Aphis fabae, Lasius niger and Arrhenatherum elatius, as well as in litter and soil samples of the different microcosm treatments. The different treatments are indicated as follows: $A-=$ without ants; $A+=$ with ants; $\mathrm{H}$ - without honeydew; $\mathrm{H}+$ with honeydew; control = without aphids and ants.

$\delta^{15} \mathrm{~N}$ values in shoots and roots of $A$. elatius measured in control microcosms were slightly lower than in microcosms with aphids (GLM with factor 'aphids', Table 1 , Figure 1 and 6 ). Stable isotopes of both plant parts were not affected by 'ants' or 'honeydew'.

$\delta^{15} \mathrm{~N}$ values in the litter layer of controls were significantly lower than in experimental microcosms (GLM with factor 'aphids', Table 1, Figure 1 and 6). Ant presence and honeydew falling on the ground led to marginally higher $\delta^{15} \mathrm{~N}$ values in the litter (Table 2, Figure 1 and 6). Additionally, ants significantly increased $\delta^{15} \mathrm{~N}$ 
values in samples from the soil surface on both, the $P$. vulgaris and the A. elatius side (Table 2, Figure 1 and 6).

\section{Basal respiration and microbial biomass}

The water content did not differ significantly between treatments in any of the soil or litter samples, but litter and soil moisture in experimental microcosms with aphids was significantly higher than in controls without aphids (GLM with factor 'aphids, Table 1, Figure 8). A marginal significant higher basal respiration was measured in microcosms with aphids (experimental microcosms $\mathrm{A}-\mathrm{H}+$, Figure 2) than without aphids (controls; GLM with factor 'aphids', Table 1, Figure 8). In the grass litter, microbial biomass $\left(\mathrm{C}_{\mathrm{mic}}\right)$ was significantly higher in microcosms with aphids than without aphids (GLM with factor 'aphids', Table 1, Figure 8), but when ants inhabited the microcosms microbial biomass significantly decreased (A-855, A+ $696 \mu \mathrm{g} \mathrm{C}_{\text {mic }} \mathrm{g}^{-}$ ${ }^{1}$ dry wt, Table 4, Figure $3 a$ and Figure 7). Without ants, BAS and $C_{\text {mic }}$ increased when honeydew could reach the litter, but when ants were present the opposite was observed (interaction between 'ants' and 'honeydew', Table 3 and 4, Figure 2a and 3a).

Basal respiration (BAS) and microbial biomass $\left(\mathrm{C}_{\text {mic }}\right)$ in soil samples taken beneath the $P$. vulgaris shoots were lower in treatments where honeydew could reach the soil surface (BAS: $\mathrm{H}-1.08, \mathrm{H}+0.89 \mu \mathrm{g} \mathrm{O}_{2} \mathrm{~g}^{-1}$ dry wt $\mathrm{h}^{-1}$, Table 3, Figure 2b; $\mathrm{C}_{\text {mic }}: \mathrm{H}-7.37, \mathrm{H}+5.01 \mu \mathrm{g} \mathrm{C}$ mic $\mathrm{g}^{-1}$ dry wt, Table 4, Figure $3 \mathrm{~b}$ and Figure 7 ), but both parameters increased when ants inhabited the microcosms (BAS: A- 0.874, A+ 1.095 $\mu \mathrm{O}_{2} \mathrm{~g}^{-1}$ dry wt $\mathrm{h}^{-1}$; Table 3, Figure 2b; $\mathrm{C}_{\text {mic }}$ : A- 5.85, A+ $6.53 \mu \mathrm{g} \mathrm{C}_{\text {mic }} \mathrm{g}^{-1}$ dry wt, Table 4 , Figure $3 b$ ). In these and the following soil samples, BAS and $\mathrm{C}_{\text {mic }}$ differed significantly between blocks (Table 3 and 4 ). 
Basal respiration

a)

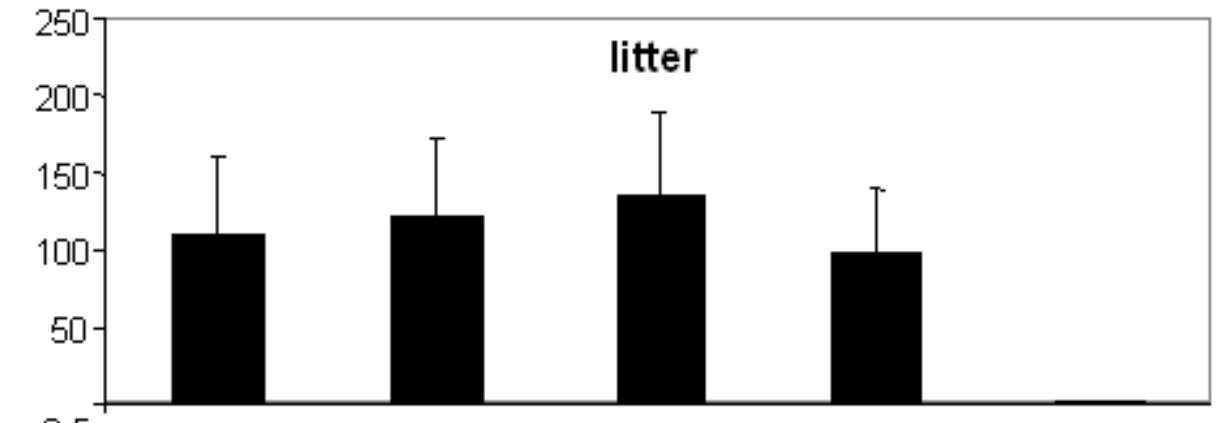

b)

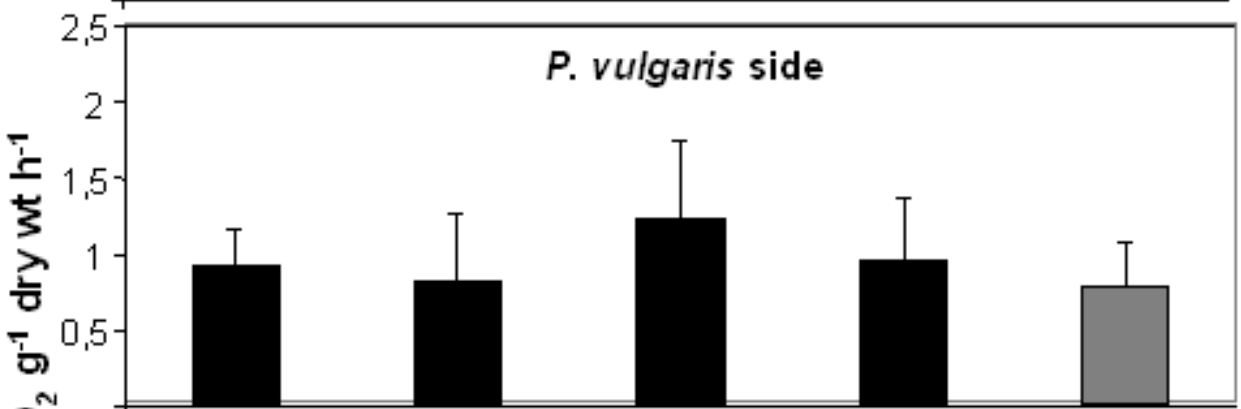

c)

오 모

d)
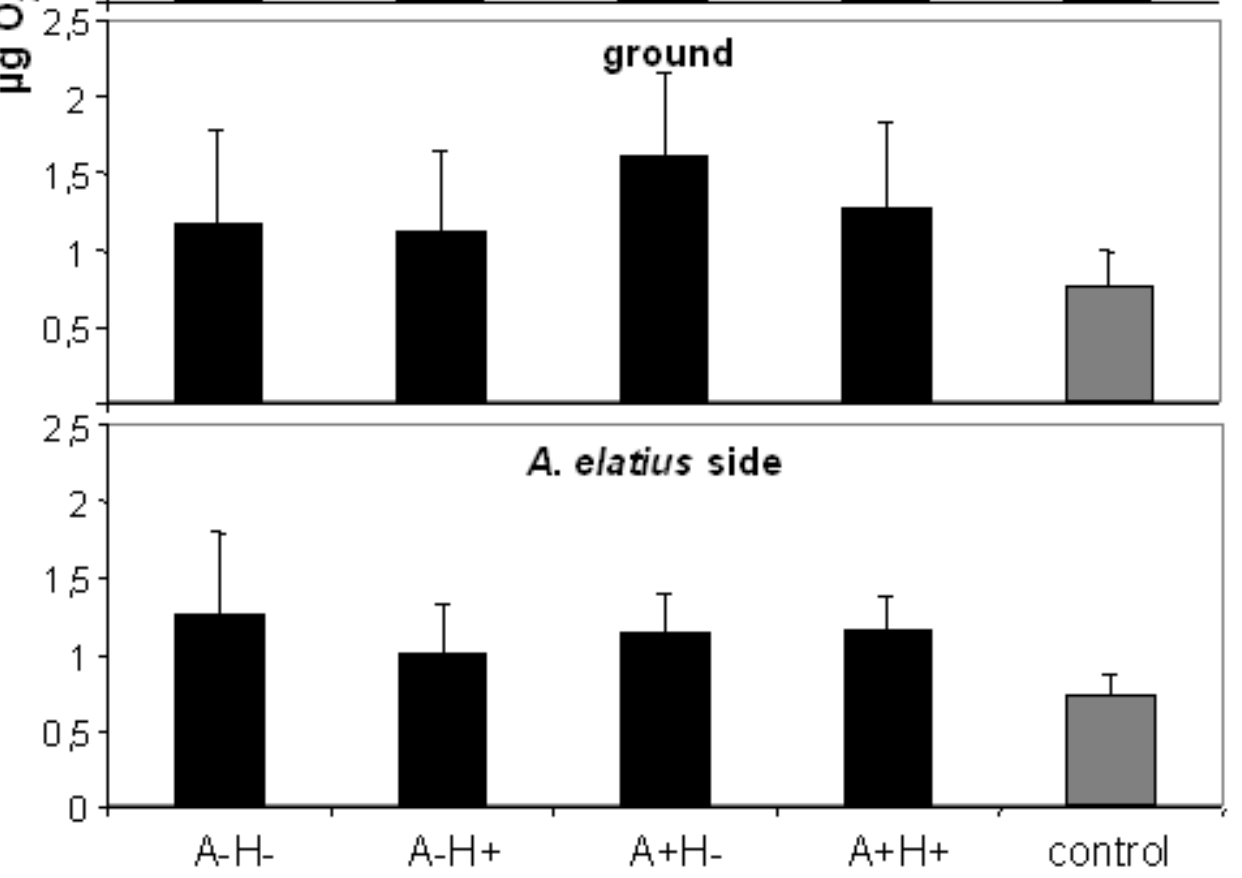

Figure 2. Graph showing the basal respiration in the litter layer (a), the soils of the $P$. vulgaris side (b), the soils of the ground (c) and the soils of $A$. elatius side (d). For abbreviations see Figure 1. 


\section{Microbial biomass}
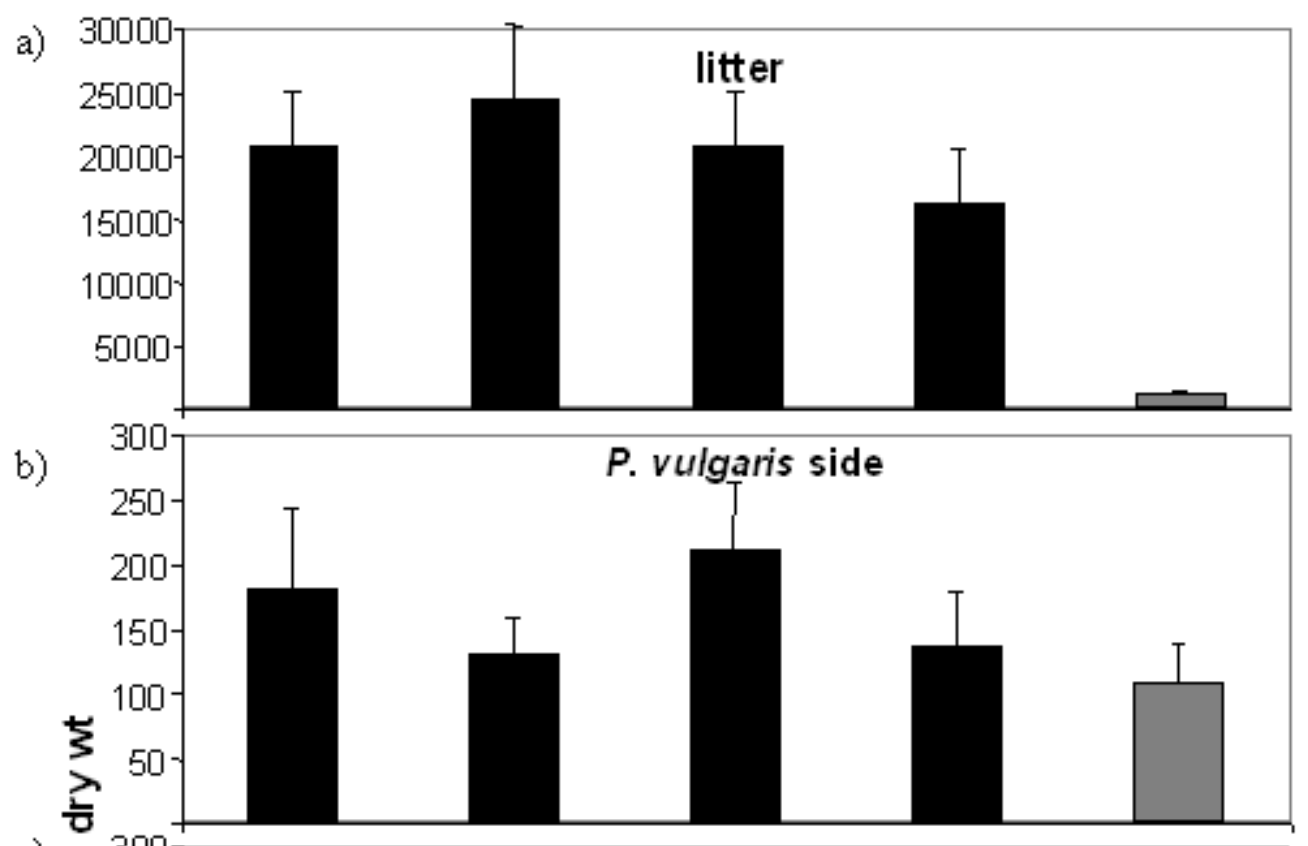

c)
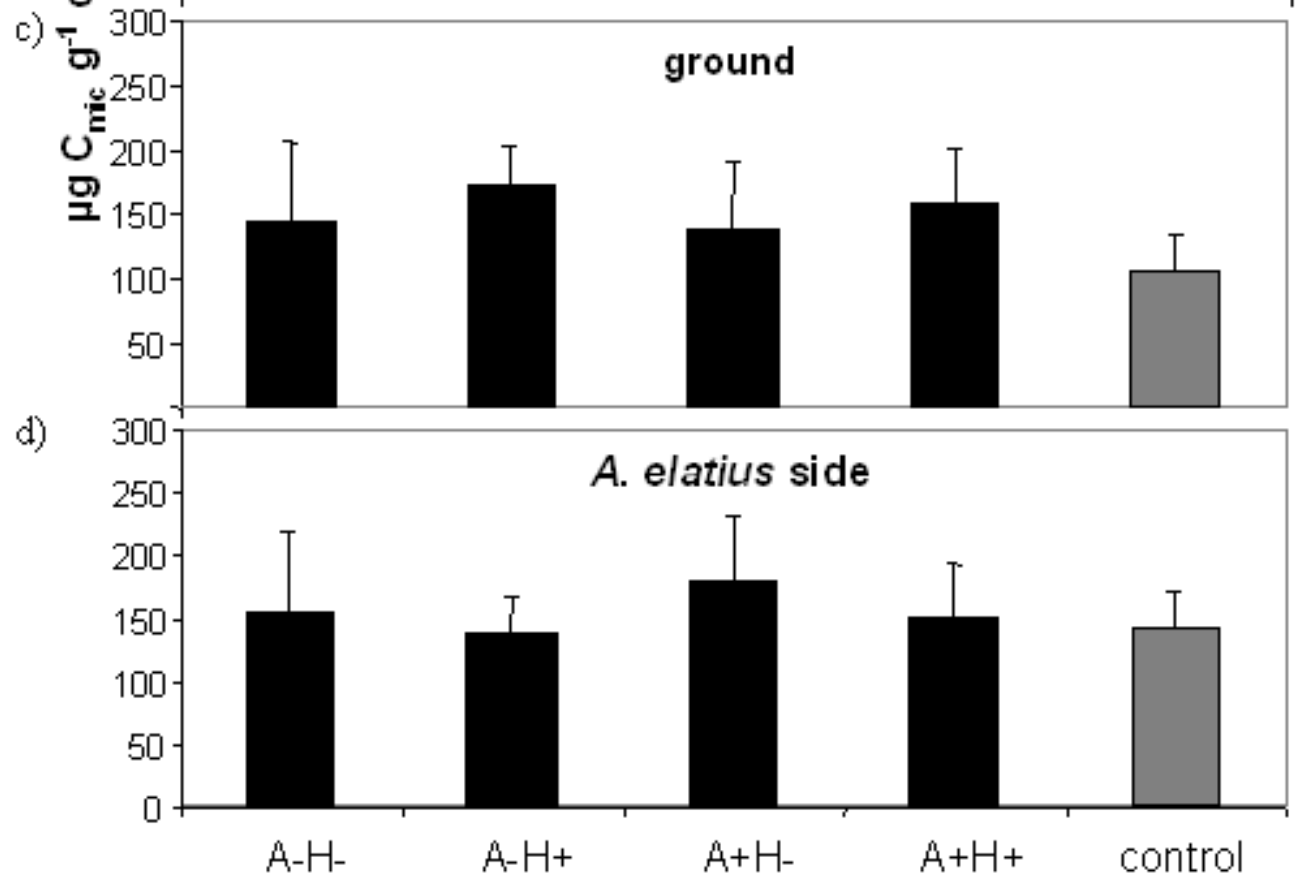

Figure 3. Illustration showing the microbial biomass in the litter layer (a), the soil of the $P$. vulgaris sides (b), the soil of the ground (c) and the soil of $A$. elatius sides (d). For abbreviations see Figure 1. 
Table 3. Effects of 'ants' and 'honeydew' on basal respiration (BAS, $\mu \mathrm{g} \mathrm{O}_{2} \mathrm{~g}^{-1}$ dry wt $\mathrm{h}^{-1}$ ). All comparisons were made using a MANCOVA with the mean soil water content as covariable. P-values of significant effects $(p<0.05)$ are presented in bold letters, those of marginal significant effects $(p<0.1)$ are presented with three decimal places. $d f=$ degree of freedom.

\begin{tabular}{|c|c|c|c|c|c|c|c|c|c|c|c|c|}
\hline & \multirow[b]{2}{*}{ df } & \multicolumn{2}{|c|}{$\begin{array}{c}\text { soil } P . \\
\text { vulgaris side }\end{array}$} & \multicolumn{2}{|c|}{ ground soil } & \multicolumn{2}{|c|}{$\begin{array}{c}\text { soil } A \text {. } \\
\text { elatius side }\end{array}$} & \multicolumn{2}{|c|}{ litter } & \multirow[b]{2}{*}{$\begin{array}{l}\text { Wilks' } \\
\text { Lambda }\end{array}$} & \multirow[b]{2}{*}{$F$} & \multirow[b]{2}{*}{$\mathrm{p}$} \\
\hline & & $\mathrm{F}$ & $p$ & $F$ & $p$ & $F$ & $p$ & $F$ & $p$ & & & \\
\hline $\begin{array}{l}\text { Mean soil } \\
\text { moisture }\end{array}$ & 1 & 3.80 & 0.065 & 0.45 & 0.51 & 5.64 & 0.0277 & 3.69 & 0.069 & 0.5466 & 3.53 & 0.0286 \\
\hline block & 7 & 2.76 & 0.0351 & 6.50 & 0.0004 & 5.95 & 0.0008 & 1.23 & 0.33 & 0.0752 & 2.35 & 0.0026 \\
\hline ants & 1 & 5.67 & 0.0273 & 5.63 & 0.0278 & 0.36 & 0.56 & 0.20 & 0.66 & 0.5874 & 2.99 & 0.0489 \\
\hline honeydew & 1 & 3.46 & 0.078 & 2.45 & 0.13 & 3.19 & 0.090 & 0.81 & 0.38 & 0.6595 & 2.19 & 0.11 \\
\hline ants*ho & 1 & 1.80 & 0.20 & 1.78 & 0.20 & 0.74 & 0.40 & 4.30 & 0.051 & 0.5394 & 3.63 & 0.0259 \\
\hline
\end{tabular}

Table 4. Effects of 'ants' and 'honeydew' on microbial biomass $\left(C_{\text {mic }}, \mu g C_{\text {mic }} g^{-1}\right.$ dry wt). All comparisons were made using a MANCOVA with the mean soil water content as covariable. $P$-values of marginal significant effects $-p<0.1-$ are presented with three decimal places. $\mathrm{df}=$ degree of freedom.

\begin{tabular}{|c|c|c|c|c|c|c|c|c|c|c|c|c|}
\hline & \multirow[b]{2}{*}{$d f$} & \multicolumn{2}{|c|}{$\begin{array}{c}\text { soil } P \text {. vulgaris } \\
\text { side }\end{array}$} & \multicolumn{2}{|c|}{ ground soil } & \multicolumn{2}{|c|}{$\begin{array}{l}\text { soil } A \text {. } \\
\text { elatius side }\end{array}$} & \multicolumn{2}{|c|}{ litter } & \multirow[b]{2}{*}{$\begin{array}{l}\text { Wilks' } \\
\text { Lambda }\end{array}$} & \multirow[b]{2}{*}{$F$} & \multirow[b]{2}{*}{$p$} \\
\hline & & $F$ & $p$ & $F$ & $\mathrm{p}$ & $\mathrm{F}$ & $p$ & $F$ & $p$ & & & \\
\hline $\begin{array}{l}\text { Mean soil } \\
\text { moisture }\end{array}$ & 1 & 0.22 & 0.65 & 1.62 & 0.22 & 6.76 & 0.0171 & 5.82 & 0.0255 & 0.5230 & 3.88 & 0.0205 \\
\hline block & 7 & 7.56 & 0.0002 & 4.90 & 0.0024 & 3.20 & 0.0194 & 2.26 & 0.073 & 0.0259 & 3.93 & $<0.0001$ \\
\hline ants & 1 & 3.47 & 0.077 & 0.29 & 0.60 & 3.57 & 0.073 & 12.87 & 0.0018 & 0.4624 & 4.94 & 0.0079 \\
\hline honeydew & 1 & 28.62 & $<0.0001$ & 1.07 & 0.31 & 2.94 & 0.10 & 0.37 & 0.55 & 0.3015 & 9.85 & 0.0003 \\
\hline ants*ho & 1 & 0.56 & 0.46 & 1.23 & 0.28 & 1.96 & 0.18 & 4.38 & 0.0493 & 0.75 & 1.38 & 0.28 \\
\hline
\end{tabular}

BAS in soil samples from microcosm ground was significantly higher when ants were present (A-1.15, $\mathrm{A}+1.45 \mu \mathrm{g} \mathrm{O}_{2} \mathrm{~g}^{-1}$ dry wt $\mathrm{h}^{-1}$, Table 3, Figure $2 \mathrm{c}$ and Figure 7). In soil samples from the $A$. elatius side BAS was marginally lower in treatments with honeydew ( $\mathrm{H}-1.21, \mathrm{H}+1.08 \mu \mathrm{g} \mathrm{O} \mathrm{g}^{-1}$ dry wt $\mathrm{h}^{-1}$, Table 3, Figure $2 \mathrm{~d}$ and Figure 7), and $C_{\text {mic }}$ marginally higher in treatments with ants (A- 5.55, A+ $6.22 \mu \mathrm{g} \mathrm{C}_{\text {mic }} g^{-1}$ dry wt, Table 4, Figure 3d and Figure 7).

Bacterial community analysis

The effect of 'ants' and 'honeydew' on the bacterial soil community was assessed by denaturing gradient gel electrophoresis (DGGE) of soil DNA derived from samples of eight replicated microcosms per treatment. The obtained DGGE fingerprints (Appendix B). were digitalized and a cluster analysis using GelCompare was performed. The resulting dendrogram (Figure 4) did not show a distinct clustering of 
the different 'ant' and 'honeydew' treatments. This is due to the high variation of the banding patterns within 'ant' treatments. Correspondingly, bacterial communities from control soil samples did not cluster in one group separate from the different treatments.

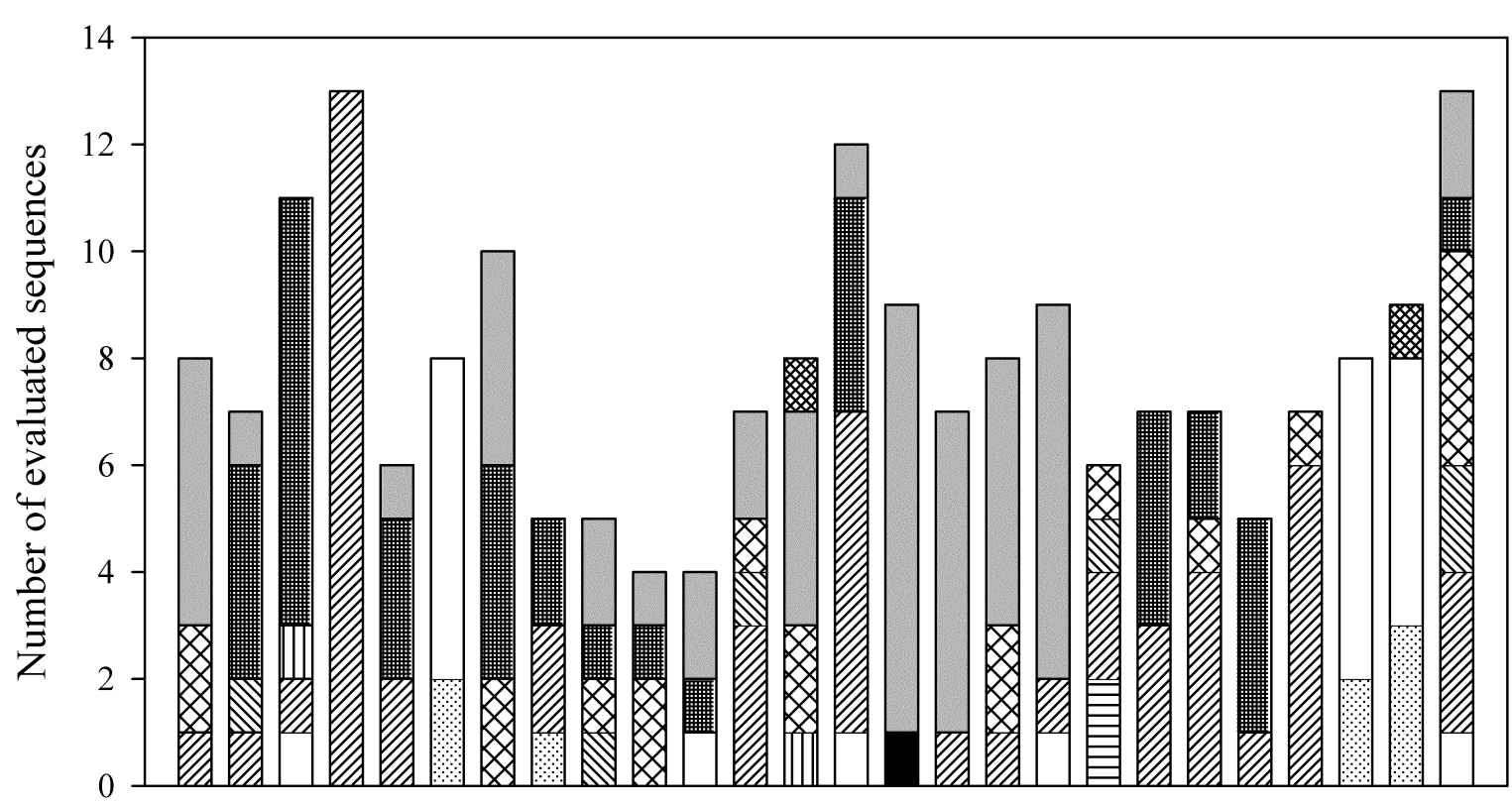

$\begin{array}{llllllllllllllllllllllllll}\text { A } & \text { B } & \text { C } & \text { D } & \text { E } & \text { F } & \text { G } & \text { H } & \text { I } & \text { J } & \text { K } & \text { L } & \text { M } & \text { N } & \text { O } & \text { P } & \text { Q } & \text { R } & \text { S } & \text { T } & \text { U } & \text { V } & \text { W } & \text { X } & \text { Y } & \text { Z }\end{array}$

DGGE banding patterns

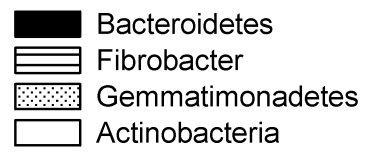

QIIA Firmicutes

MIV Acidobacteria

एण Deltaproteobacteria

XXX Alphaproteobacteria

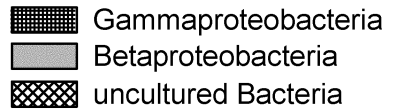

uncultured Bacteria

Figure 4. Bar chart showing the distribution of phyla derived from the excised banding patterns of the DGGE fingerprints. Letters indicating the, in Appendix B A. and B. marked, excised banding patterns.

Twenty six dominant bands (marked in Appendix B) were excised from the Gels, cloned and sequenced. Phylogenetic analysis of the 16S rRNA gene sequence data showed that the Proteobacteria were most abundant, representing $55 \%$ of the analyzed sequences (Figure 5). The Firmicutes accounted for $25 \%$, the Actinobacteria for $11 \%$, the Gemmatimonadetes for $4 \%$ and Acidobacteria for $3 \%$ of the analyzed 16S rRNA gene sequences. Within the phylum Proteobacteria, the Betaproteobacteria (46\%) were the predominant class followed by the Gammaproteobacteria (35\%) and the Alphaproteobacteria (17\%). The DGGE patterns from the control microcosms were dominated by five intense bands, which represent the Gammaproteobacteria), Betaproteobacteria, Alphaproteobacteria and 
Firmicutes (Figure 6 and Appendix B, bands $\mathrm{O}, \mathrm{P}, \mathrm{R}, \mathrm{G}$ and $\mathrm{V}$ ) and a number of fainter bands. In four of the eight replicates of experimental microcosm without ants and honeydew (A- $\mathrm{H}-$ ) appear bands at the same height as band $\mathrm{O}$, which was derived from analysis of the control soil (Appendix B). The other four replicates show a more diverse banding pattern. Bands running at the same height as band $O$ were visible in all treatments, but not in all replicates. For example, analysis of bands A (A$\mathrm{H}+)$ and $\mathrm{Q}(\mathrm{A}+\mathrm{H}-)$ revealed that both bands represented the same phyla (Betaproteobacteria, Alphaproteobacteria, and Firmicutes). In control soil bands appear at the same height as band $\mathrm{P}$, derived from analysis of an experimental microcosm without ants and aphids (A- $\mathrm{H}-)$.

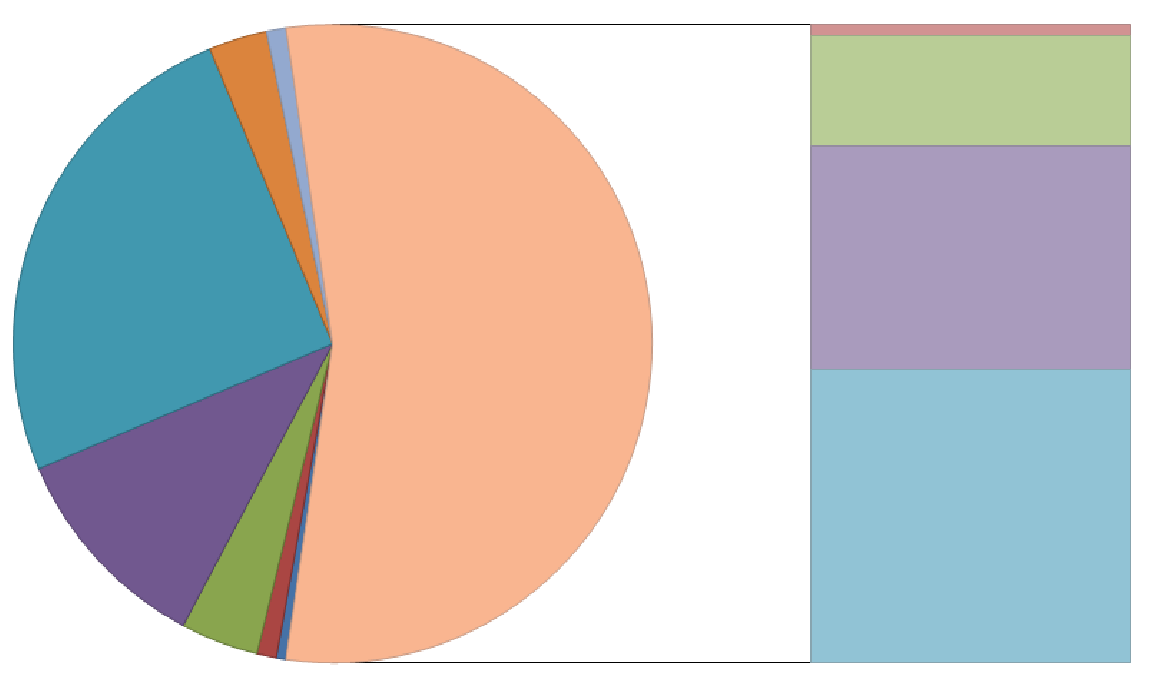

$\square$ Bacteroidetes

- Fibrobacter

$\square$ Gemmatimonadetes

- Actinobacteria

$\square$ Firmicutes

$\square$ Acidobacteria

$\square$ uncultured Bacteria

- Deltaproteobacteria

$\square$ Alphaproteobacteria

$\square$ Gammaproteobacteria

$\square$ Betaproteobacteria

Figure 5. Pie chart illustrating the distribution of the occurred phyla amongst all analysed sequences of the selected and excised DGGE banding patterns, marked in Appendix B. 
Dice (Tol 1.0\%-1.0\%) (H>0.0\% $S>0.0 \%)[0.0 \%-100.0 \%]$

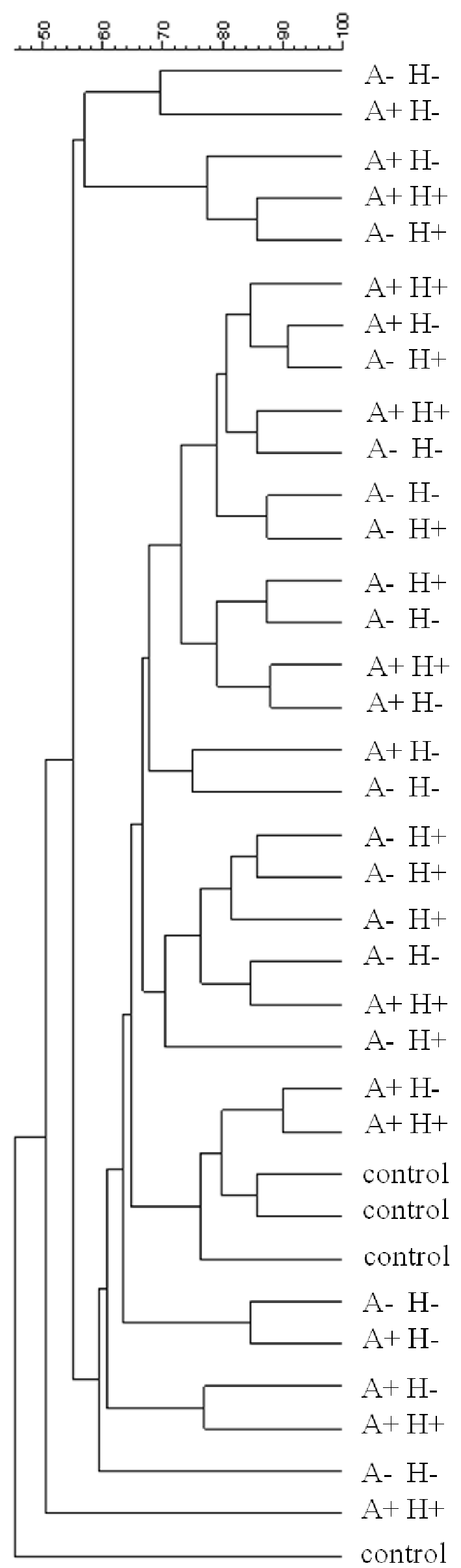

Figure 6. Cluster analysis of the digitized bacterial DGGE fingerprint from Appendix B. The UPMGA method was applied, which takes the presence or absence of bands at certain positions in each lane into account 
Similarly, bands running at the same height as band $\mathrm{G}$ (treatment $\mathrm{A}+\mathrm{H}-$ ) were present in all treatments, but in some more intense than in others. The analysis of bands $\mathrm{G}, \mathrm{H}$, and $\mathrm{T}$ revealed that all these bands occurring at the same height mainly represented the Betaproteobacteria, Gammaproteobacteria as well as the Alphaproteobacteria and Firmicutes.

In all 'no ant' treatments appear bands at the same position as band E, but not in all 'ant' treatments. Bands at the height of band $D$ appeared in eight of the sixteen 'ant' as well as in eight of the sixteen 'no ant' treatments, with different intensities (Appendix B). The sequences, which were determined for band $\mathrm{D}$, were all affiliated to the Firmicutes. Honeydew dropping resulted in more diverse bacterial communities and increased the intensity of bands $B, C$ and $V$ (treatment $A-H+$, Appendix B). Bands B, C, and V were dominated by Gammaproteobacteria and Firmicutes. In the absence of honeydew, the intensity of band $L$ increased. The dominating phyla in band $L$ were the Firmicutes and the Betaproteobacteria. When ants inhabited the microcosm (treatments $\mathrm{A}+\mathrm{H}-, \mathrm{A}+\mathrm{H}+$ ) a high variation of number and location of abundant bands within the replicated treatments was observed (see bands $U, P, A$, $S, R$ and I in Appendix B).

In summary, no distinct separation of the different treatments was visible in the DGGE banding patterns and the cluster analysis.

Figure 7 summarizes the effect of aphid honeydew compared to controls and Figure 8 summarizes the effect of 'ants' and 'honeydew' when experimental treatments were compared. 


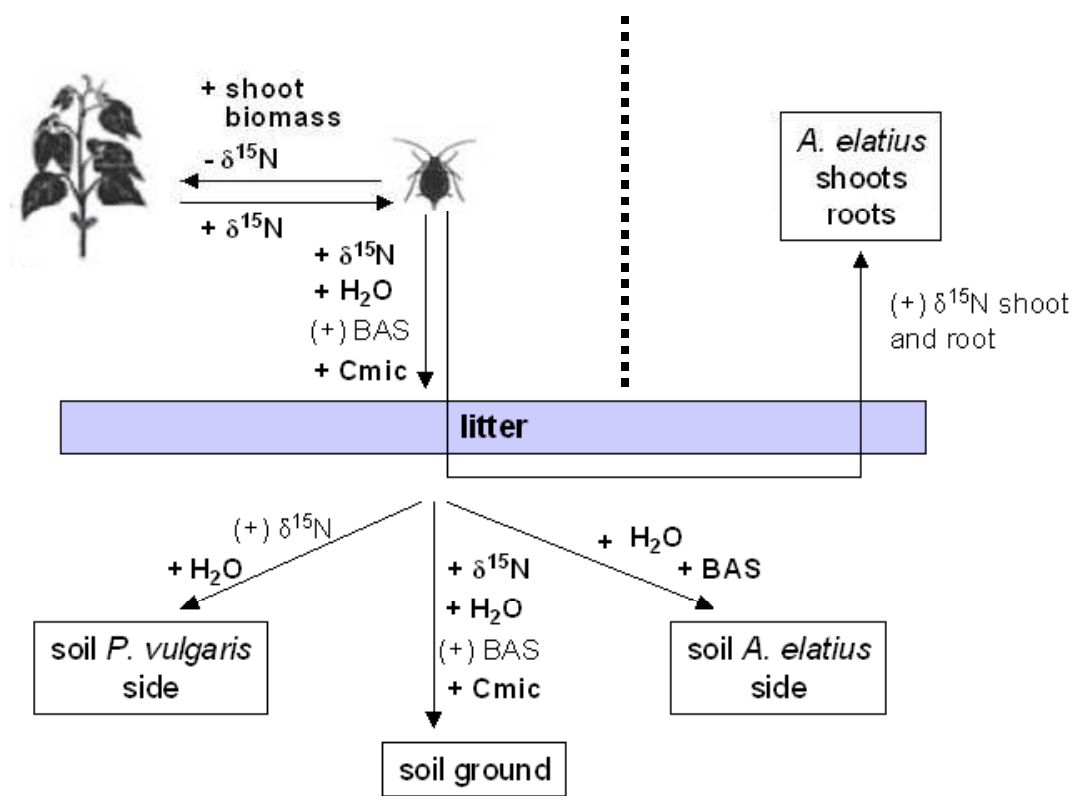

Figure 7. Above- and belowground effect of 'aphids', analysed in a one-way GLM comparing controls with the treatment 'no ants' and 'honeydew'

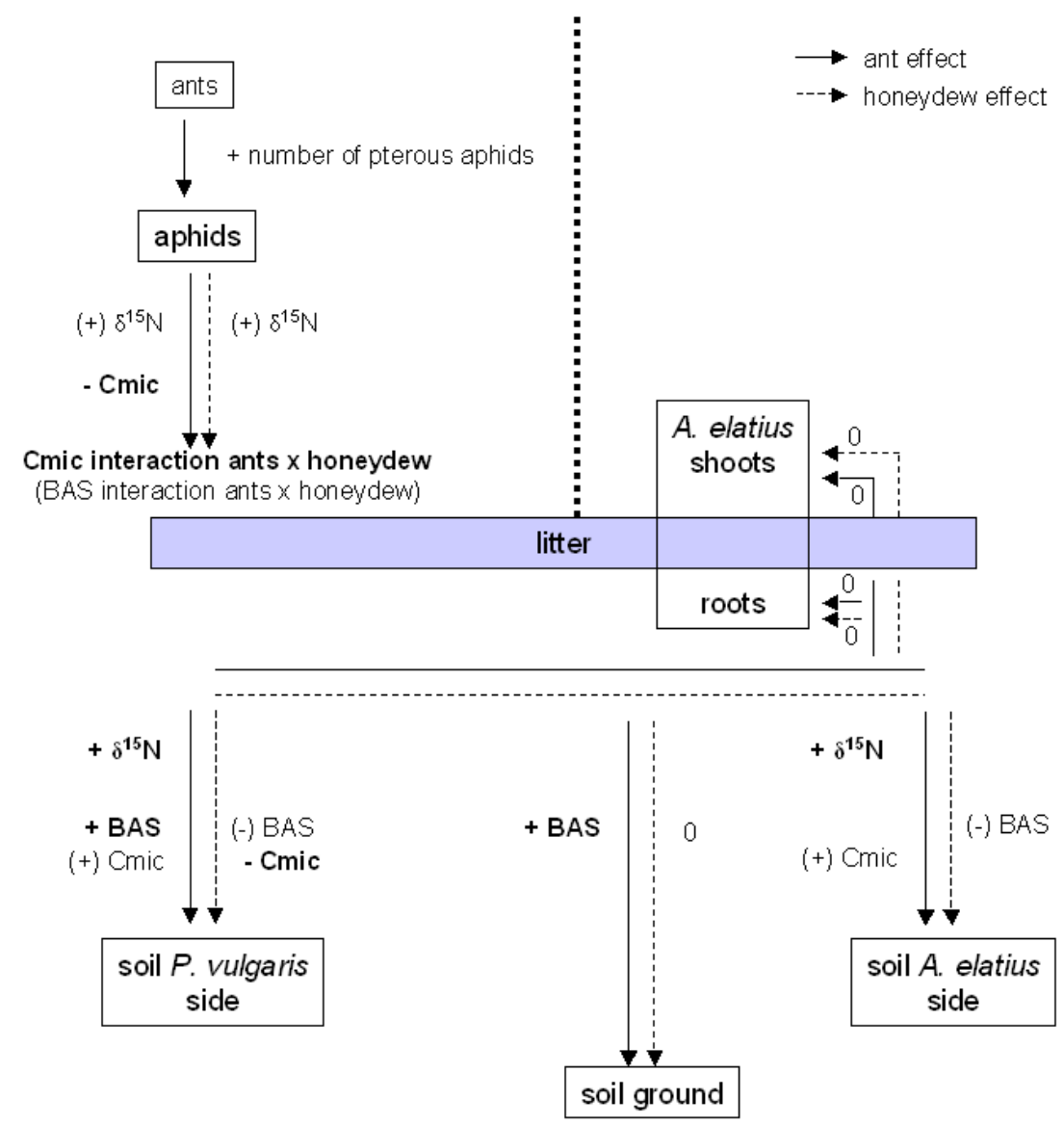

Figure 8. Effects of 'ants' and 'honeydew' in above- and belowground systems. Solid line=ant effect, dotted line=honeydew effect. 


\section{Discussion}

Biomass and stable isotopes

When $P$. vulgaris served as a host for aphids, $\delta{ }^{15} \mathrm{~N}$ labelling in shoots was lower than in control microcosms without aphids, indicating that aphid infestation reduced the labelling strength. Aphids feed on the sugar-rich but amino acid-poor phloem sap of their host plant and excrete honeydew as a sugary waste product (Way, 1963). The uptake of the ${ }^{15} \mathrm{~N}$ isotopes by aphids was measured in aphids' tissue. Aphids' $\delta^{15} \mathrm{~N}$ signature in unlabelled plants in a similar experiment amounted to $4.1 \%$ (Schumacher and Platner, 2009). In our experiment, the labelling procedure of plants increased the $\delta^{15} \mathrm{~N}$ content in aphids to $136.1 \%$ and allowed us to follow the nitrogen flow via honeydew, litter, and soil between the different compartments within the microcosms.

Ants collect the honeydew to cover their demand on carbohydrates. In return, ants protect the aphids against predators and parasitoids and reduce fungal disease by removing honeydew and exuviae (Stadler and Dixon, 2005). Experimental ant colonies originated from one collected colony that was divided into 16 experimental sub-colonies. The $\delta^{15} \mathrm{~N}$ of the original colony was nearly equal between ants $(2.4 \%)$ and their larvae $(2.3 \%)$. These values represented the initial value of ants and larvae at the start of the experiment. At the end of the experiment larvae had incorporated more of the $\delta^{15} \mathrm{~N}$ isotope (5.6\%) into their tissue compared to larvae from the origin colony, showing the material flow from aphids to ant larvae. Moreover, adult ant workers showed an increase in $\delta^{15} \mathrm{~N}$ values higher than 4-fold, compared to their larvae at the end of the experiment $(16.9 \%)$. The crop content of workers could not be responsible for isotope signature, because plants and aphids were removed five days before ants were collected and the crops should have been empty. The increase of $\delta^{15} \mathrm{~N}$ in workers may reflect the larval diet, as ants are holometabolous insects which obtain their biomass mainly during the larval stage (Blüthgen et al., 2003). However, Fischer et al. (2005a) calculated a daily nitrogen incorporation rate of $0.05 \%$ of bulk body nitrogen from a labelling experiment for Myrmica rubra workers.

In the ant-aphid mutualism, the advantage for aphids in this study was restricted to the reduction of fungal disease by hygienic services, as no predators and parasitoids could reach the aphid colonies and no other honeydew producers competed for ant attendance. In our study, no changes in aphid colony biomass were 
detected due to ant presence, but attendance led to the development of significantly more alate aphids. This result indicated that ants promoted aphids' spreading during the experiment. Contrary to our results, recent studies have found that the occurrence of winged adults is negatively associated with ant attendance (Dixon, 1998; Kindlmann et al., 2007). Due to protection by ants, aphids might be less induced to escape from their natural enemies by dispersal (Dixon and Agrawala, 1999; Müller and Godfray, 1999; Kunert and Weisser, 2003). In our study, the honeydew and protein demand for ants might be reduced over time, as on average $61 \%$ of the added workers died and $56 \%$ of the added larvae died or developed to adult workers during the experiment. The lower demand possibly resulted in a lower tending activity and less hygienic service by ants. Decreasing ant activity on previously tended aphid colonies could have stimulated the production of winged individuals.

When aphids are tended by ants, aphids can increase the frequency of honeydew excretion to increase attractiveness for ants. Moreover, the honeydew of tended aphids contains significantly higher concentration of amino acids (Yao and Akimoto, 2002), sucrose and trehalose (Yao and Akimoto, 2001). Llewllyn and Leckstein (1978) reported that unattended larval $A$. fabae reared on broad beans utilized $54 \%$ of their energy intake for growth, $4 \%$ was lost during respiration and $42 \%$ was excreted as honeydew. Völkl et al. (1999) measured a total sugar concentration of $29.1 \mu \mathrm{g}$ sugar per $\mu \mathrm{l}$ honeydew in honeydew of $A$. fabae reared on Tanacetum vulgare when aphids were tended by ants. Fischer et al. (2005b) found a total sugar concentration ranging from 27 to $42 \mu \mathrm{g}$ sugar per $\mu \mathrm{l}$ honeydew in $A$. fabae on various host plants. Honeydew and its varying amounts and ingredients due to ant attendance can also have effects in the belowground system. Compared to controls, aphids' honeydew led to significantly higher $\delta^{15} \mathrm{~N}$ values in the litter layer. In experimental microcosms, both 'honeydew' and 'ants' led to a marginal significant increase $\delta^{15} \mathrm{~N}$ values in the litter. But in soil samples from experimental microcosm without ants, no effect of honeydew was found, showing that the $\delta^{15} \mathrm{~N}$ trace of honeydew did not reach the soil and that the material flow ended in the litter layer. The presence of ants, however, significantly increased $\delta^{15} \mathrm{~N}$ content in the upper soil samples ( $P$. vulgaris side and $A$. elatius side), indicating that ant activity stimulates the pathway from the aboveground to the belowground system. 
Comparison of controls with treatments 'no ants' and 'no honeydew' indicated, that honeydew was not completely excluded in 'no honeydew' treatments by pane. In 'no ants' and 'honeydew' treatment, $\delta^{15} \mathrm{~N}$ values were significantly higher in ground soil samples when compared to control, but when compared to other experimental treatments, $\delta{ }^{15} \mathrm{~N}$ values did not differ significantly. This indicates that despite pane, honeydew reached the soil what would weaken the clarity of the honeydew effect in experimental treatments. A reason for the missing $\delta^{15} \mathrm{~N}$ trace of honeydew in soil samples in our experiment can be associated with watering the microcosms only on the $A$. elatius side to prevent honeydew from leaching off the perspex pane and reaching the soils in 'no honeydew' microcosms. Perhaps condensed water washed off honeydew attached on microcosm cylinder into the soil. Also in natural systems the effect of honeydew may be stronger because rain may wash the honeydew through the litter into the soil.

Planting $A$. elatius in the microcosms should show a possible ${ }^{15} \mathrm{~N}$ flow from $P$. vulgaris via honeydew to the neighboured $A$. elatius plants. When comparing controls with the treatment 'no ants' and 'honeydew' we could show marginal higher $\delta{ }^{15} \mathrm{~N}$ values in roots and shoots of $A$. elatius plants in microcosm with aphids. However, no significant effect of 'ant' or 'honeydew' on the $\delta^{15} \mathrm{~N}$ content of $A$. elatius roots or shoots was detected.

\section{Basal respiration and microbial biomass}

Microbial biomass and basal respiration in the litter layer depended on aphid and ant activity. Compared to controls, aphid presence led to significantly higher microbial biomass in the litter layer. This indicated that aphids positively affect litter microorganism by delivering nutrients derived from honeydew excretion. Without ants, honeydew fell onto the litter and its input increased microbial biomass and basal respiration, but both parameters were dependent on ant activity and decreased when ant inhabited the 'honeydew' treatments (interaction ants*honeydew). With ants in microcosms, the amount of honeydew reaching the litter might have been reduced, because ants collect the honeydew as energy resource. Thus, sugar resources of litter microorganisms might have been decreased. Wellenstein (1980) reported that under natural conditions approximately $1 / 3$ of honeydew may fall straight to the ground. This additional sugar source can be an important component of soil fertility (Choudhury, 1985) and ant consumption can reduce the amount of honeydew 
reaching the soil surface by $50 \%$ (Seeger and Filser, 2008). In contrast to litter, ants significantly increased basal respiration and marginally microbial biomass in soils. These results indicated that resources for microorganisms were transported from the aboveground to the belowground by ants. Significantly increased microbial biomass and basal respiration in natural $L$. flavus nests in comparison to the surrounding soils were reported in a study carried out by Platner (2006) in a calcareous grassland. The increase of these soil parameters due to ant presence might be caused by the intake of prey and mixing soil and litter due to nest construction (Skinner, 1980). In contrast to ant presence, 'honeydew' significantly decreased microbial biomass and marginally basal respiration in the upper soil. On the one hand, the decreased microbial biomass in 'honeydew' treatments can be explained by the lack of additional nutrients for microbial development provided by ants. On the other hand, honeydew dropping onto the litter might be quickly consumed by microbes and did not reach the soil without ants. In the ground soils, no 'honeydew' effect was found. However, ants increased basal respiration even in the ground samples.

\section{Bacterial community analysis}

To determine the effect of 'ants' and 'honeydew' on bacterial community composition within the different microcosms, we applied PCR-DGGE. Therefore a 560 bp fragment of the $16 \mathrm{~S}$ rRNA including the variable regions V3, V4 and V5 was amplified and applied for DGGE analysis.

The cluster analysis of the DGGE fingerprints showed no distinct separation of the different treated microcosms and the controls. In ground soil samples, three of the five main bands (see $\mathrm{O}, \mathrm{T}$ and $\mathrm{V}$ in Appendix B, B.) of the controls also occurred in $\mathrm{A}-\mathrm{H}+$ treatments, but with higher intensities. In addition, a number of faint bands observed in controls, became more pronounced in $\mathrm{A}-\mathrm{H}+$ treatments. The comparison of bacterial DGGE fingerprints from control soils with soil from microcosm with honeydew and without ants $(\mathrm{A}-\mathrm{H}+)$ indicated that honeydew can increase the dominance of the already existing soil bacterial populations. In the case of banding patterns O, T and V, the Gammaproteobacteria, Betaproteobacteria and the Firmicutes were affected positively. Sugar-rich honeydew is an readily available resource for microorganisms and can be quickly consumed. It has been assumed that beside other substrates, the most common limiting factor for microbial growth in soils is the lack of carbon (Scheu and Schaefer, 1998). An increasing dominance of 
bacterial populations within the ground soil, however, did not result in changes of microbial biomass or basal respiration. This might be due to reverse reaction in fungal community, but this was not investigated. However the presence of ants changed banding patterns from few dominant bands in controls to patterns with more distinct bands of equal intensity, indicating that ants can change bacterial populations by promoting a more balanced dominance structure between populations. The number and position of the different bands (see Appendix B, bands U, P, A, S and R) strongly differed within the 'ant' treatment. As mentioned before, this allowed no clear separation of 'ant' vs. 'no-ant' treatments in the dendrogram analysis. Bacterial communities directly inhabiting ant nests might be stronger affected by ants than bacterial populations outside ant nests. This might lead to differences in response to the ant effect between the different microcosms.

\section{Conclusions}

The $\delta^{15} \mathrm{~N}$ signal of plants spread from aphids to aphids' honeydew and to ants. We followed the $\delta^{15} \mathrm{~N}$ trace from the aboveground to the belowground system into the litter and, into the soil in the presence of ants. Without ants, honeydew increased the biomass of litter microorganisms, whereas ant presence altered honeydew amounts in the litter and consequently biomass of litter and also soil microorganisms. In ground soil, honeydew increased the abundance of the already existing soil bacterial populations, whereas ants promoted a more balanced dominance structure between populations, but with different patterns. In this experiment, we could show, that aphids can increase nutrient availability for microorganisms inhabiting the litter and that ants alter the nutrient flow within the system and transfer of nutrients into soil. Thus, aphids have a strong impact on the belowground system, nutrient availability and microbial communities, and this effect is highly dependent on the tending activity of ants. 


\section{Acknowledgements}

We thank Matthias Schaefer, Sonja Migge-Kleian and Carola Simon for valuable discussions and comments on the manuscript.

\section{References}

Anderson, J.P.E., Domsch, K.H., 1978. A physiological method for the quantitative measurement of microbial biomass in soils. Soil Biol. Biochem. 10, 215-221.

Anderson, C., McShea, D.W., 2001. Intermediate-level parts in insect societies: adaptive structures that ants build away from the nest. Insectes Soc. 48, 291301.

Banks, J.C., 1962. Effects of the ant Lasius niger (L.) on insects preying on small populations of Aphis fabae (Scop.) on bean plants. Ann. Appl. Biol. 50, 669679.

Banks, J.C., Macaulay, E.D.M., 1967. Effects of Aphis fabae (Scop.) and of its attendant ants and insects predators on yields of field beans (Vicia faba L.). Ann. Appl. Biol. 60, 445-453.

Blüthgen, N., Gebauer, G., Fiedler, K., 2003. Disentangling a rainforest food web using stable isotopes: dietary diversity in a species-rich ant community. Oecologia 137, 426-435.

Brian, M.V., 1983. Social insects. Chapman and Hall, London.

Bristow, C.M., 1984. Differential benefits from ant attendance to two species of Homoptera on New York iron weed. J. Anim. Ecol. 53, 775-726.

Bronstein, J.L., 1994. Conditional outcomes in mutualistic interactions. Trends Ecol. Evol. 9, 214-217.

Choudhury, Y.D., 1985. Aphid honeydew - a reappraisal of Owen and Wiegert Hypotheses. Oikos 45, 287-290.

Cushman, J.H., Addicot, J.F., 1991. Conditional interactions in ant-herbivore mutualism. In: Ant-plant interactions. Ed. by Huxley CR, Cutler DF, Oxford University Press, Oxford, 92-119.

Cushman, J.H., Whitham, T.G., 1991. Competition mediating the outcome of a mutualism: protective services of ants as a limiting resource for membracids. Am. Nat. 138, 789-797. 
Dixon, A.F.G., Agarwala, B.K., 1999. Ladybird-induced life-history changes in aphids. Proc. R. Soc. Lond B 266,1549-1553.

Fischer, M.K., Shingleton, A.W., 2001. Host plant and ants influence the honeydew sugar composition of aphids. Funct. Ecol. 15, 544550.

Fischer, R.C., Ölzand, S.M., Wanek, W., Mayer, V., 2005a. The fate of Corydalis cava elaiosomes within an ant colony of Myrmica rubra: elaiosomes are preferentially fed to larvae. Insec. Soc. 52, 55-62.

Fischer, M.K., Völkl, W., Hoffmann, H., 2005b. Honeydew production and honeydew sugar composition of polyphagous black bean aphid, Aphis fabae (Hemiptera, Aphididae) on various host plants and implications for ant attendance. Eur. J. Entomol. 102, 155-160.

Gratton, C., Forbes, A.E., 2006. Changes in $\delta^{13} \mathrm{C}$ stable isotopes in multiple tissues of insect predators fed isotopically distinct prey. Oecologia 147, 615-624.

Hölldobler, B., Wilson, E.O., 1990. The ants. Springer, Berlin, Heidelberg, New York. Jones, C.G., Lawton, J.H., Shachak, M., 1994. Organisms as ecosystem engineers. Oikos 69, 373-386.

Kindlmann, P., Hullé, M., Stadler, B., 2007. Timing of dispersal: effects of ants on aphids. Oecologia 152, 625-631.

Kunert, G., Weisser, W.W., 2003. The interplay between density- and trait mediated effects in predator-prey interactions: a case study in aphid wing polymorphism. Oecologia 135, 304-312.

Letourneau, D.K., Dyer, L.A., 1998. Experimental test in lowland tropical forest shows top-down effects through four trophic levels. Ecology 79, 1678-1687.

Llewellyn, M., Leckstein, P.M., 1978. A comparison of energy budgets and growth efficiency for Aphis fabae Scop. reared on synthetic diets with aphids reared on broad beans. Ent. exp. and appl. 23, 66-71.

Lobry de Bruyn, L.A., Conacher, A.J., 1990 The role of termites and ants in soil modification: a review. Aust. J. Soil Res. 28, 55-93.

Matsuura, K., Yashiro, T., 2006. Aphid egg protection by ants: a novel aspect of the mutualism between the tree-feeding aphid Stomaphis hirukawai and its attendant ant Lasius products. Naturwissenschaften 93, 506-510.

Morales, M.A., 2000. Survivorship of ant-tended membracid as a function of ant recruitment. Oikos 90, 469-476. 
Müller, C.B., Godfray, H.C.J., 1999. Predators and mutualists influence the exclusion of aphid species from natural communities. Oecologia 119, 120-125.

Muyzer, G., Teske, A., Wirsen, C.O., Jannasch, H.W., 1995. Phylogenetic relationships of Thiomicrospira species and their identification in deep-sea hydrothermal vent samples by denaturing gradient gel electrophoresis of $16 \mathrm{~S}$ rDNA fragments. Arch. Microbiol. 164, 165-172.

Muyzer, G., Smalla, K., 1998. Application of denaturing gradient gel electrophoresis (DGGE) and temperature gradient gel electrophoresis (TGGE) in microbial ecology. Antonie van Leewenhoek 73, 127-141.

Pêtal, J., 1998. The influence of ants on carbon and nitrogen mineralization in drained fen soil. Appl. Soil Ecol. 9, 271-275.

Platner, C., 2006. Ameisen als Schlüsseltiergruppe in einem Grasland. Studien zu ihrer Bedeutung für die Tiergemeinschaft, das Nahrungsnetz und das Ökosystem. Biodiversity and Ecology Series 1, Universitätsverlag, Göttingen.

Pontin, A.J., 1958. A preliminary note on the eating of aphids by ants of the genus Lasius (Hym., Formicidae). Entomol. Monthly Mag. 94, 9-11.

Post, D.M., 2002. Using stable isotopes to estimate trophic position: models methods and assumptions. Ecology 83, 703-718.

Reineking, A., Langel, R., Schikowski, J., 1993. 15N, 13C-online measurements with an elemental analyser (carbo erber, NA 1500), a modified trapping box and a gas isotope mass spectrometer (Finnigan, MAT 251). Isotopenpraxis Environ. Health Stud. 29, 169-174.

Sanders, D., Platner, C., 2007. Intraguild interactions between spiders and ants and top-down control in a grassland food web. Oecologia 150, 611-624.

Scheiner, S.M., 2001. Manova. In: Scheiner, S.M. \& Gurevitch, J.: Design and Analysis of Ecological Experiments. 2nd ed. Oxford University Press, Oxford, New York.

Scheu, S., 1992. Automated measurement of the respiratory response of soil microcompartments: active microbial biomass in earthworm faeces. Soil Biol. Biochem. 24, 1113-1118.

Scheu, S., Schaefer, M., 1998. Bottom-up control of the soil macrofauna community in a beechwood on limestone: Manipulation of food resources. Ecology 79, 1573-1585. 
Schmidt, O., Scrimgeour, C.M., 2001. A simple urea leaf-feeding method for the production of $13 \mathrm{C}$ and $15 \mathrm{~N}$ labelled plant material. Plant Soil 229, 197-202.

Schumacher, E., Platner, C., 2009. Nutrient dynamics in a tritrophic system of ants, aphids and beans. J. Appl. Entomol. 133, 33-46.

Seeger, J., Filser, J., 2008. Bottom-up down from the top: Honeydew as a carbon source for soil organisms. Eur. J. Soil Biol. 44, 483-490.

Skinner, G.J., 1980. The Feeding Habits of the Wood-Ant, Formica rufa (Hymenoptera: Formicidae), in Limestone Woodland in North-West England. J. Anim. Ecol. 49, 417-433.

Stadler, B., Dixon, A.F.B., 2005. Ecology and evolution of aphid-ant interactions. Ann. Rev. Ecol. Evol. Syst. 36, 345-372.

Stadler, B., Schramm, A., Kalbitz, K., 2006. Ant-mediated effect on spruce litter decomposition, solution chemistry, and microbial activity. Soil Biol. Biochem. 38, 561-572.

Styrsky, J.D., Eubanks, M.D., 2007. Ecological consequences of interactions between ants and honeydew-producing insects. Proc. R. Soc. B. 274, 151-164.

Sokal, R.R., Rohlf, F.J., 2001. Biometry. 4th edition. WH Freeman and Co., New York.

Tillberg, C.V., McCarthy, D.P., Dolezal, A.G., Suarez, A.V., 2006. Measuring the trophic ecology of ants using stable isotopes. Insect. Soc. 53, 65-69.

Völkl, W., Woodring, J., Fischer, M., Lorenz, M.W., Hoffmann, K.H., 1999. Ant-aphid mutualisms: the impact of honeydew production and honeydew sugar composition on ant preferences. Oecologia 118, 483-491.

Way, M.J., 1954. Studies on the association of the ant Oecophylla longinoda (Latr.) (Formicidae) with the scale insect Saissetia zanzibarensis Williams (Coccidae). Bull. Entomol. Res. 45, 113-134.

Way, M.J., 1963. Mutualism between ants and honeydew-producing Homoptera. Ann. Rev. Entomol. 8, 307-344.

Wellenstein, G., 1980. Auswirkung hügelbauender Waldameisen der Formica rufaGruppe auf forstschädliche Raupen und das Wachstum der Waldbäume. Z. Ang. Entomol. 89, 144-157.

Woodring, J., Wiedemann, R., Fischer, M.K., Hoffmann, K.H., Völkl, W., 2004. Honeydew amino acids in relation to sugars and their role in the establishment 
of ant-attendance hierarchy in eight species of aphids feeding on tansy (Tanacetum vulgare). Physiol. Entomol. 29, 311-319.

Yao, I., Akimoto, S., 2001. Ant attendance changes the sugar composition of the honeydew of the drepanosiphid aphid Tuberculatus quercicola. Oecologia 128, 36-43.

Yao, I., Akimoto, S.-I., 2002. Flexibility in the composition and concentration of amino acids in honeydew of the drepanosiphid aphid Tuberculata quericola. Ecol. Entomol. 27, 745-752. 


\section{Appendix}
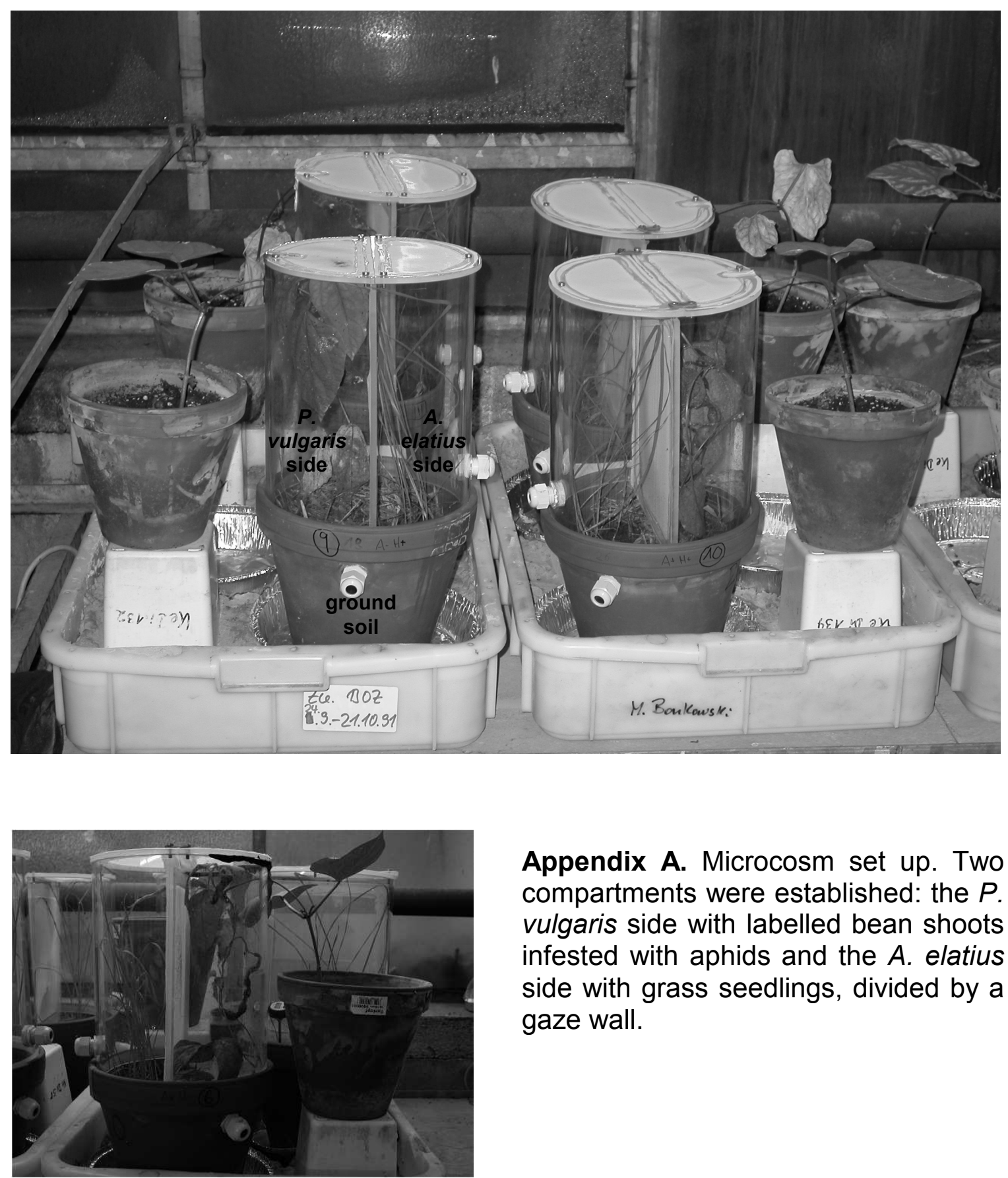

Appendix A. Microcosm set up. Two compartments were established: the $P$. vulgaris side with labelled bean shoots infested with aphids and the $A$. elatius side with grass seedlings, divided by a gaze wall. 


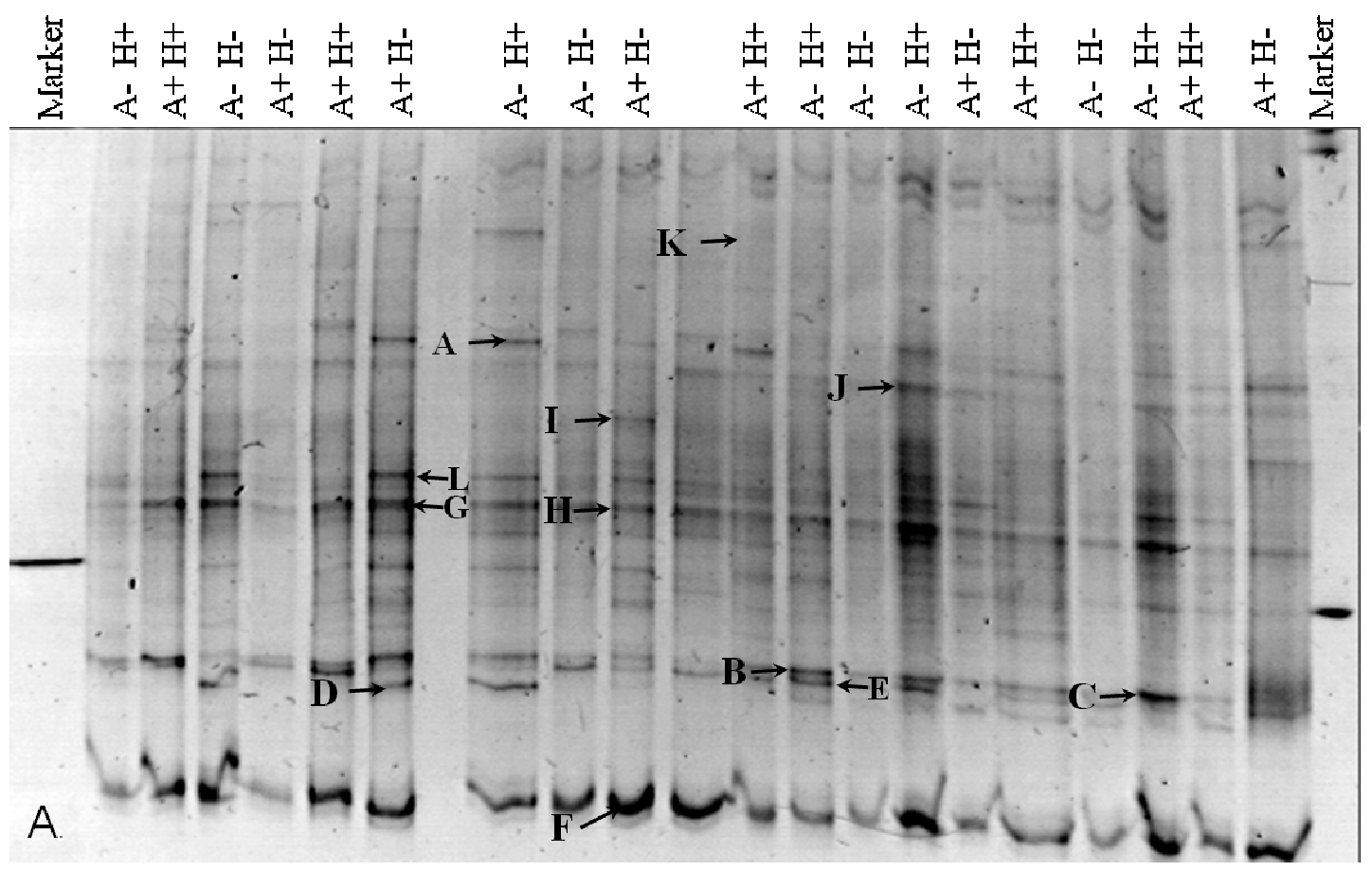

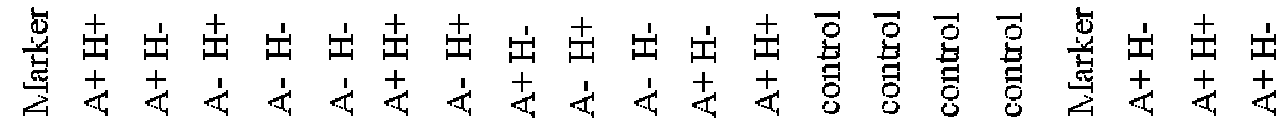

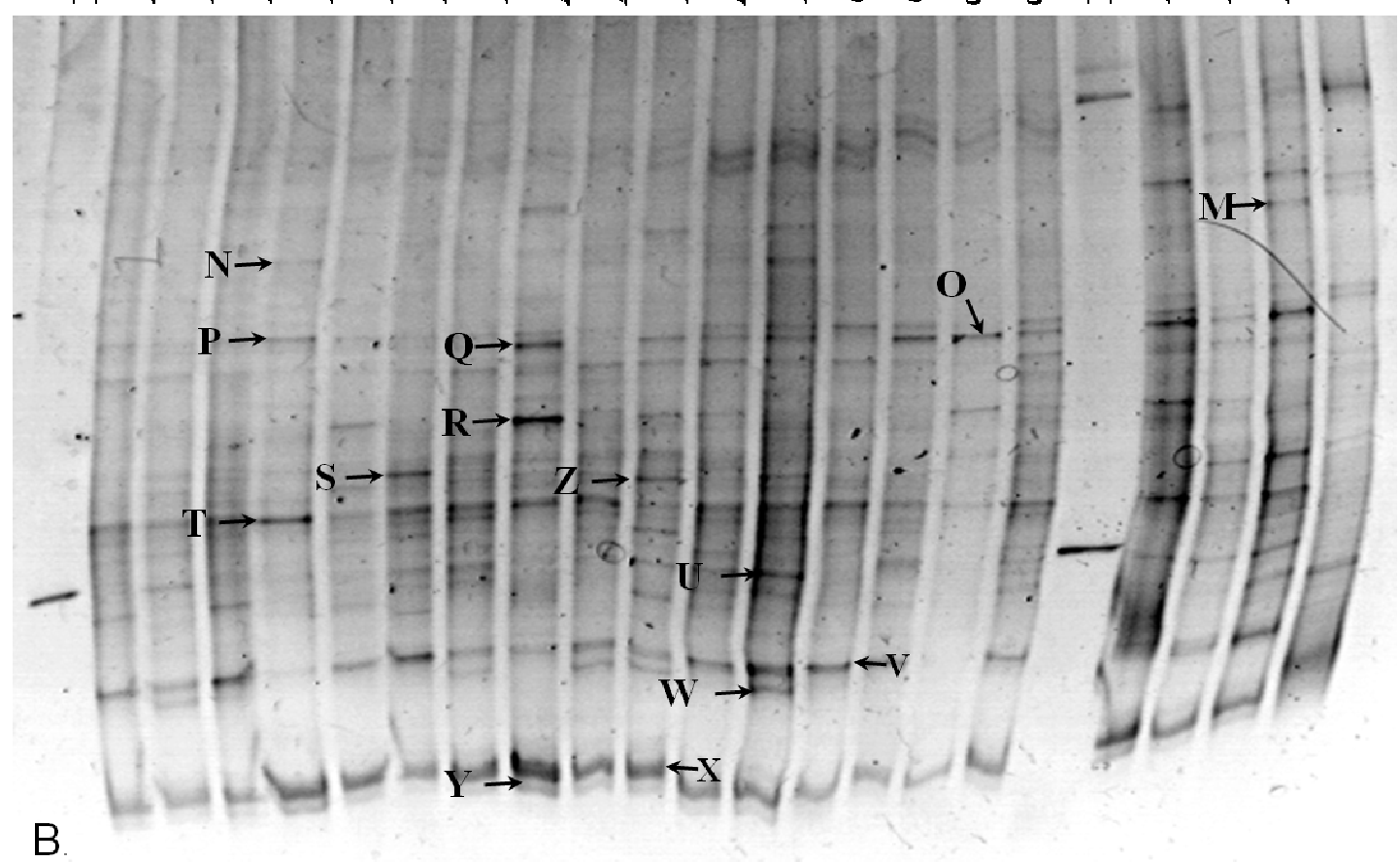

Appendix B. DGGE profiles (A. and B.) derived from the bacterial community of the ground soil of the four different treatments. For each sample $500 \mathrm{ng}$ of PCR-product were applied to a DGGE gel containing $9 \%$ acrylamide and 45 to $60 \%$ denaturant. The excised and sequenced banding patterns (Figure 4) are marked. 


\section{Chapter 4}

\section{The impact of Lasius ants on soil properties and microfungal communities of a temperate grassland}

Evelyn Schumacher, Sonja Migge-Kleian and Christian Platner

This paper will be submitted to ;Applied Soil Biology' 


\begin{abstract}
Diversity of the active fungal community, microbial biomass, basal respiration as well as soil properties (contents of $\mathrm{NO}_{3}, \mathrm{PO}_{4}$, soil moisture) were studied in four ant nest mounds and the surrounding soil from a dry grassland in Central Germany. The composition of the active fungal communities was analysed by a modified washing and plating method while microbial biomass and respiration were measured by substrate-induced respiration. A characteristic feature of the nest sites was a considerably increased amount of $\mathrm{PO}_{4}-\mathrm{P}$ and $\mathrm{NO}_{3}-\mathrm{N}$, but seasonal changes in nutrient concentrations and soil moisture strongly affected microbial activity and fungal abundance. Basal respiration, microbial biomass and abundance of fungi were correlated with soil water content. Decreasing soil water content and nutrient concentrations in spring resulted in lower basal respiration and led to increased fungal abundance, especially in ant nests. The most frequent taxa were Penicillium species with a total of $38 \%$ of the fungal individuals. We isolated 78 fungal species from ant nests and 54 from surrounding soils, with 63 species exclusively found in ant nests. Significant differences in fungal community composition between ant nest mounds and surrounding soil and a considerably higher fungal diversity in ant nests indicate that ants fundamentally alter soil conditions and the fungal community. We conclude, that ants as a widespread and dominant keystone group have the potential to considerably change soil microbial communities and act as a driving factor for mineralization processes and therefore modulate bottom-up forces for the whole food web by altering the resource supply to other species.
\end{abstract}

\title{
Keywords
}

Formicidae; Ant mounds; ecosystem engineers; fungi; microbial activity; soil nutrients 


\section{Introduction}

Soil is a structured and heterogeneous system that is generally poor in nutrients and energy resources. The chemical, physical and biological conditions in soil vary in space and time. Soil microorganisms play an important role in belowground systems, but they are controlled by energy and nutrient availability and by environmental forces (Nannipieri et al., 2003). Soil factors in turn can be influenced by soilinhabiting ants, as these eusocial soil animals act as ecosystem engineers by nest construction (Jones, 1994), modifying soil properties such as soil structure, particle size distribution, bulk density, water holding capacity, soil $\mathrm{pH}$, organic matter, nitrogen and exchangeable $\mathrm{Ca}, \mathrm{Mg}, \mathrm{K}$ and $\mathrm{PO}_{4}$ (Pêtal, 1978; Lobry de Bruyn and Conacher, 1990 and 1994; Nkem et al., 2000; Frouz et al., 2003). Further, the intake of organic substances, prey and honeydew from their mutualistic partners, and the secretion of waste products leads to the accumulation of nutrients in ant nests. Thus, ants may influence activity and functional diversity of soil microorganisms and this likely varies with ant species (Dauber and Wolters, 2000; Holec and Frouz, 2006). Indeed, fungi may be favoured in ant nests at the expense of bacteria as indicated by analysing nests of Lasius flavus (Platner, 2006). However, little is known on the structure and species richness of fungal communities in mounts of grassland ants. Changes in microbial community composition can influence higher trophic levels because microbes represent the base of the belowground food web (Pokarzhevskii et al., 2003) and many soil animal groups show distinct feeding preferences for certain microorganisms (Bonkowski et al., 2000; Maraun et al., 2003). Thus knowledge on the community composition of microbes is important for understanding belowground diversity and functioning.

We studied the active fungal communities in material from ant nest mounds in comparison to the surrounding soil. In order to find qualitative patterns we used the traditional washing and plating method isolating active mycelial fungi and analysed the results with multivariate statistics. More specifically, we studied (1) whether the effect of Lasius ants on soil chemical properties changes with season throughout the year, and (2) whether the activity of ants affected the structure of the fungal community in nest mounds. 


\section{Materials and Methods}

\section{Sampling and chemical analysis}

The study was carried out in a dry calcareous grassland located on the south-west facing slope of the Werra valley (Witzenhausen Freudenthal, Northern Hesse, Germany) at $180 \mathrm{~m}$ a.s.I. The former pasture has been abandoned for 20 years and the soil is a shallow Pararendzina (Leptosol) on Triassic limestone with a diverse herb layer dominated by Brachypodium pinnatum $\mathrm{L}$. The soil fauna is dominated by earthworms, isopods, mites, plant lice, centipedes and ants (for further details see Platner, 2006). The climate is characterized by mild winters and humid summers (average annual precipitation $700 \mathrm{~mm}$, mean annual temperature $9^{\circ} \mathrm{C}$ ).

In Germany, there are 21 ant species of the genus Lasius (Seifert, 2007), many of them building nest mounds in soil. At the study site three species were recorded with the subterranean yellow ant, Lasius flavus Fabr., being the most abundant species (Platner, 2006). This species tends plant-feeding root aphids and predominantly feeds on their droppings. At optimal habitat conditions its biomass reaches up to $150 \mathrm{~kg} \mathrm{ha}^{-1}$ (Nielsen et al., 1976), heaps large amounts of soil to the surface and constructs mounds as breeding centre for the underground colony. Lasius niger L. is a semi-predatory species, partly feeding on grass seeds and also breeding aphids within the nest (Czerwiński et al., 1971), while the third species, Lasius alienus Förster is rare.

Four similar nest sites (plots) were chosen as replicates across the grassland. In December 2005 and February, Mai and October 2006 nest samples were taken from the middle of nest mounds to a depth of $10 \mathrm{~cm}$. Respective control soil samples were taken at a distance of $1 \mathrm{~m}$ from each nest with no indication of ant activity. Each sample was sieved $(4 \mathrm{~mm})$ at the time of collection and stored at field moisture at $5^{\circ} \mathrm{C}$.

In each of the samples, we determined soil water content (gravimetrically), nitrate $\left(\mathrm{KAl}\left(\mathrm{SO}_{4}\right)_{2}\right.$ extract; analysed by steam destillation), and phosphate $\left(\mathrm{NaHCO}_{3}\right.$ extract, analysed photometrically as ammonium molybdate complex). Further, microbial biomass $\left(\mathrm{C}_{\mathrm{mic}}\right)$ was determined using the substrate-induced respiration method (Anderson and Domsch, 1978) measuring oxygen consumption in an $\mathrm{O}_{2^{-}}$ microcompensation apparatus (Scheu, 1992). The average of the lowest three readings within the first $11 \mathrm{~h}$ was taken as "maximum initial respiratory response" (MIRR, $\left.\mu \mathrm{O} \mathrm{O}_{2} \mathrm{~g}^{-1} \mathrm{~h}^{-1}\right)$ and microbial biomass $\left(\mathrm{C}_{\text {mic }} ; \mu \mathrm{g} \mathrm{C} \mathrm{g}^{-1}\right)$ was calculated as $38 \times$ 
MIRR (Beck et al., 1997). Basal respiration (BAS) was measured without substrate addition at field moisture (lowest three readings after $16 \mathrm{~h}$ ). Basal respiration of soil samples from May was additionally analysed for rewetted soil samples (with a water content of $40 \%$ of fresh weight) to compensate for the drought in May.

\section{Fungal diversity}

Microfungi were isolated with the washing/sieving-method (cf. Gams and Domsch, 1967). Approximately $4 \mathrm{~g}$ of the soil samples collected in December 2005, May and October 2006 were placed into a special washing apparatus. The sample was placed on a $250 \mu \mathrm{m}$ gaze, which was fastened above a $125 \mu \mathrm{m}$ gaze. Each sample was washed $10 \mathrm{~min}$ with a constant flow of sterile water to remove fungal spores. Mineral particles with a size between 125-250 $\mu \mathrm{m}$ could be removed from the lower gaze and 45 of these particles per nest and control soil of the three sampling dates were plated separately on $2 \%$ malt extract agar containing streptomycine-sulphate and chlorotetracycline (0.1 and $0.05 \mathrm{~g} \mathrm{l}^{-1}$, respectively) to inhibit bacterial growth. Petri-dishes were stored at room temperature.

We recorded the frequency of fungi developing from 45 plated particles and determined the sporulating fungi in nests and surrounding soils. Fungi were determined primarily with using Domsch et al. (1993). Additionally, the books of Barron (1968), Carmichael et al. (1980), von Arx (1981) and Ellis (1971 and 1976) were used.

\section{Statistical analyses}

Data for soil parameters and basal respiration were analysed by a repeated measures analysis of variances (SAS 8.1; SAS Institute Inc., Cary, NC) with 'ants' (nest vs. surrounding) and 'plot' (four nest sites) as factors for between subject effect and 'time' as the repeated factor. The relationship between basal respiration, microbial biomass, fungal abundances and water content was analysed by Spearman's rank correlation. Data were log-transformed to improve homogeneity of variance if necessary. Means of different treatments were tested for significant differences using Tukey's honestly significant difference test (Sokal and Rohlf, 2001).

Fungal diversity was estimated by calculating Simpson's Reciprocal Index (1/D) and species density was calculated with EstimateS (Version 8.0.0, Copyright R. K. 
Colwell: http://viceroy.eeb.uconn.edu/estimates) for every sample size using Mao Tau and charted by an ordination of the species-area curves.

To compare the fungal communities of nest mounds and surrounding soils we used discriminant function analyses (DFA, Statistica Version 7, StatSoft) following a non-metric multidimensional scaling (NMDS) of the distance matrix based on a nonparametric Gamma correlation of the relative frequencies of fungal taxa (isolates per 45 particles), as described by Tiunov and Scheu (2000). Independently for every season, the coordinates of each of the eight samples for four meaningful dimensions were used for DFA with 'ants' (nest or surrounding) as a grouping variable. Squared Mahalanobis distances between group centroids and the reliability of sample classification were determined.

To analyse overall differences in fungal communities NMDS was performed for the combined dataset of the three sampling dates. The coordinates of the 24 samples for four meaningful dimensions were used for DFA with 'ants' (nest or surrounding) as a grouping variable to analyse the overall squared Mahalanobis distances between group centroids for nest and surrounding soil. In addition, the combination of 'ants' and 'time' resulting in six groups was used to compare the ant effect at the three sampling dates simultaneously in one analysis. For the interpretation of the discriminant axis derived from the DFA with the factor 'ants', a linear correlation was calculated between the discriminant function score for each sample (values for root of first axis) and the relative dominance of each fungal taxon isolated from the respective sample.

\section{Results}

Soil and microbial parameters

Generally the variation between nest sites was high masking differences between soil and nest samples of many soil and microbial parameters throughout the year. Measurements from surrounding soil on the other hand did not differ as strongly between plots (Figure 1, Appendix A). For example, mean differences between minima and maxima were $21.2 \mu \mathrm{g} \mathrm{NO}_{3}-\mathrm{N} \mathrm{g}^{-1}$ soil dry wt for nests compared to $7.2 \mu \mathrm{g}$ $\mathrm{NO}_{3}-\mathrm{N} \mathrm{g}^{-1}$ soil dry wt for soil. Similar differences were detected for $\mathrm{PO}_{4}-\mathrm{P}$ with 45.3 and $12.2 \mathrm{\mu g} \mathrm{g}^{-1}$ soil dry wt in nests and soil, respectively.

Mean concentrations of $\mathrm{NO}_{3}-\mathrm{N}$ were significantly higher in ant nests than in the surrounding soil (Table 1, Figure 1a, Appendix A, B). Further, concentrations of $\mathrm{PO}_{4}$ $P$ were twice to five times higher in ant nests than in control soil at all four sampling 

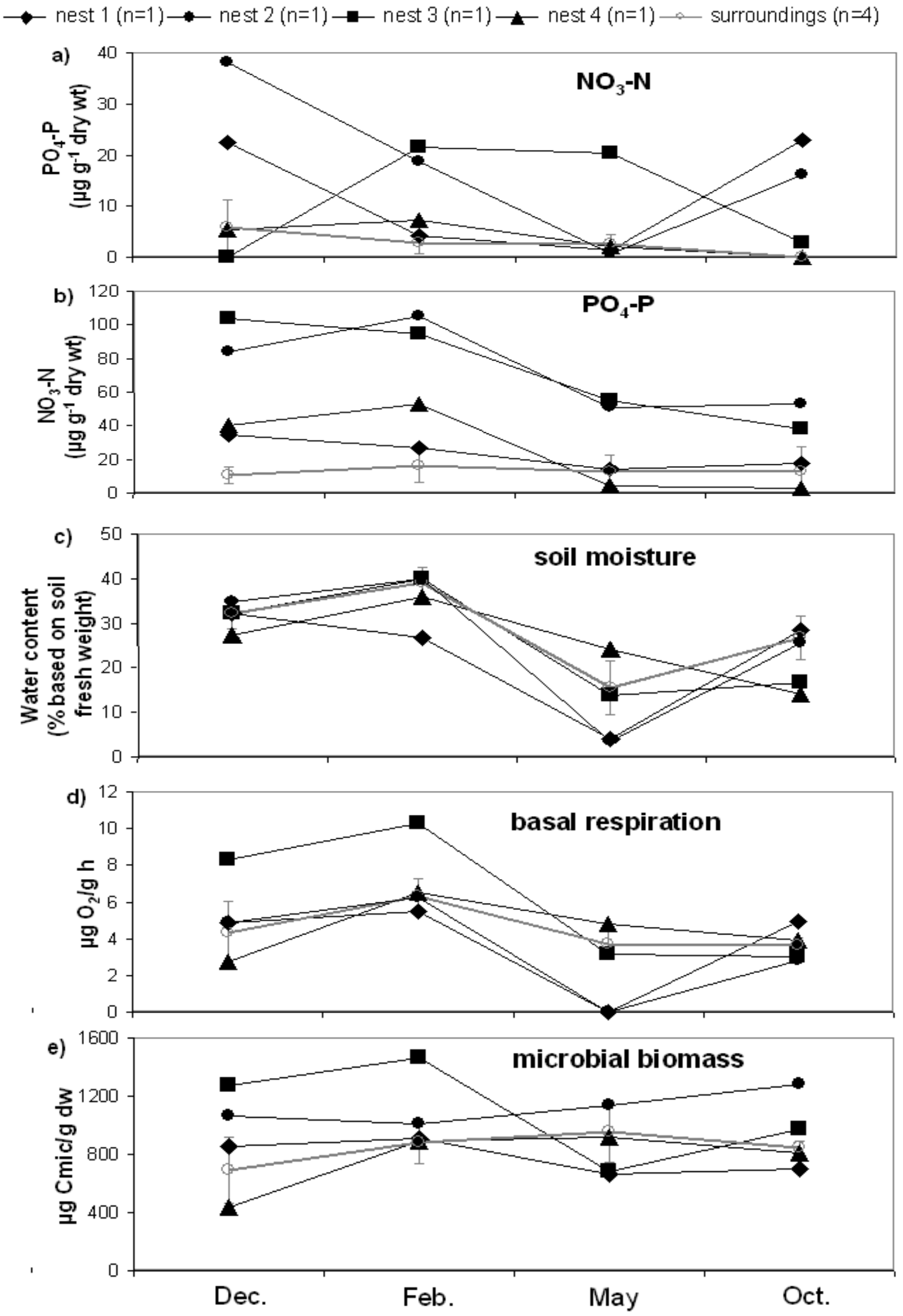

Figure 1. Amounts of a) $\mathrm{NO}_{3}-\mathrm{N}$, b) $\mathrm{PO}_{4}-\mathrm{P}$, c) water content, d) basal respiration and e) microbial biomass in four different ant nests (black lines) and respective surrounding soils (shown as a mean in grey line) in December 2005, February, May and October 2006. dw=dry weight. 
Table 1. The effects of the factors 'ants', 'plot', and 'time' on the different soil and microbial parameters were tested with repeated measures ANOVA. Data for $\mathrm{NO}_{3}-\mathrm{N}$ and basal respiration were log-transformed. $\mathrm{df}=$ degrees of freedom, wt=weight.

\begin{tabular}{|c|c|c|c|c|c|c|c|c|c|c|c|}
\hline & \multirow[b]{2}{*}{$\mathrm{df}$} & \multicolumn{2}{|c|}{$\begin{array}{c}\mathrm{NO}_{3}-\mathrm{N} \\
\left(\mu g^{-1} \text { dry wt) }\right.\end{array}$} & \multicolumn{2}{|c|}{$\begin{array}{c}\mathrm{PO}_{4}-\mathrm{P} \\
\left(\mu \mathrm{g} \mathrm{g}^{-1} \text { dry wt) }\right.\end{array}$} & \multicolumn{2}{|c|}{$\begin{array}{c}\text { water content } \\
(\%)\end{array}$} & \multicolumn{2}{|c|}{$\begin{array}{l}\text { basal respiration } \\
\left(\mu \mathrm{g} \mathrm{O}_{2} \mathrm{~g}^{-1} \text { dry wt } \mathrm{h}^{-1}\right)\end{array}$} & \multicolumn{2}{|c|}{$\begin{array}{c}\text { microbial } \\
\text { biomass } \\
\text { ( } \mu \mathrm{g} \mathrm{C}_{\text {mic }} \mathrm{g}^{-1} \text { dry wt) }\end{array}$} \\
\hline & & $F$ & $p$ & $\mathrm{~F}$ & $p$ & $F$ & $p$ & $F$ & $p$ & $F$ & $p$ \\
\hline \multicolumn{12}{|l|}{ December } \\
\hline ants & 1 & 0.46 & 0.55 & 1533.86 & 0.0007 & 0.16 & 0.71 & 1.23 & 0.35 & 2.58 & 0.21 \\
\hline $\begin{array}{l}\text { plot } \\
\text { February }\end{array}$ & 3 & 1.34 & 0.41 & 45.86 & 0.0214 & 3.23 & 0.18 & 3.53 & 0.16 & 2.13 & 0.27 \\
\hline ants & 1 & 14.21 & 0.0327 & 7.55 & 0.11 & 3.95 & 0.14 & 0.26 & 0.65 & 1.30 & 0.34 \\
\hline $\begin{array}{l}\text { plot } \\
\text { May }\end{array}$ & 3 & 3.47 & 0.17 & 2.07 & 0.34 & 7.31 & 0.0683 & 2.78 & 0.21 & 2.12 & 0.28 \\
\hline ants & 1 & 0.57 & 0.51 & 2.30 & 0.27 & 0.35 & 0.60 & 9.87 & 0.0516 & 1.40 & 0.32 \\
\hline $\begin{array}{l}\text { plot } \\
\text { October }\end{array}$ & 3 & 0.25 & 0.86 & 3.05 & 0.26 & 0.12 & 0.94 & 1.95 & 0.30 & 1.46 & 0.38 \\
\hline ants & 1 & 6.38 & 0.0858 & 3.50 & 0.20 & 1.39 & 0.32 & 0.54 & 0.52 & 0.14 & 0.74 \\
\hline plot & 3 & 1.00 & 0.50 & 4.40 & 0.19 & 0.56 & 0.68 & 1.91 & 0.30 & 1.29 & 0.42 \\
\hline ants & 1 & 24.08 & 0.0162 & 12.83 & 0.0699 & 3.91 & 0.14 & 1.53 & 0.30 & 0.74 & 0.45 \\
\hline plot & 3 & 2.17 & 0.27 & 3.56 & 0.23 & 0.88 & 0.54 & 1.37 & 0.40 & 3.66 & 0.16 \\
\hline time & 3 & 1.33 & 0.32 & 6.26 & 0.0280 & 13.38 & 0.0011 & 31.59 & $<0.0001$ & 0.79 & 0.53 \\
\hline time*ants & 3 & 0.48 & 0.70 & 4.28 & 0.0616 & 0.18 & 0.91 & 8.73 & 0.0050 & 1.75 & 0.23 \\
\hline time* plot & 9 & 0.88 & 0.57 & 1.63 & 0.28 & 0.34 & 0.94 & 3.49 & 0.0385 & 0.85 & 0.60 \\
\hline
\end{tabular}

dates but the concentrations differed significantly with sampling date (Table 1). Differences in phosphate content between nest and control soils were most pronounced in December (42.6 $\mathrm{ug} \mathrm{P} \mathrm{g}^{-1}$ soil dry wt) and February (53.2 $\mu \mathrm{g} \mathrm{P} \mathrm{g}{ }^{-1}$ soil dry wt) and decreased in May (18.6 $\mu \mathrm{g} \mathrm{P} \mathrm{g}^{-1}$ soil dry wt) and October (14.9 $\mathrm{\mu g} \mathrm{P} \mathrm{g}^{-1}$ soil dry wt; Figure 1b, Appendix A). 
Water content also differed significantly between sampling dates (Table 1) with February being the wettest and May the driest month (Figure 1c). Mean soil water content was slightly lower in ant nests $\left(19.3 \% \mathrm{H}_{2} \mathrm{O}\right.$ of soil fresh weight) than in the surrounding soil $(21.7 \%)$. Two of the nests (plot 1 and 2) had very low water contents. These nests dried out to $3.6 \%$ (Figure 1c) compared to $15.9 \% \mathrm{H}_{2} \mathrm{O}$ of soil fresh weight in the respective control samples.

Similar to soil moisture, basal respiration strongly depended on sampling date being highest in February and lowest in May and October (significant time effect, Table 1). Generally, differences between nests and surrounding soil were only marginally significant in May with a mean respiration of 1.3 and $3.7 \mu \mathrm{O} \mathrm{O}_{2} \mathrm{~g}^{-1}$ soil dry wt $\mathrm{h}^{-1}$, respectively (Table 1, Figure 1d, Appendix A), except for the two driest nests where in this month basal respiration was much lower than in respective surrounding soil (time $\times$ plot interaction; Table 1). Additionally, we measured basal respiration in May samples with soil moisture increased to $40 \%$ which strongly increased basal respiration from 0 to $14.7 \mu \mathrm{g} \mathrm{O}_{2} \mathrm{~g}^{-1}$ soil dry wt $\mathrm{h}^{-1}$ in the two driest nests, whereas only minimal changes occurred in the respective surrounding soil (from 3.3 to $4.3 \mu \mathrm{g} \mathrm{O}_{2} \mathrm{~g}^{-}$ ${ }^{1}$ soil dry $w \mathrm{~h}^{-1}$ ). Also, in the other nests basal respiration increased only little due to the addition of water (plot 3, ant nest from 3.2 to $5.4 \mu \mathrm{g} \mathrm{O}_{2} \mathrm{~g}^{-1}$ soil dry wt $\mathrm{h}^{-1}$, surrounding soil from 3.5 to $6.0 \mu \mathrm{g} \mathrm{O}_{2} \mathrm{~g}^{-1}$ soil dry wt $\mathrm{h}^{-1}$; plot 4 , ant nest from 2.1 to $3.3 \mu \mathrm{g} \mathrm{O}_{2} \mathrm{~g}^{-1}$ soil dry wt $\mathrm{h}^{-1}$, surrounding soil from 4.8 to $5.0 \mu \mathrm{g} \mathrm{O}_{2} \mathrm{~g}^{-1}$ soil dry wt $\mathrm{h}^{-1}$ ).

Microbial biomass did not differ as strongly as basal respiration between nests and surrounding soil or between sampling months. Thus we could not detect any significant differences (Table 1, Figure 1e). However, basal respiration and microbial biomass were positively correlated with soil water content (Table 2).

Table 2. The relationship between basal respiration, microbial biomass and water content, analysed by Spearman's rank correlation.

\begin{tabular}{lcccc}
\hline & $\begin{array}{l}\text { basal respiration } \\
\left(\mu \mathrm{g} \mathrm{O}_{2} \mathrm{~g}^{-1} \text { dry } \mathrm{wt}^{-1}\right)\end{array}$ & \multicolumn{2}{c}{$\begin{array}{c}\text { microbial biomass } \\
\left(\mu \mathrm{g} \mathrm{Cmic} \mathrm{g}^{-1} \text { dry wt }\right)\end{array}$} \\
\hline \multirow{3}{*}{ December } & $\mathrm{R}$ & $\mathrm{p}$ & $\mathrm{R}$ & $\mathrm{p}$ \\
February & $\mathbf{0 . 7 1}$ & $\mathbf{0 . 0 4 6 5}$ & $\mathbf{0 . 6 9}$ & $\mathbf{0 . 0 5 8 0}$ \\
May & $\mathbf{0 . 8 8}$ & $\mathbf{0 . 0 0 3 9}$ & $\mathbf{0 . 6 4}$ & $\mathbf{0 . 0 8 5 6}$ \\
October & 0.32 & 0.4346 & -0.29 & 0.4927 \\
& 0.38 & 0.3518 & 0.29 & 0.4927 \\
\hline
\end{tabular}


Fungal abundance and diversity

Altogether 292 fungi were isolated, 149 originating from nests and 143 from the surrounding soil. Eighty-five isolates were sterile while the remaining 207 isolates included 117 species with 60 of the isolated species occurring only once and only a few species occurring in higher abundances. While 15 species were found in both samples, 63 species were recorded exclusively in nest samples and 39 species exclusively in control samples. The list of taxa from each sampling date and their abundance are given in Table 3. Rare species with total abundance $<2$ were counted under their genus or, when a genus was found only once, as "single occurrence".

Table 3. Abundances of dominant fungi in ant nest mounds and surrounding soils and linear correlation ( $r$-values) between the frequency of fungal taxa and the discriminant function score for the first root of discriminant function analysis with ant treatment as grouping variable ('Ant root'; see text for details). Superscript a, b, c, d, e indicate different species within the number of individuals, ${ }^{(*)} p<0.1,{ }^{*} p<0.05$.

\begin{tabular}{l|ccc|c|c|} 
& \multicolumn{3}{|c|}{ nest } & surrounding & ant root \\
\hline Nest mound taxa & Dec. & May & Oct. & Dec. May Oct. & \\
\hline Chrysosporium spp & $1^{\mathrm{a}}$ & $2^{\mathrm{b}}$ & $2^{\mathrm{c}}$ & & \\
Penicillium spec 1 & & 4 & & & $0.39^{(*)}$ \\
Penicillium spec 4 & & 4 & & & \\
Penicillium spec 6 & 3 & & & & \\
Trichosporiella spp & & $2^{\text {ab }}$ & $1^{\mathrm{c}}$ & & \\
Acremonium spec 9 & & & 2 & & $0.39^{(*)}$ \\
Penicillium spec 11 & & & 2 & & \\
Spec 5 & & & 2 & & $0.49^{*}$ \\
Spec 6 & & 1 & 1 & & $0.39^{(*)}$ \\
Spec 18 & 1 & & 1 & & $0.36^{(*)}$ \\
\hline
\end{tabular}

unspecific taxa

Penicillium spec 12

Paecilomyces spec 1

Chaetosphaeria spp

Penicillium spec 5

Cladosporium spp

Trichoderma spp

Verticillium spp

Acremonium spec 3

Penicillium spec 8

Aspergillus spp

Humicola spp

Oideodendron spp

Penicillium spec 10

Mortierella spec 1

Wardomyces spp

Acremonium butyri

Acremonium spec 2

Penicillium spec 3

\begin{tabular}{|c|c|c|c|c|c|c|}
\hline & 5 & 2 & \multicolumn{3}{|c|}{3} & 0.42 * \\
\hline 2 & 2 & & 2 & & & \\
\hline & $4^{\mathrm{abcc}}$ & & & $1^{c}$ & $1^{\mathrm{e}}$ & $-0.07^{(\operatorname{spec} 2)}$ \\
\hline & 2 & 1 & & 2 & & \\
\hline $1^{a}$ & $1^{b}$ & $1^{\mathrm{c}}$ & $1^{d}$ & $1^{b}$ & & $-0.11^{(\operatorname{spec} 4)}$ \\
\hline $1^{a}$ & $1^{\mathrm{b}}$ & $1^{c}$ & & $1^{d}$ & $1^{c}$ & $0.15^{(\operatorname{spec} 3)}$ \\
\hline $1^{a}$ & & $2^{b c}$ & $1^{d}$ & & $1^{\mathrm{b}}$ & $0.03^{(\operatorname{spec} 3)}$ \\
\hline & & 2 & & & 1 & 0.18 \\
\hline & & 2 & & & 1 & 0.06 \\
\hline $2^{a b}$ & & & $1^{c}$ & & & \\
\hline & $2^{a b}$ & & & $1^{a}$ & & $-0.07^{(\operatorname{spec} 1)}$ \\
\hline $1^{\mathrm{a}}$ & & & & & $1^{b}$ & \\
\hline & & 1 & & & $\begin{array}{l}1 \\
1\end{array}$ & \\
\hline & 1 & $1^{\mathrm{a}}$ & & $1^{b}$ & 1 & \\
\hline & & 1 & & & 4 & \\
\hline & 1 & & & 4 & & -0.24 \\
\hline & 4 & & & 13 & & 0.04 \\
\hline
\end{tabular}




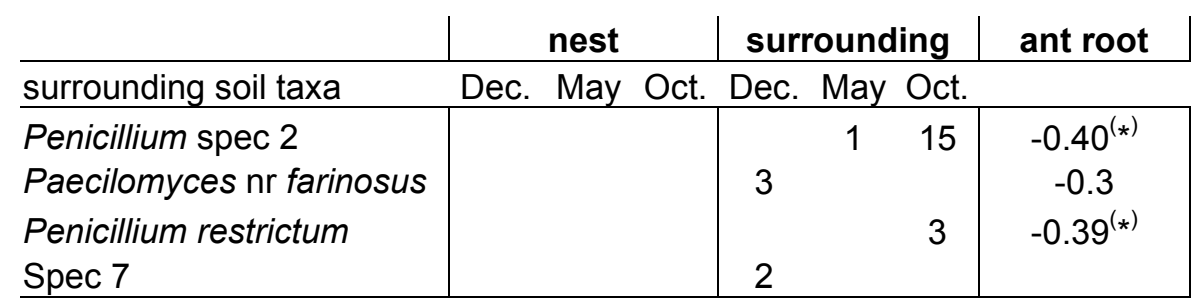

\section{Others}

Yeasts

sterile hyaline

sterile dematicous

single occurrence

number of idientfied taxa

number of fertile individuals

\begin{tabular}{|c|c|c|c|c|c|c|}
\hline & & & 1 & 3 & 1 & $-0.39^{(*)}$ \\
\hline 6 & 14 & 9 & 10 & 7 & 9 & \\
\hline 2 & 9 & 1 & 2 & 3 & 13 & \\
\hline 10 & 15 & 9 & 8 & 9 & 9 & \\
\hline 20 & 35 & 27 & 15 & 20 & 20 & \\
\hline 23 & 51 & 34 & 19 & 40 & 40 & \\
\hline
\end{tabular}

We found significant differences in fungal community composition between ant nest mounds and surrounding soils (DFA with 2 groups of 'ants', Wilks' lambda 0.5764, $p=0.0268$; Figure 3). The higher fungal diversity in ant nests with a Simpson's Reciprocal Index (1/D) of 103.2 in nests and 21.2 in the control soil supports this finding. Fungal diversity was increased at each of the sampling dates (December, nests 63.3, surrounding soil 30.6; May, nests 41.1, surrounding soil 8.6; October, nests 80.1, surrounding soil 7.0). Moreover, the species area curves show a higher slope for nests than for control soil, but both curves do not reach saturation (Figure 2).

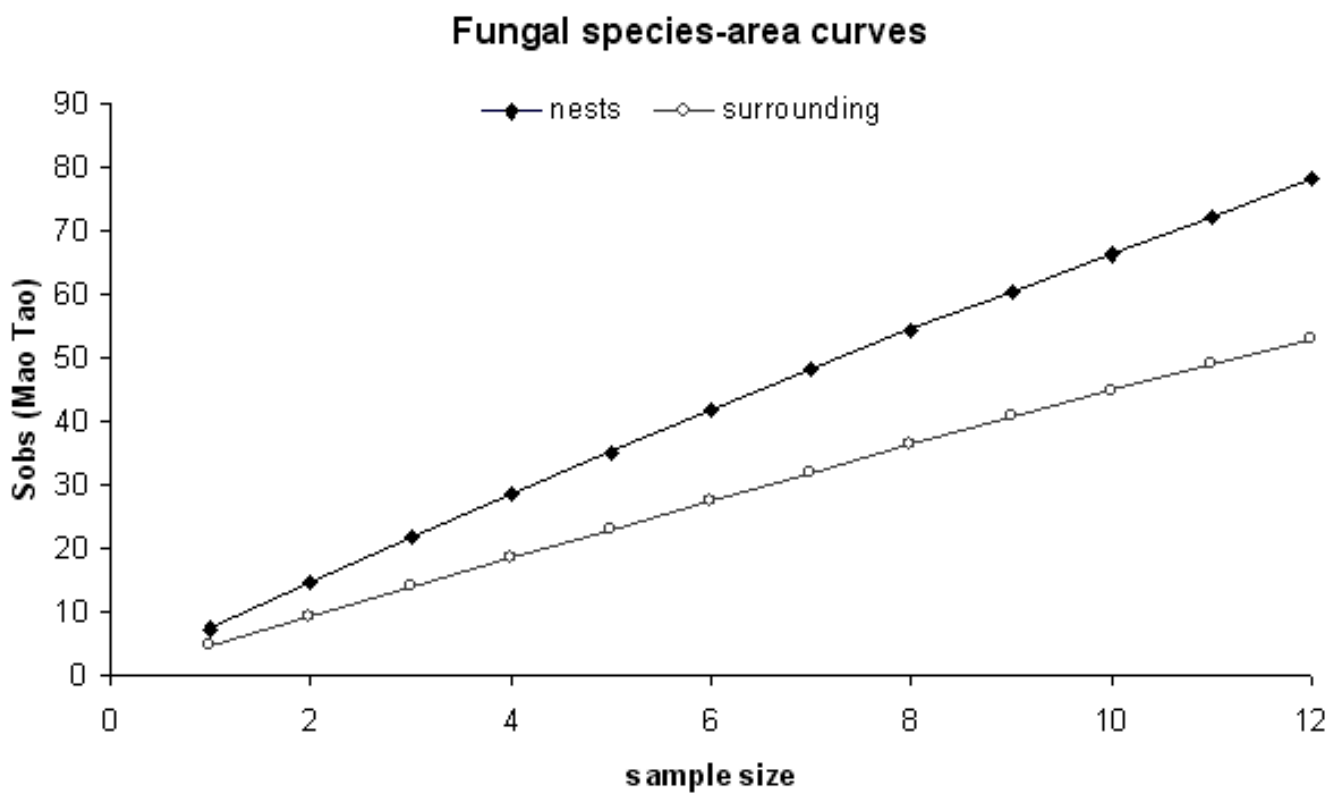

Figure 2. Species-area curves of fungal species occurring in nest and surrounding soils during the sampling season. 
The fungal communities were significantly influenced by the factor 'time' (DFA with 3 groups of 'time', Wilks' lambda 0.1782, $\mathrm{p}<0.0001$; squared Mahalanobis distance between December and May 5.50, $\mathrm{p}=0.0088$, and between May and October 10.87, $p=0.0003$ ), and the abundance of fungi was negatively correlated with the soil water content $(R=-0.46, p=0.0255)$. The location of sampling sites had no effect (DFA with 4 groups of 'plot', Wilks' lambda 0.5275, p=0.4379). In an independent analysis for nests and surrounding soil, the communities in nest substrates changed significantly in the course of the year, but no or only marginally significant differences were found in the surrounding soil (DFA with 6 groups of 'ants' and 'time' combination, Wilks' Lambda 0.0700, p=0.0005, Table 4). However, nest and surrounding soil communities were well separated in each season (Figure 3 ).

\section{Fungal community composition}

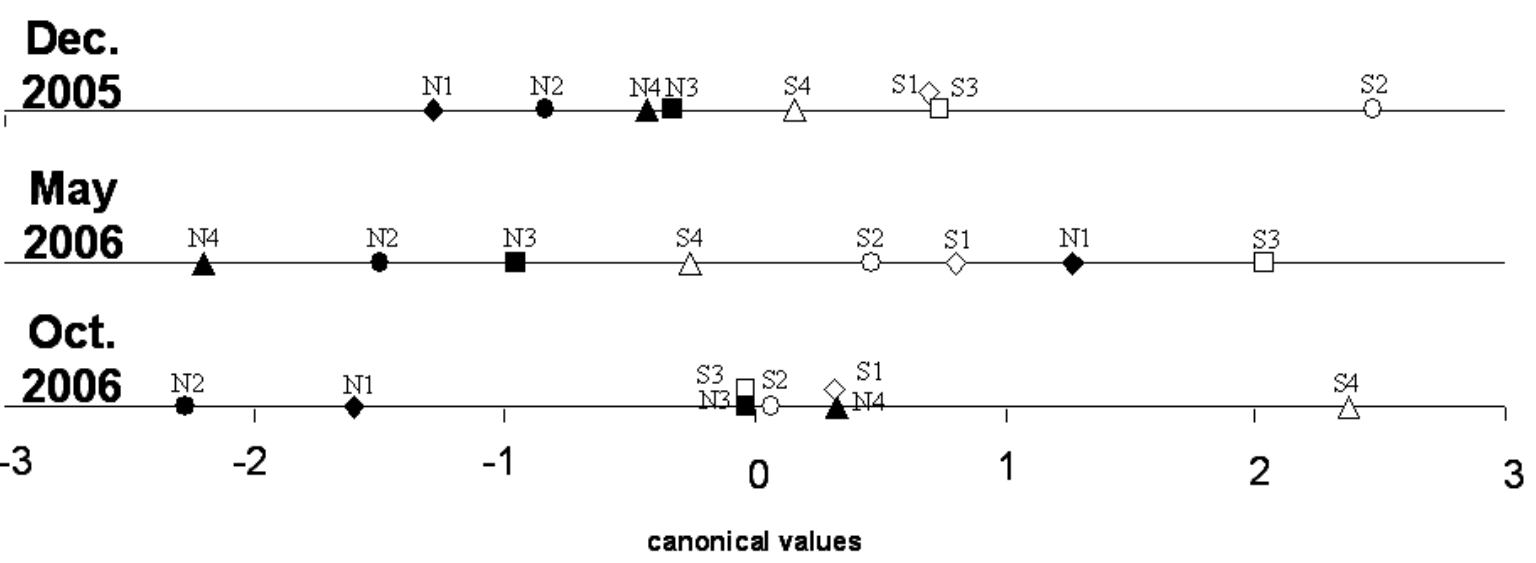

Figure 3. Fungal community composition in ant nests and surrounding meadow soils. Discriminant function analyses for each season using the ant treatments (nest vs. surrounding) as grouping variable and showing canonical values. $\mathrm{N}=\mathrm{nest}, \mathrm{S}=$ surrounding, numbers=plot. 
Table 4. Squared mahalanobis distance between group centroids and reliability of discrimination based on data on fungal dominance structure.

\begin{tabular}{lccccc}
\hline & \multicolumn{2}{c}{ Dec-May } & & \multicolumn{2}{c}{ May-Oct } \\
\cline { 2 - 3 } & $\begin{array}{l}\text { Mahalanob } \\
\text { isdistance }\end{array}$ & p-value & & $\begin{array}{c}\text { Mahalanobis } \\
\text { distance }\end{array}$ & p-value \\
\hline nest & $\mathbf{9 . 7 2}$ & $\mathbf{0 . 0 2 0 2}$ & & $\mathbf{1 9 . 3 9}$ & $\mathbf{0 . 0 0 1 1}$ \\
surrounding & 3.51 & 0.2631 & & 6.31 & 0.0762 \\
\hline
\end{tabular}

Besides the different occurrences of rare species, two dominant fungal taxa were also responsible for community changes throughout the year and for differences between nests and surrounding soil. The most frequent taxon was Penicillium with 77 isolates (38\% of sporulating fungal individuals). The occurrences of the Penicillium species differed between ant nests; it was highest in the material from plot 4 . In this nest and the respective control soil, no Penicillium was isolated in December, but their presence increased in the warmer months, especially in the control soil.

Acremonium with 29 isolates (14\% of fertile fungal indiviuals) was also occurred frequently. The distribution of Acremonium species between nest and control soil was similar in May and October (May, ant nest $5.5 \%$, control soil $6.6 \%$ of sporulating fungal individuals; October, ant nest 9.5\%, control soil $8.1 \%$ ). In contrast, in December the frequency of Acremonium species in ant nests was lower than in surrounding soil (ant nest $2.4 \%$, control soil $9.5 \%$ ).

\section{Discussion}

Soil parameters

Ants can directly and indirectly influence mineralisation processes, because they do not only create patches with high soil fertility, but they also change the conditions within the nest by altering temperature and humidity (Blomqvist et al., 2000; Dauber et al., 2008). Organic substances and products of their decomposition, such as ammonia, nitrate and phosphate, often are enriched in ant nests in comparison to the surrounding soil (Czerwinski et al., 1971; Wagner et al., 1997; Nkem et al., 2000; Platner et al., 2001). Wagner et al. (1997), for example, found a significantly higher $\mathrm{N}$-mineralisation rate in nests of Formica perpilosa in comparison to the surrounding soil. Stadler et al. (2006) reported that inorganic nitrogen concentration in litter increased significantly when ants were present. This is in correspondence with our findings of higher $\mathrm{NO}_{3}-\mathrm{N}$ and $\mathrm{PO}_{4}-\mathrm{P}$ concentrations in ant nests, which can be explained by the accumulation and subsequent decay of food resources in the nests 
(Frouz et al., 1997). However, the increase in nutrients varied with season and also microbial biomass was not uniformly increased in ant nests compared to surrounding soil because changes in soil water content had a strong impact on the microbial community. The utilisation of organic matter by soil microorganisms is known to strongly depend on soil water content, as microbial activity in bound to the availability of water (Frouz, 2000); this is also reflected by the positive correlation between basal respiration and soil moisture in December and February.

In our study, soil moisture was often lower in ant nests than surrounding soil, but due to strong differences between the nests, these findings were not significant. Investigating ant species and abundance in the different nests ( $E$. Schumacher, unpubl. data) revealed that plot 1 and 2 were inhabited each by a large colony of Lasius flavus while plot 3 was inhabited by $L$. niger and in plot 4 the $L$. flavus colony was old and showed little activity. Active $L$. flavus colonies seem to influence nutrient contents and microbial communities in their nests differently than other Lasius species. In May, with soil moisture decreasing to $4 \%$, concentrations of $\mathrm{NO}_{3}-\mathrm{N}$ and $\mathrm{PO}_{4}-\mathrm{P}$, and basal respiration also declined in the active $L$. flavus nests. The decreased basal respiration due to low humidity may reduce mineralisation, which led to a lower production of $\mathrm{NO}_{3}-\mathrm{N}$ and $\mathrm{PO}_{4}-\mathrm{P}$.

Basal respiration in active $L$. flavus nests increased again with water availability in October which indicates, that in May the limiting factor for microbial activity in these nest mounds was the water content and not the nutritional status of the soils. This conclusion was supported by a strongly increased basal respiration when substrates of active $L$. flavus nests were adjusted to a soil moisture of $40 \%$. Also Jones and Murphy (2007) found rapid stimulation of microbial activity in response to water addition, and Holec and Frouz (2006) hypothesized that soil moisture is an important factor limiting soil processes inside ant nests. This corresponds to results of our study and the study of Grayston et al. (2001) where basal respiration and microbial biomass were correlated with soil moisture content. In the surrounding soil, limitation by soil water content may be lower, because basal respiration in these soils was not affected by rewetting. Presumably, basal respiration was limited by nutrients, because on average we found lower nutrient concentrations in surrounding soil and no increase if water was added.

The increase in basal respiration after rewetting was much higher in active $L$. flavus nests compared to $L$. niger nests where rewetting had only little effect. In the 
latter, field moisture in May was as low as $12 \%$, which still allowed microbial respiration and active mineralisation, while respiration in active $L$. flavus nests was negligible. This indicates that there is a critical soil moisture content in soil below which microbial respiration is reduced dramatically and mineralisation processes come to halt. However, only one of the nests was inhabited by L. niger and more investigations are needed to support this indication.

In conclusion, under high soil moisture conditions ants create an environment more favourable for mineralisation than the surrounding soil, because readily decomposable residues in ant nests are available and can be used if water is present. Variations in nutrient concentrations during the year were stronger in ant nests than in the surrounding soil, but the influence of ants on soil parameters depended on species and colony age. Pêtal and Kusinska (1994) already observed, that microbial community composition and the accompanying decomposition processes depend on the biology of the ant species. Additionally, seasonal effects have to be considered when evaluating differences in soil parameters of ant nests; in dry seasons the pattern for environmental factors in nests and control soils can be reversed.

\section{Fungal abundance and diversity}

Many fungal species were found only once. Hence the species composition of fungal communities changed markedly between the different months, especially in ant nests. For example, out of 35 species isolated in December only 5 species had an abundance $>1$ and only one species was isolated a second time in another month.

Most species and sporulating individuals were isolated in May when water content was low and the lowest number of species was recorded in December when water content was high. In moist soils, microhabitats have contact by the formation of water bridges between soil particles and aggregates. Bacteria are dependent on these water films to reach new resources. Drainage maintains spatial isolation among the various habitats (Nannipieri et al., 2003). Fungi act on a larger habitat scale and are able to relocate nutrients and water within their growing hyphae. Fungi better sustain conditions of low soil water content than bacteria. The relative frequency of fungal isolates is known to increase with increasing dehydration of soils, whereas at high soil moisture conditions bacteria prevail (Scheffer and Schachtschabel, 2002; Gordon et al., 2008). A similar negative correlation between 
soil water content and fungal abundance was observed in our study. The high soil moisture in December resulted in high microbial biomass (especially in L. niger nest), but fungal abundance in nests was lowest in this month, indicating that variations in total microbial biomass do not reflect variations in fungal abundance (Grayston et al., 2001). As a consequence, the high microbial biomass in December was predominantly caused by high bacterial numbers or by fungi we were unable to culture. It is well documented that bacteria have a higher metabolic activity than fungi (Anderson and Domsch, 1975) which can explain the higher $\mathrm{NO}_{3}-\mathrm{N}$ and $\mathrm{PO}_{4}-\mathrm{P}$ amounts in this month.

The composition of fungal communities was also significantly affected by the factor "time". The fact that few fungi that were isolated repeatedly suggest high seasonal turnover of fungal communities. However, when nest mounds and surrounding soils were tested separately for the factor 'time', only in ant nests fungal communities changed significantly between December and May and between May and October. In ant nest habitat conditions including nutrient concentrations, temperature and humidity are varying widely in time and space (Frouz, 2003; Platner, 2006; S. Schuch, pers. communication). In our study, nutrient concentrations in nest soil also varied stronger as in surrounding soil. Thus, ants form heterogeneous habitats for microorganisms, possibly resulting in higher fungal diversity and changes in fungal associations. Bailey (1920) found numerous fungal spores or fragments of hyphae in infrabuccal pellets of most studied ant species. And Mcllveen and Cole (1976) described high concentrations of spores of Endogonaceae in casts of ants. Moreover, ants are mixing soil for nest construction and consequently mix soil particles inhabited by different microorganisms thereby potentially increasing microbial diversity. Especially fungal species which produce large numbers of dry (e.g. Penicillium) or sticky (e.g. Acremonium) spores may be spread widely. Both, Penicillium and Acremonium, were the most abundant taxa in ant nests of our investigation. 


\section{Conclusion}

Ants as ecosystem engineers have a strong impact on nutrient concentrations and fungal diversity in soil, but the effects vary with season and depend on soil water content. However, ant nests appear not to be colonized by specific fungal species, rather, opportunistic fungi living on honeydew or dead ant bodies, or species brought into the nest accidentally are thriving. Intensive grooming combined with potent antibiotic secretions from the metapleural gland and other exocrine organs are used by ants as defence against fungi (Hölldobler and Wilson, 1990). These universal and phylogenetically old characters of ants are assumed to be important adaptations to living in large numbers in warm subterranean galleries, an ideal habitat for fungi. 


\section{Acknowledgement}

We thank Matthias Schaefer, Klaus Hoevemeyer and Stefan Scheu for valuable discussions and comments on the manuscript.

\section{References}

Anderson, J.P.E., Domsch, K.H., 1975. Measurement of bacterial and fungal contributions to respiration of selected agricultural soils. Can. J. Microbiol. 21, 314-322.

Anderson, J.P.E., Domsch, K.H., 1978. A physiological method for the quantitative measurement of microbial biomass in soils. Soil Biol. Biochem. 10, 215-221.

Arx von, J.A., 1981. The Genera of Fungi Sporulating in Pure Culture. Third edition. Gantner Verlag, Vaduz.

Bailey, I.W., 1920. Some Relations between Ants and Fungi. Ecology 1, 174-189.

Barron, G.L., 1968. The genera of hyphomycetes from soil. Krieger Publishing Company, Florida.

Beck, T., Joergensen, R.G., Kandeler, E., Makeschin, F., Nuss, E., Oberholzer, H.R., Scheu, S., 1997. An inter-laboratory comparison of ten different ways of measuring soil microbial biomass C. Soil Biol. Biochem. 29, 1023-1032.

Blomqvist, M.M., Olff, H., Blaauw, M.B., Bongers, T., van der Putten, W.H., 2000. Interactions between above- and belowground biota: importance for small-scale vegetation mosaics in a grassland ecosystem. Oikos 90, 582-598.

Bonkowski, M., Griffiths, B.S., Ritz, K., 2000. Food preferences of earthworms for soil fungi. Pedobiologia 44, 666-676.

Carmichael, J.W., Kendrick, W.B., Connors, I.L., Sigler, L., 1980. Genera of hyphomycetes. The University of Alberta Press, Edmonton.

Czerwiński, Z., Jakubczyk, H., Pêtal, J., 1971. Influence of Ant hills on the Meadow Soils. Pedobiologia 11, 277-285.

Dauber, J., Wolters, V., 2000. Microbial activity and functional diversity in the mounds of three different ant species. Soil Biol. Biochem. 32, 93-99.

Dauber, J., Niechoj, R., Baltruschat, H., Wolters, V., 2008. Soil engineering ants increase grass root arbuscular mycorrhizal colonization. Biol. Fertil. Soils 44, 791-796.

Domsch, K.H., Gams, W., Anderson, T.H., 1993. Compendium of soil fungi. Vol. I and II, IWH Verlag, Eching. 
Ellis, M.B., 1971. Dematiaceous hyphomycetes. CAB International, Wallingfort.

Ellis, M.B., 1976. More dematiaceous hyphomycetes. CAB International, Wallingford. Frouz, J., Santruckova, H., Kalcik, J., 1997. The effect of wood ants (Formica polyctena Foerst.) on the transformation of phosphorus in a spruce plantation. Pedobiologia 41, 437-447.

Frouz, J., 2000. The effect of nest moisture and daily temperature regime in the nests of Formica polyctena wood ants. Insectes Soc. 47, 229-235.

Frouz, J., Holec, M., Kalčík, J., 2003. The effect of Lasius niger (Hymenoptera, Formicidae) ant nest on selected soil chemical properties. Pedobiologia 47, 205-212.

Gams, W., Domsch, K.H., 1967. Beiträge zur Anwendung der Bodenwaschtechnik für die Isolierung von Bodenpilzen. Arch. Mikrobiol. 58, 134-144.

Gordon, H., Haygarth, P.M., Bardgett, R.D., 2008. Drying and rewetting effects on microbial community composition and an instance of a repeated event. Soil Biol. Biochem. 40, 302-311.

Grayston, S.J., Griffith, G.S., Mawdsley, J.L., Campbell, C.D., Bardgett, R.D., 2001. Accounting for variability in soil microbial communities of temperate upland grassland ecosystems. Soil Biol. Biochem. 33, 533-551.

Heuer, H., Smalla, K., 1997. Application of denaturing gradient gel electrophoresis (DGGE) and temperature gradient gel electrophoresis (TGGE) for studying soil microbial communities. In: van Elsas JD, Wellington EMH, Trevors JT (eds) Modern soil microbiology. Dekker, New York, pp 353-373.

Hölldobler, B., Wilson, E.O., 1990. The ants. Springer, Berlin, Heidelberg, New York. Holec, M., Frouz, J., 2006. The effect of two ant species Lasius niger and Lasius flavus on soil properties in two contrasting habitats. Eur. J. Soil Biol. 42, 213217.

Jones, C.G., Lawton, J.H., Shachak, M., 1994. Organisms as ecosystem engineers. Oikos 69, 373-386.

Jones, D.L., Murphy, D.V., 2007. Microbial response time to sugar and amino acid additions to soil. Soil Biol. Biochem. 39, 2178-2182.

Lobry de Bruyn, L.A., Conacher, A.J., 1990. The role of termites and ants in soil modification: a review. Aust. J. Soil Res. 28, 55-93. 
Lobry de Bruyn, L.A., Conacher, A.J., 1994. The effect of biopores on water infiltration in soils in undisturbed bushland and farmland in a semi-arid environment. Pedobiologia 38, 193-207.

Maraun, M., Martens, H., Migge, S., Theenhaus, A., Scheu, S., 2003. Adding 'the enigma of soil animal diversity': fungal feeders and saprophagous soil invertebrates prefer similar food substrates. Eur. J. Soil Biol. 39, 85-95.

Mcllveen, W.D., Cole, H., 1976. Spore dispersal of Endogonaceae by worms, ants, wasps, and birds. Can. J. Bot. 54, 1486-1489.

Nannipieri, P., Ascher, J., Ceccherini, M.T., Landi, G., Pietramellara, G., Renella, G., 2003. Microbial diversity and soil functions. Eur. J. Soil Sci. 54, 655-670.

Nielsen, M.G., Skyberg, N., Winther, L., 1976. Studies on Lasius flavus F. (Hymenoptera, Formicidae): I. Population density, biomass, and distribution of nests. Ent. Meddr. 44, 65-75.

Nkem, J.N., Lobry de Bruyn, L.A., Grant, C.D., Hulugalle, N.R., 2000. The impact of ant bioturbation and foraging activities on surrounding soil properties. Pedobiologia 44, 609-621.

Pêtal, J., 1978. The role of ants in ecosystems. Production ecology of ants and termites (ed M. V. Brian), Cambridge University Press, Cambridge.

Pêtal, J., Kusinska, A., 1994. Fractional composition of organic matter in the soil of anthills and of the environment of meadows. Pedobiologia 38, 493-501.

Platner, C., Schaefer, M., Scheu, S., 2001. Der Einfluss von Ameisen auf den Boden und die mikrobielle Gemeinschaft trockener Brachwiesen. Mitt. Dtsch. Bodenkdl. Ges. 95, 84-87.

Platner, C., 2006. Ameisen als Schlüsseltiergruppe in einem Grasland. Studien zu ihrer Bedeutung für die Tiergemeinschaft, das Nahrungsnetz und das Ökosystem. Biodiversity and Ecology Series 1, Universitätsverlag, Göttingen.

Pokarzhevskii, A.D., van Straalen, N.M., Zaboev, D.P., Zaitsev, A.S., 2003. Microbial links and element flows in nested detrital food-webs. Pedobiologia 47, 213-224.

Scheffer, F., Schachtschabel, P., 2002. Lehrbuch der Bodenkunde. 15th edition. Spektrum Akademischer Verlag, Heidelberg, Berlin.

Scheu, S., 1992. Automated measurement of the respiratory response of soil microcompartments: active microbial biomass in earthworm faeces. Soil Biol. Biochem. 24, 1113-1118.

Seifert, B., 2007. Die Ameisen Mittel- und Nordeuropas. Lutra Verlag, Tauer. 
Sokal, R.R., Rohlf, F.J., 2001. Biometry. 4th edition. WH Freeman and Co., New York.

Stadler, B., Schramm, A., Kalbitz, K., 2006. Ant-mediated effect on spruce litter decomposition, solution chemistry, and microbial activity. Soil Biol. Biochem. 38, 561-572.

Tiunov, A.V., Scheu, S., 2000. Microfungal communities in soil, litter, and casts of Lumbricus teresstris L. (Lumbricidae): a laboratory experiment. Appl. Soil Ecol. 14, 17-26.

Wagner, D., Brown, M.F.J., Gordon, D.M., 1997. Harvester ant nests, soil biota and soil chemistry. Oecologia 112, 232-23. 


\section{Appendix}

Appendix A Soil- and microbial parameters in the different sampling months, calculated as a mean ( \pm SD) of four different nests and the four respective surrounding soils.

\begin{tabular}{lccccc}
\hline & $\begin{array}{c}\mathrm{NO}_{3}-\mathrm{N} \\
\left(\mu \mathrm{g} \mathrm{g}^{-1} \mathrm{dry} \mathrm{wt}\right)\end{array}$ & $\begin{array}{c}\mathrm{PO}_{4}-\mathrm{P} \\
\left(\mu \mathrm{g} \mathrm{g}^{-1} \mathrm{dry} \mathrm{wt}\right)\end{array}$ & $\begin{array}{c}\text { Water content } \\
(\%)\end{array}$ & $\begin{array}{c}\text { Basal respiration } \\
\left(\mu \mathrm{g} \mathrm{O}_{2} \mathrm{~g}^{-1} \mathrm{dry} \mathrm{wt}^{-1}\right)\end{array}$ & $\begin{array}{c}\text { Microbial biomass } \\
\left(\mu \mathrm{g} \mathrm{Cmic} \mathrm{\textrm {g } ^ { - 1 }} \mathrm{dry} \mathrm{wt}\right)\end{array}$ \\
\hline nests Dec. & $22.02( \pm 16.45)$ & $53.17( \pm 26.97)$ & $31.59( \pm 3.04)$ & $5.30( \pm 2.15)$ & $937.40( \pm 304.43)$ \\
nests Feb. & $12.97( \pm 8.54)$ & $61.36( \pm 36.55)$ & $35.67( \pm 6.22)$ & $6.92( \pm 2.29)$ & $1036.01( \pm 298.34)$ \\
nests May & $6.19( \pm 9.46)$ & $23.12( \pm 25.56)$ & $11.33( \pm 9.74)$ & $1.33( \pm 1.59)$ & $785.61( \pm 236.90)$ \\
nests Oct. & $10.45( \pm 10.83)$ & $24.36( \pm 22.04)$ & $21.17( \pm 6.87)$ & $3.32( \pm 1.12)$ & $900.60( \pm 292.44)$ \\
\hline controls Dec. & $5.74( \pm 5.40)$ & $10.64( \pm 4.90)$ & $32.24( \pm 3.41)$ & $4.31( \pm 1.70)$ & $692.88( \pm 228.74)$ \\
controls Feb. & $2.74( \pm 2.15)$ & $16.36( \pm 9.97)$ & $39.14( \pm 3.49)$ & $6.33( \pm 0.91)$ & $884.59( \pm 144.48)$ \\
controls May & $2.50( \pm 1.91)$ & $12.36( \pm 10.09)$ & $15.53( \pm 6.02)$ & $3.70( \pm 0.78)$ & $954.87( \pm 210.78)$ \\
controls Oct. & $0( \pm 0)$ & $12.92(14.50)$ & $26.75( \pm 4.93)$ & $3.64( \pm 0.41)$ & $849.54( \pm 38.89)$ \\
\hline
\end{tabular}

Appendix B Soil- and microbial parameters in the four different nest and surrounding soils, calculated as a mean ( \pm SD) of all tested month.

\begin{tabular}{|c|c|c|c|c|c|c|}
\hline Plot & Ant activity & $\begin{array}{c}\mathrm{NO}_{3}-\mathrm{N} \\
\left(\mu \mathrm{g} \mathrm{g}^{-1} \text { dry wt) }\right.\end{array}$ & $\begin{array}{c}\mathrm{PO}_{4}-\mathrm{P} \\
\left(\mu \mathrm{g} \mathrm{g}^{-1} \text { dry wt) }\right.\end{array}$ & $\begin{array}{c}\begin{array}{c}\text { Water content } \\
(\%)\end{array} \\
\end{array}$ & $\begin{array}{l}\text { Basal respiration } \\
\left(\mu \mathrm{g} \mathrm{O}_{2} \mathrm{~g}^{-1} \text { dry wt } \mathrm{h}^{-1}\right)\end{array}$ & $\begin{array}{l}\text { Microbial biomass } \\
\left(\mu \mathrm{g} \mathrm{Cmic} \mathrm{g}^{-1} \text { dry wt }\right)\end{array}$ \\
\hline 1 & active $L$. flavus & $12.77( \pm 11.51)$ & $23.25( \pm 9.40)$ & $22.88( \pm 12.71)$ & $3.83( \pm 2.57)$ & $780.92( \pm 117.80)$ \\
\hline 2 & active $L$. flavus & $18.46( \pm 15.39)$ & $73.20( \pm 26.06)$ & $25.88( \pm 16.18)$ & $3.49( \pm 2.72)$ & $1123.95( \pm 120.34)$ \\
\hline 3 & L. niger nest & $14.96( \pm 10.47)$ & $62.38( \pm 29.01)$ & $25.66( \pm 12.49)$ & $6.20( \pm 3.67)$ & $1095.53( \pm 342.85)$ \\
\hline 4 & low-active L. flavus & $3.68( \pm 3.21)$ & $25.06( \pm 25.31)$ & $25.34( \pm 9.03)$ & $3.35( \pm 1.58)$ & $659.21( \pm 85.67)$ \\
\hline 1 & control active L. flavus & $3.96( \pm 6.14)$ & $2.94( \pm 1.65)$ & $28.07( \pm 8.72)$ & $4.78( \pm 1.28)$ & $796.28( \pm 139.54)$ \\
\hline 2 & control active L. flavus & $2.87( \pm 2.07)$ & $19.75( \pm 4.08)$ & $30.01( \pm 9.77)$ & $4.09( \pm 1.85)$ & $865.55( \pm 185.16)$ \\
\hline 3 & control L. niger nest & $2.22( \pm 2.83)$ & $21.25( \pm 8.30)$ & $31.54( \pm 10.09)$ & $4.64( \pm 1.69)$ & $956.62( \pm 189.93)$ \\
\hline 4 & $\begin{array}{l}\text { control low-active } L \text {. } \\
\text { flavus }\end{array}$ & $1.93( \pm 2.50)$ & $8.33( \pm 7.38)$ & $24.03( \pm 12.92)$ & $4.48( \pm 1.59)$ & $763.44( \pm 221.74)$ \\
\hline
\end{tabular}


Chapter 5

The impact of Lasius ants on soil properties and functional diversity of soil microbes

Evelyn Schumacher, Sonja Migge-Kleian and Christian Platner

This paper will be submitted to ;Applied Soil Biology' 


\section{Abstract}

Functional diversity of soil microorganisms as well as soil properties (contents of $\mathrm{NO}_{3}, \mathrm{PO}_{4}$ and elements) were studied in four ant nest mounds and surrounding soil from a dry, calcareous grassland habitat. Functional diversity was quantified by in situ respiration response to an array of 13 substrates that were added as C-source alone, or in combination with nitrogen $(\mathrm{CN})$ or nitrogen and phosphorus (CNP). Active and potential catabolic profiles were analysed with multivariate statistics. A characteristic feature of the nest sites were increased concentrations of $\mathrm{NO}_{3}-\mathrm{N}, \mathrm{PO}_{4}-$ $P$, and potassium with the latter two nutrients being highly correlated with a high utilization of melecitose and mannose, as well as ascorbic, formic and glutaric acid. This indicates that the nutrient and element contents of soils are major structuring forces for the microbial community. Despite higher nutrient contents in nests, nutrients limited microbial growth in nests as well as in surrounding soil. Actual catabolic profiles measured as initial response to the 13 substrates, mainly separated nest from surrounding soil by different utilization of carboxylic acids. The respiratory response to formic and ascorbic acid was always higher in ant nests than in surrounding soil, whereas glutaric acid was metabolized faster in surrounding soil.

Overall, ants fundamentally alter soil conditions and microbial community functioning. The in situ respiratory response is a promising tool to study effects of soil engineering organisms such as ants on microbial community functioning. Presumably, ants as widespread and dominant keystone taxa act as driving factor for nutrient mineralisation and change the diversity of soil microbial communities.

\section{Keywords}

Formicidae; Ant mounds; ecosystem engineers; microbial activity; physiological profile; substrate-induced respiration 


\section{Introduction}

Ants are dominant soil animals in most terrestrial ecosystems and directly and indirectly affect plant and animal populations (Hölldobler and Wilson, 1990). A number of studies focused on the effects of ants on the aboveground food web, including interactions between ants and both their prey and their mutualistic partners (Lenoir et al., 2003; Stadler and Dixon, 2005). Ants also act as ecosystem engineers (Jones, 1994) influencing physical and chemical properties of soils by nest construction, and foraging and consumption of food (Pêtal, 1978; Lobry de Bruyn and Conacher, 1990 and 1994; Nkem et al., 2000; Frouz et al., 2003).

Microorganisms in soil are controlled by energy and nutrient availability and by environmental forces. Thus, nutrient accumulation and changes in microhabitats due to ant activity can influence soil microorganisms and alter decomposition rates and soil fertility affecting plant productivity (Dauber and Wolters, 2000; Holec and Frouz, 2006). Lack of degradable $C$ sources can limit $N$ mineralisation and therefore plant growth (Magill and Aber, 2000). The accumulation of ammonium, nitrate and phosphate in ant nests is well documented (Czerwinski et al., 1971; Wagner et al., 1997; Nkem et al., 2000; Platner et al., 2001). This concentration of nutrients may induce higher microbial turnover resulting in higher decomposition rates. The rate of decomposition is also dependent on the diversity of the decomposer community (Setälä and McLean, 2004; Tiunov and Scheu, 2005). Thus, ants indirectly influence organic matter decomposition by stimulating or inhibiting different physiological groups of microorganisms (Jakubczyk et al., 1972). Differences in feeding patterns of ant species can also influence microbial physiological profiles.

Changes in microbial community composition can influence higher trophic levels because microbes represent the base of the belowground food web (Pokarzhevskii et al., 2003). Thus, knowledge on community composition of microorganisms and their range of substrate utilization is important for understanding key ecological processes.

Lasius ants distinctly enhanced microfungal diversity (Schumacher et al., unpublished). To obtain more insights in the soil microbial functioning, we analysed the functional diversity of soil microbes from the same site by measuring the actual and potential catabolic response of the microbial community to the addition of different substrates in ant nest mounds in comparison to the surrounding soil. More specifically, we studied (1) whether Lasius ants affect soil chemical properties, and 
(2) whether altered soil and nutritional conditions in ant nest mounds affect microbial community functioning.

\section{Material and Methods}

Sampling and chemical analysis

Samples from Lasius ant nests and surrounding soil were taken from a dry calcareous grassland located on the south-west facing slope of the Werra valley (Witzenhausen Freudenthal, Northern Hesse, Germany) at 180 m a.s.l. The diverse herb layer was dominated by Brachypodium pinnatum L. and the soil is a shallow Pararendzina (Leptosol) on Triassic limestone. The area is characterized by mild winters and humid summers (average annual precipitation $700 \mathrm{~mm}$, mean annual temperature $9^{\circ} \mathrm{C}$ ).

In winter 2005, we established four plots (similar looking nest sites, see also Schumacher et al., unpublished) to compare ant nest mound material with surrounding soil. From the middle of nest mounds soil samples were taken to a depth of $10 \mathrm{~cm}$. Respective control soil samples were taken at a distance of $1 \mathrm{~m}$ from each nest. Each sample was sieved $(4 \mathrm{~mm})$ at the time of collection and stored at field moisture at $5^{\circ} \mathrm{C}$.

In ant mound and control samples, we analysed soil water content (gravimetrically), nitrate $\left(\mathrm{KAl}\left(\mathrm{SO}_{4}\right)_{2}\right.$ extraction, measured by steam destillation), phosphate $\left(\mathrm{NaHCO}_{3}\right.$ extraction, measured photometrically by the ammonium molybdate complex method) and total elements (Na, K, Mg, S, Fe, Al, P; ICP-AES after pressure digestion, Department of Soil Science of Temperate and Boreal Ecosystems, Göttingen, Germany). In each of the samples microbial respiration was analysed after substrate addition (Anderson and Domsch, 1978) measuring oxygen consumption in an $\mathrm{O}_{2}$-microcompensation apparatus (Scheu et al., 1992).

Additionally, physiological profiles of microbial communities after separate addition of 13 different substrates were measured. We used the following substances of five chemical groups: carbohydrates $(D(+)$-glucose, $D(+)$-mannose and $D(+)$ melecitose-monohydrate), carboxylic acids (glutaric, fumaric, ascorbic, formic, phenylacetic and oxalic-dihydrate acid), polymers ( $\alpha$-cyclodextrine and chitin), amino acids (L-tyrosine) and amines ( $D(-)-N$-methylglucamine). Ten of these substrates were chosen because they gave most variable and distinct responses across five different soils in the study by Degens and Harris (1997). Furthermore, three ant- 
related substances were tested: melecitose as one of the dominant sugars in honeydew produced by aphids (Fischer et al., 2005) and used by ants as an energy resource, and phenylic and formic acid as gland secretions by ants with possibe antibiotic activity (Hölldobler and Wilson, 1990). Substrates were added equivalent to $3.2 \mathrm{mg} \mathrm{C} \mathrm{g}^{-1}$ soil dry weight and were added to samples without additional nutrients, and in combination with nitrogen (ammonium sulphate) and nitrogen and phosphorus (di-potassium hydrogen phosphate) as mass ratio of 10:2:1 (Anderson and Domsch, 1980). The respiratory response of microbial communities was measured for $48 \mathrm{~h}$ at $22^{\circ} \mathrm{C}$. Different microbial parameters were distinguished: basal respiration (BAS, measured as a control without substrate addition at field moisture), maximum initial respiratory response (MIRR, reflecting the actual catabolic activity; Scheu et al., 2002), microbial growth rate (slope) and the integral of the respiration curves (reflecting the potential catabolic activity; Scheu et al., 2002) Values for MIRR and integral were calculated as the difference between samples with substrate addition and controls without substrate addition (BAS). Integral and slope gave similar results, therefore only results of integral were presented in the results. Details for slope were shown in the Appendix.

\section{Statistical analyses}

Data for soil parameters were pooled from December 2005 and February 2006 samples and analysed by two-factor analysis of variances (SAS 8.1; SAS Institute Inc., Cary, NC), and means of different treatments were tested for significant differences by Tukey's honestly significant difference test (Sokal and Rohlf, 2001). The MIRR and the slope and integral of the respiratory response were analysed by a repeated measures ANOVA with 'ants' and 'plot' as factors for between subject effect and nutrient addition treatment (C, CN, CNP) as the repeated factor (explaining the effect of $\mathrm{N}$ or $\mathrm{P}$ ). Data were log-transformed to improve homogeneity of variance if necessary. Means of different treatments were tested for significant differences using Tukey's honestly significant difference test.

Actual and potential catabolic profiles in response to 13 substrates were analysed by discriminant function analyses (DFA) using the factor 'ants' as a grouping variable (two groups each: nest mounds and surrounding soil) in independent analyses for each nutrient treatment (C, CN, CNP; Appendix B and C). For each of the nine independent analyses (MIRR, slope, and integral, each with three nutrient 
treatments) a multidimensional scaling (MDS) of the distance matrix based on a nonparametric Gamma correlation was done to asses a reduced set of meaningful dimensions. In a further DFA of the combined dataset of the three nutrient treatments of each sample (handled as a total of 24 samples) the catabolic parameters 'initial'and 'integral' could be used without prior transformation by MDS, because in this case the number of samples exceeded the number of substrates. To compare the effect of ants with plot (nest age, ant species) and nutrient addition we did four additional DFAs for the combined dataset with 'plot' (4 groups), 'nutrients' (3 groups: $\mathrm{C}, \mathrm{CN}$ and CNP), the combination of 'plot' with 'ants' (8 groups) and 'nutrients' with 'ants' (6 groups) as grouping variables (Table 1).

In order to depict similarities in the microbial response among the 13 substrates and between them and the factors 'ants' (nest and surrounding) and 'plot', respiration data of the ant mound and soil samples were analysed by principal components analysis (PCA) and redundancy analysis (RDA) using CANOCO for Windows 4.5 (Ter Braak, 1988). For these analyses only $C$ treatments were used. After excluding soil parameters highly correlated with each other $\left(\mathrm{PO}_{4}\right.$ positively with $\mathrm{NO}_{3} ; \mathrm{Fe}$ positively with $\mathrm{Al}$ and $\mathrm{Mn}$ and negatively with $\mathrm{Na}, \mathrm{Mg}, \mathrm{Ca}, \mathrm{S}$ and $\mathrm{pH}$ ) by using the variance inflation factors (to reach values below 20 ) and forward selection, a reduced set of parameters was used as explanatory (environmental) variables in the RDA, while 'ant nest' and 'surrounding soil' were included in the analyses as passive variables, i.e. without affecting the ordination.

\section{Results}

Soil and microbial parameters

$\mathrm{NO}_{3}-\mathrm{N}$ and $\mathrm{PO}_{4}-\mathrm{P}$ concentrations were significantly higher in ant nests than in the surrounding soil $(F=13.13, p=0.0040$, Figure $1 a$ and $F=52.58, p=<0.0001$, Figure $1 b$, respectively). Both concentrations differed between the tested plots $(F=3.30$, $p=0.0617$, Figure $1 a$ and $F=7.34, p=0.0057$, Figure $1 b$, respectively).

The $\mathrm{K}$ content in soil samples was significantly higher in ant nests $\left(8.05 \mathrm{mg} \mathrm{g}^{-1}\right.$ soil dry wt) than in respective surroundings $\left(7.29 \mathrm{mg} \mathrm{g}^{-1}\right.$ soil dry wt; ANOVA $F=12.63$, $p=0.038$ ). The other elements did not differ significantly between nests and surroundings. 
a)

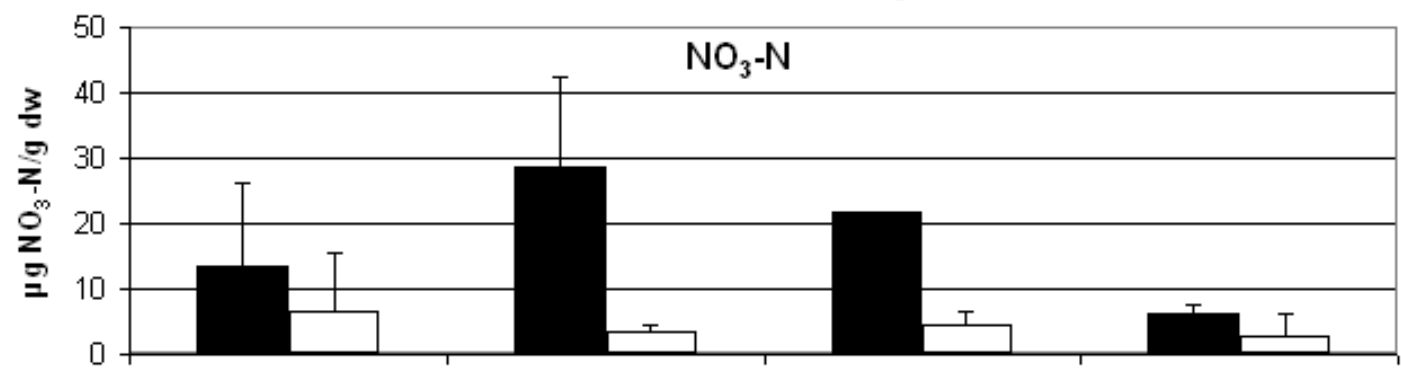

b)

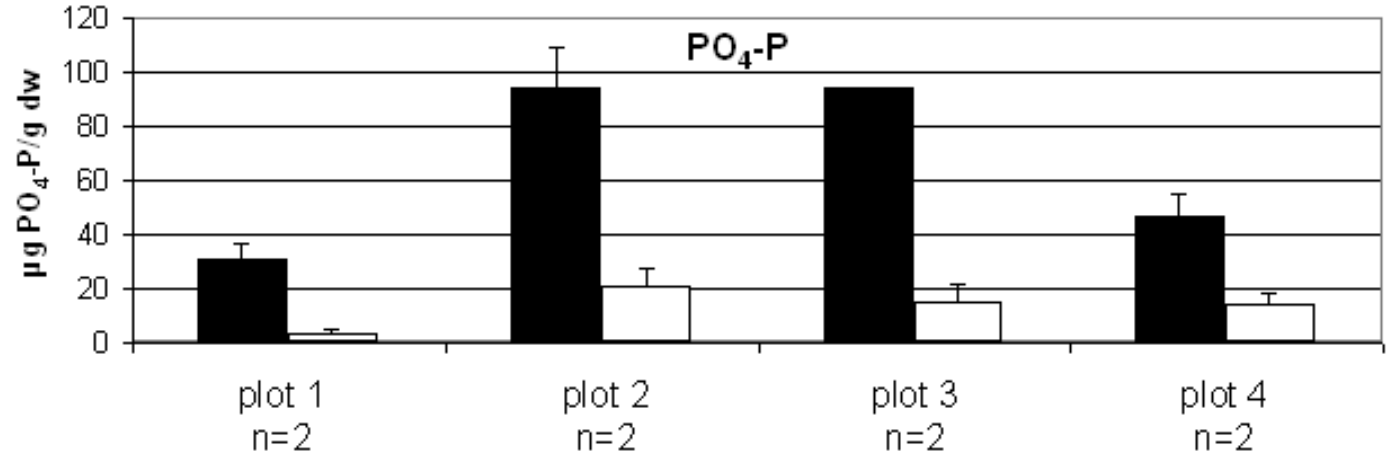

Figure 1. Amounts of a) $\mathrm{NO}_{3}-\mathrm{N}$ and b) $\mathrm{PO}_{4}-\mathrm{P}$ in four different ant nests (black bars) and respective surrounding soils (white bars). Dw=dry weight.

Physiological profiles

Physiological profiles were obtained from nest mound material and respective surrounding soil. For the three microbial parameters the ant effect differed. The actual catabolic activity (MIRR) of nest materials and surrounding soils was well separated in a discriminant function analysis (DFA) using a combined dataset of the three nutrient addition treatments (factor 'ants' in Table 1).

Table 1. Response of the microbial community to separate addition of 13 different substrates in nests in comparison to the surrounding soils. Discriminant function analyses for two respiratory response parameters (substrate initial response and integral of respiratory response) separately using the factors ants ( $v=2$ treatments), plot $(v=4)$, nutrients $(v=3)$, and the combinations of ant-treatments with plot- (ants | plot, $v=8$ ) and nutrient- treatments (ants | nutr, $v=6$ ) as grouping variables (for each analysis a combined dataset of three nutrient addition treatments for the 4 ant nest and respective control samples was used; $n=24$ ).

\begin{tabular}{llllll} 
& ants & plot & nutrients & ants | plot & ants | nutr \\
\hline Initial (MIRR) & & & & \\
\hline Wilks' Lambda & $\mathbf{0 . 1 6 9}$ & 0.060 & $\mathbf{0 . 0 0 1}$ & $<0.001$ & $<0.001$ \\
p-value & $\mathbf{0 . 0 2 1}$ & 0.515 & $<0.001$ & $\mathbf{0 . 0 2 3}$ & $<0.001$ \\
\hline Integral & \multicolumn{5}{c}{} \\
\hline Wilks' Lambda & 0.331 & $\mathbf{0 . 1 6 1}$ & $\mathbf{< 0 . 0 0 1}$ & $<0.001$ & $<0.001$ \\
p-value & 0.245 & $\mathbf{0 . 0 4 9}$ & $<0.001$ & 0.360 & $<0.001$ \\
\hline
\end{tabular}


With the combination of the factors 'ants' and 'nutrients' as grouping variables the initial response also separated the three nutrient treatments with the separation being significant (Figure 2). Within the nutrient treatments nests and surrounding soil were divided by the first root, indicating a higher nutrient status in nests.

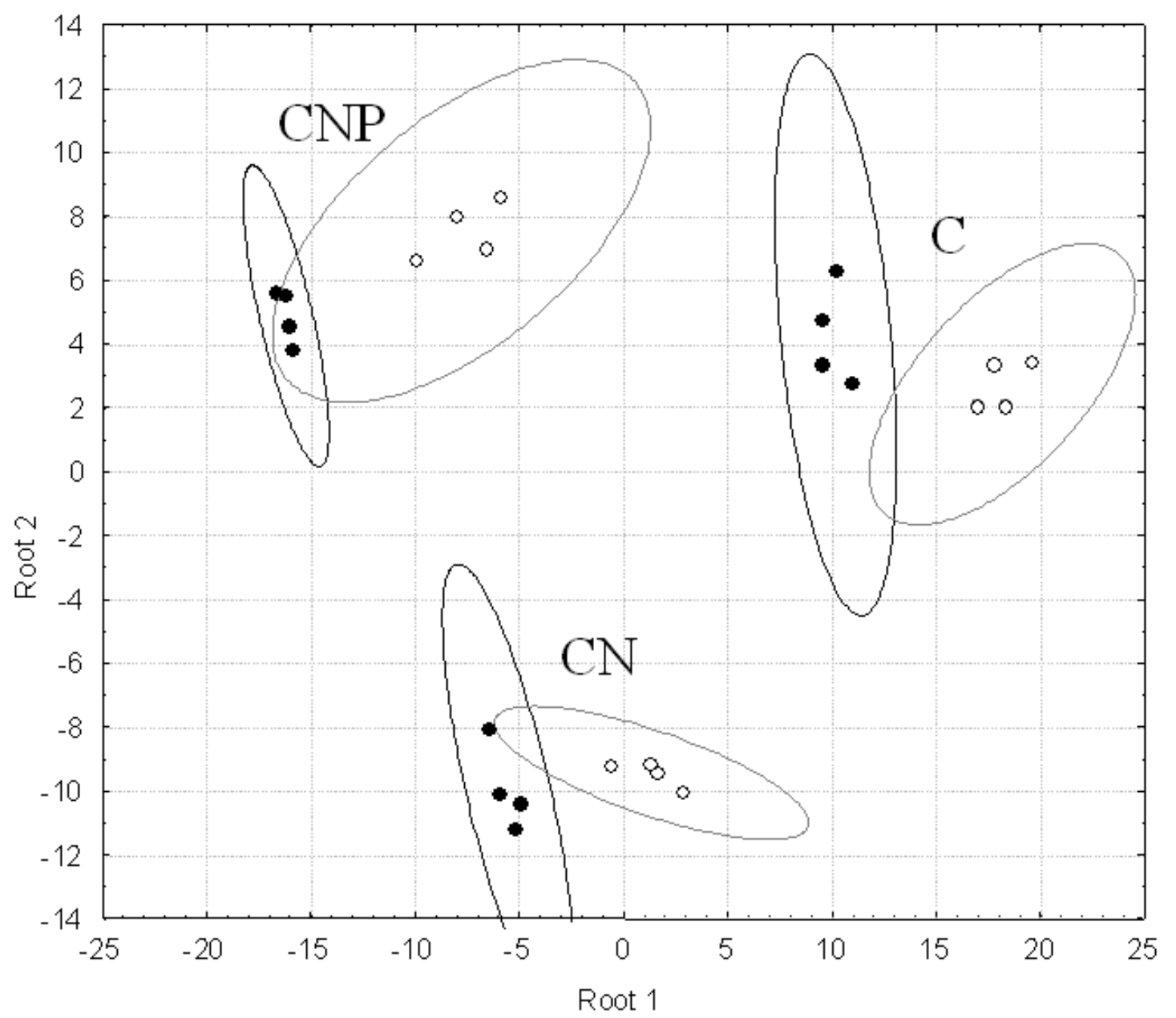

Figure 2. Response of the microbial community to separate supplement of 13 different substrates in nests (solid circles) in comparison to the surrounding soils (open circles). Discriminant function analysis for initial respiratory response using a combination of the factors "ants" and "nutrients" (ants | nutr) as grouping variables (a combined dataset of three nutrient addition treatments for the 4 ant nest and respective control samples was used; $n=24)$.

However, in the independent analyses of the three nutrition-treatments, a separation between nest and soil materials was only marginal significant for the integral when CNP was added (Appendix B and C). Repeated measurement analysis of variance showed distinctions between nests and surroundings especially when carboxylic acids were added (rmANOVA, ascorbic acid, glutaric acid and formic acid, Appendix A), but with different patterns of utilization. Mean respiration response to formic and ascorbic acid was always higher in ant nests than in surrounding soils, whereas it was lower when glutaric acid was added. However, this effect was 
dependent on nutrient supply (significant interaction between 'ant' and 'nutrient' effect, Appendix A).

Similar to the initial response, nutrient addition treatments were significantly separated by the first root in DFA for the integral of respiration curve when a combined dataset was used (Table 1, graphics not shown). We found single substances of different substrate groups that separated nest and surrounding soils. The integral of the respiration response was significantly higher in nests in case of mannose, melecitose, ascorbic acid, and tyrosine for all nutrient treatments. The differences between nests and controls in the case of cyclodextrine and chitin were dependent on nutrient availability (see Appendix A).

Correlation of element contents with microbial community functioning

Complex relationships between nest and control in situ respiration profiles and properties of respective materials were studied using multivariate ordination methods (PCA and RDA). PCA of actual and potential in situ respiration profiles clearly separated the studied samples. The first axis had high eigenvalues (>0.5, Table 2 ) and together with the second axis represented $80.9 \%$ and $78.4 \%$ of the variation in substrate initial response and integral of respiratory response, respectively. We included chemical conditions of surrounding soil as predictor variables for the respiratory response using the direct gradient analysis (RDA), which resulted in an only slight decline of variance represented by the first and second axis (66.9 and $75.7 \%$ of variation explained by both axes for initial and integral, respectively) compared to the PCA (Eigenvalues see table 2). $\mathrm{K}, \mathrm{Fe}$, and $\mathrm{PO}_{4}$ contents contributed

Table 2 Eigenvalues from principal component analysis (PCA) and redundancy analysis (RDA) of actual and potential in situ respiration profiles (substrate initial response and integral of respiratory response) with soil nutrient contents as environmental variables. Each PCA and RDA was done for $C$ treatments with the complete set of 13 supplementary substrates. P-values from a Monte Carlo test of significance of all canonical axes $\left({ }^{\S}\right)$ and the first axis.

\begin{tabular}{rlll}
\hline & PCA & RDA & $\boldsymbol{P}$ \\
\hline Initial (MIRR) & & & $\mathbf{0 . 0 1 6 ^ { \S }}$ \\
Axis 1 & 0.690 & 0.597 & $\mathbf{0 . 0 0 1}$ \\
Axis 2 & 0.119 & 0.072 & \\
Integral & & & $0.107^{\S}$ \\
Axis 1 & 0.579 & 0.579 & $\mathbf{0 . 0 3 6}$ \\
Axis 2 & 0.205 & 0.178 &
\end{tabular}


significantly to the explanation of initial response (Figure 3), while $\mathrm{Na}, \mathrm{K}, \mathrm{Mg}, \mathrm{Fe}$, and $\mathrm{PO}_{4}$ contents to those of integral of respiratory response.

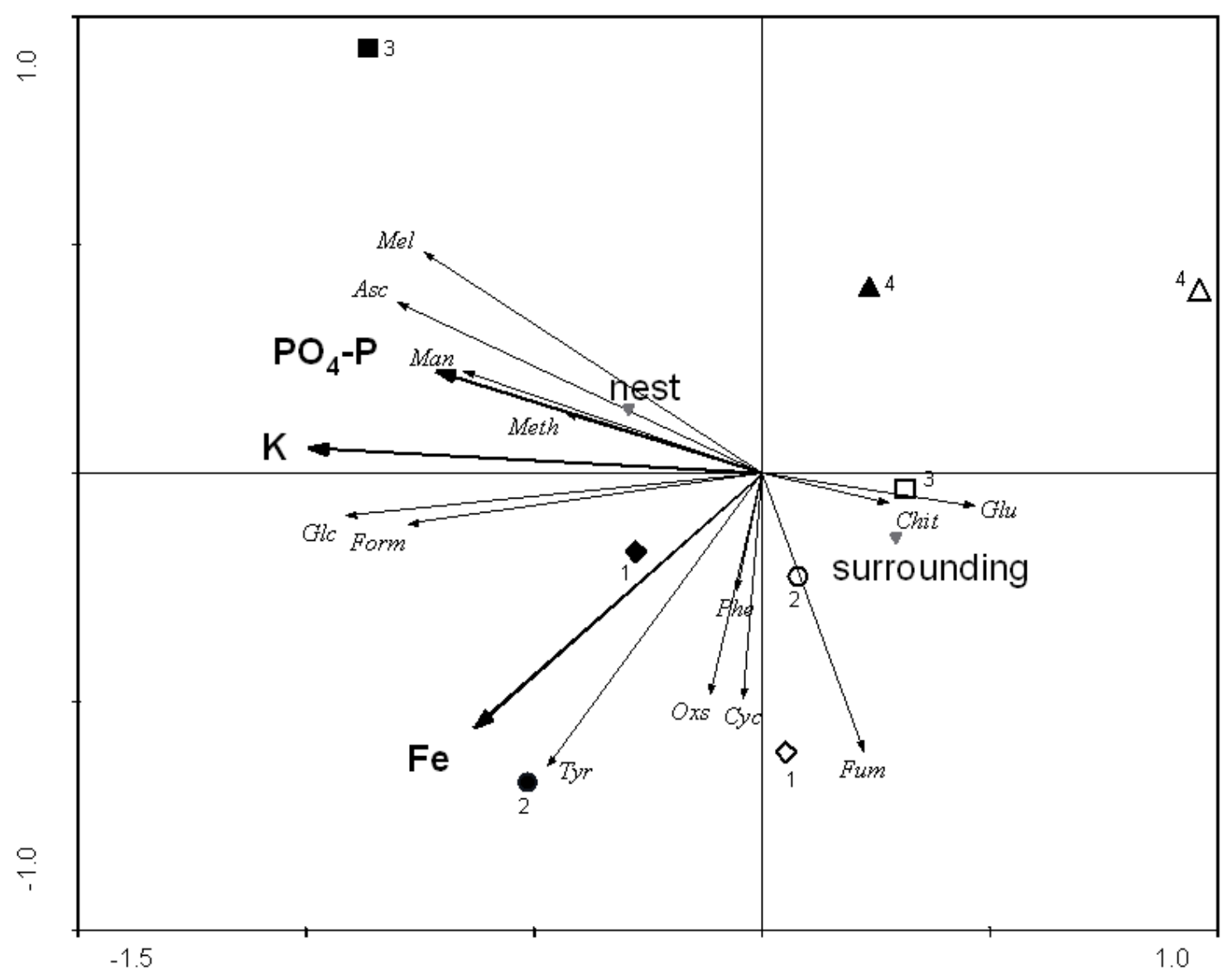

Figure 3. Substrate initial respiration response for 13 different substrates (small arrows, italic) as explained by soil chemical parameters (large arrows) of nests (solid symbols) and surrounding soil (open symbols) using RDA of the $C$ treatments. Asc=ascorbic acid, Chit=chitin, Cyc=cyclodextrine, Form=formic acid, Fum=fumaric acid, Glc=glucose, Glu=glutaric acid, Man=mannose, Mel=melecitose, Meth=methylglucamine, Oxs=oxalic acid, Phe=phenylic acid, Tyr=tyrosine. $\mathrm{N}=$ =nest, $\mathrm{S}=$ surrounding, numbers=plots.

Initial respiration separated best between ant nest and surrounding soil. High substrate utilization of melecitose, mannose, glucose, methylglucamine, ascorbic acid, and formic acid by microorganisms was closely correlated with higher $\mathrm{PO}_{4}-\mathrm{P}$ and $\mathrm{K}$ contents in nests (Figure 3). On the other hand, microorganisms in surrounding soil had a high initial respiration when chitin and glutaric and fumaric acid were added and $\mathrm{PO}_{4}-\mathrm{P}$ and $\mathrm{K}$ contents were low. 


\section{Discussion}

The nutrient and element contents of soils are major structuring forces for the microbial community, as the multivariate ordination methods (PCA and RDA) demonstrated in the present study. A characteristic feature of the studied nest sites were the considerably increased amounts of $\mathrm{PO}_{4}-\mathrm{P}$ and $\mathrm{NO}_{3}-\mathrm{N}$ in ant nests. High mineralization rates in ant nests have been reported previously from nests of Formica (Wagner et al., 1997; Domisch et al., 2008), Myrmica (Pêtal, 1998) and Iridomyrmex greensladei (Nkem et al., 2000). High nutrient contents in soil can lead to higher fungal diversity and changes in fungal associations in ant nests. However, in the ant nests investigated in this study fungal abundance has been shown to be low in December as reported in Schumacher et al. (unpublished), indicating that microbial respiration measured in the present study was predominantly due to bacteria.

The DFA of the initial respiratory response to the 13 substrates and the factors 'ants' and 'nutrients' as grouping variables separated three nutrient addition treatments (C, CN and CNP) along the first axis. This indicates nutrient limitation of the microbial community with nitrogen being the most important limiting mineral element. Soils are dynamic systems and soil nutrient content varies in space and time. Thus, different nutrient limitations in habitats can mask ant effects, especially when different locations or seasonal changes are compared (Frouz et al., 2003; Platner, 2006). However, within these treatments nests and surroundings were also separated along the first axis, indicating that despite differences in nutrient contents between nest mounds and surroundings nutrient limitation played a role even in ant nests. This was also shown in the combined analysis (DFA with factor 'ants') where ants significantly affected microbial initial respiratory response to the 13 substrates.

Utilization of carboxylic acids was dependent on nutrient supply. These findings indicate that the initial response better reflects the ant effect when different nutrient combinations were used. It has been assumed that the most common limiting factor for microbial growth in soils is the lack of carbon, but the utilization of different $C$ resources depends on the availability of other nutrients (Scheu and Schaefer, 1998).

The independent analysis of initial respiration did not reveal a general ant effect, but canonical values show a good separation of nest 1 and 2 and respective surroundings when CNP was added. These nests were visited in summer and showed a high activity of ant workers. By contrast, in nest 4 only low activity was observed which was shown in the low degree of separation. Scheu et al. (2002) 
reported that the initial in situ catabolic activity may be a more sensitive parameter than microbial growth activity (integral) to study the physiological status of soil microbial communities. This can be supported by our findings of activity-based differences that were reflected in the degree of separation in the initial respiration.

In the ordination diagram of the initial respiratory response, the three carboxylic acids separated ant nests from surrounding soil. Also, Degens and Harris (1997) reported that carboxylic acids are most powerful separating different soils. Additionally, in our study also three different sugars were better utilized in nest material as compared to the surrounding soil. These sugars and formic and ascorbic acid were closely correlated with $\mathrm{PO}_{4}$ and $\mathrm{K}$ content, which supports the conclusion that addition of different nutrients improve the ability to detect differences in microbial communities functioning.

Of the ant-related substances, melecitose was the only $C$ source that significantly separated nest from surrounding soil in the rmANOVA: the integral of the respiration curve was always higher in ant nests. An expected antibiotic character of phenylic and formic acid could not be confirmed.

\section{Conclusions}

Ants as ecosystem engineers had a strong impact on soil nutrient concentrations and functional diversity of soil microbes, but this effect depended on the availability of $\mathrm{N}$ and $P$.

Initial respiration gave the best separation of nest treatments, especially when different nutrient combinations (C/CN/CNP) were used. The degree of separation was dependent on ant activity, and was predominantly caused by differences in the utilization of carboxylic acids.

The use of physiological profiles is a promising tool to study differences in the functional diversity of soil microbes, but to understand key ecological processes, the knowledge about the groups of microorganisms leading to functional changes is important. To obtain information on microbial community composition in soils, genetic approaches can be appropriate. The DGGE method could be used for profiling fungal and bacterial communities in soils, because a rapid screening of many samples is possible (Heuer and Smalla, 1997). Certainly, this method does not allow to distinguish between active and inactive stages of microorganisms, thus it should be combined with a simultaneous analysis of physiological profiles. 


\section{Acknowledgement}

We thank Matthias Schaefer and Sonja Migge-Kleian for valuable discussions and comments on the manuscript.

\section{References}

Anderson, J.P.E., Domsch, K.H., 1978. A physiological method for the quantitative measurement of microbial biomass in soils. Soil Biol. Biochem. 10, 215-221.

Anderson, J.P.E., Domsch, K.H., 1980. Quantities of plant nutrition in the microbial biomass of selected soils. Soil Sci. 130, 211-216.

Braak ter, C.J.F., Smilauer, P., 2002. CANOCO Reference manual and CanoDraw for Windows User's guide: Software for Canonical Community Ordination (vers. 4.5). Ithaca: Microcomputer Power.

Blomqvist, M.M., Olff, H., Blaauw, M.B., Bongers, T., van der Putten, W.H., 2000. Interactions between above- and belowground biota: importance for small-scale vegetation mosaics in a grassland ecosystem. Oikos 90, 582-598.

Czerwiński, Z., Pêtal, J., Jakubczyk, H., 1969. The influence of ants of the genus Myrmica on the physico-chemical and microbiological properties of soil within the compass of anthill in Strzeleckie meadows. Pol. J. Soil Sci. 2, 51-58.

Czerwiński, Z., Jakubczyk, H., Pêtal, J., 1971. Influence of Ant hills on the Meadow Soils. Pedobiologia 11, 277-285.

Dauber, J., Wolters, V., 2000. Microbial activity and functional diversity in the mounds of three different ant species. Soil Biol. Biochem. 32, 93-99.

Dauber, J., Niechoj, R., Baltruschat, H., Wolters, V., 2008. Soil engineering ants increase grass root arbuscular mycorrhizal colonization. Biol. Fertil. Soils 44, 791-796.

Degens, B.P., Harris, J.A., 1997. Development of a physiological approach to measuring the catabolic diversity of soil microbial communities. Soil Biol. Biochem. 29, 1309-1320.

Domisch, T., Ohashi, M., Finér, L., Risch, A.C., Sundström, L., Kilpeläinen, J., Niemelä, P., 2008. Decomposition of organic matter and nutrient mineralisation in wood ant (Formica rufa group) mounds in boreal coniferous forests of different age. Biol. Fertil. Soils 44, 539-545.

Fischer, M.K., Völkl, W., Hoffmann, H., 2005. Honeydew production and honeydew sugar composition of polyphagous black bean aphid, Aphis fabae (Hemiptera, 
Aphididae) on various host plants and implications for ant attendance. Eur. J. Entomol. 102, 155-160.

Frouz, J., Santruckova, H., Kalcik, J., 1997. The effect of wood ants (Formica polyctena Foerst.) on the transformation of phosphorus in a spruce plantation. Pedobiologia 41, 437-447.

Frouz, J., Holec, M., Kalčík, J., 2003. The effect of Lasius niger (Hymenoptera, Formicidae) ant nest on selected soil chemical properties. Pedobiologia 47, 205-212.

Heuer, H., Smalla, K., 1997. Application of denaturing gradient gel electrophoresis (DGGE) and temperature gradient gel electrophoresis (TGGE) for studying soil microbial communities. In: van Elsas JD, Wellington EMH, Trevors JT (eds) Modern soil microbiology. Dekker, New York, pp 353-373.

Holec, M., Frouz, J., 2006. The effect of two ant species Lasius niger and Lasius flavus on soil properties in two contrasting habitats. Eur. J. Soil Biol. 42, 213217.

Hölldobler, B., Wilson, E.O., 1990. The ants. Springer, Berlin, Heidelberg, NY.

Jakubczyk, H., Pêtal, J., Czerwiński, Z., Chmielewski, K., 1975. Influence of ants on changes of the microbial activity of the soil in environment treated by mineral nitrogen compounds. Deteriorization regionis 1, 42-53.

Jakubczyk, H., Czerwiński, Z., Pêtal, J., 1972. Ants as agents of soil habitat changes. Ekologia Polska 20, 153-161.

Jones, C.G., Lawton, J.H., Shachak, M., 1994. Organisms as ecosystem engineers. Oikos 69, 373-386.

Lenoire, L., Bengtsson, J., Tryggve, P., 2003. Effects of Formica ants on soil fauna results from short-term exclusion and a long-term natural experiment. Oecologia 134, 423-430.

Lobry de Bruyn, L.A., Conacher, A.J., 1990. The role of termites and ants in soil modification: a review. Aust. J. Soil Res. 28, 55-93.

Lobry de Bruyn, L.A., Conacher, A.J., 1994. The effect of biopores on water infiltration in soils in undisturbed bushland and farmland in a semi-arid environment. Pedobiologia 38, 193-207.

Magill, A.H., Aber, J.D., 2000. Variation in soil net mineralisation rates with dissolved organic carbon additions. Soil Biol. Biochem. 32, 587-601. 
Nielsen, M.G., Skyberg, N., Winther, L., 1976. Studies on Lasius flavus F. (Hymenoptera, Formicidae): I. Population density, biomass, and distribution of nests. Ent. Meddr. 44, 65-75.

Nkem, J.N., Lobry de Bruyn, L.A., Grant, C.D., Hulugalle, N.R., 2000. The impact of ant bioturbation and foraging activities on surrounding soil properties. Pedobiologia 44, 609-621.

Pêtal, J., 1998. The influence of ants on carbon and nitrogen mineralization in drained fen soil. Appl. Soil Ecol. 9, 271-275.

Pêtal, J., Kusinska, A., 1994. Fractional composition of organic matter in the soil of anthills and of the environment of meadows. Pedobiologia 38, 493-501.

Pêtal, J., 1978. The role of ants in ecosystems. Production ecology of ants and termites (ed M. V. Brian), Cambridge University Press, Cambridge.

Platner, C., 2006. Ameisen als Schlüsseltiergruppe in einem Grasland. Studien zu ihrer Bedeutung für die Tiergemeinschaft, das Nahrungsnetz und das Ökosystem. Universitätsverlag, Göttingen.

Platner, C., Schaefer, M., Scheu, S., 2001. Der Einfluss von Ameisen auf den Boden und die mikrobielle Gemeinschaft trockener Brachwiesen. Mitt. Dtsch. Bodenkdl. Ges. 95, 84-87.

Pokarzhevskii, A.D., van Straalen, N.M., Zaboev, D.P., Zaitsev, A.S., 2003. Microbial links and element flows in nested detrital food-webs. Pedobiologia 47, 213-224.

Scheu, S., 1992. Automated measurement of the respiratory response of soil microcompartments: active microbial biomass in earthworm faeces. Soil Biol. Biochem. 24, 1113-1118.

Scheu, S., Schaefer, M., 1998. Bottom-up control of the soil macrofauna community in a beechwood on limestone: Manipulation of food resources. Ecology 79, 1573-1585.

Scheu, S., Schlitt, N., Tiunov, A.V., Newington, J.E., Jones, T.H., 2002. Effects of the presence and community composition of earthworms on microbial community functioning. Oecologia 133, 254-260.

Setälä, H., McLean, M.A., 2004. Decomposition rate of organic substrates in relation to the species diversity of soil saprophytic fungi. Oecologia 139, 98-107.

Stadler, B., Dixon, A.F.B., 2005. Ecology and evolution of aphid-ant interactions. Ann. Rev. Ecol. Evol. Syst. 36, 345-372. 
Sokal, R.R., Rohlf, F.J., 2001. Biometry. 4th edition. WH Freeman and Co., New York.

Tiunov, A.V., Scheu, S., 2005. Facilitative interactions rather than resource partitioning drive diversity-functioning relationship in laboratory fungal communities. Ecology Letters 8, 618-625.

Wagner, D., Brown, M.F.J., Gordon, D.M., 1997. Harvester ant nests, soil biota and soil chemistry. Oecologia 112, 232-236. 
Appendix A Mean (SD) of the MIRR ( $\mu \mathrm{g} \mathrm{O}_{2} \mathrm{~g}^{-1}$ soil dry wt $\mathrm{h}^{-1}$ ) and the slope (of log-transformed data from initiation to maximum) and integral ( $\mu \mathrm{g}$ $\mathrm{O}_{2} \mathrm{~g}^{-1}$ soil dry $\mathrm{wt} \mathrm{h}^{-1}$ ) of the respiratory response to 13 different substrates were analysed by a repeated measures ANOVA with 'ants' and 'plot' as factors for between subject effect and nutrient addition treatment $(C, C N, C N P$ ) as the repeated factor (explaining the effect of $N$ or $P$ ). $\S=$ Significant ant effect (Tukey tests), surr=surrounding.

\begin{tabular}{|c|c|c|c|c|c|c|c|c|c|c|c|c|c|c|}
\hline & $\begin{array}{c}\text { nests } \\
\text { C }\end{array}$ & $\begin{array}{c}\text { surr } \\
\text { C }\end{array}$ & $\begin{array}{l}\text { nests } \\
\mathrm{CN}\end{array}$ & $\begin{array}{l}\text { surr } \\
\mathrm{CN}\end{array}$ & $\begin{array}{l}\text { nests } \\
\text { CNP }\end{array}$ & $\begin{array}{l}\text { surr } \\
\text { CNP }\end{array}$ & \multicolumn{2}{|c|}{ ant effect } & \multicolumn{2}{|c|}{ nutrients } & \multicolumn{2}{|c|}{$\begin{array}{l}\text { nutrients* } \\
\text { ants }\end{array}$} & \multicolumn{2}{|c|}{$\begin{array}{l}\text { nutrients * } \\
\text { plot }\end{array}$} \\
\hline \multicolumn{15}{|c|}{ carboxylic acids } \\
\hline formic acid & & & & & & & $F$ & $p$ & $F$ & $p$ & $F$ & $p$ & $F$ & $p$ \\
\hline Initial (MIRR) & $\begin{array}{l}9.31 \\
(1.54) \S\end{array}$ & $\begin{array}{l}6.57 \\
(1.71) \S\end{array}$ & $\begin{array}{l}8.30 \\
(3.76)\end{array}$ & $\begin{array}{l}5.41 \\
(1.04)\end{array}$ & $\begin{array}{l}5.01 \\
(2.98)\end{array}$ & $\begin{array}{l}2.14 \\
(1.45)\end{array}$ & 6.07 & 0.0906 & 12.85 & 0.0068 & 0.00 & 0.9957 & 1.00 & 0.5022 \\
\hline Slope & $\begin{array}{l}0.007 \\
(0.017)\end{array}$ & $\begin{array}{l}0.001 \\
(0.013)\end{array}$ & $\begin{array}{l}0.653 \\
(0.583)\end{array}$ & $\begin{array}{l}0.415 \\
(0.220)\end{array}$ & $\begin{array}{l}0.038 \\
(0.011) \S\end{array}$ & $\begin{array}{l}0.061 \\
(0.015) \S\end{array}$ & 1.04 & 0.3824 & 23.77 & 0.0014 & 1.41 & 0.3154 & 3.22 & 0.0901 \\
\hline Integral & $\begin{array}{l}837 \\
(284) \\
\end{array}$ & $\begin{array}{l}501 \\
(285) \\
\end{array}$ & $\begin{array}{l}643 \\
(310) \\
\end{array}$ & $\begin{array}{l}429 \\
(126) \\
\end{array}$ & $\begin{array}{l}555 \\
(151) \\
\end{array}$ & $\begin{array}{l}508 \\
(192) \\
\end{array}$ & 3.10 & 0.1764 & 1.76 & 0.2508 & 1.52 & 0.2914 & 0.93 & 0.5346 \\
\hline \multicolumn{15}{|l|}{$\begin{array}{l}\text { phenylacetic } \\
\text { acid }\end{array}$} \\
\hline Initial (MIRR) & $\begin{array}{l}4.94 \\
(0.96)\end{array}$ & $\begin{array}{l}6.35 \\
(1.24)\end{array}$ & $\begin{array}{l}8.80 \\
(2.93)\end{array}$ & $\begin{array}{l}8.16 \\
(1.76)\end{array}$ & $\begin{array}{l}1.75 \\
(3.26)\end{array}$ & $\begin{array}{l}-0.29 \\
(1.06)\end{array}$ & 0.28 & 0.6343 & 25.52 & 0.0012 & 1.25 & 0.3527 & 0.32 & 0.9023 \\
\hline Slope & $\begin{array}{l}0.037 \\
(0.007) \S\end{array}$ & $\begin{array}{l}0.020 \\
(0.002) \S\end{array}$ & $\begin{array}{l}0.074 \\
(0.011)\end{array}$ & $\begin{array}{l}0.072 \\
(0.026)\end{array}$ & $\begin{array}{l}0.077 \\
(0.009)\end{array}$ & $\begin{array}{l}0.090 \\
(0.014)\end{array}$ & 0.07 & 0.8142 & 39.47 & 0.0004 & 2.56 & 0.1570 & 0.63 & 0.7064 \\
\hline Integral & $\begin{array}{l}604 \\
(250)\end{array}$ & $426(86)$ & $\begin{array}{l}1641 \\
(93)\end{array}$ & $\begin{array}{l}1371 \\
(444)\end{array}$ & $\begin{array}{l}1079 \\
(550)\end{array}$ & $\begin{array}{l}1366 \\
(540)\end{array}$ & 0.07 & 0.8123 & 17.29 & 0.0032 & 1.48 & 0.2998 & 0.69 & 0.6671 \\
\hline \multicolumn{15}{|l|}{ ascorbic acid } \\
\hline Initial (MIRR) & $\begin{array}{l}26.75 \\
(4.08)\end{array}$ & $\begin{array}{l}22.41 \\
(2.73)\end{array}$ & $\begin{array}{l}35.22 \\
(3.57)\end{array}$ & $\begin{array}{l}34.10 \\
(2.41)\end{array}$ & $\begin{array}{l}34.31 \\
(6.60)\end{array}$ & $\begin{array}{l}27.91 \\
(1.61)\end{array}$ & 58.72 & 0.0046 & 8.38 & 0.0183 & 0.57 & 0.5953 & 0.29 & 0.9231 \\
\hline Slope & $\begin{array}{l}-0.022 \\
(0.005)\end{array}$ & $\begin{array}{l}-0.022 \\
(0.003)\end{array}$ & $\begin{array}{l}0.016 \\
(0.012)\end{array}$ & $\begin{array}{l}0.013 \\
(0.021)\end{array}$ & $\begin{array}{l}0.016 \\
(0.006)\end{array}$ & $\begin{array}{l}0.022 \\
(0.005)\end{array}$ & 0.07 & 0.8035 & 91.97 & $<0.0001$ & 0.80 & 0.4933 & 3.70 & 0.0682 \\
\hline Integral & $\begin{array}{l}1209 \\
(113) \S\end{array}$ & $\begin{array}{l}1040 \\
(99) \S\end{array}$ & $\begin{array}{l}2196 \\
(119)\end{array}$ & $\begin{array}{l}1911 \\
(503)\end{array}$ & $\begin{array}{l}2614 \\
(115)\end{array}$ & $\begin{array}{l}2526 \\
(96)\end{array}$ & 11.90 & 0.0410 & 116.62 & $<0.0001$ & 0.53 & 0.6140 & 1.29 & 0.3839 \\
\hline
\end{tabular}


Continuation of Appendix A

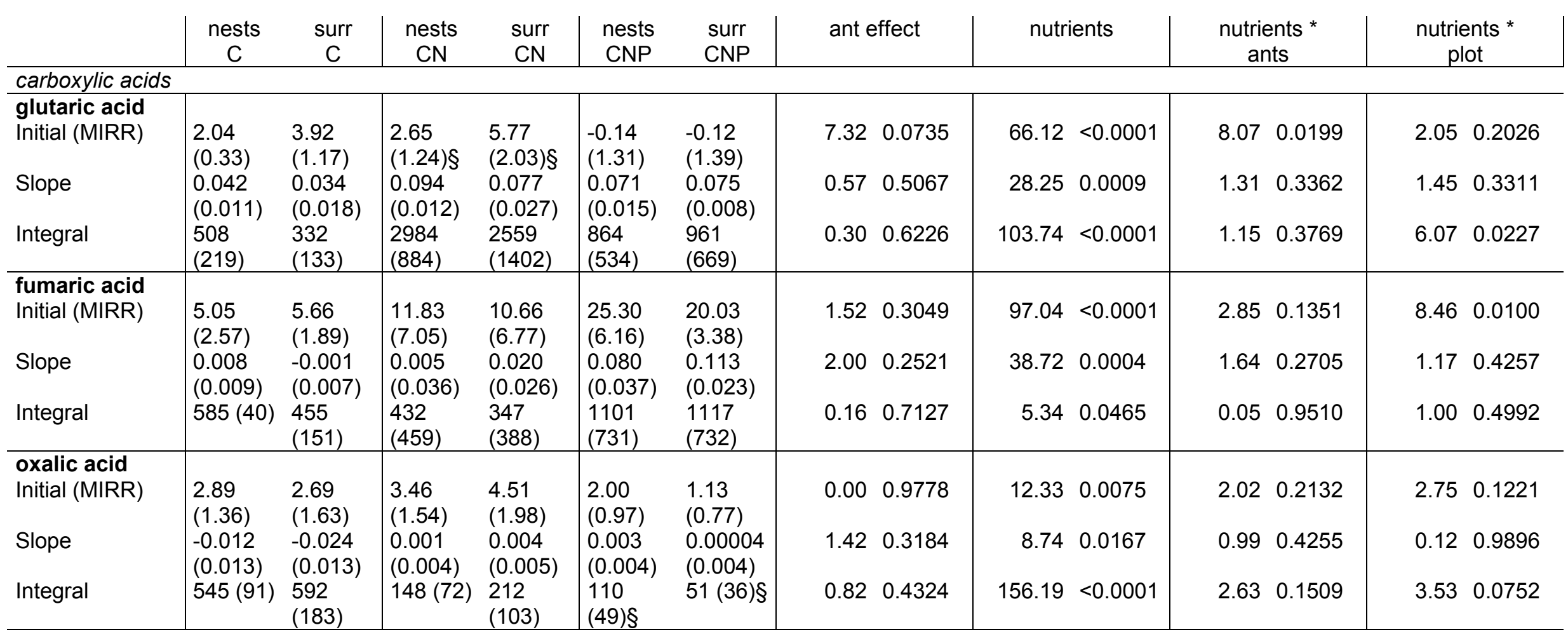


Continuation of Appendix A

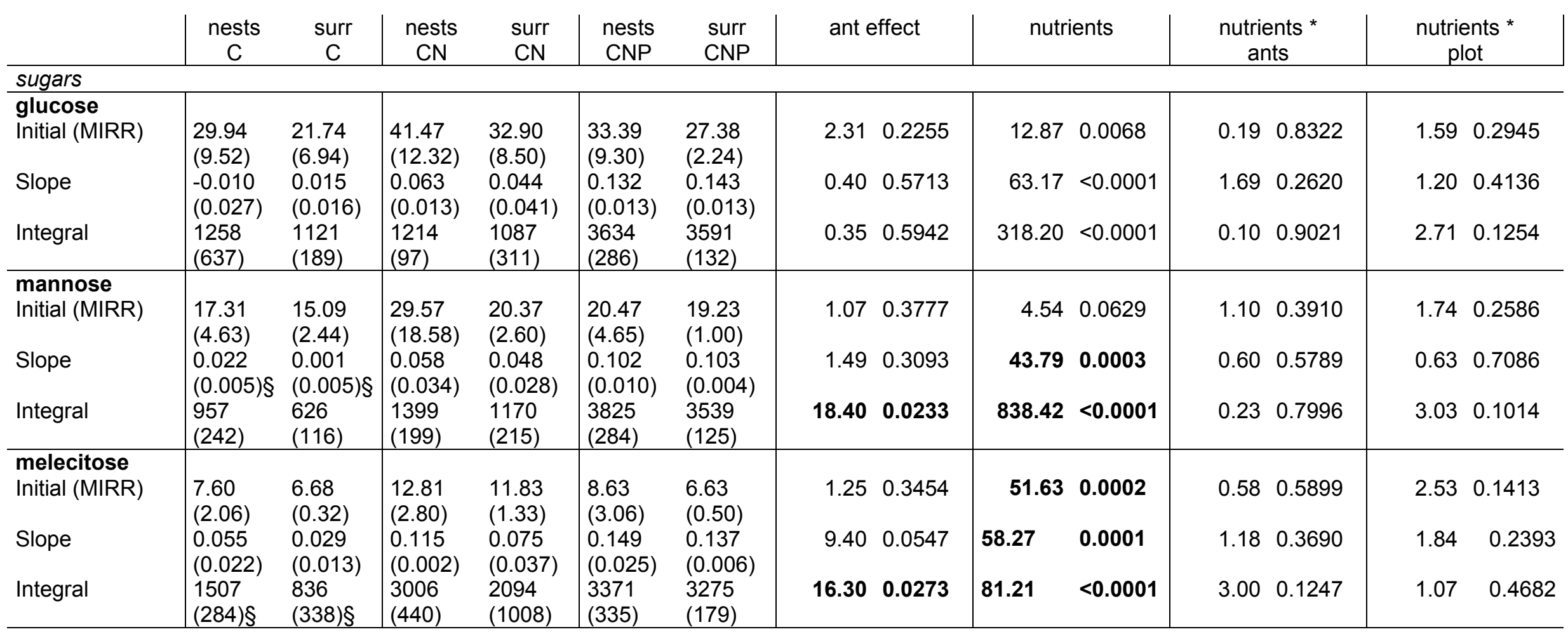


Continuation of Appendix A

\begin{tabular}{|c|c|c|c|c|c|c|c|c|c|c|c|c|c|c|}
\hline & $\begin{array}{c}\text { nests } \\
\text { C }\end{array}$ & $\begin{array}{c}\text { surr } \\
\text { C }\end{array}$ & $\begin{array}{c}\text { nests } \\
\text { CN }\end{array}$ & $\begin{array}{l}\text { surr } \\
\mathrm{CN}\end{array}$ & $\begin{array}{l}\text { nests } \\
\text { CNP }\end{array}$ & $\begin{array}{l}\text { surr } \\
\text { CNP }\end{array}$ & \multicolumn{2}{|c|}{ ant effect } & \multicolumn{2}{|c|}{ nutrients } & \multicolumn{2}{|c|}{$\begin{array}{l}\text { nutrients * } \\
\text { ants }\end{array}$} & \multicolumn{2}{|c|}{$\begin{array}{l}\text { nutrients * } \\
\text { plot }\end{array}$} \\
\hline \multicolumn{15}{|l|}{ polymers } \\
\hline \multicolumn{15}{|l|}{ chitin } \\
\hline Initial (MIRR) & $\begin{array}{l}-1.31 \\
(0.85)\end{array}$ & $\begin{array}{l}-0.47 \\
(1.41)\end{array}$ & $\begin{array}{l}2.26 \\
(1.70)\end{array}$ & $\begin{array}{l}3.23 \\
(1.25)\end{array}$ & $\begin{array}{l}0.38 \\
(1.29)\end{array}$ & $\begin{array}{l}0.12 \\
(0.66)\end{array}$ & 2.49 & 0.2126 & 23.89 & 0.0014 & 0.77 & 0.5027 & 1.35 & 0.3633 \\
\hline Slope & $\begin{array}{l}0.147 \\
(0.037)\end{array}$ & $\begin{array}{l}0.124 \\
(0.066)\end{array}$ & $\begin{array}{l}0.016 \\
(0.002)\end{array}$ & $\begin{array}{l}0.019 \\
(0.005)\end{array}$ & $\begin{array}{l}-0.0001 \\
(0.005)\end{array}$ & $\begin{array}{l}0.003 \\
(0.007)\end{array}$ & 0.23 & 0.6659 & 63.92 & $<0.0001$ & 0.68 & 0.5430 & 1.82 & 0.2427 \\
\hline Integral & $22(32)$ & $51(83)$ & $169(96)$ & $\begin{array}{l}251 \\
(105)\end{array}$ & $17(59)$ & $-6(24)$ & 9.23 & 0.0560 & 30.44 & 0.0007 & 1.75 & 0.2524 & 1.86 & 0.2348 \\
\hline $\begin{array}{l}\text { cyclodextrine } \\
\text { Initial (MIRR) }\end{array}$ & $\begin{array}{l}5.34 \\
(1.82)\end{array}$ & $\begin{array}{l}6.91 \\
(4.42)\end{array}$ & $\begin{array}{l}9.99 \\
(4.41)\end{array}$ & $\begin{array}{l}10.11 \\
(1.21)\end{array}$ & $\begin{array}{l}8.49 \\
(2.76)\end{array}$ & $\begin{array}{l}8.36 \\
(0.80)\end{array}$ & 0.30 & 0.6246 & 3.94 & 0.0806 & 0.22 & 0.8121 & 0.41 & 0.8488 \\
\hline Slope & $\begin{array}{l}0.025 \\
(0.017)\end{array}$ & $\begin{array}{l}0.016 \\
(0.023)\end{array}$ & $\begin{array}{l}0.073 \\
(0.010) \S\end{array}$ & $\begin{array}{l}0.043 \\
(0.023) \S\end{array}$ & $\begin{array}{l}0.076 \\
(0.007)\end{array}$ & $\begin{array}{l}0.076 \\
(0.006)\end{array}$ & 2.20 & 0.2342 & 28.38 & 0.0009 & 2.04 & 0.2107 & 0.78 & 0.6170 \\
\hline Integral & $\begin{array}{l}346 \\
(174)\end{array}$ & $\begin{array}{l}398 \\
(357)\end{array}$ & $\begin{array}{l}2137 \\
(681) \S\end{array}$ & $\begin{array}{l}1371 \\
(693) \S\end{array}$ & $\begin{array}{l}2327 \\
(278)\end{array}$ & $\begin{array}{l}2097 \\
(35)\end{array}$ & 17.89 & 0.0242 & 99.59 & $<0.0001$ & 4.68 & 0.0596 & 3.92 & 0.0603 \\
\hline \multicolumn{15}{|l|}{ amino acid } \\
\hline tyrosine & & & & & & & & & & & & & & \\
\hline Initial (MIRR) & $\begin{array}{l}14.75 \\
(2.73)\end{array}$ & $\begin{array}{l}14.61 \\
(1.50)\end{array}$ & $\begin{array}{l}6.40 \\
(2.19)\end{array}$ & $\begin{array}{l}8.00 \\
(2.30)\end{array}$ & $\begin{array}{l}14.87 \\
(4.52)\end{array}$ & $\begin{array}{l}14.85 \\
(1.22)\end{array}$ & 0.14 & 0.7311 & 34.65 & 0.0005 & 0.43 & 0.6683 & 0.17 & 0.9745 \\
\hline Slope & $\begin{array}{l}0.060 \\
(0.008)\end{array}$ & $\begin{array}{l}0.042 \\
(0.023)\end{array}$ & $\begin{array}{l}0.058 \\
(0.012)\end{array}$ & $\begin{array}{l}0.044 \\
(0.023)\end{array}$ & $\begin{array}{l}0.093 \\
(0.010)\end{array}$ & $\begin{array}{l}0.096 \\
(0.007)\end{array}$ & 1.47 & 0.3120 & 28.89 & 0.0008 & 1.27 & 0.3470 & 0.48 & 0.8016 \\
\hline Integral & $\begin{array}{l}2321 \\
(99)\end{array}$ & $\begin{array}{l}1886 \\
(736)\end{array}$ & $\begin{array}{l}1499 \\
(302) \S\end{array}$ & $\begin{array}{l}1037 \\
(440) \S\end{array}$ & $\begin{array}{l}4168 \\
(406)\end{array}$ & $\begin{array}{l}3941 \\
(237)\end{array}$ & 9.40 & 0.0547 & 108.76 & $<0.0001$ & 0.22 & 0.8103 & 0.96 & 0.5203 \\
\hline
\end{tabular}




\section{Continuation of Appendix A}

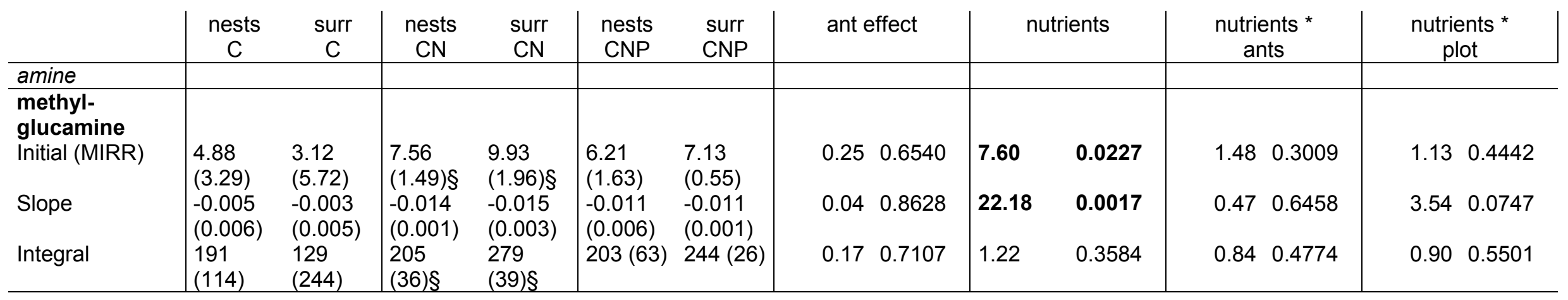


Appendix B Response of the microbial community to separate addition of 13 different substrates in nests in comparison to the surrounding soils. Discriminant function analyses for three nutrient addition treatments (independent analyses, each with 4 ant nest and respective control samples; $n=8$ ), using the ant treatments (nest vs. surrounding) as grouping variable.

\begin{tabular}{lccc}
\hline & $\begin{array}{c}\text { Mahalanobis- } \\
\text { distance }\end{array}$ & Wilks' Lambda & p-value \\
\hline Initial (MIRR) & & & \\
\hline C & 0.9806 & 0.7537 & 0.7395 \\
CN & 6.6230 & 0.3118 & 0.1620 \\
CNP & 5.6630 & 0.3463 & 0.1969 \\
\hline Integral & & & \\
\hline C & 2.5767 & 0.5380 & 0.4325 \\
CN & 4.4200 & 0.4043 & 0.2614 \\
CNP & $\mathbf{1 3 . 7 8 0 4}$ & $\mathbf{0 . 1 7 9 0}$ & $\mathbf{0 . 0 5 6 2}$ \\
\hline Slope & & & \\
\hline C & 1.9170 & 0.6101 & 0.5338 \\
CN & 2.8034 & 0.5169 & 0.4039 \\
CNP & 4.0711 & 0.4243 & 0.2851 \\
\hline
\end{tabular}


C

a)

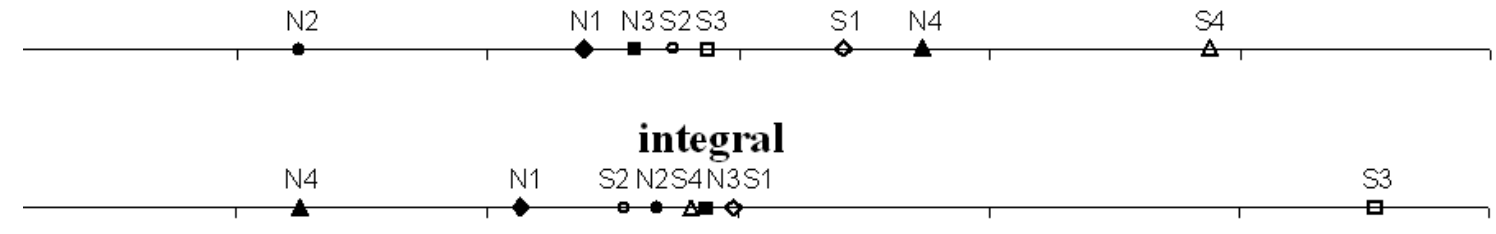

c)

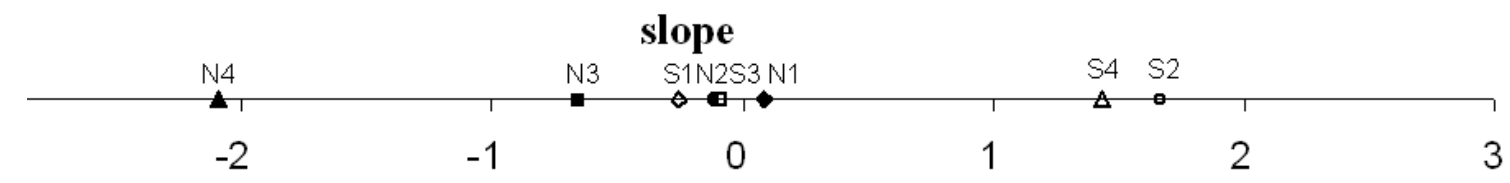

\section{CN}

d)

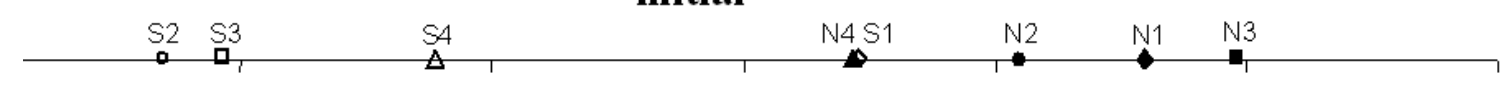

e)

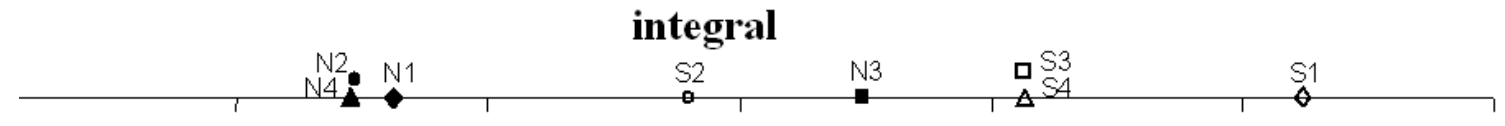

f)

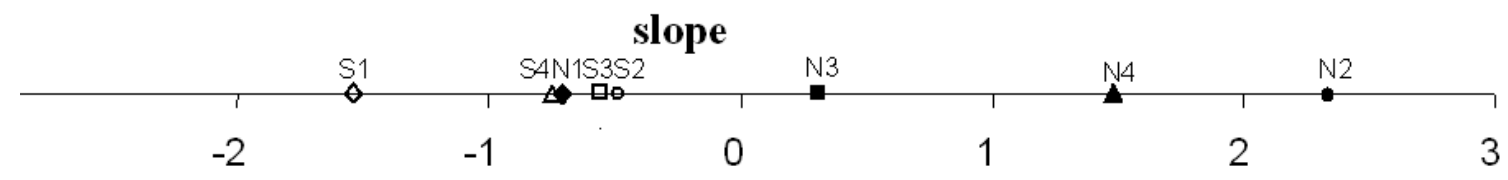

CNP

g)

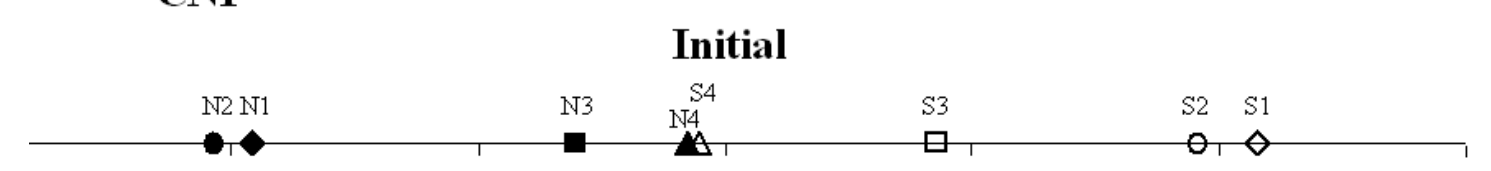

Integral

h)

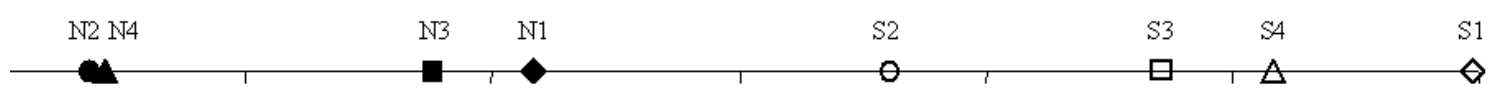

Slope

i)

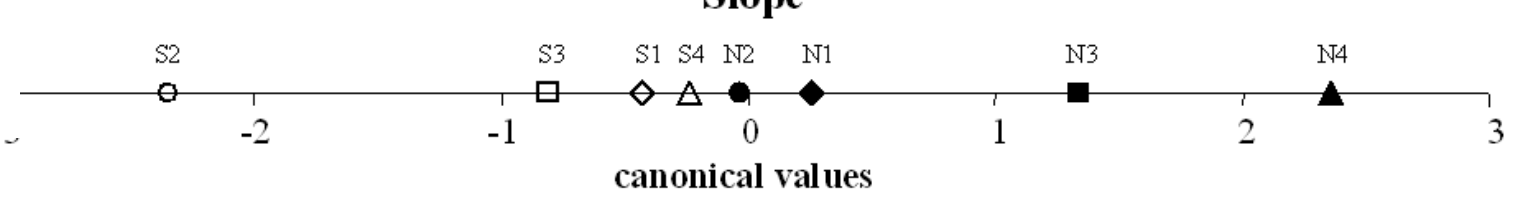

Appendix C. Response of the microbial community to separate supplement of 13 different substrates in nests (solid symbols) in comparison to the surrounding soils (open symbols). Discriminant function analyses for the three nutrient treatments (independent analyses, each with 4 ant nest and respective control samples; $n=8$ ) using the ant treatments (nest vs. surrounding) as grouping variable and showing canonical values. Initial respiration response, integral of respiration curve, and slope of respiration curve are shown when C-substrates were added alone (a-c), together with nitrogen (d-f) and in combination with nitrogen and phosphate $(\mathrm{g}-\mathrm{i}) . \mathrm{N}=$ nest, $\mathrm{S}=$ surrounding, numbers=plots . 
Chapter 6

\section{Microbial functional diversity - a molecular approach}

Evelyn Schumacher, Birgit Pfeiffer, Rolf Daniel and Christian Platner 


\section{Abstract}

Microbial diversity in soils is enormous high and still provides a largely untapped genetic reservoir. One of the most functionally important and ecologically dominant animal groups in the soil of open habitats is the ants, but their influence on microbial diversity remains under-explored. We studied functional diversity of microorganisms in Lasius ant nests and surrounding soil from two different grasslands (Leptosol and Cambisol) by in situ respiration response to an array of substrates in combination with a comparison of the involved bacterial community structures by denaturing gradient gel electrophoresis (DGGE). Respiration responses of soil microorganisms to eight different carbon substrates were measured using an $\mathrm{O}_{2}$-microcompensation apparatus. Substrate usage of microorganisms was dependent on ant presence. Especially ant-related substances (melecitose, formic acid and phenylic acid) were used by soil microorganisms present in ant nests. At the Cambisol (sampling site 2), initial respiration response and integral of respiration curve to most substrates was higher in nests than in the surrounding control soils. This trend was not found at the Leptosol (site 1). These results indicated that no uniform effect of ants on microbes exists in the two sampling sites, and that the ant effect was dependent on ant nest site. This was supported by DGGE analyses as differences in bacterial communities occurred in site 2 , but not in site 1 . In a separate analysis, substrate utilization was compared between site 1 and 2 in nest soils and in surrounding control soils. In nest soils, the number of substrates that differed significantly between site 1 and 2 was three times higher than in control soils. These observations led to the assumption that ants enhanced the already existing differences between site 1 and 2 . However, a cluster analysis of the obtained DGGE patterns separated all ant nest bacterial communities from the surrounding soil communities.

Combined results from functional and molecular approaches indicated that ants affected functional diversity and bacterial community composition in their nests by their nest building activity and accumulation of organic substances and food. The degree of Lasius ants' impact on soil microorganisms was more dependent on habitat characteristics than on differences in mode of life and trophic function between Lasius niger and L. flavus. However, we conclude that soil nesting ants intensify differences in soil conditions and thereby enhance the overall habitat diversity for the microbial community. 
Chapter 6

\section{Keywords}

Formicidae, ant mounds, microbial activity, physiological profile, substrate-induced respiration 


\section{Introduction}

Soil organisms are involved in complex food webs that are fuelled by dead plant matter (detritus) and living plant roots (Wardle et al., 2004). Belowground organisms are important structuring forces in terrestrial ecosystems acting as drivers of ecosystem functioning, such as decomposition, nutrient cycling and plant nutrition (Bardgett et al., 2005), thereby affecting the plant community and their consumers. Soil microorganisms form the base of soil food webs and are crucial for $\mathrm{C}$ and $\mathrm{N}$ cycling. In this way, they condition the availability of nutrients for plants and regulate populations of other soil organisms. Shifts in the activity of microbial communities due to environmental changes (e.g. soil management, climate change) can have lasting effects on ecosystem functioning (Emmerling et al., 2002). As ecosystem engineers ants are able to change or create their habitat through nest building activity (Jones et al., 1994; Dauber and Wolters, 2000). Intake of organic substances and foraging activities lead to accumulation of nutrients within their nests (Wagner et al., 1997; Nkem et al., 2000). Thus, ants modify the trophic resource base of organisms that are small, less mobile, and dependent on nutrients on-site. High nutrient availability in nests can create ,hot spots' for microbial activity that enhance nutrient turnover, soil fertility, primary productivity and plant and herbivore biomass. In a study carried out by Fountain et al. (2008), consequences of the bottom-up effect caused by nutrient input were an increase in the number of juvenile Collembola, and changes in community composition of spiders. Thus, ants can induce a nutrientbased bottom-up effect on higher trophic level in the aboveground as well as in the belowground system.

In this study, we quantified the functional diversity of soil microbial community in response to an array of different substrates and compared Lasius ant nest mounds with surrounding soils. To gain insights in the complex microbial community, we investigated the soil bacterial communities with molecular approaches. Denaturing gradient gel electrophoresis (DGGE) was used as powerful tool for a rapid screening of many samples (Heuer and Smalla, 1997). Since this method does not allow to distinguish between active and dormant microorganisms, it was combined with measurement of community functions (respiration response, physiological profile). 


\section{Material and Methods}

Sampling sites and organisms

We chose ten Lasius ant nests from two sample sites in summer 2007 to compare the nest mound material with surrounding soil. Three Lasius niger nests and three Lasius flavus nests were located on dry calcareous grassland situated on the southwest facing slope of the Werra valley (Witzenhausen Freudenthal, Northern Hesse, Germany) at $180 \mathrm{~m}$ a.s.l. (site 1). The former pasture in site 1 has been abandoned for 20 years and the soil is a shallow Rendzina (Leptosol) on Triassic limestone with a diverse herb layer dominated by Brachypodium pinnatum L. with a soil pH of 7.4. The mean annual temperature is $9{ }^{\circ} \mathrm{C}$, and the average annual precipitation $700 \mathrm{~mm}$. Additionally, four Lasius niger nests were chosen from another abandoned grassland site (Reinhausen, site 2), located $3 \mathrm{~km}$ south of Göttingen (Lower Saxony, northern Germany) near the river Leine at $160 \mathrm{~m}$ a.s.I. This soil is a Cambisol on a loamy floodplain consisting on clayey silt exhibiting a soil $\mathrm{pH}$ of 7.5. The herb layer was dominated by Picris hieracioides $\mathrm{L}$. The mean annual temperature in Göttingen is 8.7 ${ }^{\circ} \mathrm{C}$, and the mean annual precipitation is $639 \mathrm{~mm}$.

Nest samples were taken to a depth of $10 \mathrm{~cm}$ from the middle of nest mounds and control soil samples at a distance of $1 \mathrm{~m}$ from each nest. After collection, each sample was sieved $(4 \mathrm{~mm})$ and stored at field moisture at $5^{\circ} \mathrm{C}$.

\section{Respiration analysis}

Physiological profiles of microbial communities were analyzed after separate addition of eight different substrates (carbohydrates: $\mathrm{D}(+)$-glucose and $\mathrm{D}(+)$-melecitosemonohydrate, carboxylic acids: glutaric, ascorbic, formic and phenylacetic acid, a polymer: a-cyclodextrine, and an amino acid: L-tyrosine) by measuring oxygen consumption in an $\mathrm{O}_{2}$-microcompensation apparatus (Scheu, 1992) for $48 \mathrm{~h}$ at $22^{\circ} \mathrm{C}$. Substrates were added equivalent to $3.2 \mathrm{mg} \mathrm{C} \mathrm{g}^{-1}$ soil dry weight, glutaric acid and cyclodextrine were added together with nitrogen (ammonium sulphate) at a mass ratio of 10:2 (Anderson and Domsch, 1980). We distinguished the maximum initial respiratory response (MIRR) and the integral of the respiration curves, which reflects the potential catabolic activity of soil microorganism (Scheu et al., 2002). Values for MIRR and integral were calculated as the difference between samples with substrate addition and without substrate addition (basal respiration, BAS). 
L. flavus and L. niger nest and control soil from site 1 were used to test for species effect by a GLM, employing 'ants' and 'species' as factors. The basal respiration response (BAS), microbial biomass $\left(C_{\text {mic }}\right)$, initial respiration response (MIRR), and integral of the respiratory response to the different substrates were analyzed by a GLM with 'ants' and 'site' as factors (SAS 8.1; SAS Institute Inc., Cary, $\mathrm{NC})$.

As we found highly significant interactions between the tested factors 'ants' and 'site' for many substrates (see results), we tested differences between the sample sites by comparing only control soils and nest soil, respectively, from the two sites. We used a one-factor analysis of variances with 'site' as factor. An additional analysis was carried out with 'ants' as factor to compare nest and surroundings in each site independently. Means of different treatments were tested for significant differences by Tukey's honestly significant difference test (Sokal and Rohlf, 2001).

\section{Molecular analysis}

The microbial community structure was analyzed by denaturing gradient gel electrophoresis (DGGE) of the bacterial community in each nest and the corresponding surrounding soil. Soil samples for molecular analyses were stored at $80{ }^{\circ} \mathrm{C}$ until use. Genomic DNA was isolated from $250 \mathrm{mg}$ of soil by employing the UltraClean PowerSoil $^{\mathrm{TM}}$ DNA Isolation Kit (MO BIO Laboratories Inc., Carlsbad, CA, USA) according to the manufacturer's protocol. The final DNA elution step was carried out with $100 \mu \mathrm{l}$ sterile water. The 16S rRNA gene was amplified with the universal bacterial primers BAC 341F (5'- CCTACGGGAGGCAGCAG-3') and BAC 907R (5'-CCGTCAATTCCTTTRAGTTT-3) according to Muyzer et al. (1995) and Muyzer and Smalla (1998). A 40 bp GC clamp (5'CGCCCGCCGCGCCCCGCGCCCGTCCCGCCGCC-CCCGCCCG-3') was attached at the 5' end of the forward primer BAC 341F (Muyzer et al., 1995). The polymerase chain reaction was carried out by employing $20 \mathrm{ng}$ soil DNA as template. The PCR mixture $(50 \mu \mathrm{l})$ contained $5 \mu \mathrm{l} 10$ fold polymerase buffer (MBI Fermentas, St. LeonRot, Germany), $200 \mu \mathrm{M}$ of each of the four deoxynucleoside triphosphates, $2 \mathrm{mM}$ $\mathrm{MgCl}_{2}, 2 \mu \mathrm{M}$ of each primer, $1 \mathrm{U}$ of Taq DNA polymerase (MBI Fermentas, St. LeonRot, Germany). The following thermal cycling scheme was used: initial denaturation at $95{ }^{\circ} \mathrm{C}$ for $2 \mathrm{~min}, 13$ cycles of denaturation at $94^{\circ} \mathrm{C}$ for $1 \mathrm{~min}$, annealing for $1 \mathrm{~min}$ at a decreasing temperature gradient ranging from $64^{\circ} \mathrm{C}$ to $51^{\circ} \mathrm{C}\left(1{ }^{\circ} \mathrm{C}\right.$ decrease per 
cycle), and extension at $72{ }^{\circ} \mathrm{C}$ for $3 \mathrm{~min}$. Subsequently, 12 cycles of denaturation at $94{ }^{\circ} \mathrm{C}$ for $1 \mathrm{~min}$, annealing for $1 \mathrm{~min}$ at $51^{\circ} \mathrm{C}$, and extension at $72{ }^{\circ} \mathrm{C}$ for 3 min were performed. Finally, an extension period at $72{ }^{\circ} \mathrm{C}$ for 10 min was carried out. PCR products were checked on $1.5 \%$ Agarose gels and purified using the CyclePure PCR purification kit (Peqlab Biotechnologie $\mathrm{GmbH}$, Erlangen, Germany) following the manufacturer's instructions. The concentration of the purified PCR products was quantified using a NanoDrop ND-1000 spectrophotometer (Peqlab Biotechnologie $\mathrm{GmbH}$ ). Approximately $500 \mathrm{ng}$ of purified amplicons were separated by electrophoresis using the INGENY phorU system (Ingeny International BV, The Netherlands). For this purpose, a $9 \%$ (wt/vol) polyacrylamide gel containing a $45 \%$ to $60 \%$ denaturing gradient $(100 \%$ denaturant consisted of $7 \mathrm{M}$ urea and $40 \%$ formamide) was applied. Electrophoresis was performed at $60{ }^{\circ} \mathrm{C}$ and $100 \mathrm{~V}$ for $16 \mathrm{~h}$ in 1 fold TAE buffer ( $0.04 \mathrm{M}$ Tris, $0.02 \mathrm{M}$ sodium acetate and $0.001 \mathrm{M}$ disodium), and the gels were stained with SYBR Gold (Invitrogen, Karlsruhe, Germany) for $30 \mathrm{~min}$. The resulting DGGE profiles were analyzed by using GelCompare II software (Applied Maths, Kortrijk, Belgium). Patterns were converted into a presence-absence matrix, and samples were grouped using the UPGMA method. Background subtraction was applied and position tolerance was set at $1 \%$.

\section{Results and discussion}

Respiration analysis

Ant species effect (Lasius niger vs. Lasius flavus) was tested in the different samples from site 1. Significant differences between the two ant species, neither for basal respiration and microbial biomass nor for initial respiration response and integral of respiration response to all substrates were recorded. Thus, in the following analyses, samples from both ant species were combined in order to evaluate the ant effect.

Basal respiration in ant nests was significantly lower than in surrounding soils (2.37 and $3.45 \mu \mathrm{g} \mathrm{O}_{2} \mathrm{~g}^{-1}$ soil dry wt $\mathrm{h}^{-1}$, respectively; Table 1, Figure 1). Microbial biomass was not significantly affected by ants over both sampling sites (Table 1, Figure 2), but both, basal respiration and microbial biomass, were significantly affected by sampling site (Table 1). A marginal significant 'ants' * 'site' interaction (Table 1) indicates that differences between sites were predominantly attributed to an increase in nest microbial biomass in Cambisol soil (site 2) and that the ant effect on soil microorganisms depended on nest site. 


\begin{tabular}{r|cc|cc|} 
& \multicolumn{2}{|c|}{ BAS } & \multicolumn{2}{c|}{$\mathrm{C}_{\text {mic }}$} \\
\cline { 2 - 5 } ant & $\mathrm{F}$ & $\mathrm{p}$ & $\mathrm{F}$ & $\mathrm{p}$ \\
\cline { 2 - 5 } site & $\mathbf{1 3 . 0 1}$ & $\mathbf{0 . 0 0 2 4}$ & 1.53 & 0.2333 \\
ant*site & $\mathbf{3 8 . 3 1}$ & $<0.0001$ & $\mathbf{9 . 4 2}$ & $\mathbf{0 . 0 0 7 3}$ \\
& 0.87 & 0.3642 & 4.02 & 0.0622
\end{tabular}

Table 1. Effects of the factors 'ants' and 'site' on basal respiration (BAS) and microbial biomass $\left(\mathrm{C}_{\text {mic }}\right)$ tested by two-factor GLM nest and surrounding soils were tested together. $\mathrm{df}=$ degrees of freedom

To gain more detailed information about differences between sampling sites (site 1 and 2) we tested control soil, independently. Analyses of microbial respiration response in surrounding control soil revealed that basal respiration differed significantly between the two sampling sites (Figure 1), being lower in site 2 than in site 1 (2.45 and $4.11 \mu \mathrm{g} \mathrm{O}_{2} \mathrm{~g}^{-1}$ soil dry $\mathrm{wt} \mathrm{h}^{-1}$, respectively ANOVA for 'site' effect on BAS $F=13.07, p=0.0068$ ). The microbial biomass differed not between both sites (Figure 2, Table 3). These contrast between control soils indicated that basal respiration is more sensitive to local differences than microbial biomass, even without ant activity. The lower specific respiration (=BAS/C $\mathrm{C}_{\text {mic }}$ given in $\mu \mathrm{O} \mathrm{O}_{2} \mathrm{~h}^{-1} \mathrm{mg}^{-1} \mathrm{C}_{\text {mic }}$ ) in control soil of site 2 (2.6) compared to site 1 (4.8) indicated better microbial conditions in site 2 , because soil microbial community in this site needed a lower respiration to develop a definite microbial biomass (Anderson and Domsch, 1978). Thus, substrate utilization was increased in site 2 .

When ant nests were tested, basal respiration was significantly lower $(F=26.88$, $\mathrm{p}=0.0008 ; 1.01$ and $3.27 \mu \mathrm{g} \mathrm{O}_{2} \mathrm{~g}^{-1}$ soil dry wt $\mathrm{h}^{-1}$, respectively) and microbial biomass significantly higher in site 2 than in site $1(F=35.80, p=0.0003 ; 1196.26$ and 796.77 $\mu \mathrm{g} \mathrm{C}_{\text {mic }} \mathrm{g}^{-1}$ soil dry wt, respectively). These differences showed that the observed sampling site effects were similar but quite stronger in nests than in surrounding soils.

To detect site-dependent differences in nest vs. control soil comparison, we separately tested the ant effect in both sites. The one-factorial GLM revealed significant differences in microbial biomass between nest and surrounding soil in site 2 (GLM for the factor 'ants' $F=11.95, p=0.0135$ ), but not in site 1 . The same trend was recorded for the specific respiration. Comparison between nest and surroundings in site 1 (nest 4.1, surrounding 4.8) revealed no difference, whereas in site 2 a significant decrease was found in ant nests (nest 0.8 , surrounding 2.6). The 
latter result indicated that out of the tested soil samples, nests in site 2 had the best conditions for soil microbial development.

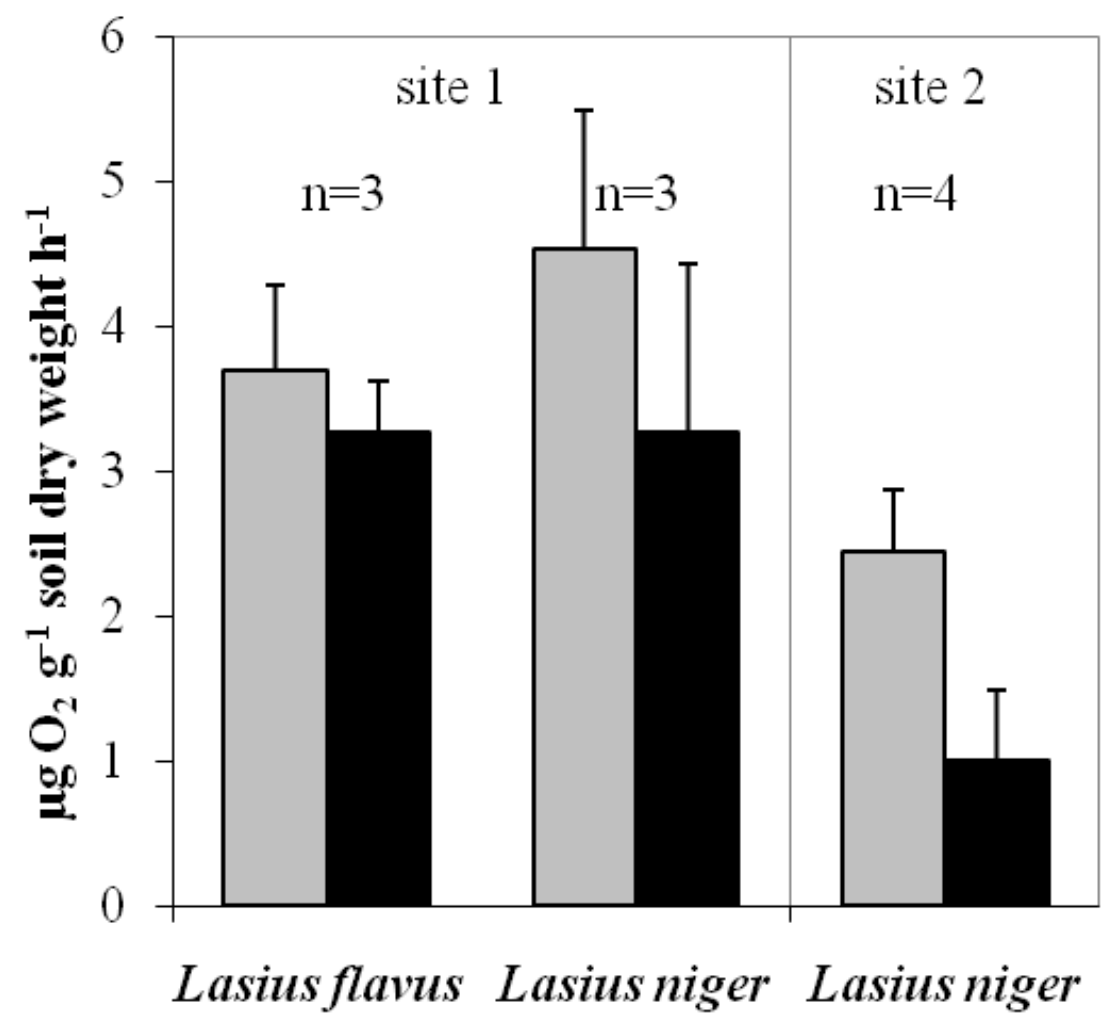

Figure 1. Influence of ants on basal respiration. Control soils are represented by grey bars and ant nests by black bars. Error bars depict standard deviations.

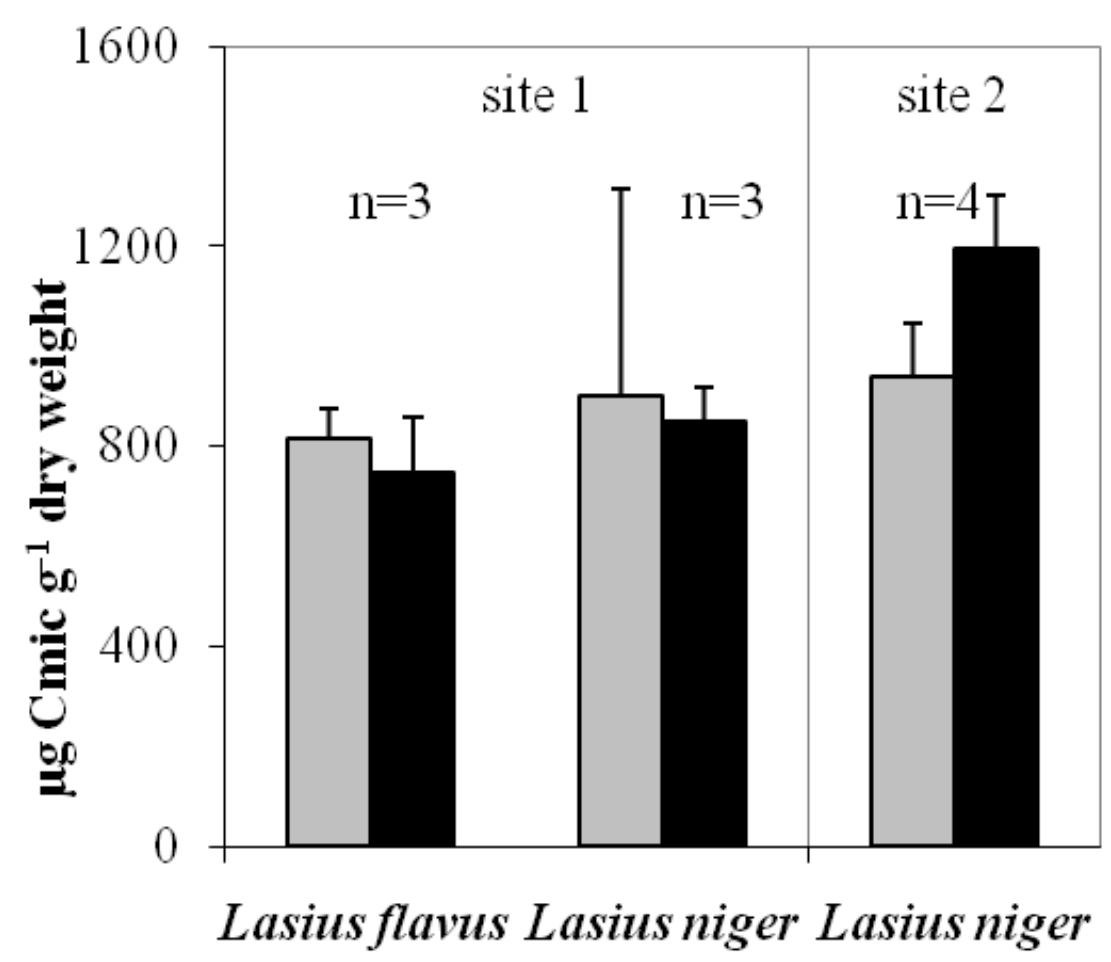

Figure 2. Influence of ants on microbial biomass. Control soils are represented by grey bars and ant nests by black bars. Error bars depict standard deviations. 
Ants can affect the soil microbial community by altering soil conditions and nutrient availability for microorganism and, thus, change community structure and ecosystem functioning. Accumulation of substances by ants can create , hot spots' for microorganism by increasing $\mathrm{NO}_{3}-\mathrm{N}$ and $\mathrm{PO}_{4}-\mathrm{P}$ amounts in nests (Nkem et al., 2000; Platner et al., 2001), but this effect on microorganisms is dependent on the nutrient status of the soil in which the nests are located. Frouz et al. (2003) reported that chemical properties of ant nests were affected by chemical properties of the surrounding soil. For example, $\mathrm{pH}$ values in nests increased in acidic soils, but the opposite was true in alkaline soil. Additionally, as the content of available $\mathrm{P}$ in the surrounding soil increased, the enrichment of the nest was higher in comparison to the control.

Ants had a strong effect on initial respiration response in Cambisol soil of site 2 with higher respiration response to all substrates, except cyclodextrine, in ant nests than in control soil. Respiration response increased by addition of glucose, ascorbic acid glutaric acid, or tyrosine 1.3-, 1.5-, 1.6-, and 1.8-fold, respectively. Three antrelated substances were tested: melecitose, as one of the dominant sugars in honeydew produced by aphids (Fischer et al., 2005) and used as an energy resource by ants, and phenylic and formic acid, as gland secretions by ants with possible antibiotic activity (Hölldobler and Wilson, 1990). The highest respiration was measured for these ant-related substrates in ant nest soil from site 2. Respiration increased for melecitose, formic acid, and phenylic acid 2.4-, 2.3-, and 2.1-fold compared to surrounding soil from site 2. Melecitose is a component of aphid honeydew with $40.5 \%$ of sugar composition in lime aphids (Dighton, 1978). It is synthesized by aphids to attract ants (Kiss, 1981). Sugars are a carbon source that can be rapidly degraded by soil microorganisms (Joergensen and Scheu, 1998). Thus aphids' honeydew has the potential to act as bottom-up force in the soil food web, but ants can reduce the amount of honeydew that reach the soil surface by 50 \% (Seeger and Filser 2008) due to tending aphids and collect their sugar-rich droppings. The intake of honeydew into their nests can increase the available carbon amount for microorganisms in nest habitats and consequently increase microbial biomass. Formic acid and phenylic acid were expected to reduce microbial respiration because of its antibiotic character, but these substrates increased respiration response. Thus, it was utilized by microorganism. Utilization of substrates differed only slightly between nest and surrounding soil in site 1 . 
The overall ant effect on initial respiration response was significant for melecitose, ascorbic acid, tyrosine, and phenylic acid, but the ant effect was dependent on sampling site (significant interaction between 'ants' * 'site' for the given substrates, Table 2, Figure $3 a, b)$ and were predominantly caused by strong response in site 2 and less by changes in site 1 .

Table 2. Effects of the factors 'ants' and 'site' on initial respiration response (MIRR) and integral of respiration curve (integral) to eight different substrates, tested by two-factor GLM. $\mathrm{df}=$ degrees of freedom

\begin{tabular}{|c|c|c|c|c|c|c|c|c|c|}
\hline \multirow[b]{2}{*}{ MIRR } & \multirow[b]{2}{*}{ df } & \multicolumn{2}{|c|}{ glucose } & \multicolumn{2}{|c|}{ melecitose } & \multicolumn{2}{|c|}{ ascorbic acid } & \multicolumn{2}{|c|}{ glutaric acid $+\mathrm{N}$} \\
\hline & & $\mathrm{F}$ & $p$ & $\mathrm{~F}$ & $p$ & $\mathrm{~F}$ & $\mathrm{p}$ & $\mathrm{F}$ & $p$ \\
\hline ants & 1 & 3.75 & 0.0705 & 18.67 & 0.0005 & 16.11 & 0.0010 & 2.12 & 0.1649 \\
\hline site & 1 & 13.47 & 0.0021 & 26.35 & 0.0001 & 20.16 & 0.0004 & 11.03 & 0.0043 \\
\hline ants*site & 1 & 3.26 & 0.0898 & 22.50 & 0.0002 & 13.47 & 0.0021 & 2.64 & 0.1239 \\
\hline \multicolumn{10}{|l|}{ Integral } \\
\hline ants & 1 & 4.57 & 0.0483 & 25.81 & 0.0001 & 33.38 & $<0.0001$ & 2.71 & 0.1190 \\
\hline site & 1 & 4.42 & 0.0516 & 3.49 & 0.0801 & 6.33 & 0.0229 & 0.08 & 0.7836 \\
\hline ants* $^{*}$ site & 1 & 0.72 & 0.4076 & 1.96 & 0.1804 & 11.70 & 0.0035 & 0.59 & 0.4541 \\
\hline \multirow[b]{2}{*}{ MIRR } & \multirow[b]{2}{*}{ df } & \multicolumn{2}{|c|}{ tyrosine } & \multicolumn{2}{|c|}{ cyclodextrine+N } & \multicolumn{2}{|c|}{ formic acid } & \multicolumn{2}{|c|}{ phenylic acid } \\
\hline & & $\mathrm{F}$ & $p$ & $\mathrm{~F}$ & $p$ & $\mathrm{~F}$ & $p$ & $\mathrm{~F}$ & $p$ \\
\hline ants & 1 & 9.50 & 0.0071 & 0.6827 & 2.93 & 0.17 & 0.6827 & 2.93 & 0.1649 \\
\hline site & 1 & 13.00 & 0.0024 & $<0.0001$ & 0.75 & 30.92 & $<0.0001$ & 0.75 & 0.0043 \\
\hline ants*site & 1 & 13.79 & 0.0019 & 0.9713 & 1.41 & 0.00 & 0.9713 & 1.41 & 0.1239 \\
\hline \multicolumn{10}{|l|}{ Integral } \\
\hline ants & 1 & 3.49 & 0.0803 & 0.3207 & 6.13 & 1.05 & 0.3207 & 6.13 & 0.1190 \\
\hline site & 1 & 3.82 & 0.0682 & 0.0180 & 30.31 & 6.94 & 0.0180 & 30.31 & 0.7836 \\
\hline ants* site & 1 & 2.08 & 0.1682 & 0.4359 & 0.01 & 0.64 & 0.4359 & 0.01 & 0.4541 \\
\hline
\end{tabular}

Table 3. Effect of ,site' in nest and surrounding soil tested both soils separately in a onefactor GLM. MIRR=maximum initial respiratory response, integral=integral of the respiration curves, $\mathrm{df}=$ degrees of freedom.

\begin{tabular}{|c|c|c|c|c|c|c|c|c|c|}
\hline & \multicolumn{5}{|c|}{ nest } & \multicolumn{4}{|c|}{ control } \\
\hline & \multicolumn{2}{|r|}{ MIRR } & \multicolumn{3}{|c|}{ Integral } & \multirow{2}{*}{$\begin{array}{c}\text { MIRR } \\
F\end{array}$} & \multicolumn{3}{|c|}{ Integral } \\
\hline & df & $\mathrm{F}$ & $p$ & $\mathrm{~F}$ & $p$ & & $p$ & $\mathrm{~F}$ & $\mathrm{p}$ \\
\hline glucose & 1 & 9.01 & 0.0170 & 9.54 & 0.0149 & 5.15 & 0.0527 & 0.51 & 0.4960 \\
\hline melec & 1 & 39.61 & 0.0002 & 5.69 & 0.0441 & 0.10 & 0.7612 & 0.10 & 0.7563 \\
\hline ascorbic acid & 1 & 28.69 & 0.0007 & 17.19 & 0.0032 & 0.40 & 0.5448 & 0.42 & 0.5353 \\
\hline glutaric acid $+\mathrm{N}$ & 1 & 6.25 & 0.0340 & 0.13 & 0.7314 & 11.44 & 0.0069 & 0.52 & 0.4923 \\
\hline tyrosine & 1 & 15.72 & 0.0041 & 7.63 & 0.0246 & 0.02 & 0.8925 & 0.11 & 0.7536 \\
\hline cyclodextrine+N & 1 & 17.98 & 0.0028 & 1.48 & 0.2590 & 13.52 & 0.0063 & 6.86 & 0.0307 \\
\hline formic acid & 1 & 0.05 & 0.8340 & 17.92 & 0.0029 & 2.33 & 0.1650 & 13.01 & 0.0069 \\
\hline phenylic acid & 1 & 38.95 & 0.0002 & 88.44 & $<0.0001$ & 3.70 & 0.0905 & 4.93 & 0.0572 \\
\hline
\end{tabular}

A stronger overall positive response to more substrates (glucose, melecitose, ascorbic-, formic-, and phenylic acid) was observed in nests from site 2 for the integral of respiration response, with significant 'ants' *'site' interaction for ascorbic- 
and phenylic acid (Table 2). The other substrates showed a similar pattern with smaller differences. Ants affect the functional diversity of soil microbial communities; however, these effects depend on the habitat characteristics. The integral of respiration response glucose, melecitose, and all to three tested carboxylic acids, were affected by sampling site. Especially the ant effect on the integral of respiration response to two carboxylic acids were dependent on the site (significant interaction 'ants' * 'site', Table 2). That carboxylic acids being most powerful for separating different soils was already reported by Degens and Harris (1997) and could been supported in our study.
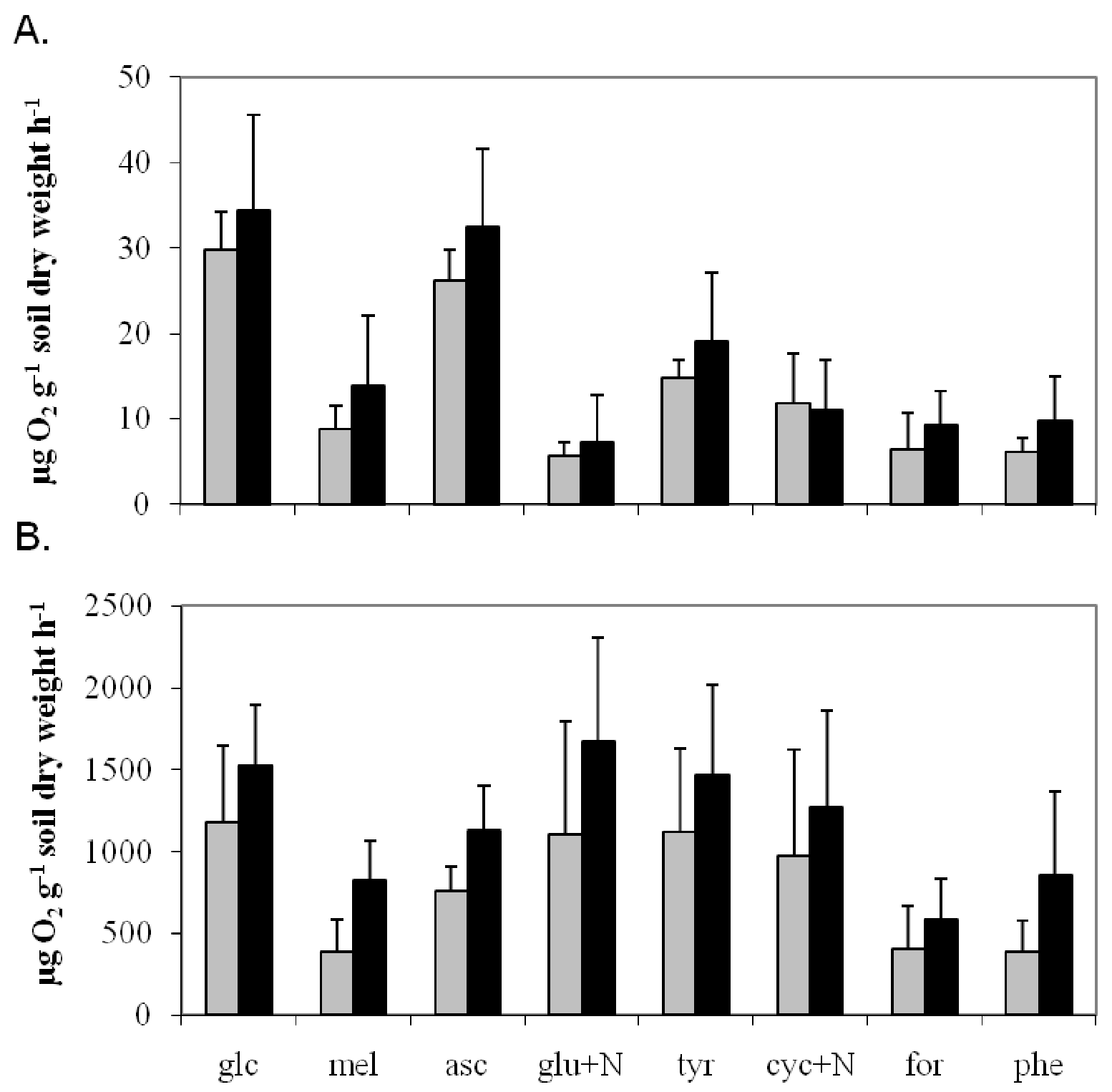

Figure 3. Initial respiration response (A.) and integral of respiration response (B.) to eight different substrates in nests (black bars) and control soils (grey bars). Glc=glucose, mel=melecitose, asc=ascorbic acid, glu=glutaric acid, tyr=tyrosine, cyc=cyclodextrine, for=formic acid, phe=phenylic acid, $+\mathrm{N}=$ added together with ammonium sulphate. 
Higher respiration response to substrates and lower basal respiration in nests of site 2 compared to surroundings can be explained by ants' activity as ecosystem engineers (Jones, 1994; Dauber and Wolters, 2000), which influence physical and chemical properties of soils by nest construction, and foraging and consumption of food (Nkem et al., 2000; Frouz et al., 2003).

The accumulation of ammonium, nitrate and phosphate in ant nests is well documented (Wagner et al., 1997; Nkem et al., 2000; Platner et al., 2001) and microorganisms in soil are controlled by energy and nutrient availability and by environmental forces. It has been assumed that the most common limiting factor for microbial growth in soils is the lack of carbon, but the utilization of different $C$ resources depends on the availability of other nutrients (Scheu and Schaefer, 1998). The site-dependent nutrient availability for soil microorganisms can explain the differences in substrate utilization between sites. The shallow Leptosol of site 1 has severe limitations to rooting and the excessive internal drainage in combination with the shallowness and the warm microclimate on the south exposed hill slope can cause severe droughts in the summer (Platner, 2006), which harms microbial communities. In contrast, moderately developed and base saturated Cambisols of temperate regions ("Braunerden"), like the soil of site 2, which derived from floodplain loess, are among the most productive soils on the earth (IUSS Working Group WRB, 2007). Soils are dynamic systems and soil nutrient content varies in space and time. Thus, different nutrient limitations in habitats can mask ant effects, especially, when different sites or seasonal changes are compared (Frouz et al., 2003; Platner, 2006).

In two separate analyses, we tested the sampling site effect in both, nest and surrounding soil. Initial respiration response to two of the eight different substrates gave significant local differences when control soil was tested. In contrast, seven substrates separated the two nest sampling sites from each other. Similar patterns were observed for the integral of respiration response with two substrates separating the both control soil sites and six substrates separating the both nest soil sites. These observations led to the assumption that ants enhanced the local differences between the two sample sites.

In control soils, differences between site 1 and site 2 were relatively low for initial respiration response in the case of following substrates: melecitose 0.58 , ascorbic acid 1.88, tyrosine 0.19 and phenylic acid $1.85 \mu \mathrm{g} \mathrm{O}_{2} \mathrm{~g}^{-1}$ soil dry wt $\mathrm{h}^{-1}$. This was in contrast to nest soils, where strong differences between sites were detected in 
response to these substrates: melecitose 14.54 , ascorbic acid 15.71 , tyrosine 12.89 and phenylic acid $9.21 \mu \mathrm{g} \mathrm{O}_{2} \mathrm{~g}^{-1}$ soil dry $\mathrm{wt} \mathrm{h}^{-1}$.

Similar to the initial respiration response, local differences of integral of respiration response were stronger in nests (glucose 525, melecitose 297, ascorbic- 436, formic403 and phenylic acid $973 \mu \mathrm{g} \mathrm{O}_{2} \mathrm{~g}^{-1}$ soil dry wt $\mathrm{h}^{-1}$ ) than in controls (glucose 222, melecitose 43 , ascorbic- 66 , formic- 390 and phenylic acid $231 \mu \mathrm{g} \mathrm{O}_{2} \mathrm{~g}^{-1}$ soil dry wt $\mathrm{h}^{-}$ $\left.{ }^{1}\right)$. These results indicated that ant presence in site 2 had a stronger impact on soil microbial communities than in site 1 . This might be a result of differences in nutrient availability and initial species diversity between sampling sites, at least during the summer. In spring and late summer, Platner (2006) could detect an overall significant higher microbial biomass in ant nests from site 1 compared to the surrounding, but not in very dry time periods or soil horizons. These observations and experimental results are consistent with our results by comparison of two different sites.

Changes in microbial community composition can influence higher trophic levels because microbes represent the base of the belowground food web (Pokarzhevskii et al., 2003). Thus, knowledge on community composition of microorganisms and their range of substrate utilization is important for understanding key ecological processes. The use of physiological profiles is a promising tool to study differences in the functional diversity of soil microbes, but to understand key ecological processes, the information on the groups of microorganisms leading to functional changes is important. To obtain information on microbial community composition in soils, we used genetic approaches.

\section{Bacterial community analysis}

To investigate the impact of the above-mentioned factors on the bacterial community, community composition of the ant nest mounds and the surrounding control soils were analyzed by using PCR-DGGE. To provide robust assessment of patterns, each sample subjected to three independent PCR-DGGE reactions. The average number of bands per sample was $14.2 \pm 3.5$.

The DGGE patterns of each nest for both ant species, L. niger and L. flavus were similar to those of the respective surrounding soil in site 1 as well as in site 2 . Nevertheless, a higher species abundance of the bacterial communities derived from the nest samples was indicated, as the bands from the nest samples showed a higher intensity than those derived from the surrounding soils. The UPGMA 
dendrogram derived from the cluster analysis of the obtained DGGE patterns generated showed two clearly separated groups (Figure 4). All nest bacterial communities grouped together and were separated from the surrounding soil communities. Two surrounding soil samples of Lasius niger nests from site 2 grouped outside.

Within the nest cluster, matches to site occurred more often than matches to the different Lasius species, indicating that site differences affected bacterial communities in nests stronger than differences in ants' life strategy. A similar trend showed the cluster analysis.

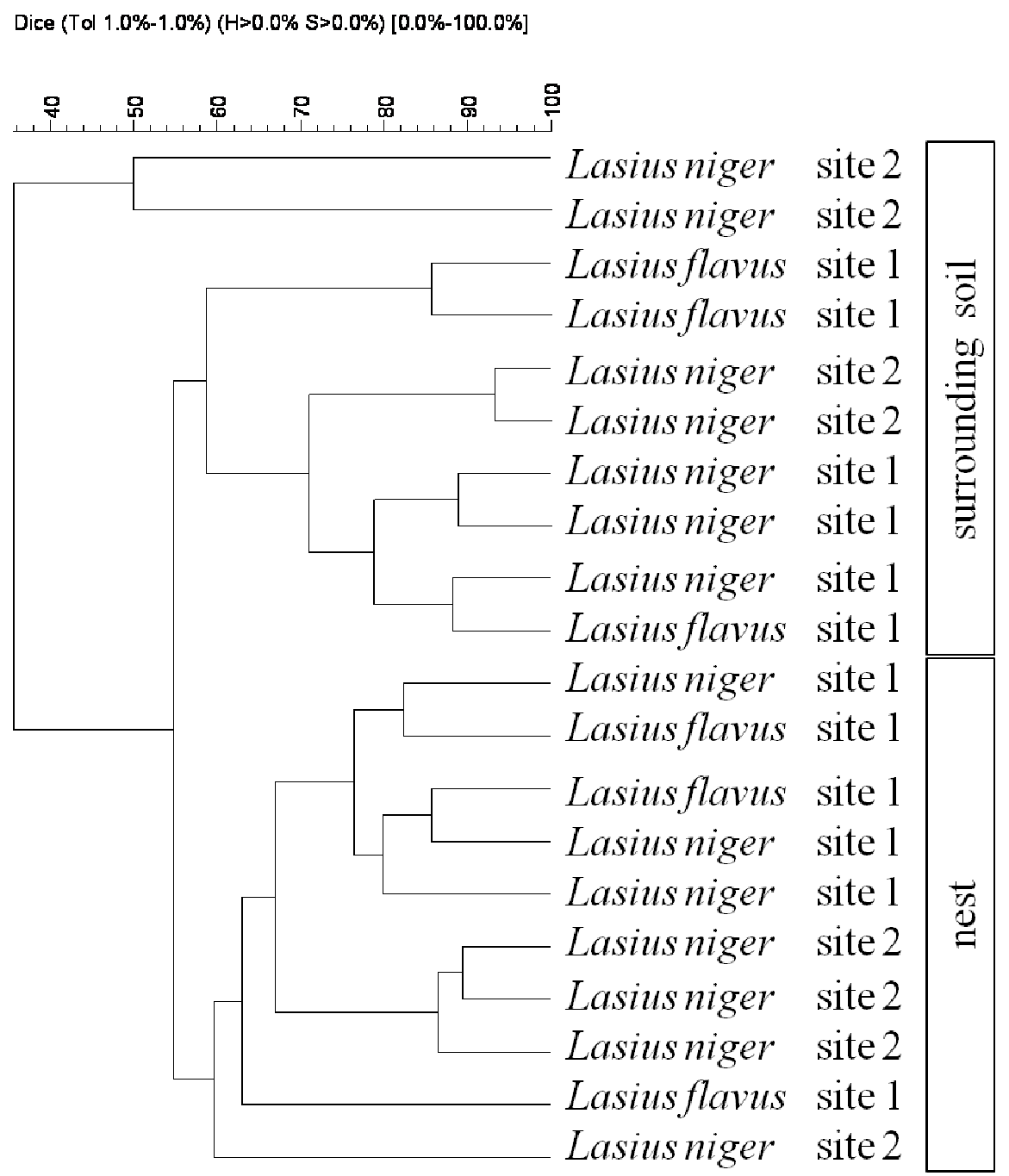

Figure 4. Dendrogram showing cluster analysis of the digitized DGGE bacterial profile from Appendix A. The UPMGA method was applied, which takes the presence or absence of bands at certain positions in each lane into account.

Correspondingly, the DGGE patterns of bacterial communities showed sitedependent differences of the ant nests. In site 1, DGGE band patterns differed only 
slightly between nest and surrounding soil, in particular one band which occurs in the profile of Lasius niger mound of site 1 (see arrow in Appendix A). The pattern of sitedependent differences was observed for microbial biomass and physiological profiles, as well.

The DGGE profile of the nest samples showed more bands, as well as more defined and intense bands compared to the surrounding soil samples. This indicates a higher abundance of species represented by these more intense patterns. Taking the limitation of the DGGE technique into account, that one band may represent more than one species (Myzer, 1999), we avoided the calculation of richness and diversity indices. Nevertheless, based on the up to 19 distinct bands per sample a high bacterial diversity is assumed.

However, these more intense DGGE patterns of the nest samples may reflect the ant activity, which led to changes in microbial biomass. Gronli et al. (2005) pointed out that the most consistent parameter for the variation in microbial soil community was the block, suggesting a strong spatial structure in the soil microbial community. Conditions for microbial development can differ between sites and the initial species diversity of soil organism strongly depends on previous land use (Hedlund et al., 2003). Ant activity can influence the microbial community in one habitat stronger than in another, dependent on initial diversity of microorganism, soil nutrients, soil water content, soil structure, and other characteristics of the respective habitats. Nutrient limitation for microorganisms can differ between environments, in some soils nutrients are already available for microorganisms, but in nutrient-poor soils ants can provide the limiting resource. The latter results in stronger ant effects on microbial community structure and activity.

\section{Conclusion}

Ant activity led to changes in bacterial communities and physiological profiles, but the degree of the ants' impact on microbial communities depended on nest site. This effect could be demonstrated by PCR-DGGE as well as through respiration analysis. Higher microbial biomass and respiration response in ant nests from site 2 in Reinhausen (Lower Saxony, Germany) was reflected in DGGE analyses by more diverse bacterial community patterns and higher abundance of bacterial soil community members. Similar patterns of physiological and DGGE profiles suggest that respiration response to the different substrates predominantly reflected activity of 
bacterial communities. In summary, the results indicated that ants affect functional diversity and bacterial community composition in their nests by their nest building activity and accumulation of organic substances and food, but the degree of ants' impact on soil microorganisms is dependent on sample site characteristics. 


\section{Acknowledgement}

We thank Matthias Schaefer and Carola Simon for valuable discussions and comments on the manuscript.

\section{References}

Anderson, J.P.E., Domsch, K.H., 1978. A physiological method for quantitative measurement of microbial biomass in soils. Soil Biology \& Biochemistry 10, 519525.

Anderson, J.P.E., Domsch, K.H., 1980. Quantities of plant nutrition in the microbial biomass of selected soils. Soil Science 130, 211-216.

Bardgett, R.D., Bowman, W.D., Kaufmann, R., Schmidt, S.K., 2005. A temporal approach to linking aboveground and belowground ecology. Trends in Ecology and Evolution 20, 634-641.

Dauber, J., Wolters, V., 2000. Microbial activity and functional diversity in the mounds of three different ant species. Soil Biology \& Biochemistry 32, 93-99.

Degens, B.P., Harris, J.A., 1997. Development of a physiological approach to measuring the catabolic diversity of soil microbial communities. Soil Biology \& Biochemistry 29, 1309-1320.

Dighton, J., 1978. In vitro experiments simulating the possible fates of honeydew sugars in soil. Soil Biology \& Biochemistry 30, 53-57.

Emmerling, C., Schloter, M., Hartmann, A., Kandeler, E., 2002. Functional diversity of soil organisms-a review of recent research activities in Germany. Journal of Plant Nutrition and Soil Science 165, 408-420.

Fischer, M.K., Völkl, W., Hoffmann, H., 2005. Honeydew production and honeydew sugar composition of polyphagous black bean aphid, Aphis fabae (Hemiptera, Aphididae) on various host plants and implications for ant attendance. European Journal of Entomology 102, 155-160.

Fountain, M.T., Brown, V.K., Gange, A.C., Symondson, W.O.C., Murray, P.J., 2008. Multitrophic effects on nutrient addition in upland grassland. Bulletin of Entomological Research 98, 283-292.

Frouz, J., Holec, M., Kalčík, J., 2003. The effect of Lasius niger (Hymenoptera, Formicidae) ant nest on selected soil chemical properties. Pedobiologia 47, 205212. 
Gronli, K.E., Frostegard, A., Bakken, L.R., Ohlson, M., 2005. Nutrient and carbon addition to the microbial soil community and ist impact on tree seedlings in a boreal spruce forest. Plant and Soil 278, 275-291.

Hedlund, K., Santa Regina, I., Van der Putten, W.H., Korthals, G.W., Diaz, T., Leps, J., Roy, J., Lavorel, S., Gormsen, D., Mortimer, S.R., Smilauer, P., Smilauerova, M., Van Dijk, C., Brown, V.K., C RB, 2003. Plant species diversity, plant biomass and responses of the soil community on abandoned land across Europe: idosyncracy or above-belowground time lags. Oikos 103, 45-58.

Heuer, H., Smalla, K., 1997. Application of denaturing gradient gel electrophoresis (DGGE) and temperature gradient gel electrophoresis (TGGE) for studying soil microbial communities. In: van Elsas, J.D., Wellington, E.M.H., Trevors, J.T. (Eds.), Modern soil microbiology. Dekker, New York, pp 353-373.

Hölldobler, B., Wilson, E.O., 1990. The ants. Springer, Berlin, Heidelberg, NY. Joergensen, R.G., Scheu, S., 1998. Response of soil microorganisms to the addition of carbon, nitrogen and phosphorus in a forest Rendzina. Soil Biology \& Biochemistry 31, 859-866.

Jones, C.G., Lawton, J.H., Shachak, M., 1994. Organisms as ecosystem engineers. Oikos 69, 373-386.

Kiss, A., 1981. Melezitose, aphids and ants. Oikos 37, 382.

Muyzer, G., Teske, A., Wirsen, C.O., Jannasch, H.W., 1995. Phylogenetic relationships of Thiomicrospira species and their identification in deep-sea hydrothermal vent samples by denaturing gradient gel electrophoresis of $16 \mathrm{~S}$ rDNA fragments. Archives of Microbiology 164, 165-172.

Muyzer, G., Smalla, K., 1998. Application of denaturing gradient gel electrophoresis (DGGE) and temperature gradient gel electrophoresis (TGGE) in microbial ecology. Antonie van Leewenhoek 73, 127-141.

Muyzer,G., 1999. DGGE/TGGE a method for identifying genes from natural ecosystems. Current Opinion in Microbiology 2, 317-322

Nkem, J.N., Lobry de Bruyn, L.A., Grant, C.D., Hulugalle, N.R., 2000. The impact of ant bioturbation and foraging activities on surrounding soil properties. Pedobiologia 44, 609-621.

Platner, C., Schaefer, M., Scheu, S., 2001. Der Einfluss von Ameisen auf den Boden und die mikrobielle Gemeinschaft trockener Brachwiesen. Mitteilungen der Deutschen Bodenkundlichen Gesellschaft 95, 84-87. 
Platner, C., 2006. Ameisen als Schlüsseltiergruppe in einem Grasland. Studien zu ihrer Bedeutung für die Tiergemeinschaft, das Nahrungsnetz und das Ökosystem. Biodiversity and Ecology Series 1, Universitätsverlag, Göttingen.

Pokarzhevskii, A.D., van Straalen, N.M., Zaboev, D.P., Zaitsev, A.S., 2003. Microbial links and element flows in nested detrital food-webs. Pedobiologia 47, 213-224.

Scheu, S., 1992. Automated measurement of the respiratory response of soil microcompartments: active microbial biomass in earthworm faeces. Soil Biology \& Biochemistry 24, 1113-1118.

Scheu, S., Schaefer, M., 1998. Bottom-up control of the soil macrofauna community in a beechwood on limestone: Manipulation of food resources. Ecology 79, 15731585.

Scheu, S., Schlitt, N., Tiunov, A.V., Newington, J.E., Jones, T.H., 2002. Effects of the presence and community composition of earthworms on microbial community functioning. Oecologia 133, 254-260.

Seeger, J., Filser, J., 2008. Bottom-up down from the top: Honeydew as a carbon source for soil organisms. European Journal of Soil Biology 44, 483-490.

Sokal, R.R., Rohlf, F.J., 2001. Biometry. 4th edition. WH Freeman and Co., New York.

Wagner, D., Brown, M.F.J., Gordon, D.M., 1997. Harvester ant nests, soil biota and soil chemistry. Oecologia 112, 232-236.

Wardle, D.A., Bardgett, R.D., Klironomos, J.N., Setala, H., Van der Putten, W.H., Wall, D.H., 2004. Ecological linkages between aboveground and belowground biota. Science 304, 1629-1633. 


\section{Appendix}

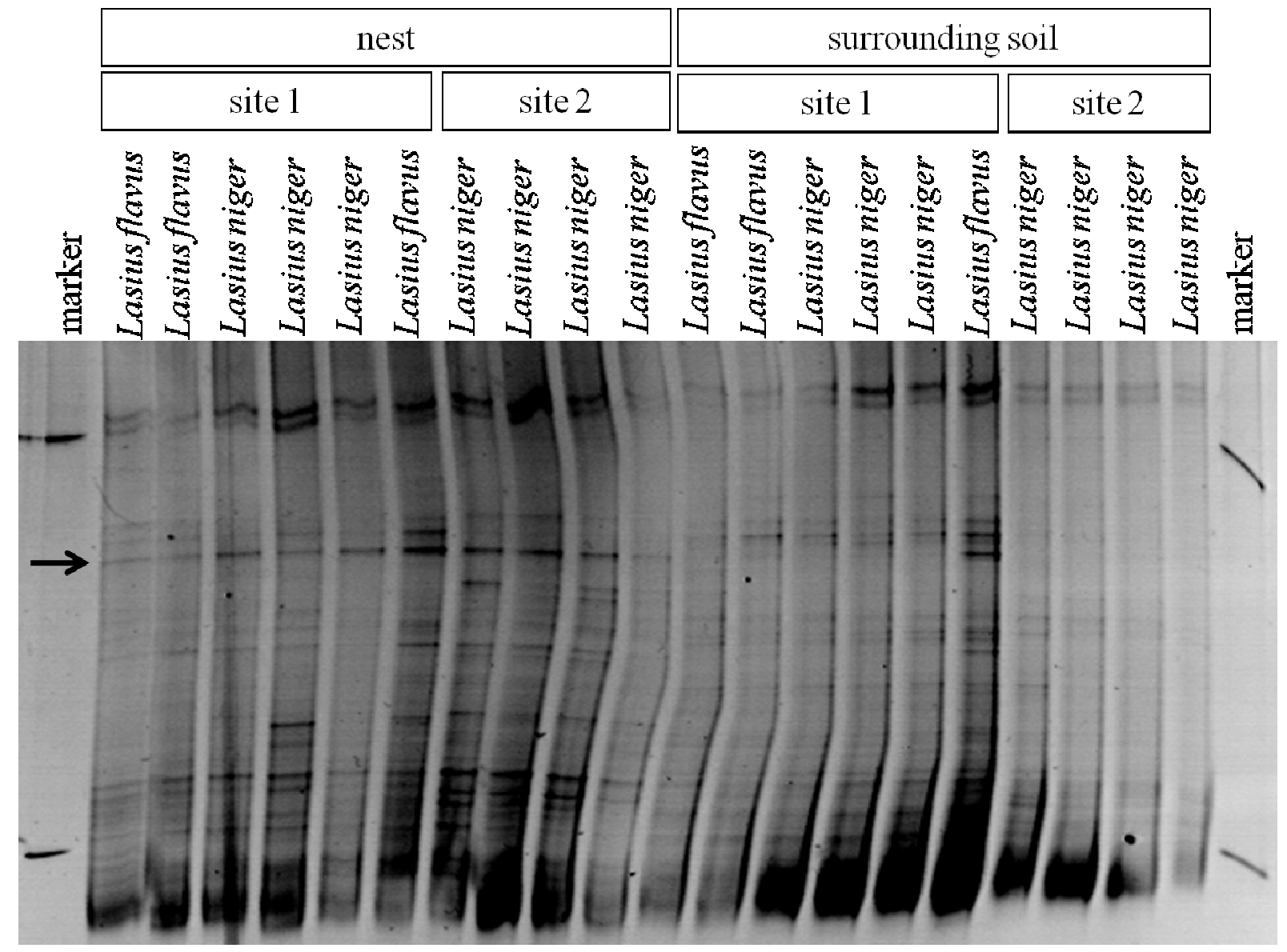

Appendix A: DGGE profile derived from the bacterial community of the four different Lasius niger ant nests and surrounding soil of site 2 and the three Lasius flavus and three Lasius niger ant nests and surrounding soil of site 1 . For each sample $500 \mathrm{ng}$ of PCR-product were applied to a DGGE gel containing $9 \%$ acrylamide and 45 to $60 \%$ denaturant. The arrow highlights the banding pattern, which separates Lasius niger nest samples from the respective surrounding soil. 
Chapter 7

\section{General Conclusions}


The aim of this study with its different experiments was to get insights into the complexity of the system involving ants with their direct and indirect effects on their mutualistic partners, the host plant of these partners and the soil microbial community with its diverse utilisation of nutrients.

\section{Does tending by ants affect the biomass of aphid colonies and does tending intensity of ants change when sugar and protein are available as alternative resources?}

The food-for-protection mutualism between ants and aphids often results in positive effects for aphids due to protection by ants against enemies (Way 1954 and 1963; Banks 1962; Banks and Macaulay, 1967; Stadler and Dixon, 2005) and hygienic services of ants (Banks, 1962). The presence of honeydew-producing hemipterans dramatically alters the abundance and predatory behaviour of ants on plants (Styrsky and Eubanks, 2007), but the intensity of mutualism depends on several factors such as the availability of alternative sugar/protein sources or the sugar/protein need of the tending ant colony. Ants often increase plant biomass by removing aphid-derived droplets of honeydew from the surface of the leaves where it would form a resource for fungal pathogens (Rico-Gray and Oliveira, 2007; Schumacher and Platner, 2009). In the two related laboratory experiments (Chapters 2 and 3 ), the positive effect of ants on aphids was confined to hygienic services, because no predators of aphids inhabited the microcosms, what made protection unnecessary and reduced the positive effect of ants. Ants positively affected aphid populations in the first experiment, but reduced tending, whilst having access to an alternative sugar resource (Figure 1). In both experiments, protein need for colonies was reduced. To avoid activity differences between experimental ant colonies, workers of one origin colony were used for the microcosm set-up. Thus no queen inhabited the microcosms and no new larvae were produced, what may have led to lower predation pressure of ants on aphids in comparison to natural conditions. Especially in the second experiment, many larvae developed to adult workers and workers died during the experiment which led to reduced protein requirements and lower aphid colony visitation by ants. Thus, the number of living aphids and aphid colony biomass were not affected by ants. However, more winged individuals were counted, indicating higher spreading tendency in colonies tended by ants, what was in contrast to other 
studies finding later spreading under ant attendance (Kindlmann et al., 2007). Altogether, ants affected aphid colonies to a low degree, but in many cases, mutualism depends on the impact of natural enemies or competitors (Tscharntke and Hawkins, 2002). These factors, influencing aphids survival, were excluded in our microcosm, thus the ants effect on aphids should be stronger in the natural systems.

\section{Which influence has the trophobiosis between ants and aphids in combination with the structural changes by nest construction on material flow between the aboveground and belowground system and on the microbial community?}

The material flow from plants via aphids and their honeydew into the system could be followed by using stable isotope technique. The isotope technique was successfully used to detect the origin of ants' food source when sugar and protein were offered as alternative resources. Labelling of plants, however, was only successful for the ${ }^{15} \mathrm{~N}$ but not for ${ }^{13} \mathrm{C}$ isotope. It could be demonstrated that ${ }^{15} \mathrm{~N}$ material was transferred from aphids to ants and their larvae (Chapter 3). The material flow may predominantly have happened via aphids used as prey, because ant larvae preferentially consume proteins, and an increased $\delta^{15} \mathrm{~N}$ value in tissues of ant workers should reflect the larval diet, because ants do not build up further biomass when they are adult (Blüthgen et al., 2003).

The input of honeydew into the litter and especially the soil and its effect on microorganisms strongly depended on the presence of ants. In microcosms without ants, a marginal $\delta^{15} \mathrm{~N}$ signature could be measured in the litter, but not in the soil samples. Only when ants were present, this signature could also be measured in the upper soil samples, indicating that ants enhance the material flow between the aboveground and belowground layer (Figure 1). Ant activity also affected litter and soil microorganisms. Ants reduced honeydew amounts reaching the litter by tending aphids, what led to lower microbial biomass in the litter in comparison to ant-free treatments where honeydew increased litter basal respiration and microbial biomass. However, basal respiration and marginally also microbial biomass in soil samples increased when ants were present. Thus ants transport resources from aboveground to belowground, what led to higher nutrient availability for soil microorganism. 
Honeydew intake by ants might be most important in systems with low rainfall, when honeydew can not be washed off the vegetation through the litter into soil. Altogether, the ant effect was stronger than the honeydew effect. This might be caused by panes that did not exclude honeydew completely, what might have weakened the honeydew effect. Consequently, in this experiment effects of ants involving nest building activity and trophic interactions with aphids do have a higher impact on soil microorganisms than aphids' honeydew alone. Honeydew effect on soil bacterial profile was an increased dominance of bacterial populations that already existed in soils (Gammaproteobacteria). Ants activity, however, led to changes in the structure of bacterial populations by promoting a more balanced dominance structure between populations. Altogether Betaproteobacteria were reduced and Firmicutes increased due to ant presence.

\section{How do ants affect soil parameters and soil microbial community and functioning in natural systems?}

Lasius ants strongly modified soil nutrients by increasing the amount of $\mathrm{PO}_{4}-\mathrm{P}$ and $\mathrm{NO}_{3}-\mathrm{N}$ in the soil of their nests by accumulation of organic substances and food (Chapter 4, Frouz et al., 1997). The creation of patches with high soil fertility and the modification of other soil properties (Pêtal, 1978; Lobry de Bruyn and Conacher, 1990 and 1994; Nkem et al., 2000; Frouz et al., 2003) can be favourable for soil microorganisms, but nutrient limitation plays a role even in ant nests (Chapter 5). I could also show, that in spite of higher nutrient availability in nests, microbial activity and fungal abundance depended on soil moisture and its seasonal changes. Basal respiration and microbial biomass were positively, fungal abundance was negatively correlated with soil water content (Chapter 4). Platner (2006) reported, that ant activity changes soil humidity within the nest in comparison to the surrounding soil, indicating that ants can directly and indirectly alter microbial community composition. I found a considerably higher fungal diversity in ant nests using the plating technique, but the bacterial component of the community was not investigated in this study.

The in situ respiration response to an array of substrates was used to quantify the ant effect on the functional diversity. With this method, the response of the whole active microbial community can be studied, but increasing the soil water content to 70 $\%$ of soil dry weight may have improved bacterial development (see Chapter 5). 
Differences in the actual catabolic activity of nest and surrounding soil communities were mainly caused by different utilization of carboxylic acids. This indicates, that ants have an effect on microbial community functioning, but the impact of ants on the soil microorganisms depended on the degree of ant activity in this experiment. Additionally, the strength of ant effects can differ dependent on ant nest location (Chapter 6). The ant effect was slightly in one location, while being strong in an other. This location dependent ant effect could be measured using physiological profile, basal respiration, microbial biomass and bacterial DGGE patterns, indicating that the ant effect vary with local conditions and initial diversity of soil microorganism.

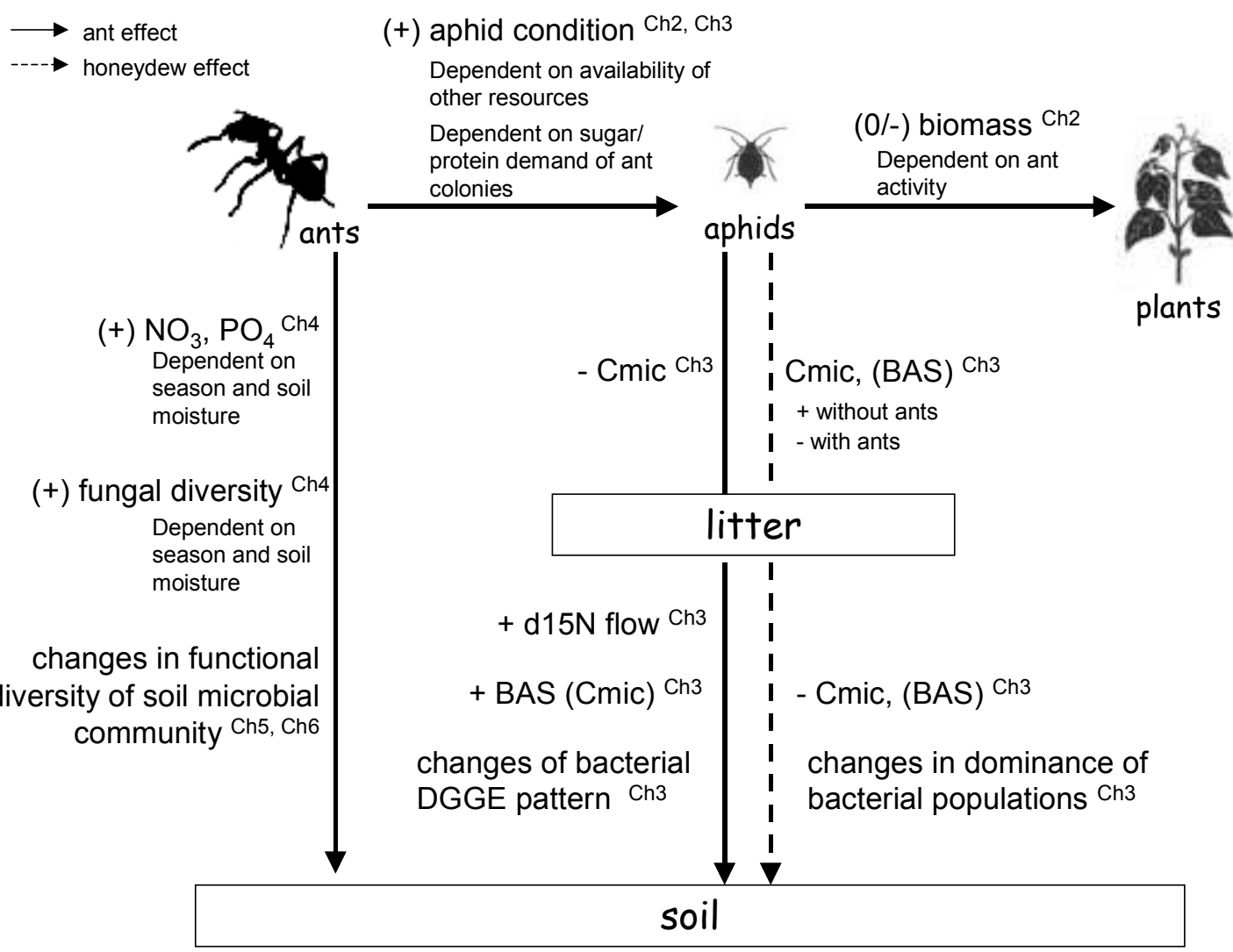

Figure 1. Effects of ants and honeydew on the different compartments of the system. Solid line=ant effect, dotted line=honeydew effect, $\mathrm{Ch}=$ Chapter. 


\section{Summary}

In conclusion, the above- and belowground material pathways play an essential role in ant-inhabited systems by different activities: the ants prey on/tend aphids, modify soil structure and influence nutrient intake by microorganisms and plants. In my studies, ants affected above- and belowground systems. Ant aboveground effects were tested in two artificial systems and resulted in marginal significant changes of aphid and plant conditions, but the ant effect depended on the availability of alternative food, what can lead to changes in ant tending activity and consequently exert effects on aphids and their host plants. Ant belowground effects were addressed in all five experiments. Out of these experiments, three studies were carried out in natural systems. Here, ants increased soil nutrients and fungal diversity and caused changes in functional diversity of soil microbial communities, but soil nutrients and fungal diversity were strongly influenced by season and soil moisture changes. In artificial systems ant induced an increased ${ }^{15} \mathrm{~N}$ flow to soil and changed microbial parameter (basal respiration, microbial biomass, bacterial DGGE profile). 


\section{References}

Banks, J.C., 1962. Effects of the ant Lasius niger (L.) on insects preying on small populations of Aphis fabae (Scop.) on bean plants. Ann. Appl. Biol. 50, 669679.

Banks, J.C., Macaulay, E.D.M., 1967. Effects of Aphis fabae (Scop.) and of its attendant ants and insects predators on yields of field beans (Vicia faba L.). Ann. Appl. Biol. 60, 445-453.

Blüthgen, N., Gebauer, G., Fiedler, K., 2003. Disentangling a rainforest food web using stable isotopes: dietary diversity in a species-rich ant community. Oecologia 137, 426-435.

Frouz, J., Santruckova, H., Kalcik, J., 1997. The effect of wood ants (Formica polyctena Foerst.) on the transformation of phosphorus in a spruce plantation. Pedobiologia 41, 437-447.

Frouz, J., Holec, M., Kalčík, J., 2003. The effect of Lasius niger (Hymenoptera, Formicidae) ant nest on selected soil chemical properties. Pedobiologia 47, 205-212.

Kindlmann, P., Hullé, M., Stadler, B., 2007. Timing of dispersal: effect of ants on aphids. Oecologia 152, 625-631.

Lobry de Bruyn, L.A., Conacher, A.J., 1990. The role of termites and ants in soil modification: a review. Aust. J. Soil Res. 28, 55-93.

Lobry de Bruyn, L.A., Conacher, A.J., 1994. The effect of biopores on water infiltration in soils in undisturbed bushland and farmland in a semi-arid environment. Pedobiologia 38, 193-207.

Müller, H., 1956. Können Honigtau liefernde Baumläuse (Lachnidae) ihre Wirtspflanzen schädigen? Z. Angew. Entomol. 39, 168-177.

Müller, H., 1960. Der Honigtau als Nahrung der hügelbauenden Waldameisen. Entomophaga 5, 55-75.

Nkem, J.N., Lobry de Bruyn, L.A., Grant, C.D., Hulugalle, N.R., 2000. The impact of ant bioturbation and foraging activities on surrounding soil properties. Pedobiologia 44, 609-621.

Pêtal, J., 1978. The role of ants in ecosystems. Production ecology of ants and termites (ed M. V. Brian), Cambridge University Press, Cambridge. 
Platner, C., 2006. Ameisen als Schlüsseltiergruppe in einem Grasland. Studien zu ihrer Bedeutung für die Tiergemeinschaft, das Nahrungsnetz und das Ökosystem. Biodiversity and Ecology Series 1, Universitätsverlag, Göttingen.

Rico-Gray, V., Oliveira, P.S., 2007. The ecology and evolution of ant-plant interactions.: The University of Chicago Press, Chicago, IL, USA and London, UK.

Schumacher, E., Platner, C., 2009. Nutrient dynamics in a tritrophic system ants, aphids and beans J. Appl. Entomol. 133, 33-46.

Stadler, B., Dixon, A.F.B., 2005. Ecology and evolution of aphid-ant interactions. Ann. Rev. Ecol. Evol. Syst. 36, 345-372.

Styrsky, J.D., Eubanks, M.D., 2007. Ecological consequences of interactions between ants and honeydew-producing insects. Proc. R. Soc. B. 274, 151-164.

Tscharntke, T., Hawkins, B.A., 2002. Multitrophic level interactions. Cambridge University Press.

Way, M.J., 1954. Studies on the association of the ant Oecophylla longinoda (Latr.) (Formicidae) with the scale insect Saissetia zanzibarensis Williams (Coccidae). Bull. Entomol. Res. 45, 113-134.

Way, M.J., 1963. Mutualism between ants and honeydew-producing Homoptera. Ann. Rev. Entomol. 8, 307-344. 


\section{Acknowledgements}

First and foremost, I would like to thank Professor Dr. Matthias Schaefer for his generous help and support. I am thankful for the opportunity to work in his group, with this excellent working atmosphere.

To all my colleagues of the Ecology group I am deeply grateful, in particular Dr. Christian Platner and Dr. Sonja Migge-Kleian for their fruitful discussions and general support, and Klaus Hövemeyer for reviewing parts of my thesis. Dieter Nünchert, Ingrid Kleinhans, Susanne Böning-Klein and Christel Fischer have been immensely helpful with all lab and technical work.

Many thanks to Nadine Weland, Simone Cesarz, Verena Eißfeller and Stephanie Beyer for the great time we spend together. My deepest thanks to my mother, Kurt Herbst and Bernd Gerund for their never-ending understanding and support. 
Curriculum vitae

\section{Personal details}

Name Evelyn Schumacher

Date of birth $\quad 06.09 .1977$

Place of birth Northeim

Nationality German

\section{Education}

2005-2010 PhD study at the Ecology Group, Johann-Friedrich-

Blumenbach Institute of Zoology, Anthropology and

Developmental Biology, Georg-August University of Göttingen

1997-2004 Study of Biology at the University of Göttingen, Germany.

Degree obtained: Diploma

1997

School leaving examination 